

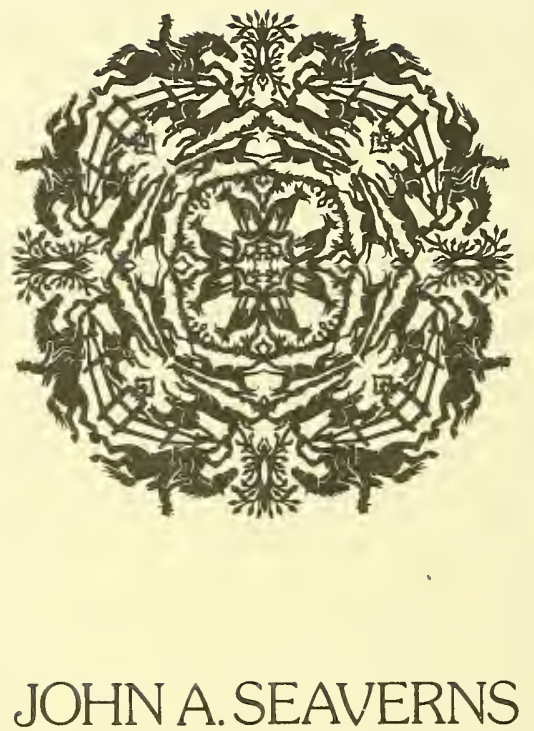


is 



\section{Breeds of}

\section{Hight Horses}

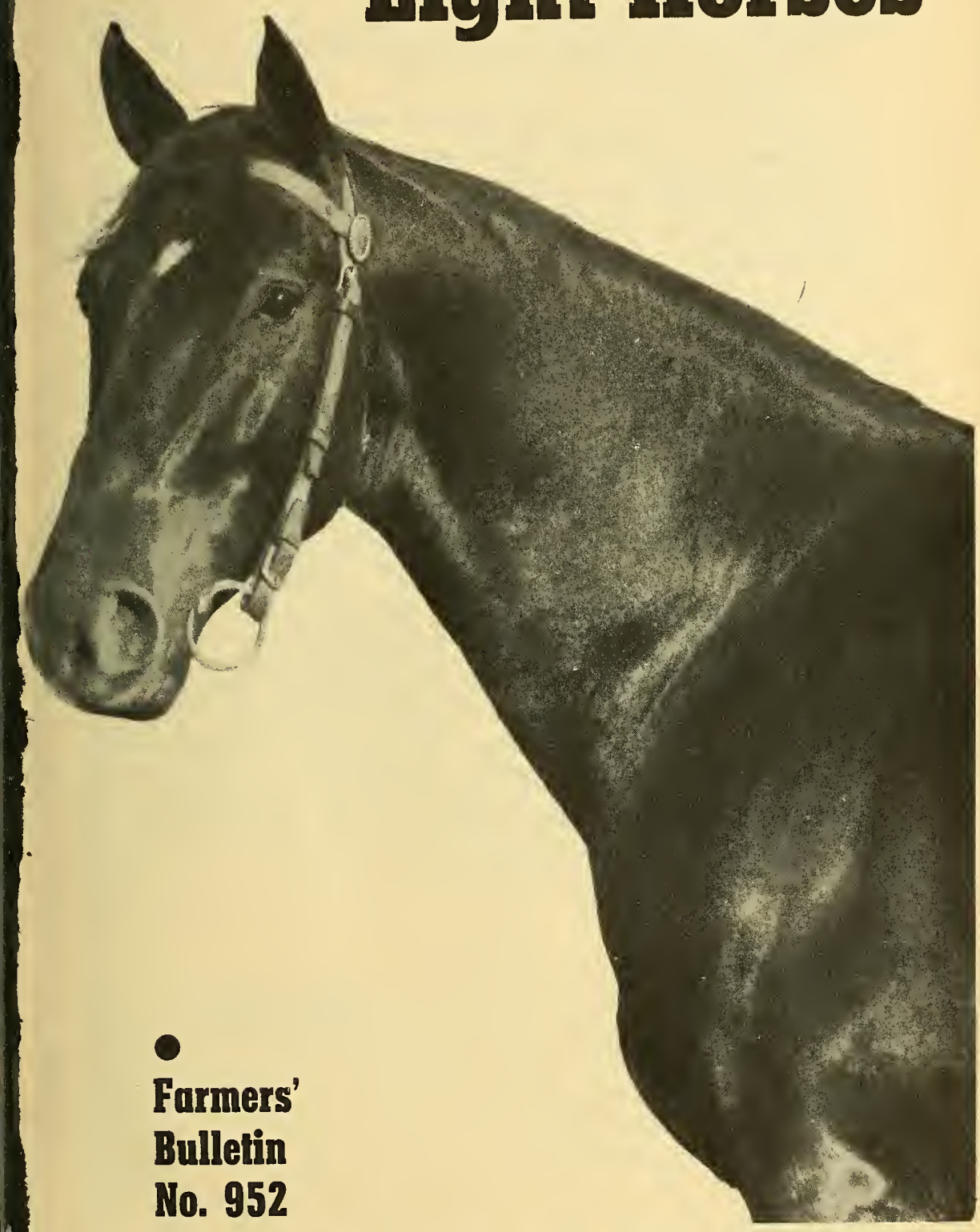

U. S. DEPARTMENT OF AGRICULTURE 
THIS BULLETIN gives concise information regarding breeds of light horses and will be particularly useful to farmers in sections where light horses are preeminently fitted for farm work, such as mountainous and hilly sections and where there are markets for horses for saddle and driving purposes.

The breeds discussed are the Arabian, Thoroughbred, Standardbred, American Saddle Horse, Morgan, Hackney, French Coach, German Coach, and Cleveland Bay. Of these, the Standardbred. American Saddle Horse, and Morgan breeds were developed in this country. The origin, development, general appearance, and adaptability of the light breeds are discussed.

There is no best breed of light horses. Some breeds are superior to others in certain respects, and one breed may be better adapted to certain local conditions than another. The general requirements for a section and the popularity of a certain breed in a locality should receive the utmost consideration in choosing a breed.

Washington, D. C. 


\section{BREEDS OF LIGHT HORSES}

By S. R. Speelman, associate animal husbandman, Animal Husbandry Division, Bureau of Animal Indusiry ${ }^{1}$

\section{Contents}

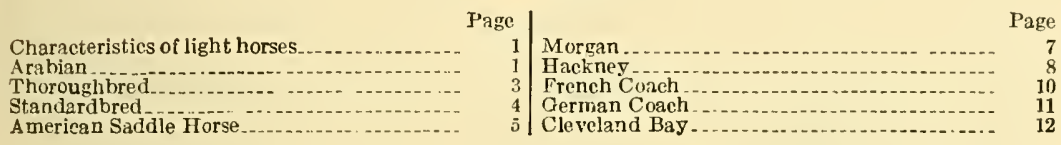

\section{CHARACTERISTICS OF LIGHT HORSES}

IGHT horses are a class intermediate in size between ponies and $\perp$ draft horses. Usually they have more range, also better action and greater speed than ponies or draft horses. A majority of light horses are from 15 to 16 hands $^{2}$ high and weigh from 900 to 1,250 pounds. Breeds of light horses, then, refer to the groups within this class which have been bred pure for a particular purpose, individual ancestry having been recorded by a registry association.

Light horses are well adapted to mountainous sections and rolling land, where they are useful for farm horse-power and for riding and driving purposes. It is in such sections that light horses should be bred and developed to supply the home demand.

The material presented herewith is intended to convey to the reader concise general information concerning the characteristics of the various breeds of light horses commonly found in this country. It is interesting to note the extent to which Arabian and Thoroughbred bloods were used in founding many of the light breeds. This relationship is briefly touched upon, but no attempt is made to give detailed information concerning early breed history. By communicating with the secretaries of the various breed associations, whose names are given, information regarding rules of registration, issuance of studbooks, and lists of breeders may be obtained.

\section{ARABIAN}

The oldest breed of horses generally recognized and the fountainhead of all our other light breeds was developed in the desert country of Arabia, from which it derives its name. Needing an animal that would carry him swiftly and safely over long stretches of sandy soil and at the same time withstand lack of feed and water to a remarkable degree, the Arab developed a type of horse that has long been noted for its activity, endurance, docility, and handsome appearance.

1 A revision of former editions by $H$. H. Reese, who resigned in 1926.

$2 \mathrm{~A}$ hand is a measurement of height equal to 4 inches. 
The Arabian horse (fig.1), while primarily developed as a saddle horse and ridden by the Arabs at a canter, is easily broken to make a safe although not fast driver. He possesses the general characteristics desired in a saddle horse, viz, good carriage of head and neck; deep, well-sloped shoulders; a short back with proportionately long underline; wide and deep quarters; short, strong loin; tail attached high; compactness of middle; and superior quality of underpinning without any tendency to appear leggy.

A typical Arabian horse has a wedge-shaped head; small nose; dish face; deep, wide jaws; eyes set low, wide apart, and near the middle of the head; a relatively large brain capacity; one less lumbar vertebra than most other horses, giving a short, weight-carrying back; one or two fewer vertebræ in the tail, which is set on a high

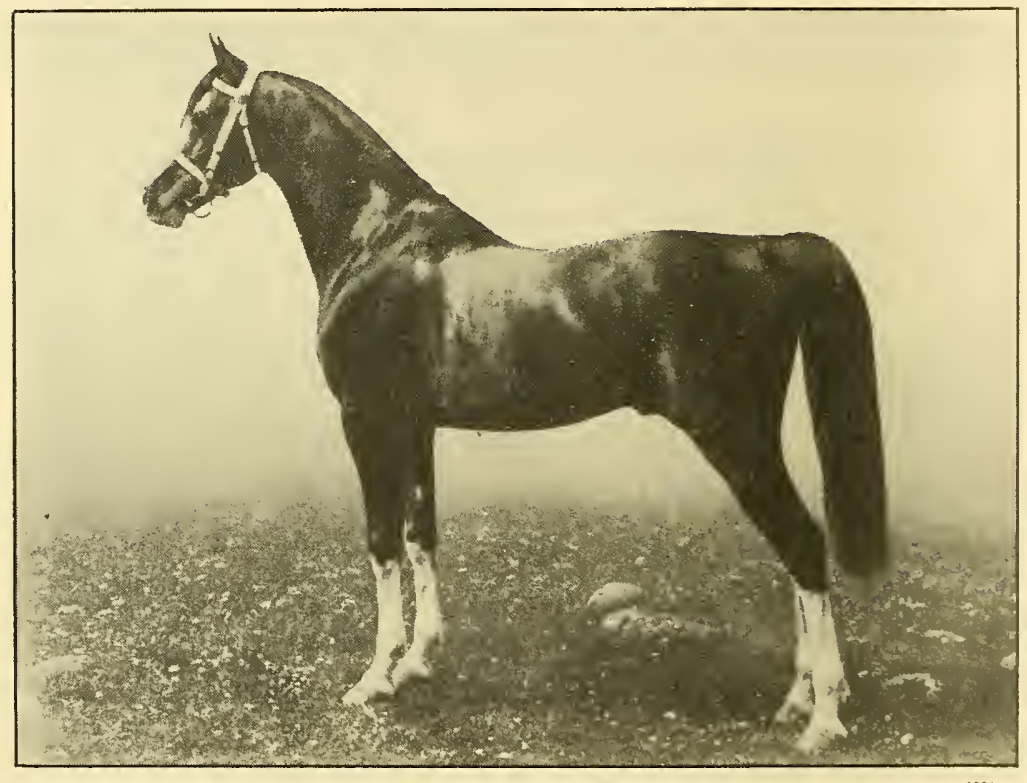

FIGURE 1.-Arabian stallion.

croup and gaily carried; ribs sprung wide and deep; large linee, hock, tendon, and hoof; dense bone; small stomach capacity, with small feed requirement and the ability to assimilate rough feed; and a marked prepotency in the stud.

Generally the Arabian horse in action shows only the walk, trot, and canter. The usual height is 14 to 15 hands and the weight from 800 to 1,000 pounds. Bay, gray, chestnut, and brown are the predominating colors, with an occasional white or black. White marks on the head and legs are common, but purebred Arabians are never piebald or spotted, notwithstanding an erroneous impression created by circus horses that are commonly called Arabians.

Crossed on farm mares, Arabian stallions have produced excellent saddle horses, but they frequently lack size when measured by presentday requirements. However, admirers of the Arabian are very en- 
thusiastie about its suitability for cavalry use, pointing out that endurance and weight-carrying ability, as demonstrated in endurance tests, even temperament, and especially ability to withstand hardships, such as seanty feed on long marches, make it especially useful for this purpose.

The Arabian Horse Club of Ameriea, Alfred R. Watt, secretary, 111 W. Monroe Street, Chicago, Ill., publishes a studbook, the latest supplement (1939) to which shows a total of 1,182 registrations of animals living and dead.

\section{THOROUGHBRED}

The name "Thoroughbred" is applied properly only to the breed of running race horses produced originally in England. Three Arabian stallions are eredited with having laid the foundation for this

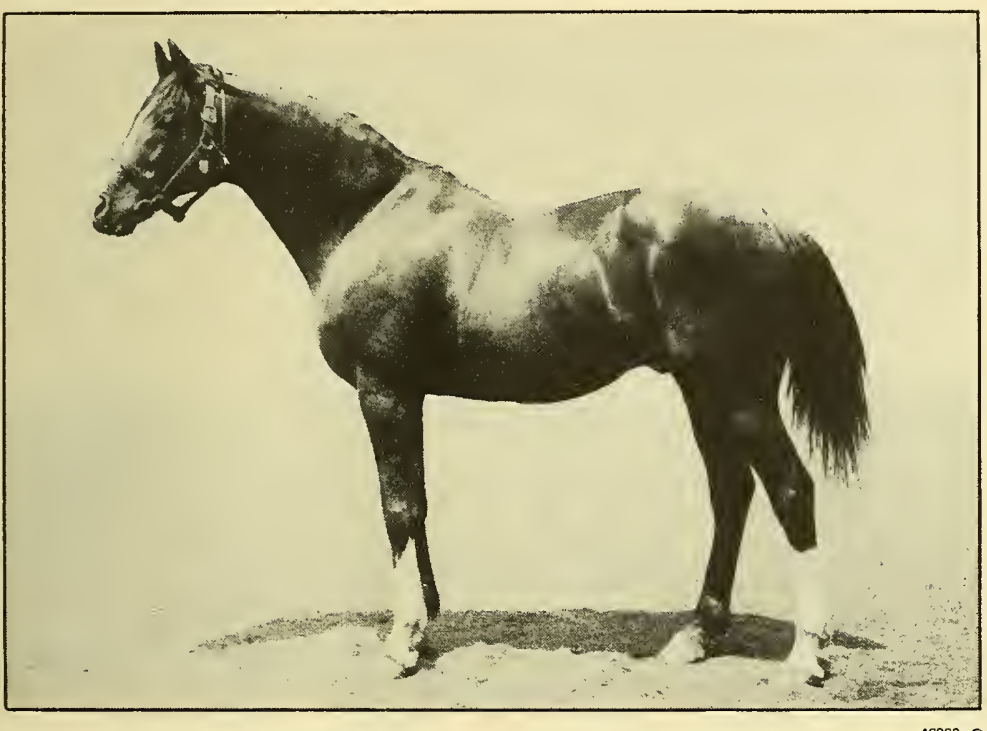

FIgURE 2.-Thoroughbred stallion.

breed-The Byerly Turk, The Darley Arabian, and The Godolphin Barb. They produced the three famous racing families, Herod, Eclipse, and Matehem, respectively. The Thoroughbred has many features of the Arabian, most notable of which is the general refinement, or "breediness" of appearance. The cross on English mares, however, and selection for running speed have resulted in the Thoroughbred's being faster at the run, larger, and commonly more angular and upstanding than the Arabian. As a running race horse the Thoroughbred is without a peer. The canter is its best utility gait. Many specimens have a splendid walk, and the trot, while not showing extreme speed or knee action, is nevertheless often desirable for saddle use. Rather wide variations in height and weight are found among horses of this breed. Many representative stallions, however, stand between 15.1 and 16.2 hands high and weigh between 1,000 and 1,150 
pounds, but mares are generally smaller in both respects. Thoroughbreds are bay, brown, chestnut, black, or, less frequently, gray. Irregular and conspicuous white marks are not uncommon. A Thoroughbred stallion is shown in figure 2 .

Thoroughbreds are bred pure almost entirely for racing purposes, a certificate of registration with the Jockey Club being required for horses entered in races on the larger tracks in the United States. To instill quality and a more active temperament, animals of this breed are sometimes used to cross with other breeds. The use of Thoroughbred sires on mares of other than pure Thoroughbred blood is quite popular in certain sections, the resultant animals being commonly termed half-breds. Such horses find ready sale as hunters, saddle horses, and polo ponies. Many excellent officers' horses and cavalry horses are produced in this way. When of proper temperament and of sufficient size, they have also been very satisfactory for general farm work on rolling land, gaining for themselves a reputation for stamina and endurance.

The Jockey Club, of which Harold O. Vosburgh, 250 Park Avenue, New York, N. Y., is registrar, registers Thoroughbreds in the United States, more than 165,000 animals having been recorded. Most of our imported Thoroughbreds come from France and England, but horses of this breed are bred in other countries as well and are widely distributed. Sixteen volumes of the American Stud Book, published by the Jockey Club, have been issued.

\section{STANDARDBRED}

The Standardbred (fig. 3) is an American breed developed primarily for extreme speed at the trot and pace. American Trotting Horse is another name for this breed. Messenger, an imported Thoroughbred stallion, and imported Bellfounder, registered in the English Hackney Stud Book, were largely responsible for the foundation of this breed, as Rysdyk's Hambletonian, a stallion to which a vast majority of the horses of this breed trace, carried the blood of both. The ancestry of the pacer is not different from that of the trotter, but today some families produce a much larger proportion of pacers than others, while some individuals show speed at both gaits. Both trotters and pacers are registered in the same studbook.

Horses of this breed generally do not show so much quality as the Thoroughbred but usually have more substance, being heavier in proportion to their height. The ears, head, and bone particularly are larger, and the hind legs are not quite so straight as in the Thoroughbred. In weight the Standardbred ranges from 900 to 1,300 pounds, and in height from 15 to 16 hands. The best specimens are often about 15.2 hands high and weigh about 1,100 pounds when in good driving condition.

These horses are bred pure largely with the intention of producing extreme trotting or pacing speed for racing purposes. Individuals not having the required racing speed have frequently been able to fill utility places on account of their size, endurance, and good disposition. This is equally true of those carrying half or more Standardbred blood. They have been used in large numbers as general-purpose farm horses; they predominate as roadsters, or driving horses, and as light deliverywagon horses. Occasionally excellent heavy-harness horses have been 
trotting bred. Durable cavalry horses frequently carry this blood. When of sufficient size, horses of this blood are the best light-artillery horses coming from a known source to be found in this country in considerable numbers. On account of their versatility, horses of trotting-bred ancestry have been very popular here, and foreign countries have paid some very attractive prices for Standardbred breeding stock, especially stallions.

The United States Trotting Association, of which Will Gahagan, Goshen, N. Y., is registrar, promotes the interest of the Standardbred and records purebred animals. Twenty-nine volumes of the studbook of this association have been issued, and more than 200,000 animals have been recorded.

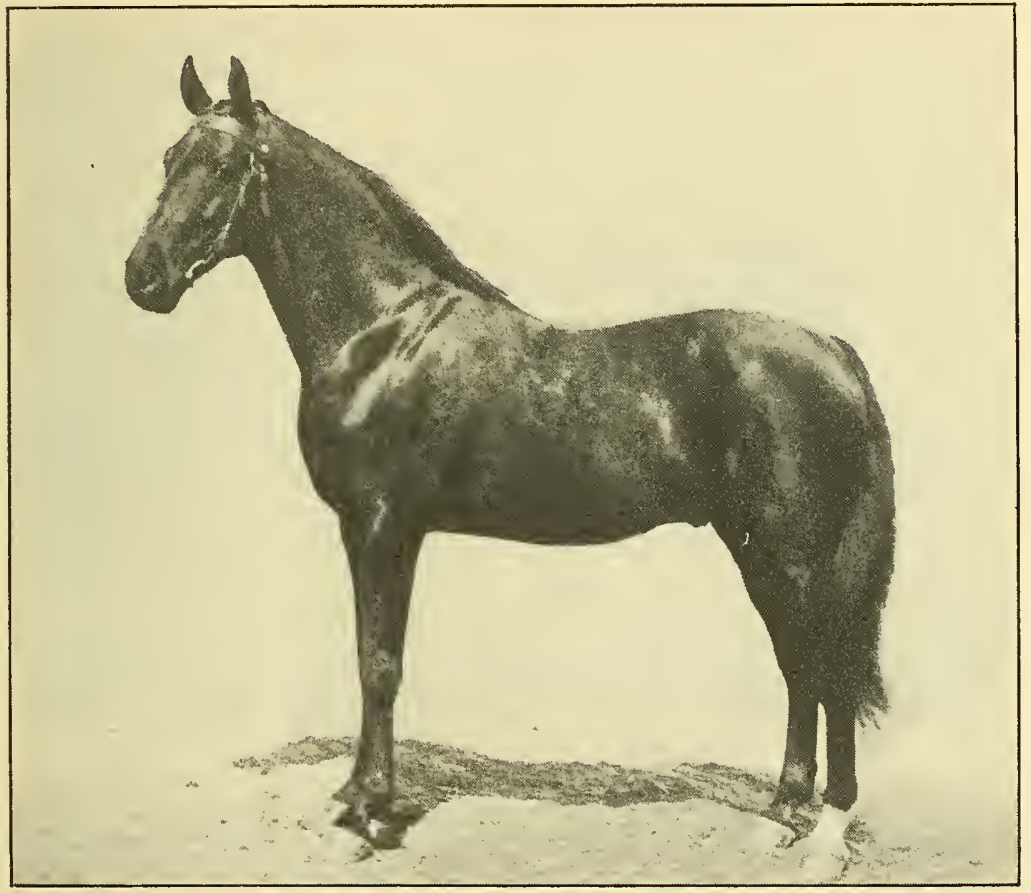

Figure 3.--Standardbred stallion.

\section{AMERICAN SADDLE HORSE}

The early residents of Kentucky, Tennessee, Virginia, and West Virginia found horses with easy gaits to be the most desirable to ride over plantations and semimountainous grazing farms and on long journeys. Preferring such gaits, they laid the foundation for and promoted the pioneer development of the American Saddle Horse. Sections of Missouri also soon took up the breeding of easy-gaited saddle horses, and today this State ranks next to the mother State, Kentucky, in the production of high-class horses of this breed.

Thoroughbred, Morgan, and Canadian bloods form the basis for this breed. The American Saddle Horse Breeders' Association 
recognized the following horses as foundation stock of the breed previous to April 10, 1908: Denmark, by Imported Hedgeford; John Dillard; Brinker's Drennon; Sam Booker; Tom Hal; Coleman's Eureka; Van Meter's Waxy; Cabell's Lexington; Copperbottom; Stump-the-Dealer; Texas; Prince Albert; Peter's Halcorn; Varnon's Roebuck; and Davy Crockett. At present, Denmark alone is recognized as foundation stock.

The chief distinguishing characteristics of the American Saddle Horse (fig. 4) are the gaits known as the rack, or single-foot, a rather fast, cultivated gait intermediate in movement between the trot and the pace; the fox trot; the running walk; and the slow pace. The last three are commonly referred to as the slow gaits, any one of which

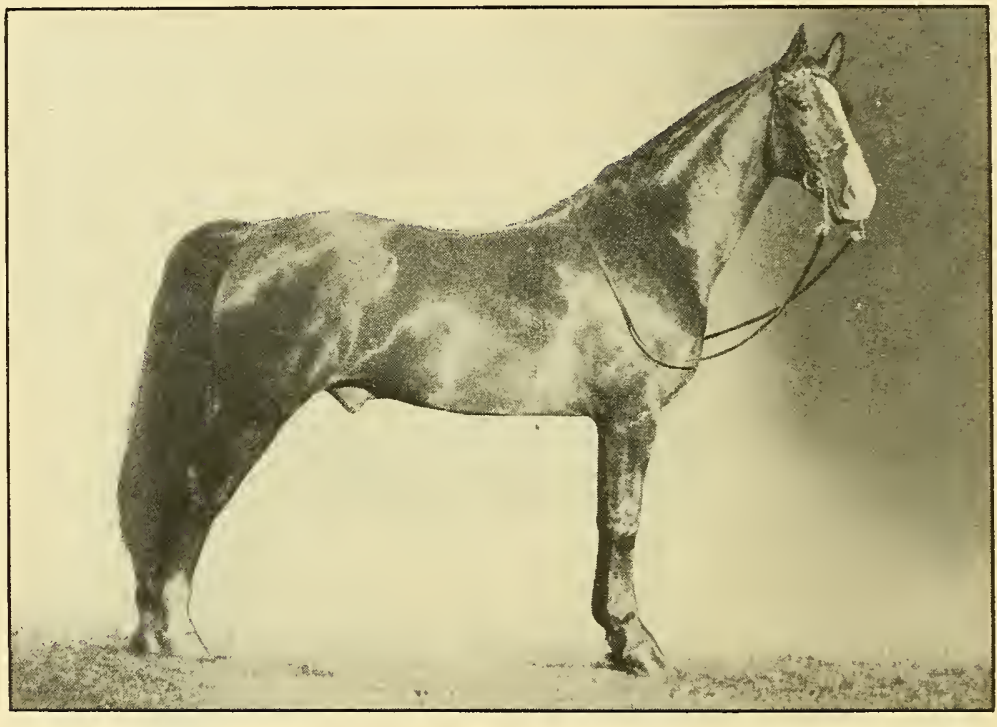

$26317-B$

Figure 4.-American Saddle Horse gelding.

is accepted as the slow gait of a five-gaited saddle horse. The other gaits demanded in a horse of this type are the canter, the trot, and the walk. The demand for hamess, combination, and walk-trot-canter saddle horses has caused many dealers and breeders to pay particular attention to the development of a balanced, fairly high, and swift trot.

Horses of this breed are usually bay, brown, chestnut, or black, and most of them stand from 15 to 16 hands high and weigh from 1,000 to 1,200 pounds.

The breeders of Kentucky and Missouri have always manifested much interest in showing their horses and colts at county and State fairs, and this undoubtedly is responsible in large measure for the constant selection in this breed for animals with a great deal of quality, unusual style, and fine disposition. Fine harness show horses frequently possess saddle blood. Those without the easy gaits but with quality and desirable saddle conformation are sold as three-gaited saddle horses 
for park and show purposes. Heavy harness horses have occasionally come from this breed. Five-gaited saddle horses seldom como from any other blood. American Saddlo Horses are being bred pure in practically every State in the Union, and many are sold to Cuba and to other countries.

The American Saddle Horse Breeders' Association, the organization recording purebred animals of this breed, reports that 17,905 stallions and 29,714 mares have bcen registered. Twenty volumes of the studbook have been issued. Charles J. Cronan, Jr., 204-6 Urban Building, Louisville, $\mathrm{Ky}$., is secretary of the association.

\section{MORGAN}

The Morgan has sometimes been considered a family of the Standardbred, but as these horses have been bred more for their utility qualities than for speed and as their characteristics are well established and perpetuated with marked regularity, it is proper to consider them a distinct breed. The early development of the Morgan took place in New England. Thus this country has the credit of founding three light breeds. The foundation of the Morgan breed is attributed to a single stallion, Justin Morgan, a horse of remarkable prepotency. Very little is definitely known of his ancestry. One investigator collected evidence showing that Justin Morgan was sired by the Thoroughbred stallion True Briton, also called Beautiful Bay, a horse that traced in direct male line to The Byerly Turk and had many other traces of Arabian blood. Another investigator contends that he was sired by a Dutch horse which, in turn, came from Arabian stock. Which of these hypotheses is correct is not important today. The presence of only five lumbar vertebrae in many Morgans points to Arabian foundation.

Morgans are generally chestnut, brown, bay, or black, white marks being uncommon. Fifteen and a half hands is the average height of good individuals, and the average weight is about 1,050 pounds, but, as in all breeds, considerable variation is found. This breed has always been noted for smooth lines, good style, easy-keeping qualities, endurance, and docility, the last, however, not being obtained at a sacrifice of ambition and courage. Small ears, good eyes, with great width between them, crested necks, well-sprung ribs, with the last one close to the point of the hip, deep barrels, fairly level croups, full quarters, and enduring legs and feet are the qualities that have made Morgan horses popular for a century. They have good natural knee action, with considerable speed at the trot, some families having contributed materially to the upbuilding of the Standardbred. Others showing more saddle characteristics have exerted a marked influence on the American Saddle Horse. A Morgan stallion is shown in figure 5.

These horses were used almost exclusively as general-purpose farm horses in New England in the early days, as well as in other sections. Today Morgans are distributed in small numbers over the important farming sections of this country and have made for themselves a reputation for hardiness, soundness, and usefulness.

Though the craze for trotting speed and the subsequent lack of demand for driving horses nearly resulted in the Morgan's being temporarily forgotten, his friends have never lost faith in him and 
have never missed an opportunity to exploit his good qualities. Recently Morgan breeding has become quite popular in some sections, the Morgan Horse Club being an outcome of this movement. Through united effort of its members, this club is endeavoring to preserve the good qualities of the Morgan. This work is analogous to that of the Department of Agriculture in regenerating the breed at the United States Morgan Horse Farm, Middlebury, Vt.

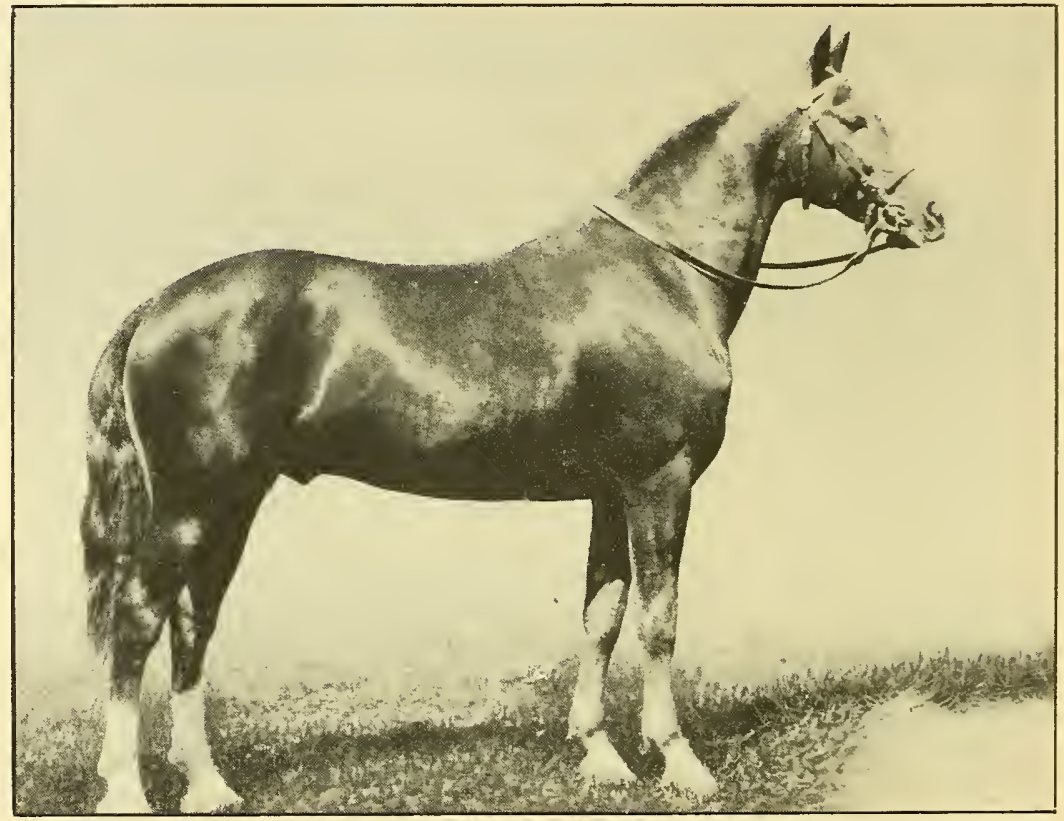

Figure 5.-Morgan stallion.

The Morgan Horse Club, Inc., publishes the American Morgan Horse Register. Five volumes have been published, recording approximately 8,200 stallions and 5,400 mares. F. B. Hills, 90 Broad Street, New York, N. Y., is the secretary.

\section{HACKNEY}

The first driving horses used in England of which much is known were the Norfolk trotters. These horses resulted largely from breeding Norfolk mares to Thoroughbred stallions, and are the foundation for the Hackney breed.

Judged by its best individuals, this breed presents a striking illustration of the high degree to which the horse-breeding art may be developed, for many of them are. wonderful specimens of horse flesh, combining extremely high all-round trotting action and fair speed with abundant substance and quality. For showing in heavy harness the Hackney is without a close rival; in fact, most of the show horses of this class belong to this breed. Purebred and grade Hackneys 
also furnished many of the utility carriage horses when this type was in demand. Crossed with trotting-bred mares, Hackncy stallions have sired many high-class carriage horses in this country. Most of the demand at present for heavy harness horses is for show purposes, and to meet this demand Hackneys are usually bred pure. A Hackney stallion is shown in figure 6 .

The versatility of the Hackney is illustrated by the fact that many successful hunters and jumpers are half-bred Hackneys. The

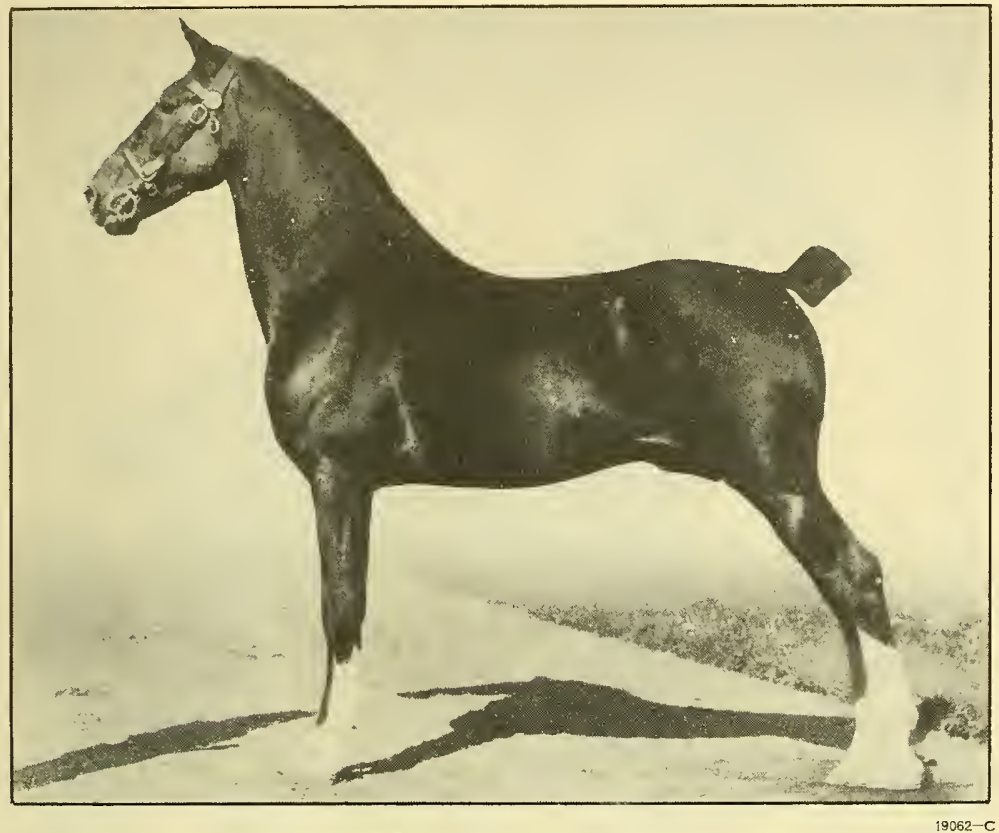

Figure 6.--Hackney stallion.

world's record-holding high jumper, Great Heart, with a record of 8 feet $13 / 16$ inch, was sired by a registered Hackney, as was the previous holder of that record, Confidence.

Chestnut, bay, and brown are the most common colors found in the Hackney breed, although there are roans and blacks. Regular white marks are rather common. In the show ring and also for distinctive carriage use, Hackneys are usually docked and have their manes pulled. In size the Hackney varies more than any other light breed. The small Hackney pony, 14.2 hands and under, and the 16-hand Hackney horse are registered in the same studbook. Hackneys are heavy in proportion to their height when compared with other light breeds, their deep chests, well-sprung ribs, low flanks, and heavy croups and quarters producing weight. The large Hackney sometimes is lacking in general quality, but this is not true of the best specimens and certainly would not be a just criticism of those standing about 14.2 to 15 hands. 
While, as previously stated, the Hackney possesses desirable heavyharness action to a greater degree than any other breed, much of this action is developed by skilled training, bitting, and shoeing.

The association in this country devoted to the interests of the Hackney breed is the American Hackney Horse Society, of which Gurney C. Gue, Merrick, N. Y., is secretary. This society publishes the American Hackney Stud Book, in which more than 2,500 stallions and 4,300 mares have been recorded.

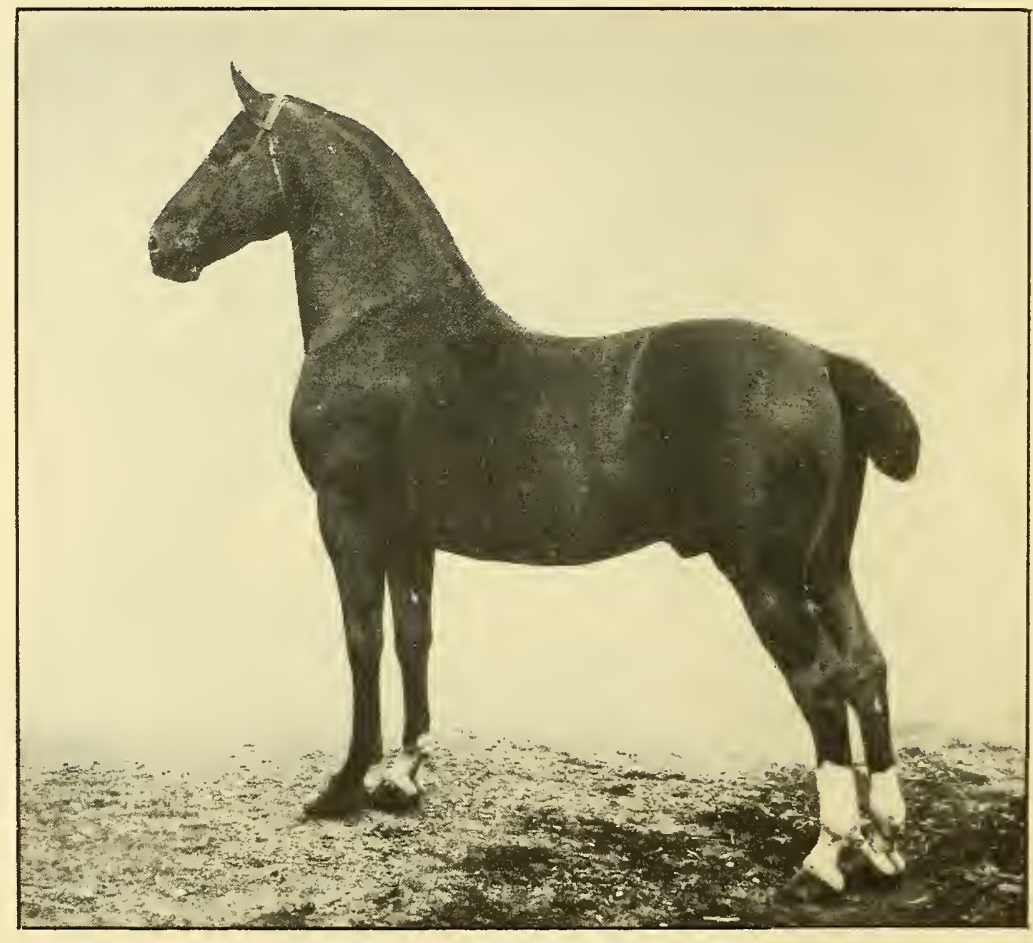

Figure 7.- -French Coach stallion.

\section{FRENCH COACH}

The name French Coach is used in the United States for a breed of horses produced in France largely by Government aid and with the special object of obtaining animals well suited for military purposes. In their native country such horses are not known as French Coach but as Demi-Sang (half-bred). In the United States the term "half-bred" is applied to horses of half or more Thoroughbred blood, and as the French use the term in a similar sense it furnishes an idea of the ancestry of this breed, which is largely the result of crossing Thoroughbred stallions on mares of desirable conformation, their breeding being of minor consicleration.

This system of breeding often resulted in an animal of beautiful conformation, with size, substance, style, and quality. In their 
selection of breeding stock for producing this class of horse, the French have laid a great deal of emphasis on a strong, enduring trot.

While the French Coach horse (fig. 7) is not so large on an average as the German Coach, many French Coach horses stand 15.3 to 16 hands and weigh 1,100 to 1,300 pounds; there is, however, considerable deviation from these measurements. These horses are generally bay or brown, but some are chestnut or black. White marks are not common and are rarely extensive.

During former years French Coach horses appealed strongly to the American importer, with the result that stallions especially were brought to this country in considerable numbers. As a harness horse, it has been very commendable, and some of the get of French Coach stallions have been successful in prominent shows. On account of their mixed ancestry, however, French Coach stallions do not always produce the kind of colts that would be expected when crossed on our mares. Lately, very few French Coach horses have been imported into the United States, and the pure breeding of this stock in this country is very limited.

The French Coach Horse Society of America has kept records of purebred horses of this breed in the United States. Two volumes of the French Coach Stud Book have been issued, and 2,384 stallions and 840 mares have been recorded. Recently the society appears to have been inactive and its officers are not known to the Department.

\section{GERMAN COACH}

Germany, with the object of producing a large, strong, active horse that would be especially well adapted to carrying the German soldier and his heavy equipment and to hauling artillery, established the breed of horses known in this country as the German Coach (fig. 8). In Germany there are several distinct breeds of such horses, each of which is registered in a separate studbook.

The German Coach horse is said to have an infusion of Thoroughbred blood, but present-day types do not show much of it. According to American standards, the German Coach horse lacks quality and is considered the most phlegmatic of the light breeds. It is also the heaviest of the light breeds, such horses often weighing over 1,400 pounds and standing over 16 hands high. Very few specimens of this breed show a tendency to good trappy action, and practically no attempt has been made to produce a fast trot. In color this breed is quite desirable, most of the horses being a rich bay or brown, though some are black. White marks are seldom conspicuous and often are absent altogether. As a general-purpose farm horse and as a heavy harness horse the German Coach at one time gained some popularity in this country, but in general the stallions did not nick well with our mares, and their use has been practically discontinued.

The German, Hanoverian, and Oldenburg Coach Horse Association of America, for a number of years, promoted the interests of this breed in the United States and issued registration papers for German Coach horses of approved breeding. Recently the association appears to have become inactive. G. R. Crouch, La Fayette, Ind., is the last secretary of whom the Department has record. 


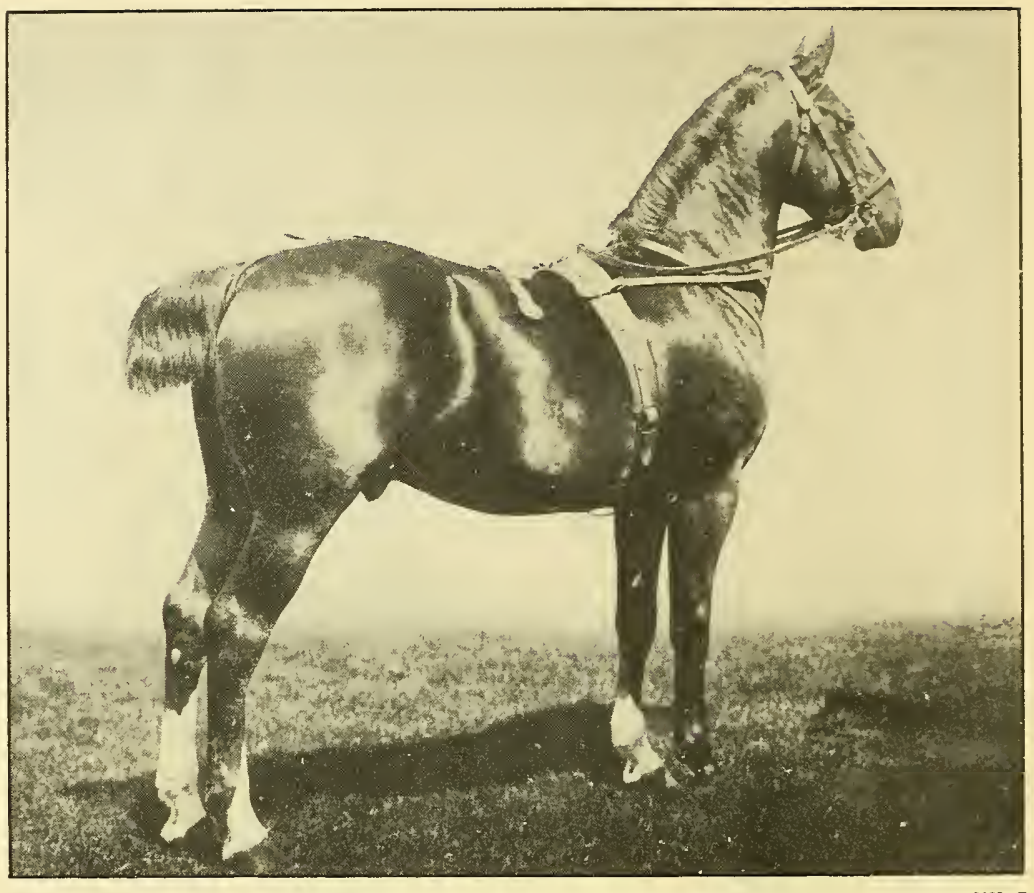

Figure 8.-German Coach stallion.

\section{CLEVELAND BAY}

The Cleveland Bay breed takes its name from the Cleveland district of Yorkshire, England, where it originated, and from its body color, which is invariably solid bay. The legs, mane, and tail are black. White markings, when present, are confined to a small star on the forehead. The breed is derived from the old Yorkshire Pack, or Chapman Horse, which was used in England during the sixteenth and seventeenth centuries, before roads were good enough to permit the utilization of wagons to transport heavy packs of merchandise. During the second half of the eighteenth century a small proportion of Thoroughbred blood was introduced into this breed. The Cleveland Bay is the oldest existing breed of general-purpose horse suitable for riding, driving, and general farm work, and records of its pedigree in many lines run back to as early as 1700 .

In type the Cleveland Bay generally resembles the Thoroughbred, but it has greater substance and power. The ideal Cleveland Bay is characterized by a well-set head; long neck; good withers and slope of shoulders; a deep chest and a large heart girth; short legs; large knees, hocks, and tendons; flat cannon bone; big but not clumsy feet; good coupling and spring of ribs; and long, level hindquarters. In the past the Cleveland Bay has been criticized because of a plain head and long back-derived from its pack-horse ancestry-but these faults have now been virtually eliminated by selective breeding. Cleveland Bays stand from 16 to 17 hands and weigh from 1,350 to 1,550 pounds; 


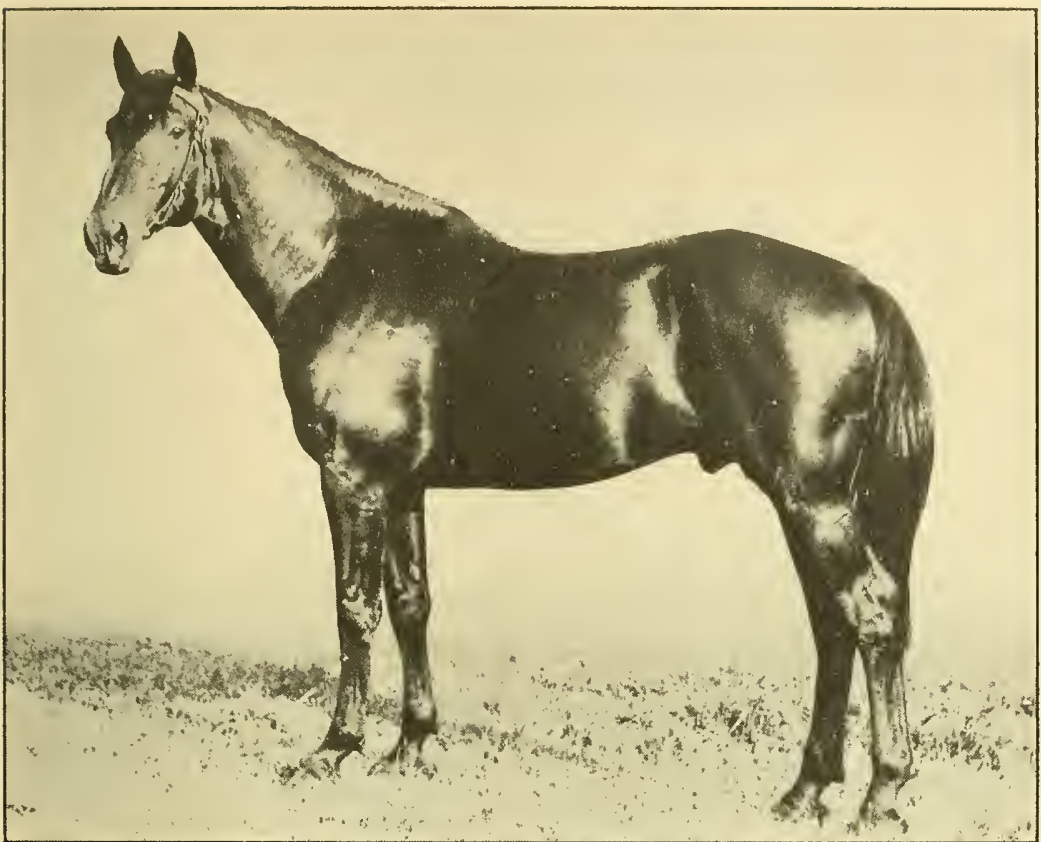

Figure 9.-Cleveland Bay stallion.

they are noted for their fast walk and general activity, for their ability to stand hot weather, and for their quiet dispositions. Owners say that these horses can be maintained on relatively small quantities of feed. Figure 9 shows a Cleveland Bay stallion.

Cleveland Bays were imported into this country as early as 1820 . The Cleveland Bay Society of America was organized in 1885 and has published three volumes of a studbook, the last in 1907 , in which are registered 1,280 stallions and 550 mares. During this period, from 1885 to 1907, Cleveland Bays were used chiefly as general-purpose horses, for driving, and for farm work. With the advent of the automobile it was thought that the demand for the general-purpose horse would cease, and consequently registrations were not kept up.

In recent years some Cleveland Bays have been imported into the United States for two purposes-first to cross with Thoroughbreds, particularly mares, to get heavyweight hunters, a method which has been used with marked success in both England and this country for over 150 years, and, second, to cross them with heavy draft mares to produce an active type of farm horse with a fast walk, resistance to heat, quiet disposition, and small feed requirements. The secretary of the Cleveland Bay Association of America is A. Mackay Smith, White Post, Va. 



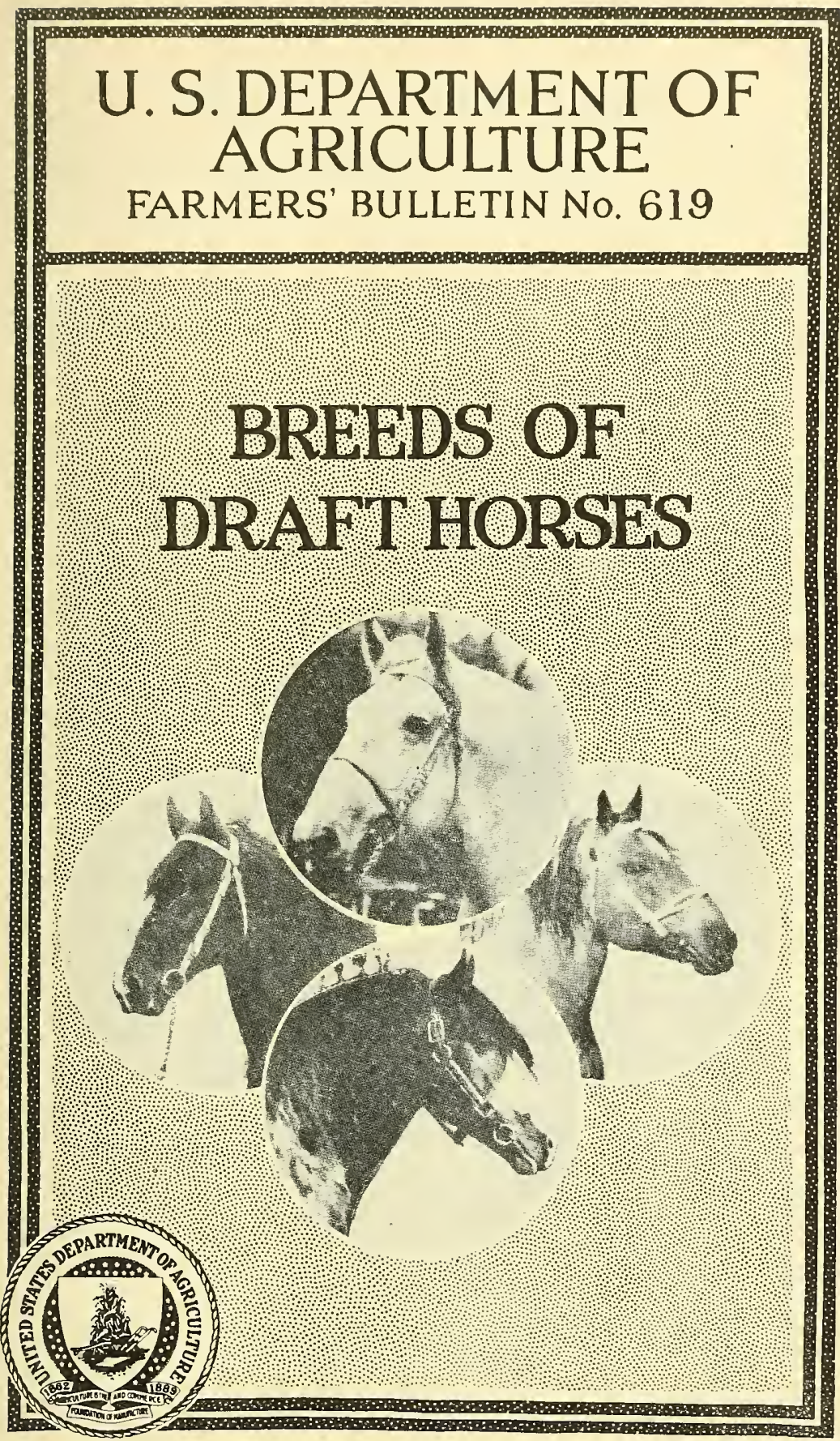


THE PRODUCTION of high-class draft lorses for 1 breeding purposes has, in recent years, assumed special importance in the United States. Formerly it was customary for breeders to import annually many stallions and mares of the draft breeds from such countries as England, Scotland, Belgium, and France. Because of the greatly depleted foreign supply, breeders in the United States are now dependent on draft horses raised in this country for their seed stock.

The purpose of this publication is to present in a concise manner the most important features of the breeds of draft horses in this country. No attempt has been made to give a history of the breeds or information about the early types, as such information would require considerable space and would be of little value to the general reader. For information regarding the rules of registry and the issuance of studbooks and for lists of breeders the reader is referred to the various associations.

Though encouraging the development of improved types of horses and other livestock, the Bureau has no jurisdiction over the registration of animals or the operation of the respective associations. 


\section{BREEDS OF DRAFT HORSES}

By Sanford R. Speelman, associale animal husbandman, Animal Husbandry Division, Bureau of Animal Industry ${ }^{1}$

\section{Contents}

Points of the draft horse

Score card for the draft horse

\section{POINTS OF THE DRAFT HORSE}

THE draft type of horse (fig. 1) is characterized by massiveness, and the particular field for this type is the hauling of heavy loads at a comparatively slow gait, usually at the walk. Therefore power and not speed is desired, and in order to possess this power the horse should be generally blocky or compact, low-set or short-legged, and sufficiently heavy to enable him to throw the necessary weight into the collar to move the heavy load and at the same time maintain a secure footing.

The market requirements classify draft horses according to weight, quality, and utility into heavy draft, light draft, and loggers. The best heavy horses, classified as heavy drafters, stand from 16 to $17 \frac{1}{2}$ hands high (a "hand" being 4 inches) and weigh from 1,750 to 2,200 pounds. The light draft horses are similar in type to the heavy draft horses but are smaller. They range in height from $15 \frac{3}{4}$ to $16 \frac{1}{2}$ hands and in weight from 1,600 to 1,750 pounds. The loggers are big, rugged horses suitable for lumbering work. Although as large and heavy as the heavy draft horses, they are plainer and sometimes slightly blemished or unsound. The range in height and weight for loggers is practically the same as for heavy drafters.

Chunks, essentially little drafters, are classified chiefly from the standpoint of conformation but are usually more blocky and compact. The eastern chunk is of true draft-horse conformation, but with less height and weight, ranging in height from 15 to 16 hands and in weight from 1,300 to 1,550 pounds. Farm chunks, commonly known as general-purpose horses, are not quite so heavy nor so good in quality as the eastern chunks. Farm chunks range in height from 15 to $15 \%$ hands and in weight from 1,200 to 1,400 pounds.

In the typical drafter the head is comparatively lean, wide between the eyes, and in size proportionate to the body. The eye is bright and fairly prominent. The neck is strong and muscular, of fair length, and somewhat arched; in the stallion it is well arched or crested, in the gelding or mare less so. The shoulders are shorter and more

\footnotetext{
1 This is a revision of former editions by G. A. Bell, who resigned in 1920 .
} 
upright than those of the light horse, and a happy medium between the straight and sloping shoulder gives the best combination of power and movement. Too straight a shoulder causes excessive concussion, and the result is bone and tendon trouble in ihe feet and legs. On the other hand, too sloping a shoulder renders it difficult to fit the heavy collars properly. In the draft horse, however, the former is much more common than the latter.

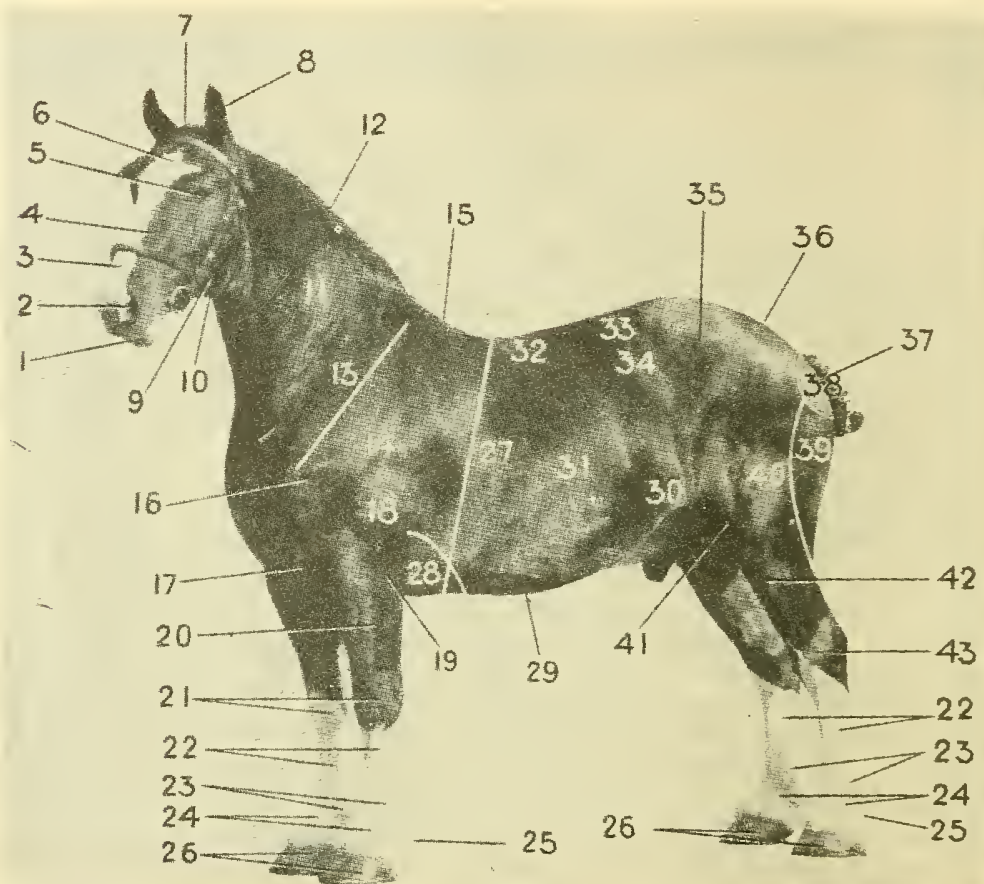

Figure 1.-The points of the horse: 1 , Mouth; 2 , nostril; 3 , nose; 4, face; 5 , eye; 6 , forehead; 7 , poll; 8 , ear; 9, lower jaw; 10, throatlatch; 11, neck; 12 , crest; 13 , shoulder bed; 14 , shoulder; 15 , withers; 16 , point of shoulder; 17 , breast; 18 , arm; 19, elbow; 20 , forearm; 21 , knees; 22 , cannons; 23 , fetlocks; 24 , pasterıs; 25 , feather; 26 , feet; 27 , heart girth; 28 , foreflank; 29 , underline; 30 , hind flank; 31 , barrel; 32 , back; 33 , loin; 34 , coupling; 35 , hip; 36 , croup; 37 , tail; 38 , buttock; 39 , quarters; 40 , thigh; 41 , stifle, 42 , gaskin; 43 , hock.

The chest is deep and comparatively broad, thus providing plenty of room for the lungs. The heart girth, or the body's circumference behind the forelegs, is large, and horses slack in that region are usually weak in constitution. The body is broad, deep, and comparatively short; the back is short and broad and the ribs well sprung, giving a round appearance to the body. The horse with a shallow body is usually a poor feeder. The loin is broad and well muscled; the croup is fairly level, long, broad, and well museled. A short, decidedly sloping croup is not so well muscled as the straighter and longer one. The hind quarters and thighs are well museled; it is from the hind quarters that the horse obtains most of its propelling power, the front legs acting largely as weight carriers. 


\section{SCORE CARD FOR THE DRAFT HORSE}

\section{SCALE OF POINTS}

GENERAL APPEARANCE-18 points

Height: Estimated hands ...... ; actual hands ......

Weight: Estimated .......; actual _....... ; according to age and type _ 4

Form: Broad, deep, massive, well proportioned, low set.......... 4

Quality and substance: Abundance of clean, flat bone; broad, welldefined joints and tendons; refined head and ears; fine skin and hair; feather, if present, silky...

Temperament: Energetic, good disposition

HEAD AND NECK-7 points

Head: Proportionate, medium size, clean cut; widle lower jaw.......

Forehead: Broad, full

Eyes: Large, prominent, bright, clear..............................

Muzzle: Broad, fine; large nostrils; trim, even lips...............

Ears: Of medium size, well-set, carried alert . . . . . . . . .

Neck: Medium long, muscular; good crest; clean throatlatch.........-

FOREHAND-26 points

Shoulders: Sloping, muscular, blending into smooth withers

Arms: Short, muscular, elbow in

Forearms: Wide, muscular

Knees: Straight, wide, deep, well supported

Cannons: Short, wide, lean, flat; large, well-defined tendons........

Fetlocks: Wide, straight, tendons well back, well supported...........

Pasterns: Of medium length, oblique (about $45^{\circ}$ ), clean, strong

Feet: Large, round, set straight; dense, smooth horn; slope of wall parallel to pastern; wide heels; concave sole; strong bars; prominent, elastic frog

Leg position: In front, a perpendicular line from point of shoulder should divide the leg and foot into lateral halves; from the side, a similar line from the bony prominence on shoulder blade should pass through the center of elbow, knee, and pastern joints, and meet the ground back of foot.

BODY-9 points

Chest: Deep, wide, large girth

Ribs: Long, well sprung, close, strongly coupled

Back: Short, broad, heavily muscled.

Loin: Short, wide, heavily muscled

Flanks: Deep, full; long, low underline.

Hips: Wide, smooth, level, well muscled.

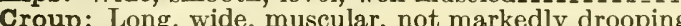

Croup: Long, wide, muscular, not markedly drooping

Tail: Set high, well carried

Quarters and thighs: Deep, thick, muscular, strongly joined to gaskins,

Stifles: Muscular, well set_.......

Gaskins (lower thighs): Wide, heavily muscled.

Hocks: Wide, deep, prominent point, clean cut, straight, well supported-

Cannons: Similar to front except a trifle longer and wider........

Fetlocks: Wide, straight, tendons well back, well supported

Pasterns: Similar to front but less sloping (about $50^{\mathrm{c}}$ )

Feet: Similar to front but not quite so large or so round

Leg position: From rear, a perpendicular line from point of buttock should divide the leg and foot into lateral halves; from the side, this same line should touch the point of hock and run parallel to the cannon. A similar line from the hip joint should meet the ground midway between the heel and toe

Walk: Straight, long stride, springy and balanced

Trot: Straight, long stride; free and regular 
Good underpinning, consisting of good legs and feet, is essential. Good, big, clean, heavy bone is necessary in order to afford attachments for the heavy muscles and to stand the wear and tear of hard work. The cannon bones are the best indication of the bone throughout. In this region the bone should feel firm, and the tendons should stand out distinctly from the bone, giving the cannon bones when viewed from the side a wide, flat appearance. The knee should be broad and deep when viewed from the front. The hock should be broad from front to back, and of strong structure. The pasterns should be fairly long and sloping. Though some draft horses possess too long and too sloping pasterns, a much larger number have too sholt and too straight pasterns. The foot should be fairly large and round and the horn dense. The dark-colored hoofs are most popular, as it is thought they denote greater durability. In the draft horse as much quality as is consistent with the required substance is desirable, but quality should not be obtained at the sacrifice of too much weight.

In temperament the draft horse is generally lymphatic, but he should not be too sluggish. Although the nature of his work requires him to be steady and easily managed, it is nevertheless essential that he perform it willingly and with some snap and vigor.

The draft-horse gait is the walk. The stride should be rapid and of good length, and the feet should be carried straight forward. This kind of action makes possible the covering of the most ground in the least possible time. While the walk is the normal gait, the ability to trot well is desirable. Often faults not noticeable at the walk are brought out at the trot.

\section{BELGIAN}

The Belgian draft horse (figs. 2 and 3), as the name indicates, originated and has been developed in Belgium, and is the only breed of horses which is bred to any extent in that country, the light horses used in Belgium being purchased largely in other countries. In 1886 the Belgian Draft Horse Society was organized for the purpose of encouraging the breeding of native draft horses and of maintaining a studbook for the breed. In June of each year the annual show of this society is held at Brussels. At the thirtieth annual show, held in June 1919, the entries totaled more than 800. In 1913 and 1914 the total number of entries for each year was in excess of 1,000. This event is probably the largest show of a single breed of horses ever held in the world. The breeding of Belgian draft horses is also promoted by the Government, which annually awards prizes and subsidies to the best animals in the various Provinces. Stallions which stand for public service must be approved by a commission appointed by the Government.

Importations of these horses into the United States were made more or less frequently during the last half of the nineteenth century, but it was not until the beginning of the twentieth century that they were imported in large numbers. The early trade was principally a stallion trade, but later a considerable number of mares were imported.

The Belgian divides honors with the Shire as being the heaviest of the breeds. Mature stallions in fair condition, weighing a ton or more, are comparatively common. In height mature stallions will 
probably average slightly over $161 / 4$ hands, and mature mares about 16 hands. In general conformation they are the most compact of all breeds, the bodies being short, wide, and deep. The head is of medium size, the neck is short and heavily crested or arched, the chest is broad and deep, the back is short and well muscled over the loin, the croup is somewhat drooping or steep, and the quarters are full and heavily muscled. The legs are short and free from the long hair or feather characteristic of the Clydesdale and the Shire. In action the Belgian is good, but is less active than the Clydesdale or the Percheron. In temperament he is docile and easily handled. He is a

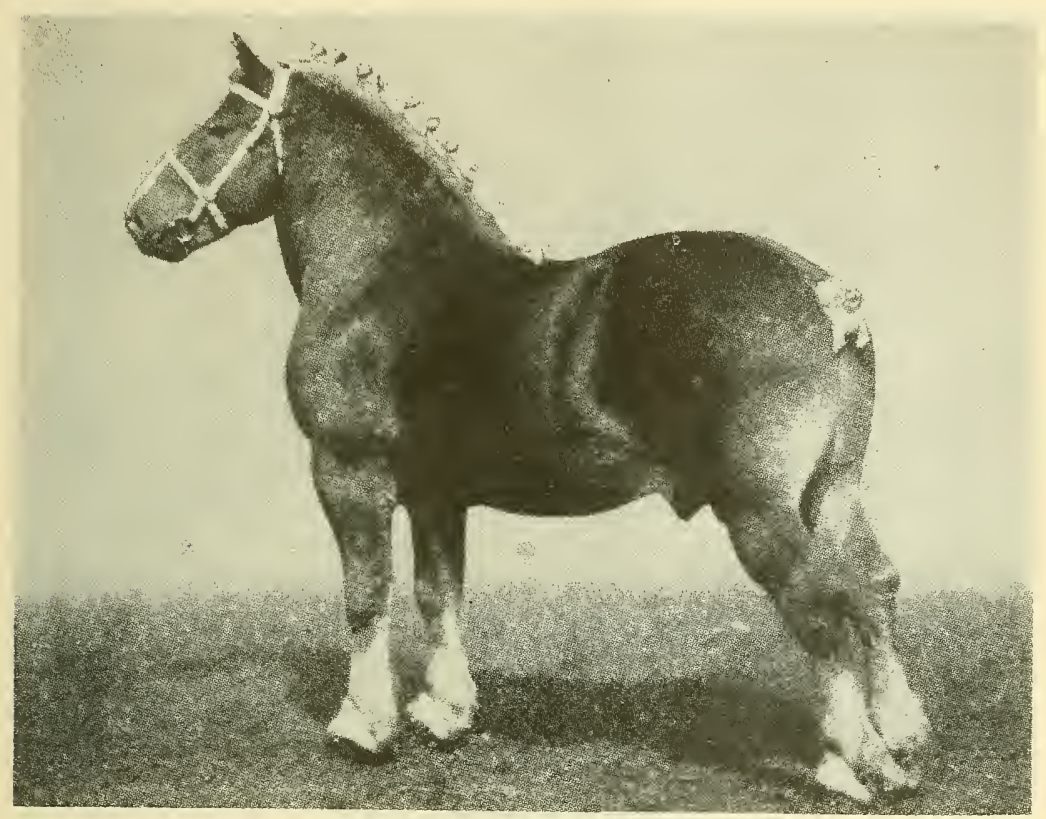

FIGURE 2.-Belgian stallion.

good feeder, is rated as an easy keeper, and stands shipment well. The colors common to the Belgian are bay, chestnut, and roan, but browns, grays, and blacks are occasionally scen.

Some of the eriticisms of the Belgian horse are that a large number have necks that are too short and heavy, too drooping a croup, a roughness about the hocks, bone that is not sufficiently flat, too short and straight a pastern, hoof deficient in circumference, and a lack of general quality; but great improvement has been noted in respect to these deficiencies in recent years. The extreme width may cause Belgians to roll somewhat at the walk, but as a class they are good movers at the trot.

In this country the Belgian sire has been valuable in improving the draft conformation of our horse stock, particularly when mated with many of our rangy, loosely coupled mares. The breed has made wonderful progress in this country, considering that it has attracted much attention only since the beginning of the twentieth century. 
In fact no breed of horses has shown a greater increase in popularity and a greater improvement during this period.

The distribution of the Belgian draft horse in the United States is widespread, but it is found in the greatest numbers in those sections where the heaviest type of draft horse is most prevalent, such as the Central West, particularly in Indiana, Iowa, Illinois, Ohio, Michigan, and Minnesota.

The American Association of Importers and Breeders of Belgian Draft Horses was organized in 1887, but the first volume of its studbook was not published until 1905. Twenty-three volumes have

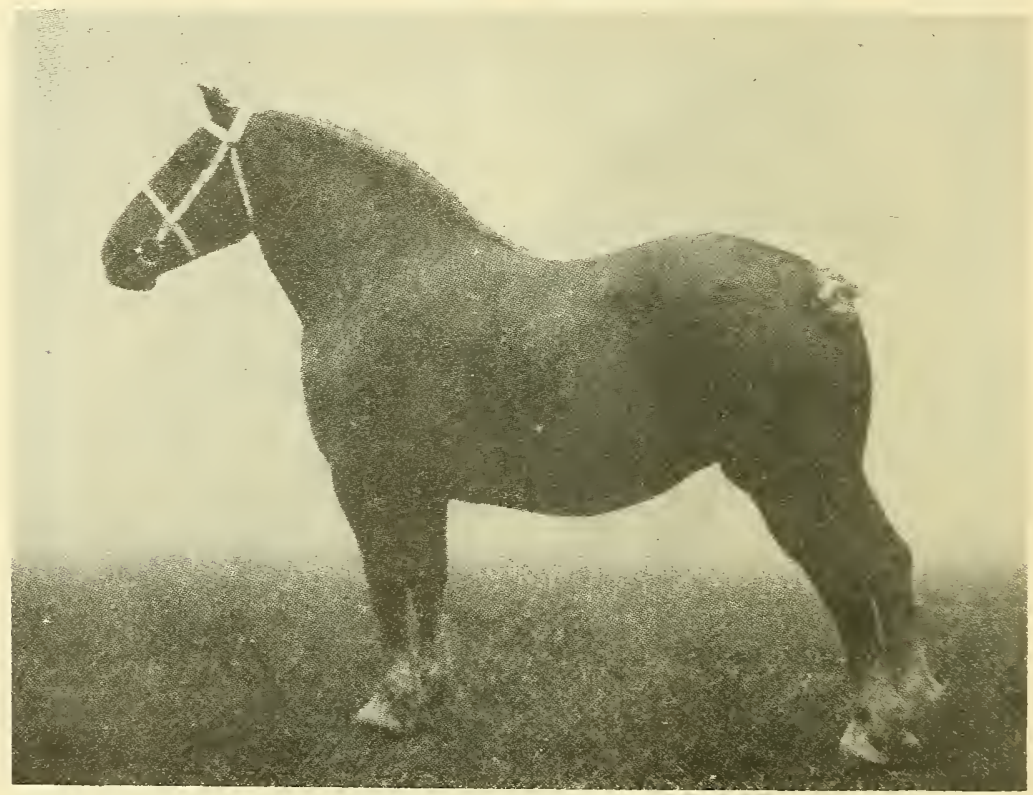

Figure 3.-Belgian mare.

been issued, and up to December 31, 1939, 25,378 stallions and 25,476 mares had been recorded. The secretary of the association, which is now known as the Belgian Draft Horse Corporation of America, is H. J. Brant, 161 Ferry Street, Wabash, Ind.

\section{PERCHERON}

The Percheron (figs. 4 and 5) originated in France and has been developed in a small district in the northwestern part of that country known as Perche. This district is about one-fifteenth the size of the State of Iowa, and only Percherons born within its boundaries are eligible to registry in the Percheron Studbook of France. Percheron foals, to be accepted for registry in the French book, must be registered during the year of their birth. Prior to such registration they must be examined by an official appointed by the Percheron Horse Society of France, who takes a careful description of their color and markings and brands them on the neck with the letters "S. P." enlaced. 
The Percheron Horse Society of France was organized in 1883, and in addition to looking after the registration of Percherons it holds an annual summer sliow in the Percheron district. The society also offers prizes at other shows. The improvement of the Percheron and other breeds in France is due to both public and private efforts. The Government has for a number of years maintained studs in which selected animals have been kept for breeding purposes. In addition, subsidies are granted to private individuals in order to keep high-class horses in the stud. Stallions intended to stand for public service in lirance must be examined by officials appointed by the Government

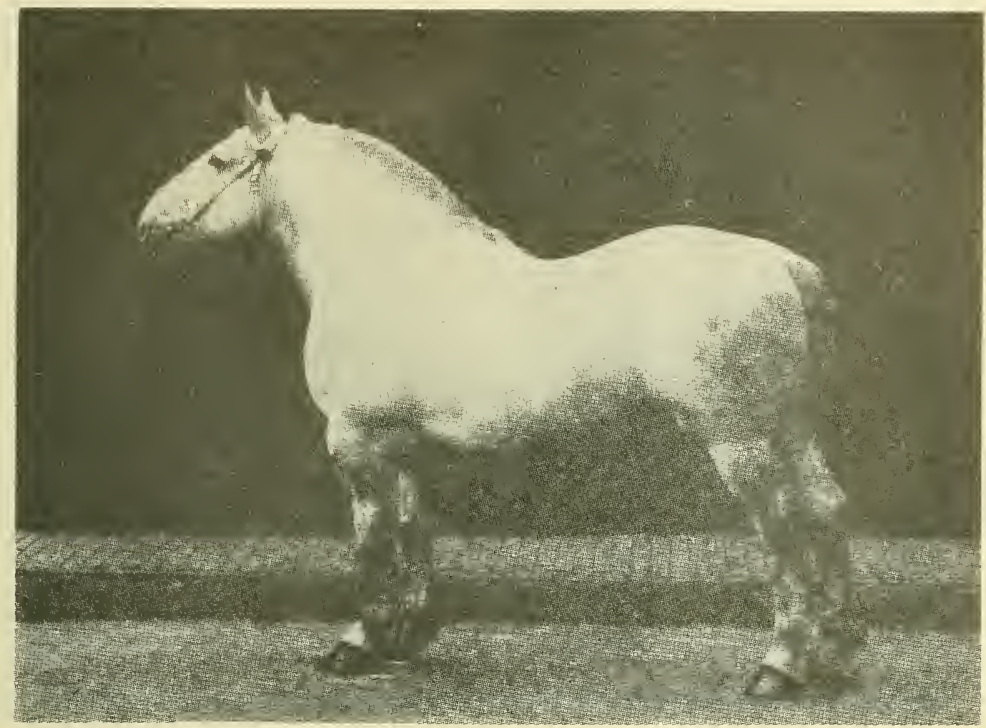

FigURE 4.-Percheron stallion.

and certified as being free from periodic ophthalmia, or moon blindness, and roaring. (thick wind).

The introduction of Percheron horses into the United States dates back many years. One of the early stallions brought to this country which exerted considerable influence on our draft stock was Louis Napoleon imported in 1851 by an Ohio firm. Other Percherons were imported about this time and during succeeding years. During the early seventies they were imported in large numbers, and these importations have continued to the present time.

The head of the Percheron is clean-cut, of medium size, and more refinement is noticed about the head and neck of the Percheron than in any other draft breed. The neck is rather short and well crested. The chest is deep and broad, the back is short, the loins smooth and well muscled. The croup is wide, and on the average is somewhat more sloping than is considered desirable, but great improvement in this respect has been made in recent years. The legs, feet, and bone are on the average good. The legs are free from the long hair 
or feather characteristic of the Clydesdale and the Shire. In action the Percheron is good at both the trot and the walk, and the trot is characterized by a snap and boldness not ordinarily displayed by most of the other draft breeds. This breed may be regarded as one of the best movers and is surpassed in style of action only by the Clydesdale.

The Percheron is not so large a horse as either the Belgian or the Shire, but as a class will probably outweigh the Clydesdale slightly. Good, mature stallions in fair condition will usually weigh from 1,800

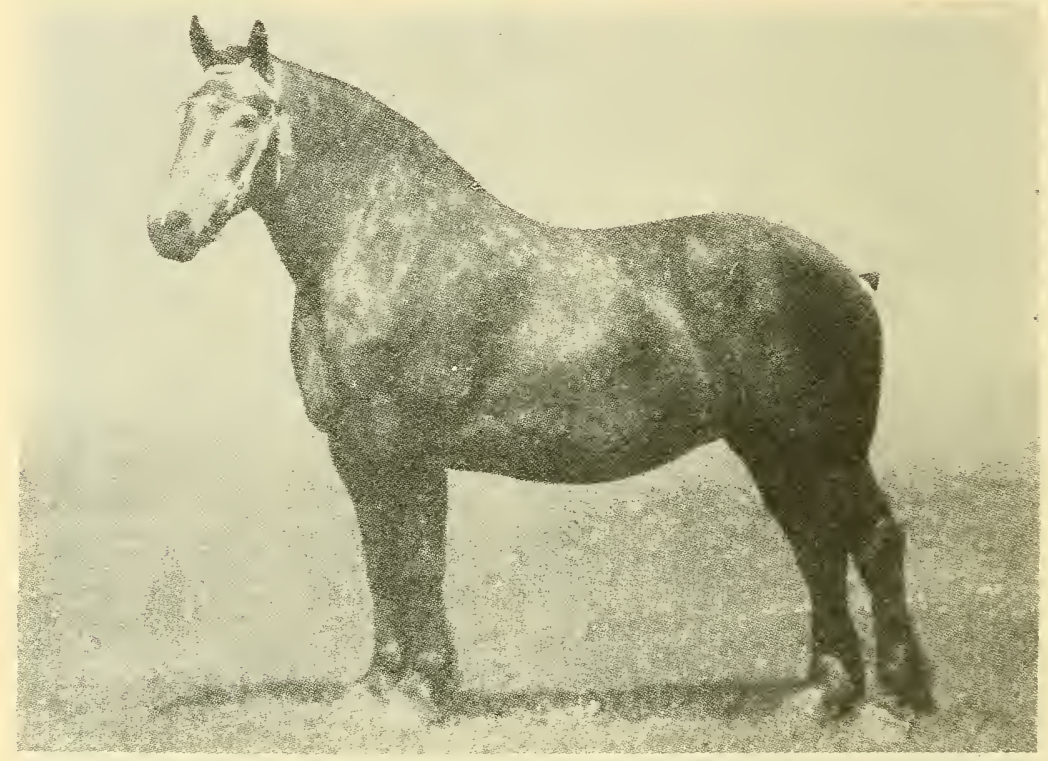

Figure 5.-Percheron mare.

to 2,000 pounds, and there are many which weigh considerably over 2,000 pounds. In height good mature stallions will measure 16 to 17 hands, generally averaging about $16 \frac{1}{2}$ hands, but of course there are some under and a few over these heights, although the rangy, tall Percheron is not in demand in this country. The popular Percheron is rather short-legged, compact, and blocky in form, less so than the Belgian, but more so than the Clydesdale or even the Shire.

The colors common to the Percheron are black and gray, although bays, browns, chestnuts, and roans are occasionally seen. It may be safely stated, however, that 90 percent of our Percherons are either black or gray.

Occasionally difficulty may be experienced in deciding whether an animal is a Percheron or a Belgian, but the two types are very distinct. The Belgian is heavier bodied, more compact, shorter legged, and his head is more nearly square in outline; the neck is shorter, more heavily muscled, and more heavily crested. Moreover, the colors common to the Belgian--namely, bay, chestnut, and roan--are 
uncommon to the Percheron, whereas the gray and black colors common to the latter are uncommon in the Belgian.

Some Percherons are criticized as having croups too sloping or steep, with the tail set too low. Others are criticized as being too fine-not sufficiently drafty-having a lack of depth and fullness of body. Other faults which are sometimes seen are cannon bones which are rather round (lacking in breadth and flatness), lack of bone for the size of the body, and pasterns which are too short and straight.

The distribution of the Percheron in this country is very widespread, and for years it has been the favorite draft horse. In the United States today Percherons outnumber all other draft breeds combined, and there does not appear to be any diminution in their popularity. This probably is due in part to the good start given the breed by the pioneer importers and breeders, but this popularity must be attributed to some extent, at least, to their general adaptability to the needs and preferences of their owners. For crossing on ordinary mares the Percheron stallion has been very popular, so that grade Percherons are very common and are great favorites in our horse markets.

In 1876 the National Association of Importers and Breeders of Percheron-Norman Horses was organized. 'The Percheron Society of America, now known as the Percheron Horse Association of America, was an outgrowth of that association. The twenty-third volume of its studbook was issued in July 1936. No later volumes have been published. Up to December 31, 1939, 236,069 animals had been accepted for registration. The secretary is Ellis McFarland, 9 Dexter Park Avenue, Union Stock Yards, Chicago, Ill.

\section{FRENCH DRAFT}

The name "French Draft" is applied broadly to all breeds of draft horses originating in France and does not refer to one specific breed, as might be inferred from its usage in this country. This classification includes the Percheron and a number of other draft breeds in France, such as the Boulonnais, Nivernais, Breton, Ardennais, and Picardy. Of all the French breeds the Percheron is by far the best known and has obtained a much greater foothold in this country than any other breed of draft horses. Of the other French breeds, the Boulonnais and the Nivernais are the only ones of any particular interest in the United States.

The Boulonnais is found in northern France in the vicinity of Boulogne and in adjoining districts in Belgium. This breed is probably a trifle larger than the Percheron and somewhat coarser but in general type resembles the Percheron rather closely. The color common to the Boulonnais is gray, but occasionally other colors are seen. This breed has been imported in larger numbers than the Nivernais.

The home of the Nivernais is in central France, in the Department of Niève. In type it is very similar to the Percheron. The color is black.

The National French Draft Horse Association of America, which for many years fostered the interests of the French Draft breeds in this country, was organized in 1885 and succeeded the National Nor- 
man Horse Association, which had its beginning in 1876. Until its dissolution the National French Draft Horse Association published a studbook in which were registered horses of the French Draft breeds. Fourteen volumes of its studbook were published, and approximately 35,000 animals were registered.

\section{CLYDESDALE}

The Clydesdale (figs. 6 and 7) originated and has been developed in Scotland, and is practically the only draft horse found or favored in that country. The breed is of mixed origin, and its early history is more or less obscure.

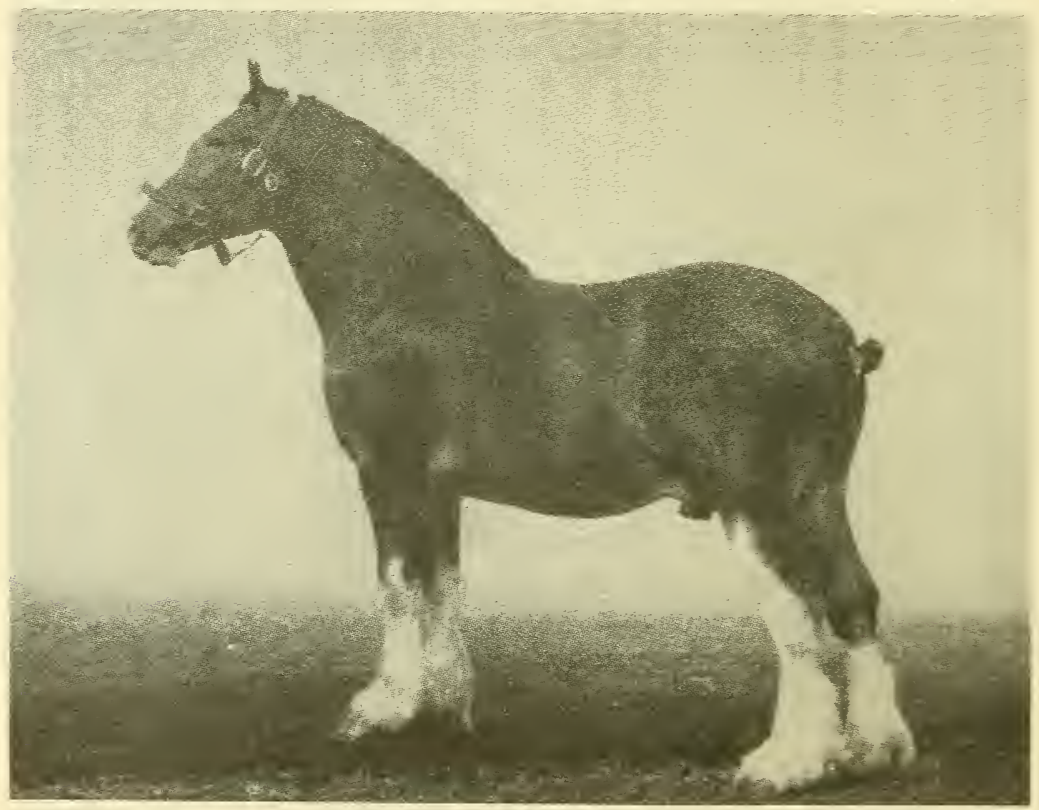

Figure 6.-Clydesdale stallion.

In the formation of the breed and during the early stages of the breed's development, however, it is probable that the blood of both Flemish and English horses was used quite largely. For a number of years the Clydesdale has been bred pure. In 1878 the Clydesdale Horse Society of Great Britain and Ireland was organized.

The first Clydesdales brought to North America were probably imported into Canada by the Scotch who had settled there. In the early seventies Clydesdales were imported into this comtry both through Canada and by direct importation. By 1880 they were being imported in large numbers, and these importations continued fol several years.

The Clydesdale is not so heary as either the Belgian or the Shire, and probably, as a class, will not weigh quite so much as the Percheron. In general conformation, the Clydesdale is more rangy and lacks the width and compactness of the other breeds mentioned. 
The Scotch breeders have paid particular attention to legs, pasterns, and feet, but have placed less emphasis on weight than has been the case in other draft breeds. Average mature Clydesdale stallions in this country will probably weigh from 1,700 to 1,900 pounds when in fair condition, with an average height of nearly $16 \% / 4$ hands. Mature mares will probably weigh 1,600 to 1,800 pounds and average about 16 hands in height.

No other draft breed equals the Clydesdale in style and action. The prompt walk with a good, long, snappy stride, and a sharp trot with hocks well flexed and carried close together are characteristic

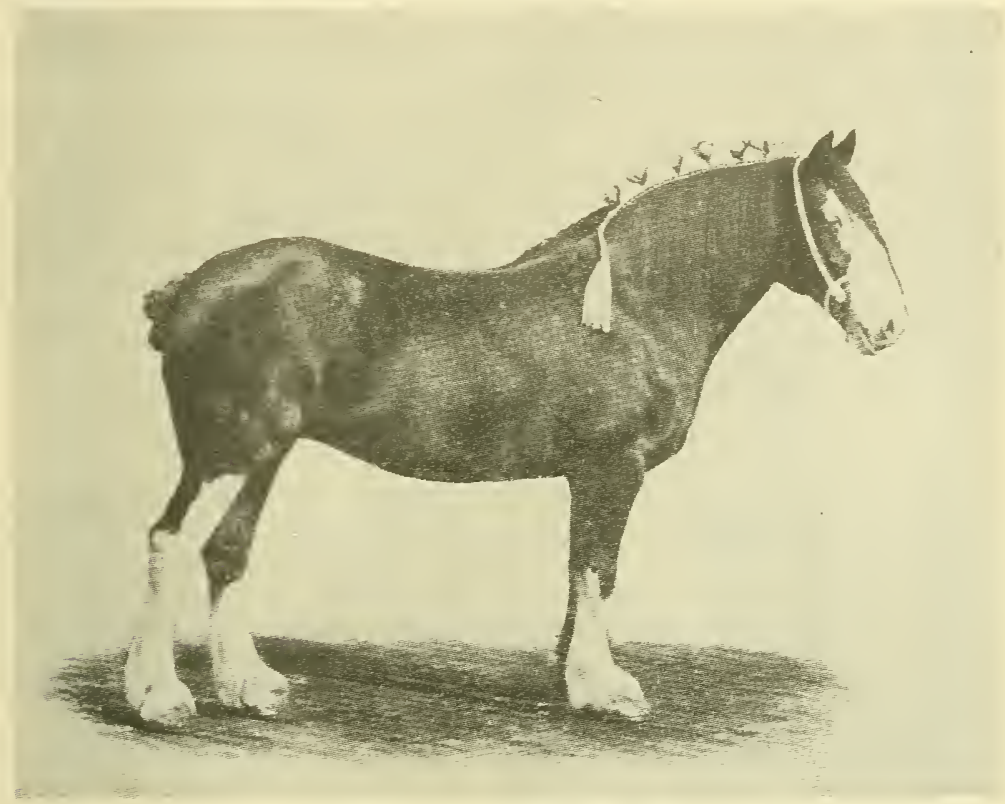

Figure 7.-Clydesdale mare.

of this breed. Sound, clean, flat bone; well-set, fairly long, sloping pasterns; large, round feet; and a moderate amount of fine feather or long hair at the rear of the legs below the knees and hocks are important and characteristic features. The colors most common are bay and brown with white markings, but blacks, grays, chestnuts, and roans are occasionally seen. The white markings are characteristic, and it is the exception to see a bay or brown Clydesdale without a white face and considerable white on the feet and legs.

Some of the criticisms of this breed have been the lack of size of body, lack of width and depth, too much feather, and too much white with no regularity of distribution. Most draft-horse users in this country, particularly farmers, dislike a horse with a white face and legs. Nor has the feather been very popular owing to the extra care necessary to keep the legs clean. This, of course, is not so objectionable in those sections where most of the roads are improved. 
It is not always easy to differentiate between Clydesdales and Shires, but taking the breeds as a whole, they are very distinct. The Clydesdale is not so heavy bodied as the Shire, has more refinement, and the feather is somewhat more silky or finer and less abundant than in the Shire.

In this country Clydesdale geldings have been very popular in the cities for use by those who want draft horses with a good, long, snappy, ground-covering stride and at the same time possessing style and action. Our native mares of draft character bred to Clydesdale stallions have produced many excellent animals.

The distribution of the Clydesdale in this country is widespread throughout the northern half; the breed is seldom found, however, in the South. It has found the most favor in Iowa, Illinois, Wisconsin, Minnesota, North Dakota, and Indiana.

The American Clydesdale Association was organized in 1879 and operated under that name until 1934, when it became known as the Clydesdale Breeders Association of the United States. Up to December 31,1939 , these associations had issued 21 volumes of the American Clydesdale Studbook. It is understood that three additional volumes are about ready for publication, and to December 31, 1939, 24,784 animals had been registered. The business of the society is handled by its secretary, Margaret Coridan, 840 Exchange Avenue, Union Stock Yards, Chicago, Ill.

\section{SHIRE}

The Shire (figs. 8 and 9) originated and was developed in England and today is bred in all sections of that country. The real origin of this breed is more or less speculative. It is known that this type of draft horse existed in England in early times. It is probable that the early Shire was of very mixed breeding, but at the present time the Shire is bred very pure. In 1878 the Shire horse breeders of England were organized under the name of the English Cart Horse Society. In 1884 the name was changed to the Shire Horse Society. In addition to the registration of horses, the society holds an annual show and sale in London, and also awards medals and prizes at the leading agricultural shows in England and at some of the fairs and expositions in the United States.

Shires were imported into this country a good many years ago. George E. Brown, in volume 1 of the American Shire Horse Studbook, states that in 1853 a Mr. Strickland imported a stallion direct from England to Aurora, Ill., where the horse was known as John Bull. Volume 1 of this studbook shows the registration of a small number of stallions imported in 1880 , and these importations increased until in 1887 more than 400 Shires were imported.

The Shire is a massive horse, with a wide, deep, and long body, and is equaled in weight only by the Belgian. Shire stallions in fair condition weighing 2,000 pounds or over are comparatively common. They are less compact, or more rangy, than the Belgian, and in height will average taller than any other draft breed. Stallions standing 17 hands or more in height are very common; in fact, the average height of mature Shire stallions in this country is close to 17 hands. Mature Shire mares will average about $16 y_{4}$ hands in height and will. 
in fair condition, average about 1,800 pounds in weight. Heavy bone and feather are characteristic of this breed. In temperament the Shire is probably more lymphatic than any of our other breeds, and therefore less active than is desired by many. The common colors are bay and brown, with white markings, although blacks, grays, chestnuts, and roans are occasionally seen.

This breed has been eriticized for lack of quality and refinement in general, a sluggish temperament, the abundance of feather, and the large amount of white, but breeders have shown marked progress in

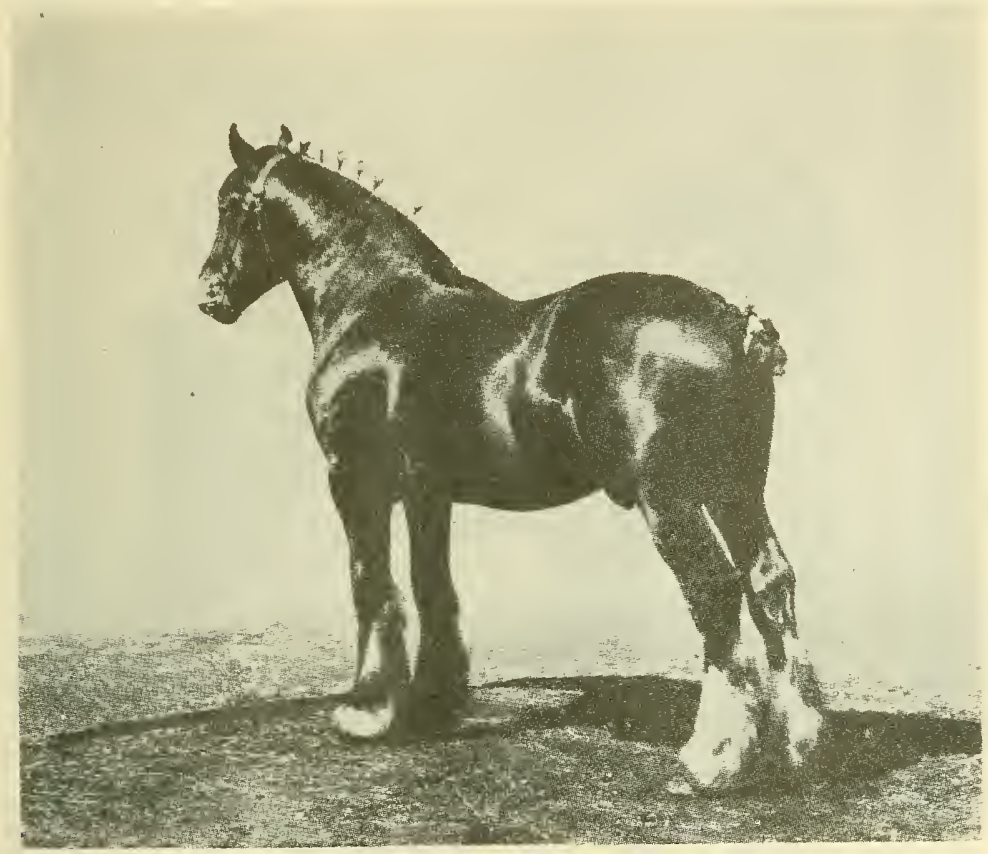

FigURE 8.-Shire stallion.

overcoming these objections during the last few years. From the standpoint of many users in the United States the abundant feather is objectionable, owing to the difficulty of keeping the legs clean.

Although some Shires and Clydesdales are so similar as to render it difficult at times to distinguish the one from the other, the two types are really very distinct. The Shire is more massive, heavier bodied, throughout, and the feather or long hair on the legs is more abundant and coarser than that of the Clydesdale.

The distribution of the Shire throughout the northern half of this country is widespread, but like the Clydesdale, it is seldom found in the Southern States. This breed has met with the most favor in the Central West, particularly in Illinois, Iowa, and South Dakota; it is also popular on the Pacific coast. A great many of our best market geldings possess some Shire blood; and where height as well as bone 
and substance is desired, it can be derived from Shire blood with greater certainty than from other breeds.

The American Shire Horse Association was organized in 1885 and has issued 14 volumes of its studbook. Up to December 31, 1939, 21,712 animals had been registered by the association. The secretary is E. F. Fox, 319 East Fourth Street, Des Moines, Iowa.

\section{SUFFOLK}

The native home of the Suffolk breed is Suffolk County, in eastern England, and the production of the breed in that country is confined

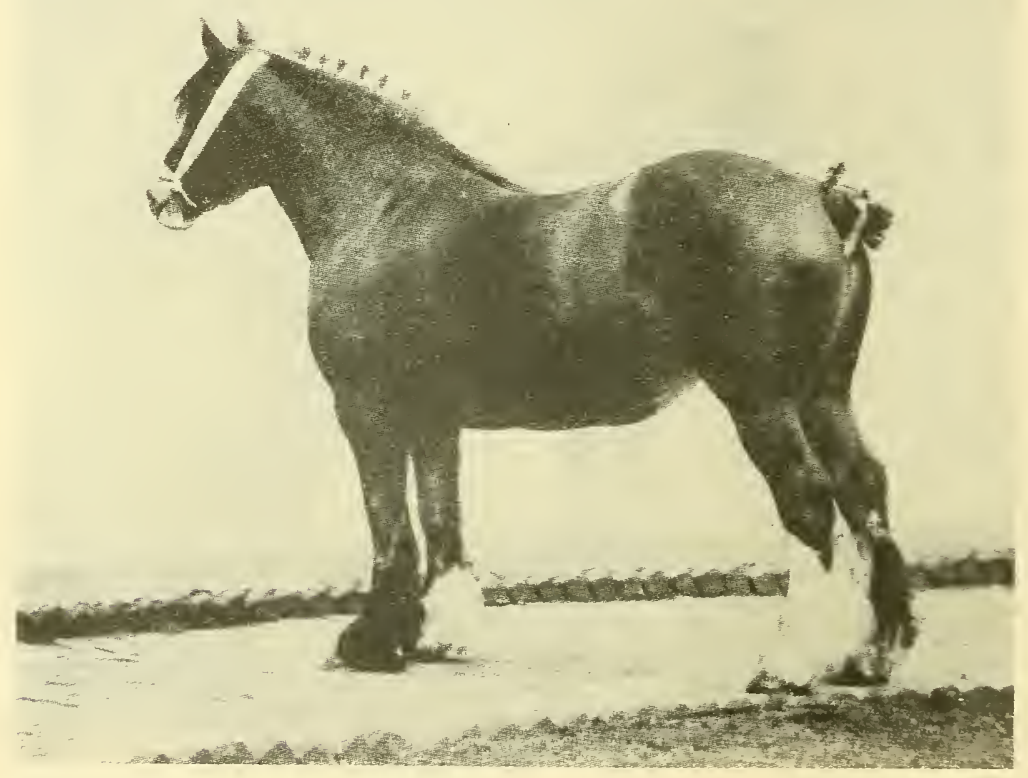

Figure 9.-Shire mare.

almost entirely to Suffolk and adjoining counties. Some authorities believe the Suffolk originated about A. D. 1700 and that possibly it is a descendant of Normandy horse stock. However, the breed's foundation is usually traced back to a prolific chestnut-colored stallion, known as the Crisp Horse, who was foaled in Sussex in 1768 and is credited with being the progenitor of all stock registered in the English and American studbooks for Suffolk horses. Throughout its relatively long history the Suffolk has been bred pure, and as a consequence the type has generally been kept quite uniform. Moreover, the Suffolk has not been bred for the heavy draft work of the city but largely for the farm, and for this purpose it ranks high among the farmers of eastern England, who consider it capable of doing a large amount of labor on a small quantity of feed and for longer periods than other drafters. The breed is used more exclusively for farm work than are any other of the draft breeds. 
In size the Suffolk (figs. 10 and 11) is smaller than other drafters; and though occasionally a mature stallion in fair condition may weigh 2,000 pounds, such a weight is not characteristic of the breed. Considering their size, the Suffolks have deep and wide bodies, and the ribs have a pronounced spring, giving the body a round and full appearance. The croup is straight, the sloping croup being scldom seen in this breed. The quarters are round and well muscled. The legs are short and are particularly free from long hair or feather, and the bone has the appearance of being small as compared with the size of the body. The color is always chestnut, varying from light to

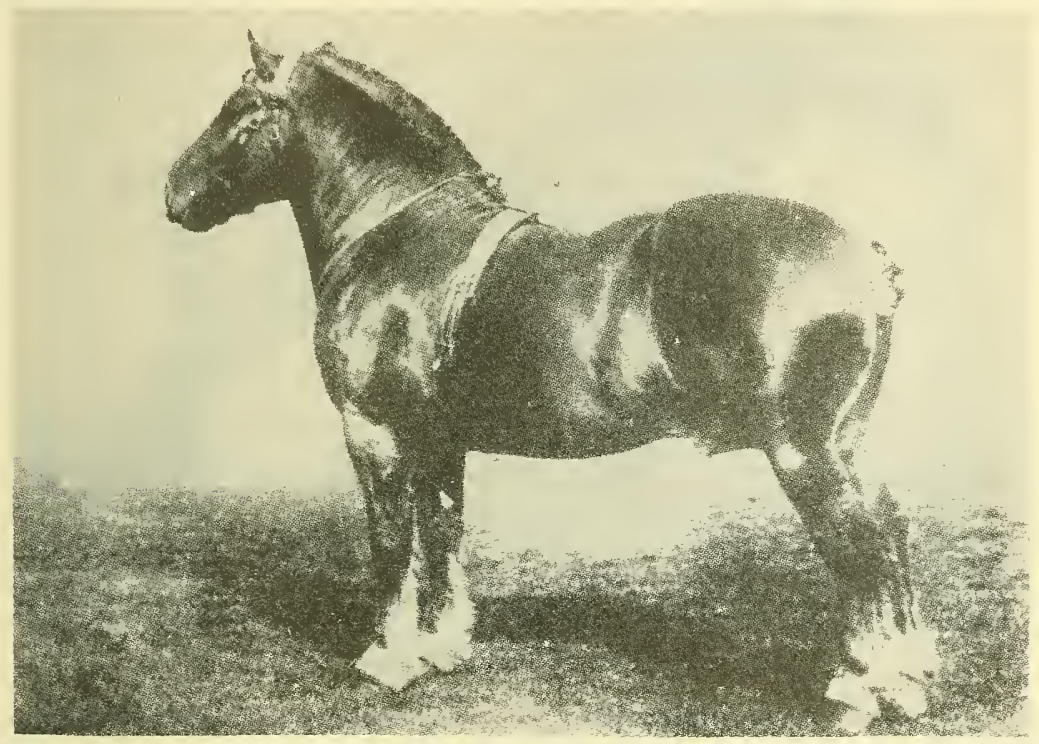

Figure 10.- Suffolk stallion.

dark. The Suffolk is active, has a good disposition, and is rated as an easy keeper.

The distinguishing characteristies of this breed may be said to be the invariable chestnut color, with little if any white; their smooth rotund form; and the elean-boned leg, devoid of the feather characteristic of the other two British draft breeds.

In former years Suffolks were criticized by some Americans for their lack of scale and for being too light in bone for the size of the body. Of these faults the lack of body size is generally not so important a factor now owing to present-day tendencies to produce somewhat lighter and handier horses for farmwork purposes. Also it is the opinion of some Suffolk owners that, on account of general cleanness of leg, the smallness of bone is probably more apparent than real.

Suffolks were first imported into this country in the early eighties and have been imported since then in small numbers, possibly because of lack of size as compared with other draft breeds. Another reason that no more have been imported has probably been that they have 
not been bred in very large numbers in England, being confined to a limited area, and the home demand of the farmers has been sufficient to take care of most of the animals produced; furthermore, buyers in other countries have purchased a good many at prices above those Americans would pay.

The Suffolks in this country are found in small numbers in a number of States, but have never gained any strong foothold, and conse-

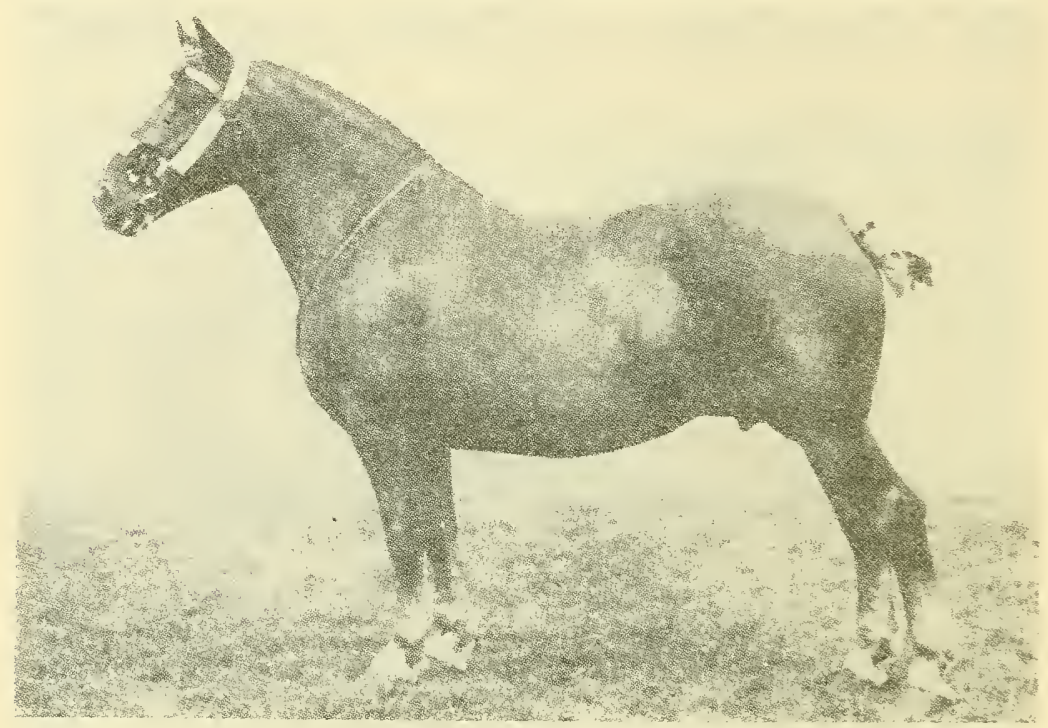

Figure 11.-Suffolk mare.

quently their adaptability to our conditions can scarcely be judged. The stallions have been crossed to some extent on mares in this country, but the demand for extreme size has prevented such crossing from being carried on sufficiently to judge of its value, except in a small way.

The American Suffolk Horse Association has issued five volumes of the Suffolk Horse Studbook, and to December 31, 1939, 2,120 animals had been registered. The secretary is J. G. Truman, Bushnell, Ill. 


HOW TO SELECT A SOUND HORSE
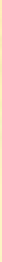

Farmers' Bulletin No. 779 
TEMPERAMENT, conformation, action, sounclness, I training, age, and adaptability to the work to be performed are the most important factors to be considered when choosing a serviceable horse.

A systematic, thorough examination of the animal will minimize the chances of overlooking important points. Ample time should be taken to make such an examination.

Common faults of conformation, from a utility standpoint, are: Narrow chest; straight, short shoulders; shallow barrels; long, weak couplings and loins; poorly developed muscles in the hind quarters; and, weak, improperly formed legs and feet.

Common unsoundnesses that impair a horse's usefulness for most tasks are: Bone spavin; extreme fistula; extreme atrophy of the muscles; roaring; heaves; ringbone; curb; splints, when close to the knee; and sidelones.

Serious faults of temperament are: Balking, kicking, rearing, backing, halter pulling, and shying.

In the final judgment of a horse's suitability, weigh the good qualities against the defects. 


\section{HOW TO SELECT A SOUND HORSE}

By H. H. ReEse, ${ }^{1}$ animal husbandman, Animal Musbandry Division, Burcau of Animal Industry

\section{Contents}

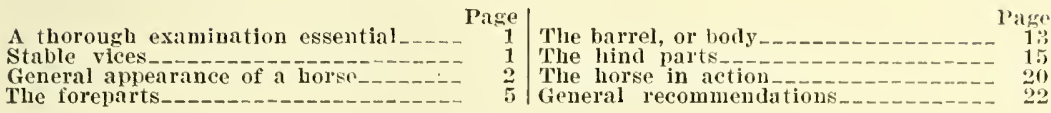

\section{A THOROUGH EXAMINATION ESSENTIAL}

An understanding of the desirable and undesirable features, conditions, and points that may be found in horses, together with a knowledge of their specific and relative values, will enable the purchaser to select a better animal, with a considerable saving of time, inconvenience, and expense. Also, a thorough examination of the horse for various forms of blemish, vice, faulty conformation, and unsoundness that may be present is absolutely essential, if serviceableness is to be secured. Moreover, a definite method of procedure should be adhered to in making the examination. It should correspond to the order in which the various steps most conveniently present themselves. Figure 1 names the different regions of the horse to which attention should be given; figure 2 shows the points at which the more common unsoundnesses occur.

\section{STABLE VICES}

Evidences of stable vices can best be seen by observing a horse in his stall.

Halter pulling.-Horses wearing extra heavy halters (particularly heavy rope halter's) or a rope around the neck should be suspected of halter pulling. Likewise, a rope tied from one stall partition to the other at about the height of the quarters, or the use of what is known as the body rope, may indicate this defect.

Cribbing and wind sucking.-Horses that suck air through the mouth, accompanying this with a grinting sound, are termed wind sucker's. Cribbers or crib biters press their teeth on some object, such as the manger, while sucking in air. They may be detected in two ways: First, by a characteristic wearing of the teeth, which can result from cribbing; and second, by the presence of a snugly buckled halter strap, which is sometimes used to restrain cribbers. Horses with these habits fill their stomachs and intestines with air, which gives a bloated appearance to the abdomen. Such animals are hard to keep in good condition and are somewhat subject to colic.

Kicking.-Heavy chains suspended from the ceiling and hanging close to a horse's hind legs, the use of chain hobbles, scars on the hind legs, and shoe prints on the stable partitions are evidences of stall kicking.

$1 \mathrm{Mr}$. Reese resigned in December, 1926. Revised by S. R. Speelman, animal husbandman, Animal Husbandry Division, Bureau of Animal Industry. 
Stall walking and stall trotting.-Energy-consuming vices which indicate a restless, nervous temperament are stall walking and stall trotting. An animal addicted to the former may be identified by well-beaten paths around the borders of his box stall, while the latter vice (indulged in by horses tied in their stalls) manifests itself in a trotting motion of the feet. Stall trotting is not so common as stall walking.

Weaving.-Weavers throw their heads and fore quarters from one side to the other and are objectionable because they use up energy

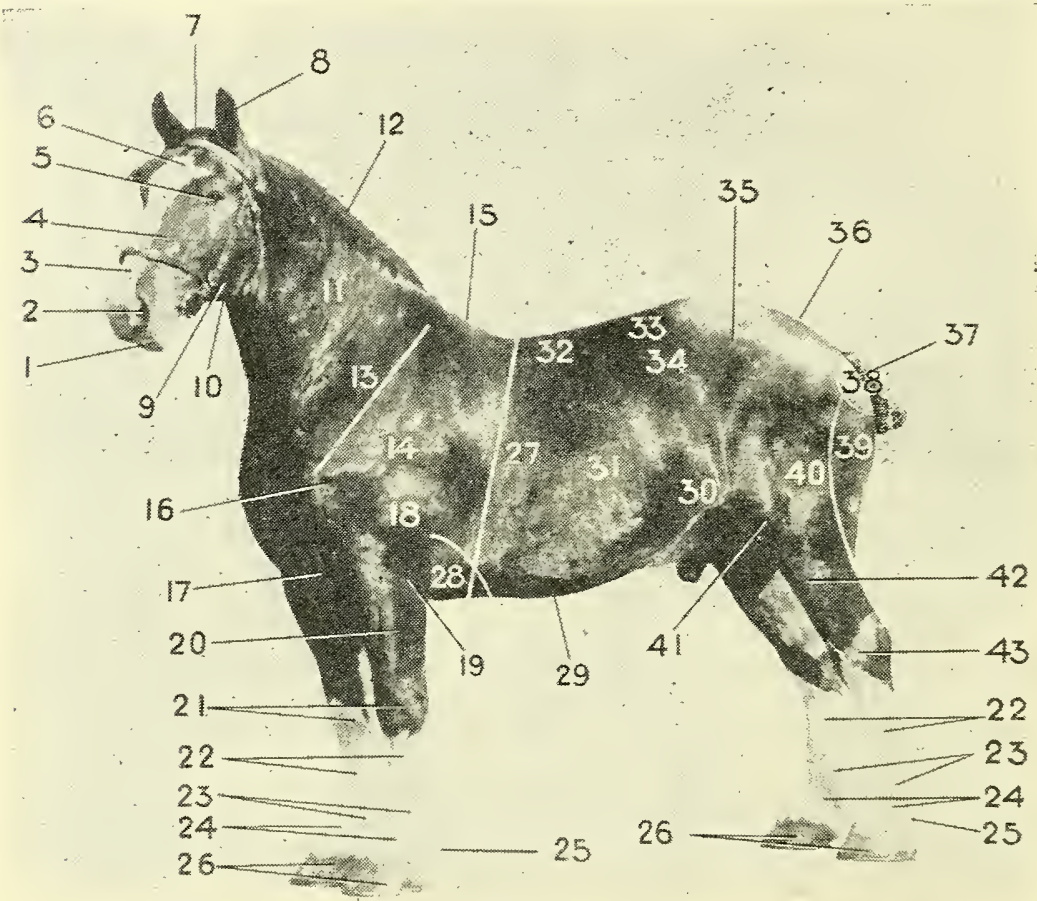

Figure 1.-Points of the horse: 1 , mouth; 2 , nostril ; 3 , nose ; 4 , face; 5 , eje; 6 , forehead ; 7 , poll ; 8 , ear ; 9 , lower jaw : 10 , throatlatch; 11 , neck; 12 , crest ; 13 , shoulder bed; 14 , shoulder; 15 , withers; 16 , point of shoulder; 17 , breast; 18, arm; 19, elbow; 20, forearm; 21, knees: 22, cannons; 23 , fetlocks ; 24 , pasterns ; 25 , feather; 26 , feet ; 27 , heart girth ; 28 , fore flank ; 29 , underline; .30 , hind flank; 31 , ballel ; 32 , hack ; 33 , loin; 34 , coupling; 35 , hip ; 36 , croup ; 37 , tail ; 38 , buttock ; 39 , quarters ; 40 , thigh ; 41 , stifle ; 42 , gaskin ; 43 , hock.

that may be needed for other purposes. They frequently stand wide on their forefeet.

Minor stable vices.-Other less important vices which may be ascertained by a stall examination are: Rubbing the mane or tail, chewing the manger, and biting and throwing back the ears when approached.

\section{GENERAL APPEARANCE OF A HORSE}

Have the horse led out of the stable, so that he may be inspected in a good light and on a level and solid footing. Normal health is 


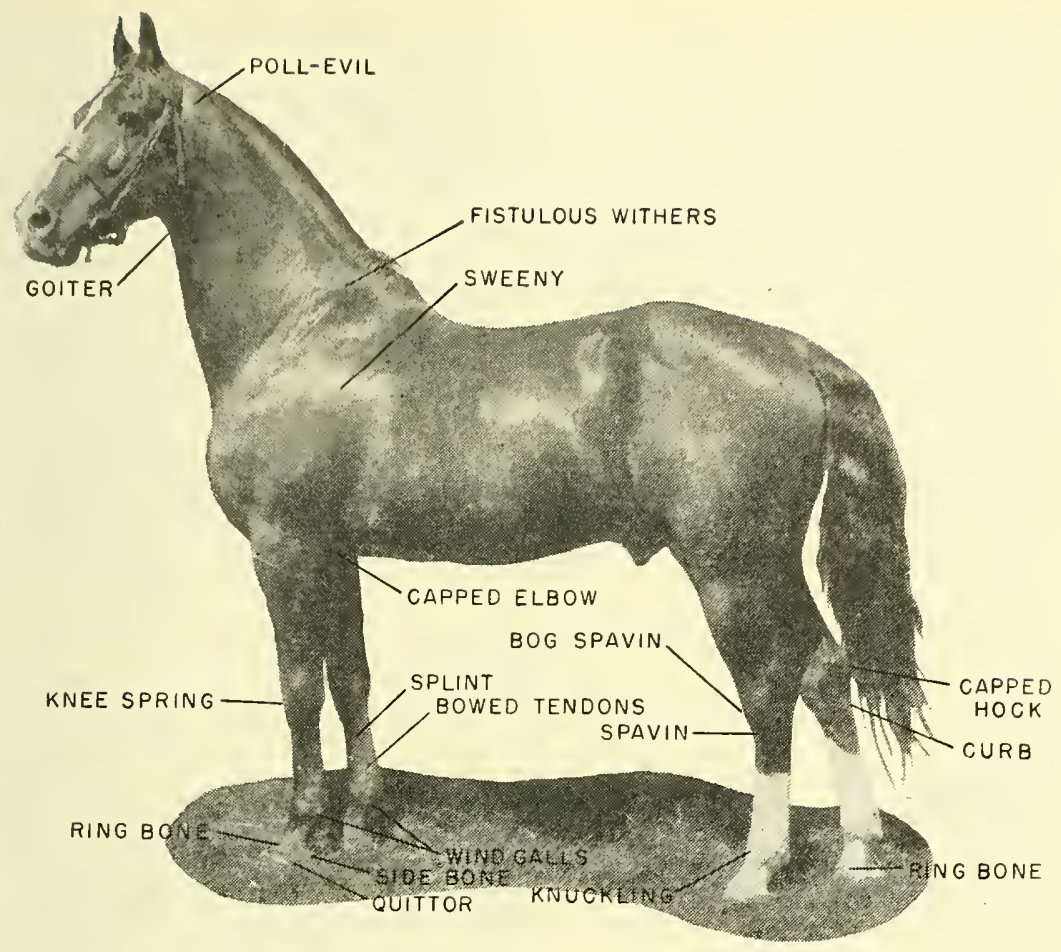

Figure 2.- Location of points of common unsoundness in horses.

indicated by an alert, graceful carriage, rich, lustrous coat, and good condition of flesh. If backed out of a single stall, look closely for extreme flexion of the hind legs, known as stringhalt, which is discussed later. Take a general survey of the horse from the front, rear, and both sides, so as to determine whether he is or is not built on the lines suitable to do the work for which he is wanted. Usually, other things being equal, the heavier the horse the more it may be worth for draft purposes. In fact, size is at a pre-

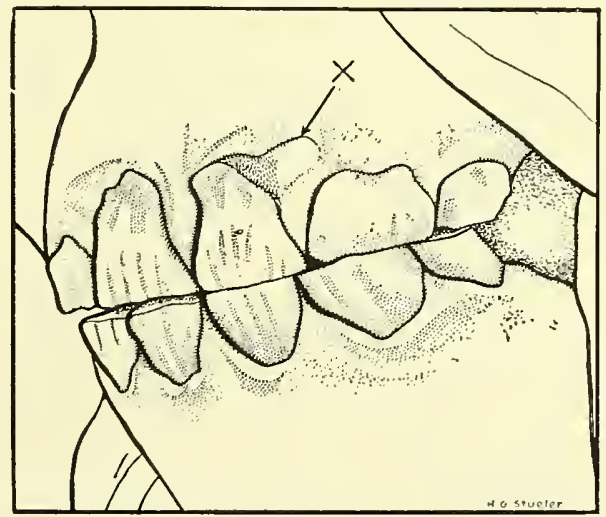

Figure 3.-Appearance of the mouth between $21 / 2$ and 3 years of age. The middle pair of temporary incisors above and below are replaced by permanent teeth at this age. A permanent tooth is making its appearance at $\mathrm{X}$. 
minm for many purposes. Undersized horses seldom bring top prices.

The height of a horse is determined by measuring the vertical distance from the highest point of the withers to the ground. The distance is expressed in hands, a hand being 4 inches. Most horses are from 15 to 16 hands high.

Temperament.-The temperament of a horse furnishes evidence concerning his disposition and his nerve force. For instance, the nervous, excitable animal (lacking a strong nervous system) is hard to control under many circumstances, while the sluggish, phlegmatic horse, though docile, lacks ambition and endurance. Generally, desirable temperament is indicated by large, mild, bright eyes; good width between the eyes and behind the ears; forehead neither too concave nor too convex; willing obedience to commands; and an alert, active, graceful carriage when in motion. Temperament and disposition are influenced to some degree by training and handling, so that it is well to keep these factors in mind when testing the horse at work.

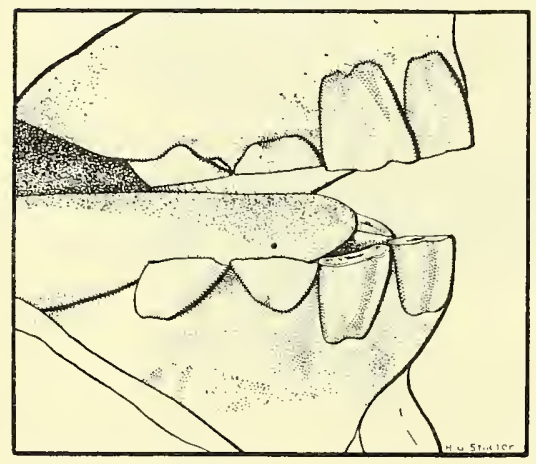

Figure 4.-The teeth at past 3 years. The gums are inflamed around the second pair of temporary teeth, slowing that they will soon be replaced by permanent teeth, when the animal will be considered 4 years old.

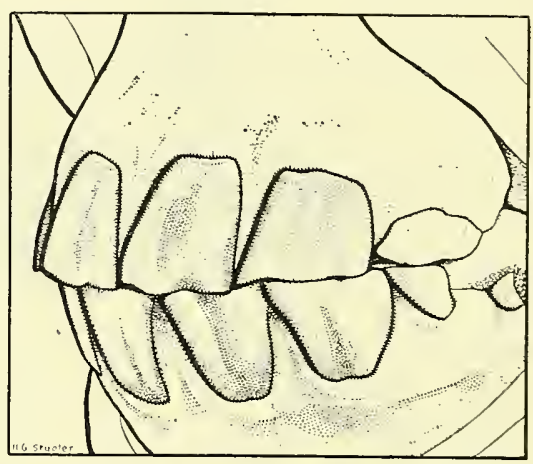

Figure 5.-A typical 4-year-old mouth. The two middle pairs of incisors above and below are permanent. The outside pairs are temporary teeth, the latter being detected by their white appearance and small size.

Quality.-Quality is denoted by fine textmre in all the parts that go to make up a horse. It is not possible to examine all these parts, but those exposed to view will give a good idea of the others, since in animals there usually is analogy between the various parts. Prominent external indications of quality in a horse are a covering of fine, snugly fitting skin and soft hair. Quality also finds expression in thoroughly defined lines between the various regions, in clean-cut features, and in a general refinement of tissue and breediness throughout.

It is a well-known fact that often the smaller bones taken from the well-bred horse have more actual strength than the larger but coarser ones taken from others. This no doubt applies in a large degree to all the other tissues, and for this reason it is to be expected that the animal with quality will have the durability and endurance necessary to per- 
form hard work for an extended period of time better than an individual of inferior merit.

Color.-Horses with any of the dark, solid colors, such as bay, brown, chestnut, and black, are serviceable and sell readily. Often dark grays are in demand for draft, show, and hunting purposes, but for other uses they are generally slow sellers, because they turn white with age. Pink-skinned whites, duns, monse color's, and spotted color's sell at a discount except for uses where unusual or gaudy colors are wanted. Grays have the reputation of standing the effect of the hot sun unusually well, whereas dark browns and blacks often sunburn readily. White marks on the legs and face are sometimes desirable for show purposes, since they give a horse a flashy appearance.

Age.-For immediate hard service a horse should not be much younger than 5 years. Often a horse's value begins to depreciate when he is 8 to 10 years old, but he may be useful with good care until he is over 20. The teeth indicate the age of a hor'se, especially from 3 to 8 years. (Figures 3 to 11.) ${ }^{2}$

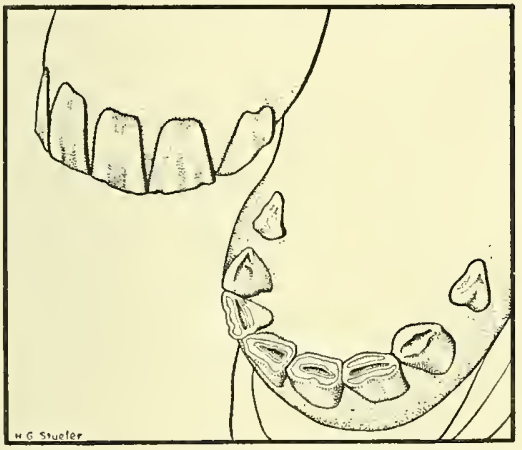

Figure 6.-A 5-year-old or full mouth. All the incisor teeth are permanent, but the corner incisors have not yet come into wear.

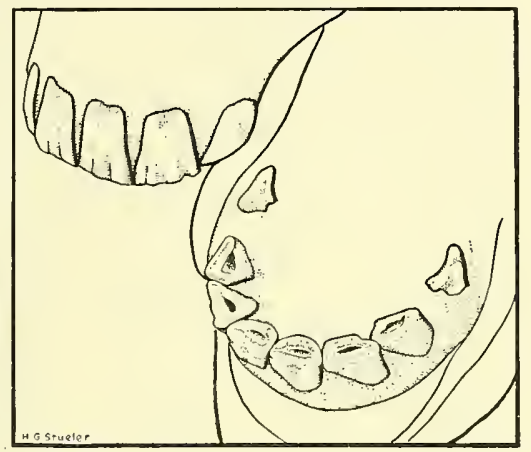

Figure 7.-At 6 years the cups in the center pair of incisors are almost obliterated by the wearing down of the teetl. The remaining teeth show well-defined cups.

\section{THE FOREPARTS}

Head.-The head should be well proportioned, refined, and cleancut. It should not be either too concave or convex between the eyes, the former suggesting a timid disposition, the latter strong will power. Compare the sides of the face and note any dissimilarity which may be due to disease. The side view of the head should show a comparatively straight line from the poll to the nose. Extremely heavy jaws are not desirable, especially in horses of the lighter classes.

Mouth. - The mouth should be examined for unsound or abnormal teeth. In the condition known as parrot mouth the front upper teeth overlap those below, while in reverse parrot mouth the lower front teeth overlap those above. If either condition is present the hor'se is not able to bite off feed; and while he may eat hay and grain by getting them into his mouth with his lips, he would starve on short pasture. A tongue held outside the mouth is unsightly.

2 For more detailed information on determining the age of horses consult Farmers' Bulletin 1721, Determining the Age of Farm Animals by Their Teeth. 
Muzale.-The nostrils shonld be large, clear, and pliable, with the inside rose colored at rest and deep red during exercise. Nostrils constantly distended and hard should lead one to suspect heaves, a disease which is discussed later. Note whether the nose is deformed or crooked-conditions which mar the horse's looks. If the underlip is not held firmly against the upper it may be due to a lack of vigor. Frequent application of a device known as a twitch leaves scars around the upper lip. 'This would lead one to suspect that the horse has some bad habit, such as being difficult to shoe.

Face.-Look for blemishes from operations such as on bad teeth or nasal tumors, conditions which may cause trouble after apparently being cured.

Eyes.-Before beginning an examination of the eyes be sure that these important and often unnoticeably defective organs are turned toward a good light. Large, full, well-placed eyes, preferably of a chestnut hue with a sparkle and a mild expression, are beantiful in appearance and are the least subject to disease. Small, sunken eyes are often weak and may accompany a sluggish temperament. Lacerations on the eyelids are more or less unsightly and give evidence of a previous injury which may have left the eye weak, especially if the

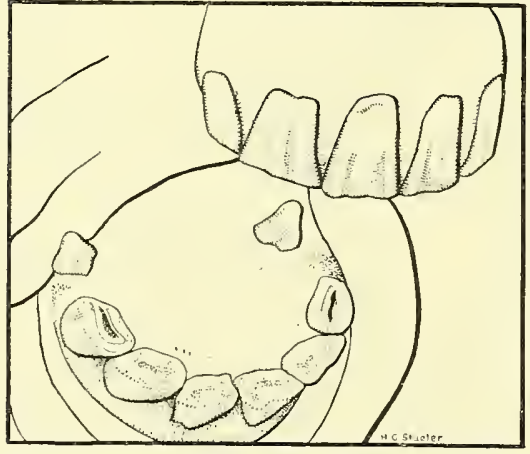

FIgURE 8.-A 7-year-old mouth. The cups show plainly only in the outside pair of incisors in the lower jaw.

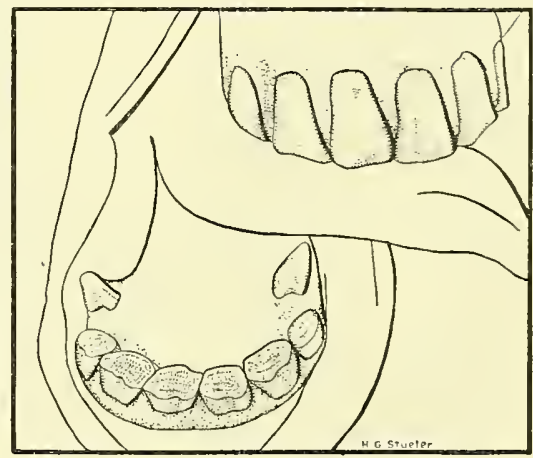

Figure 9.-An 8-year-old month. The cups are woln out of all the lowel teeth.

eye sheds tears frequently. To test the sight make a quick motion of the hand and see if the lids are closed to protect the eyeballs. In doing this it is necessary to be careful not to cause a current of air to strike the eye, since a blind horse may close the eyelid from such a cause alone. If still doubtful about the sight have the animal led over obstacles over which a blind horse would stumble, in which case a horse with good sight will carefully raise and plant his feet over them. A more detailed test consists in taking the horse from darkness to light, and vice versa, and seeing that the pupils dilate and contract alike. Totally blind horses generally hold their heads sideways. Hollows over the eyes denote old age or a lack of vitality. Unnscrupulous dealers have sometimes inflated these hollows with air, but this can readily be detected by pressing with the fingers, which forces the air into the adjacent cavities, leaving the natural hollowness.

Ears.-Horses are not often troubled with deafness; still it is advisable to test the hearing by noting responses to the roice. The ears 
should be placed fairly close together at the highest point of the poll and should usually be carried forward. To add to the appearance they should be of delicate texture, taper to graceful points, and be covered with fine hair. Lopped ears are very unsightly. Many tricks are used to cover up such defects, such as tying together with fine

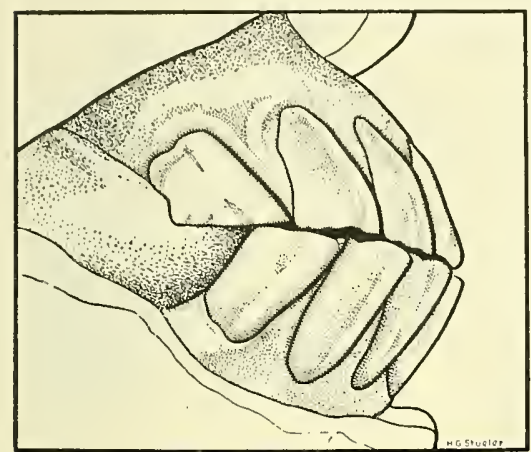

Figure 10.-A 14-year-old mouth. After 8 years the age is estimated by the angle at which the incisors come together, by their leugth, and by the shape of the wearing surface. The older the horse the nearer this surface approaches a triangle. It is practically impossible to estimate the age correctly after the cups have disappeared from the teeth.

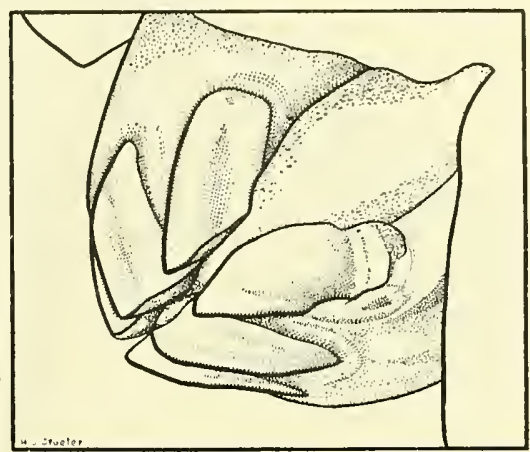

Figure 11.-A 22-year-old mouth. The incisor's meet at an acute angle and the wearing surfaces have a triangular shape.

thread the ear nets which the horse may be wearing; or the ears themselves may be tied together, the hairs of the foretop hiding the thread. Slight operations are also performed with the object of remedying this defect. Cropping or splitting the ears simply disfigures them.

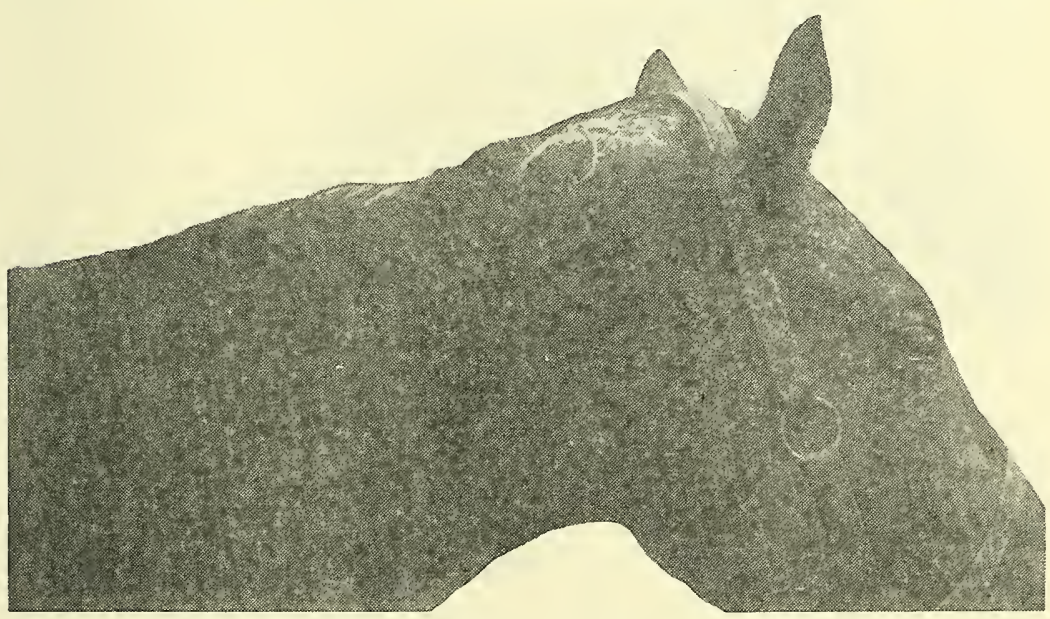

FigUre 12.-Poll evil. 
Horses that constantly keep the ears moving should be suspected of being blind or of bad temperament.

Poll.-The poll should be examined for signs of poll evil (fig. 12), a disease caused by bruising the top of the head. Inflammation in this region, usually accompanied by discharge of pus, wonld lead one to suspect this disease, which is often slow to yield to treatment and which may break out again after it is thought to be cured. It often leaves ugly scars after healing.

Neck-A clean-cut throatlatch on a crested neck of good length gives a horse style and beanty of outline and consequently enhances his value. In mature stallions the development of a full crest is an indication of masculinity. Evidences of bleeding, indicating previous bad health, should be looked for on the jugular vein, and it is also advisable to lay back the mane and look for scars. The neck should join the shoulders smoothly.

Shoulders.-Short shoulders do not generally indicate sufficient room for a large heart and for lungs capable of handling a maximum quantity of air. Straight shoulders favor a low, short, stubby action of the front feet. A low carriage of the head, with a heavy, irresponsive mouth are often associated with a long back and a correspondingly short underline, whereas the opposite proportions, namely, a short back and a long underline, are desirable. The concussions or jars on the front legs resulting from their striking the ground are considerably relieved by sloping shoulders, while straight shoulders, by not having this effect, tend to promote early unsoundness of these limbs. Strong constitution, endurance, good front action, and style are associated with deep, well-sloped shoulders. For draft purposes the shoulders should have pronounced offsets, so that the face of the collar will have plenty of bearing surface. Fignre 13 shows a shoul-

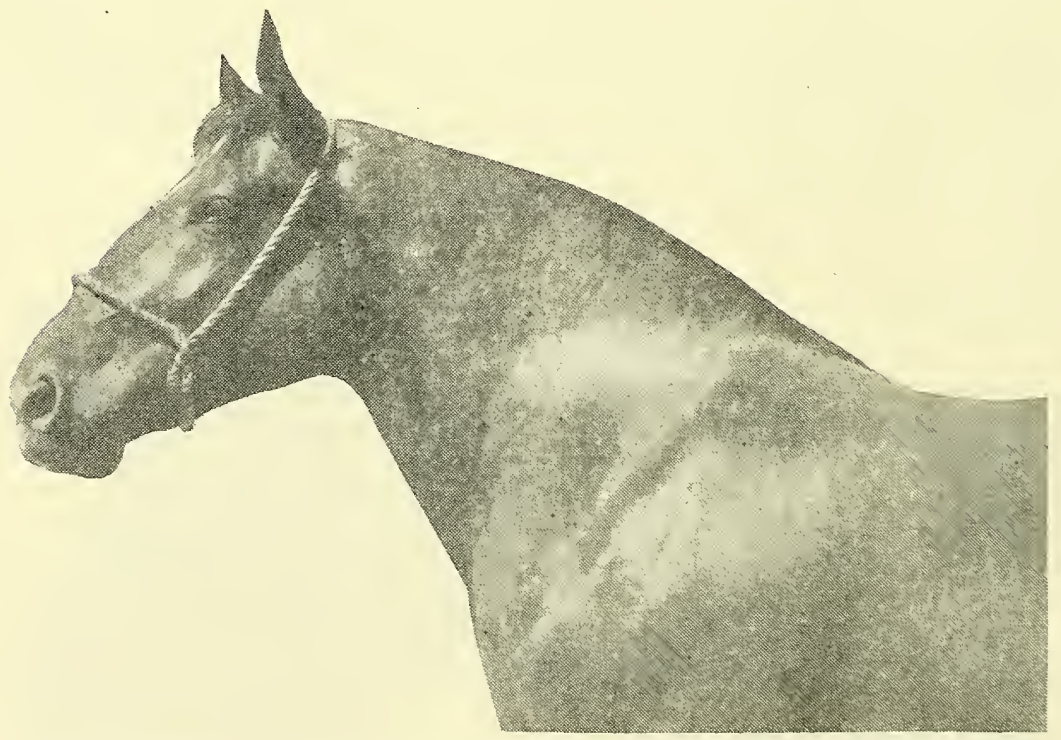

Figure 13.-Deep, well-sloped shoulders which make a good seat for the collar. Desirable conformation for the draft horse. 


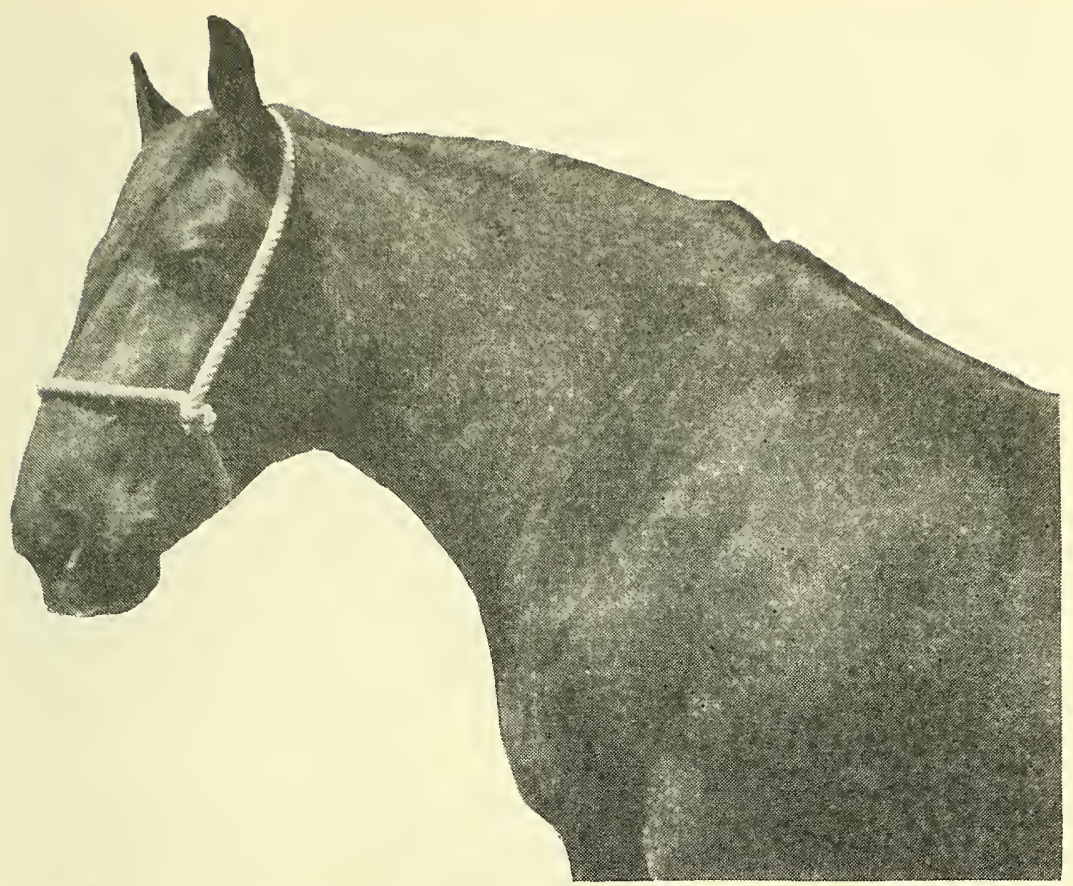

FIGURE 14.-Straight shoulders. Undesirable conformation and usually associated with short, stubby pasterns.

der of proper conformation to receive a collar. The position of the collar on such a shoulder is not materially changed, no matter how hard the pull. On shoulders such as those shown in figure 14 the heavier the pull the tighter the collar is squeezed back, with the result that the skin and muscles beneath the collar are apt to become sore. Sharp, thin, prominent withers add depth and wearing qualities to the shoulder. Withers that rum well into the back in the saddle horse aid in holding the saddle in place. Compare figures 13 and 14.

Examine the withers for fistula, a disease similar to poll evil, except that it is differently located. Fistula is thought to result from bruising the withers, the resulting inflammation and pus being slow to yield to treatment, so that cases are often of very long standing. The disease sometimes appears to be of very minor importance, but figure 15 shows the large amount of tissue that may become involved. Fistula should not be confused with collar sores, which are often found on the top of the neck just in front of the withers. Collar sores also often occur on the sides of the neck. When not of too long standing they heal readily, if on properly formed shoulders. Calloused thickened spots resulting from old collar sores are apt to get sore again unless the collar can be kept from pressing on them. In so-called sweenied shoulders the muscles have atrophied or shrunk, and horses with such defects are practically valueless for work, for the time being at least. Attempts are sometimes made to hide this trouble by applying irritants or by blowing air beneath the 
skin, giving the normal full appearance. Atrophied shoulder muscles may recover their size and derelopment by the removal of lameness which often arises from injury or inflammation below the knee.

Chest.-A wide chest provides abundant room for the heart and lungs; consequently a horse with such conformation would be likely to have a strong constitution. Excessive width in the chest, however. with the forelegs set too near the outsicle, is liable to cause the horse to paddle with his front feet. On the other hand, a narrow chest is generally associated with a weak constitution and forelegs set too close together, predisposing the horse to strike these limbs together when moving. Scars on the chest are not generally any more objectionable than their disfiguring appearance.

Forelegs.-The proper and the faulty direction of the forelegs when viewed from the front are shown in figure 16 . A vertical line from the point of the shoulder should fall on the center of the knee, cannon. pastern, and foot. The right conformation is shown at A; in B the forefeet toe out; in C the bowed legs are weak: D shows the extreme of knees set close together with toes pointing outward, and horses with such conformation almost invariably interfere; $\mathrm{E}$ illustrates a form of conformation predisposing to interfering; in $\mathrm{F}$ the knees are set close together, showing a tendency to knee hitting; while in G the subject will wing or throw out his feet as they are elevated, which retards action.

The forelegs when viewed from the side should have the general direction of $\mathrm{A}$ in figure 17. A vertical line from the center of the elbow joint should fall on the knee and pastern and back of the foot. and a vertical line from the middle of the arm should fall on the center of the foot. A represents the right conformation; B shows forelegs too far under the body; in $\mathrm{C}$ they are too far advanced; in D the subject is knee-sprung; and in $\mathrm{E}$ is illustrated what is commonly known as calf leg. Knee-sprung horses are apt to stumble; calf-legged horses often are sore in their forelegs after they have been used a while.

The structural examination of the forelegs logically begins with the forearm, which shonld show strong muscular development on the outside just below its junction with the shoulder. For speed it should be much longer than the cannon. The kneecap should be broad. Scars on the inside of the knee may come from the horse's hitting these members in moving. Figure 18 shows a cannon too light just below the knee, while figure 19 illustrates a conformation that will give better service. The cannon in which the tendons and bones show prominently beneath the skin will stand hard wear, because the tissues are of a clense, tough character.

The fetlock joint should be large enough to denote strength without being coarse. Pasterns that are moderately long and that slope at an angle of about $45^{\circ}$ with the ground aid in producing elastic, springy action and will absorb concussions or jars much better than short, upright pasterns. Pasterns too long and too near the horizontal are weak. The foot that is not too wide or too narrow and long, but which is fairly concave, with the frog and bars prominent, will have durability. Low or contracted heels are more liable to become unsound than are fairly deep and open heels. Cracks and many nail holes indicate poor quality of the hoof. 
The following are unsommluess and blemishes of the forelegs: Shoe boils, which are elassed as blemishes, are cansed by the horse lying down cow fashion, thus pressing the elbow with the shoe. 'The albows are sometimes irritated by the girth, which can easily be parded or properly placed, thus avoiding a continuance of the trouble. The

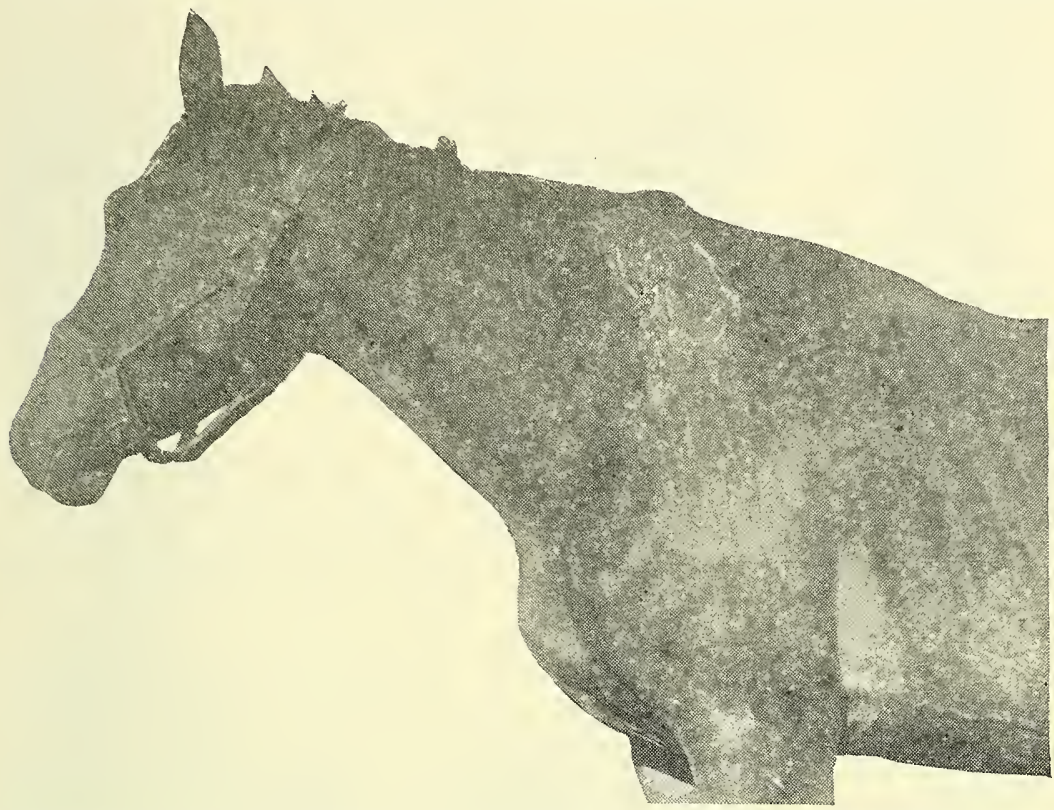

Figure 15.-Fistula of long standing. There is considerable inflammation, with hair, skin, and underlying tissues destroyed.

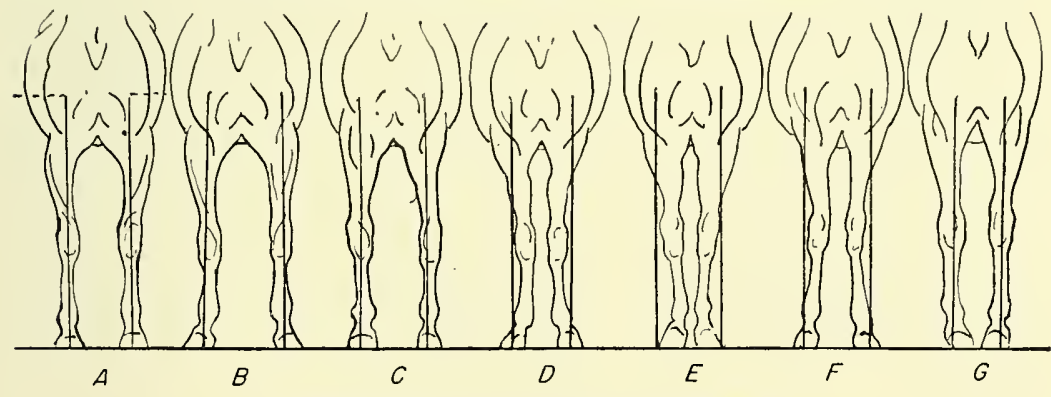

Figure 16.-Front view of the forelegs.

forearm is usually free from unsoundness, but it may be blemished by injuries such as wire cuts. Scars on the front of the knees would lead one to suspect a stumbler.

Bony prominences known as splints (fig. 20), found on the inside of the cannon just below the knee, may cause lameness when first developing or when close enough to the knee to interfere with its movement. Splints frequently disappear from young horses. 
The front of the cannon may be full, or the tendons at the back may be enlarged, as shown in figure 21; they are conditions brought about by training and racing, and are known, respectively, as bucked shins and bowed tendons. They incapacitate a horse for fast work. The scars often associated with these conditions are due to the firing iron.

Wind puffs, illustrated in figure 22 , are due to fast or continnous road work, and while they do not decrease a horse's immediate usefulness, they show that the animal has had considerable use. If the fetlock joint is unduly large it is more or less unsound (fig. 23). This enlargement may be permanent, from an old injury, or it may be due to hard or fast work followed by a lack of exereise, or to disease. The slight fullness that promptly disappears with exercise is about as objectionable as wind puffs, but may lead to scratches, leg sores, or a disease commonly known as milk leg. Interfering when associated with forelegs set close together or with toeing out considerably depreciates the value of a horse, especially for anything other than slow work, and it is to be suspected when sears are found on the inside of the fetlock joint.

Ringbone (fig. 24) is an unsoundness characterized by bony enlargements on the front and sides of the pastern, which cause lameness when developed to sufficient size to interfere with the action of the joints and tendons. These bony prominences can be detected by passing the hand over the pastern if they are not large enough to be seen when in front or at the sides of the forelegs.

Sidebones can be best seen from the front, as shown in figure 25 . They occur on the sides of the coronet. When not prominent enough to be noticed by the eye their presence may be detected by grasping the back of the coronet between the thumb and fingers and pressing. If healthy it will yield to pressure; if unsound it will be hard and rigid. Sidebones on the forefeet interfere with action and may cause lameness.

Scratches is the name given to a cracked condition of the skin at the back of the pasterns and over the heels. This trouble is not serious, provided it does not result from other causes, but may be hard to heal unless the horse can remain inactive for some time. The quarters may show scars from hitting this region with the hind foot, which may be due to faulty action or to improper handling or shoeing of a gaited

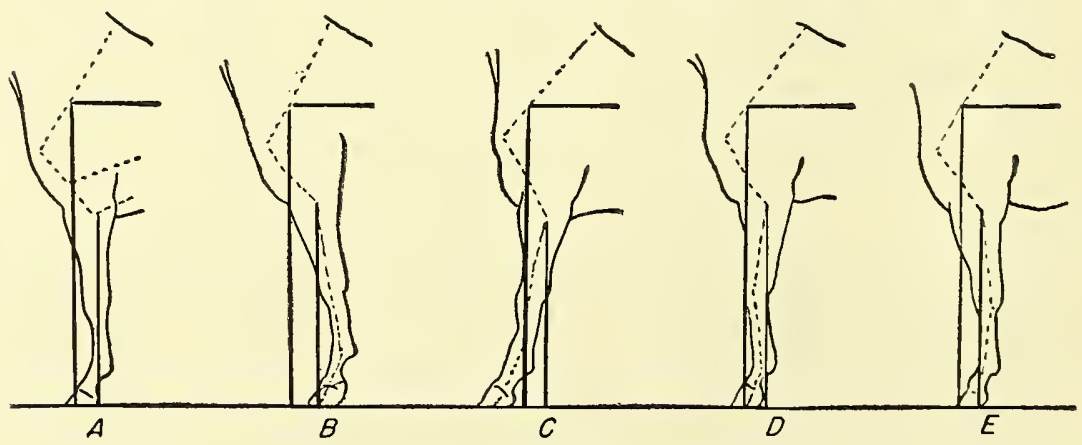

Figure 17.-Side view of forelegs. 
sadille horse or pacer. Generally, seal's resulting from barbed-wire cuts are objectionable only on acrount of their noliness.

Pick up a foot and note the willingness with which a horse lets you hold it. This should aid in discovering a subject difficult to shoe. The feet should be free from diseases such as thrush and corns, which hinder action. Navicular disease is to be suspected when a horse stands with a forefoot extended and with only the toe resting on the ground.

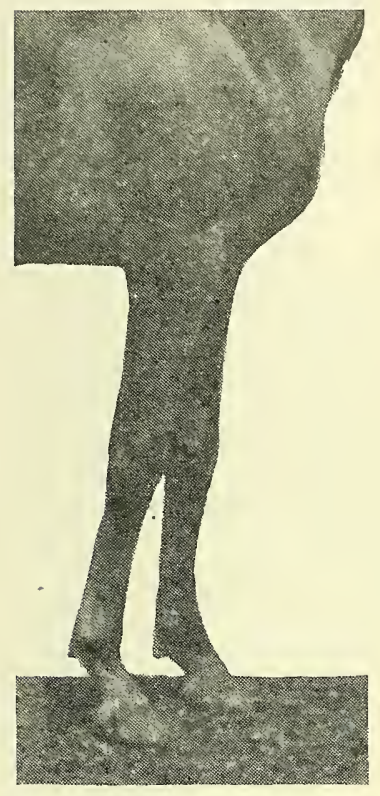

Figure 18.-A fault of conformation known as "cut out" below the knees. The subject is apt to become knee-sprung.

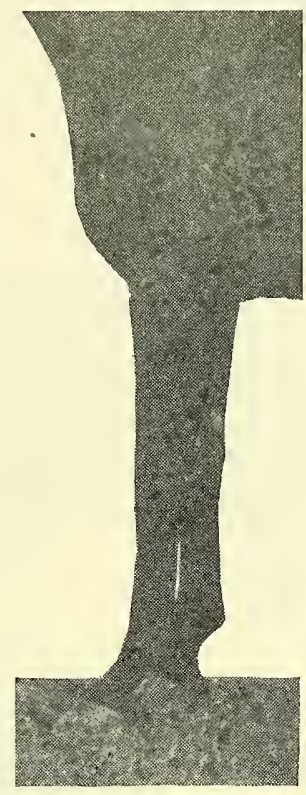

Figure 19.-Forelegs with desirable conformation.
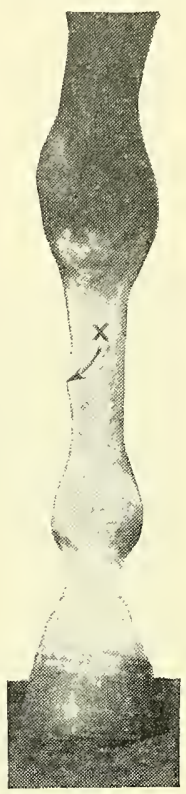

Figure 20.Splint at $\mathrm{X}$.

This disease seriously impedes the gait and usually causes lameness. Slight ridges on the walls of the hoofs parallel with the coronary band may result from stomach and intestinal disorders, while more pronounced ridges close together at the toe and far apart at the heel. if accompanied by dropped sole, would indicate a previous case of founder, a disease which usually leaves a horse sore and stiff in his forefeet.

\section{THE BARREL, OR BODY}

Proper conformation of the barrel has much to do with a horse's health and appearance, as it determines to a considerable degree the size and strength of the vital organs. The back should be short and straight, the ribs well sprung from the backbone and of sufficient length to form a deep barrel. The distance between the last, or floating, rib and the point of the hip should be short. The last rib should not be sunken but should be prominent, giving a smooth coupling. With 


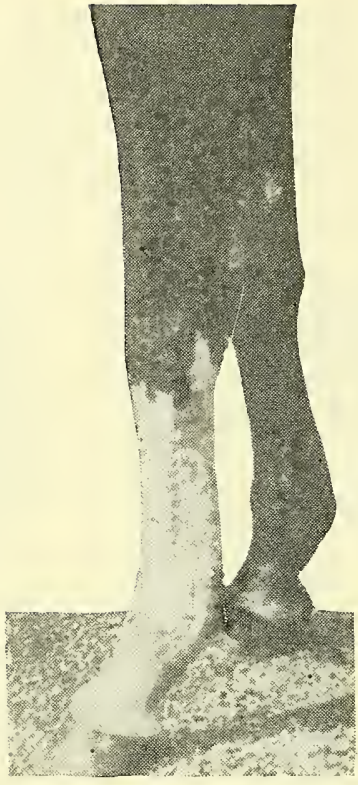

Figure 21.-Bowed tendon.

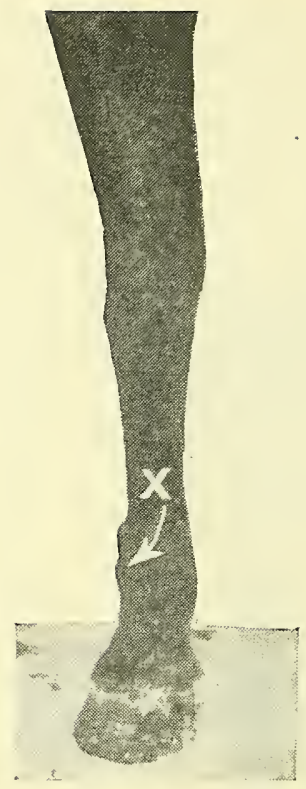

Figure 22.-Wind puff at $\mathbf{X}$.

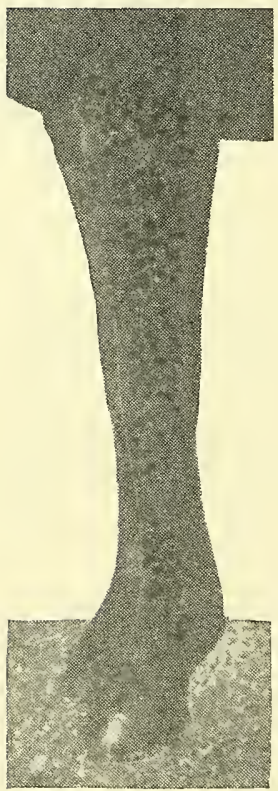

Figure 23.-Enlarged fetlock joint.

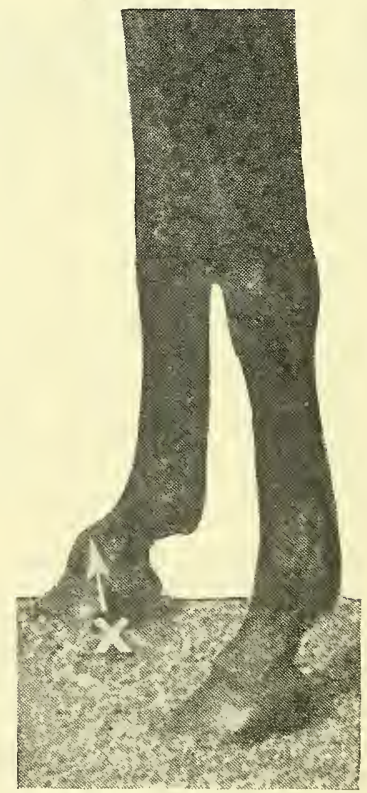

Figure 24.-Ringbone at $\mathrm{X}$.

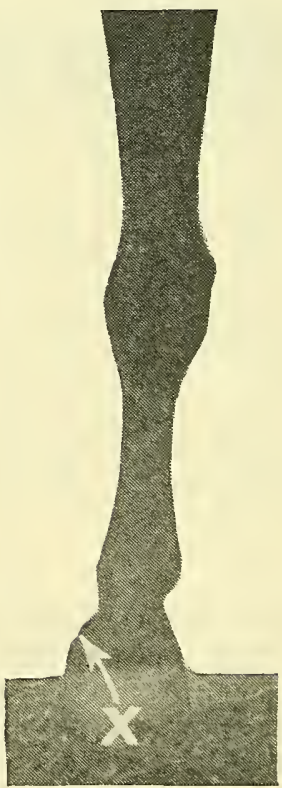

Figure 25.-Sidebone at $\mathrm{X}$. 
a short, well-muscled loin and a deep flank (together with a smooth compling) a horse should be an easy keeper and should not look tucked up or gamnt after a hald day's work.

As regards unsonndness or blemish in these parts, hernia or rupture may occur on the abdomen at or near the navel. Small hernias, such as shown in figure 26, are merely unsightly, while larger ones demeciate a horse's value in direct proportion to their size. The barrel should be free from sitfasts or saddle and girth sores. An enlarged sheath is generally due to disease. Mature stallions should have two prominent testicles; ridgelings have one testicle that has not descended into the scrotum, and while they are often sold as geldings after the descender testicle has been removed they may be very annoying to handle because they have the desires and actions of a stallion. They can be completely castrated only by a severe surgical operation. Mares which have produced colts have well-developed teats.

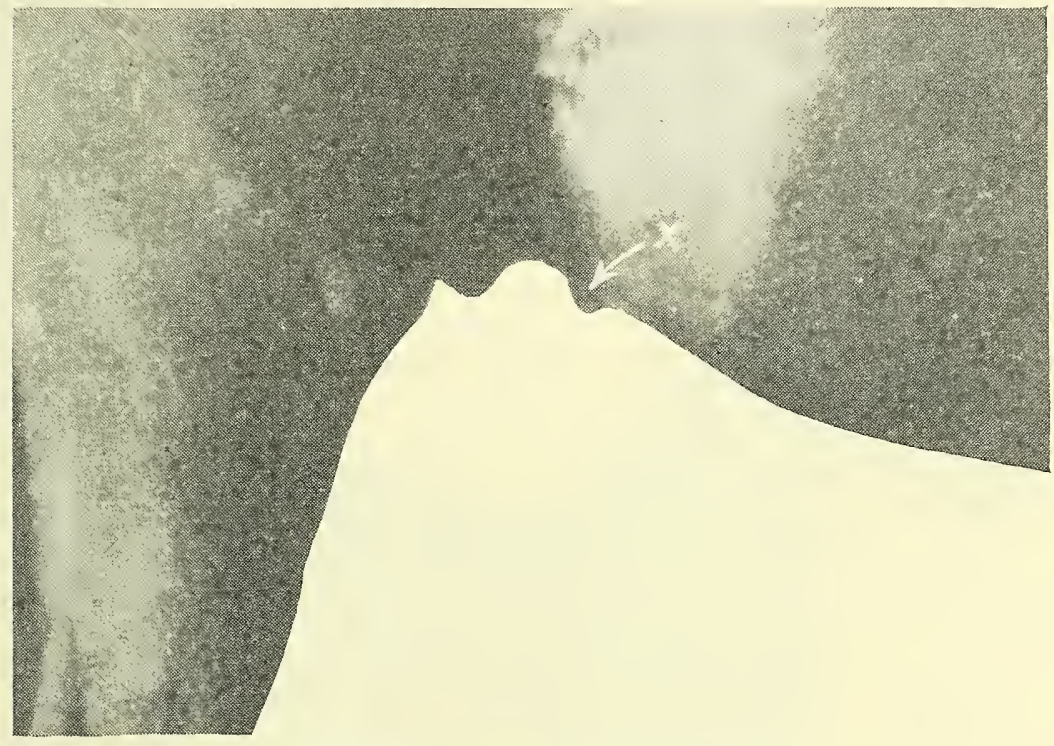

Figure 26.-Hernia, or rupture, at $\mathrm{X}$.

\section{THE HIND PARTS}

Hind quarters.-Both points of the hips should be similar and on the same level. They should not be too prominent (condition as to flesh being considered), but should be a good distance from the point of the buttock. A low or capped hip detracts from a horse's appearance. In draft horses the hips should be broad, and the muscles on either side should stand well above the level of the spine if the horse is in good order. In the lighter types the hips should be smooth and more nearly circular in outline. In general, width across the hips with proper muscling denotes power. A fairly level croup with the tail attached high gives the horse beauty of outline, and this is increased by a long tail carried out gracefully from the body. A tail 
carried to one side or with a crook in it mars the animal's attractiveness. If the tail has been rubbed it may be due to intestinal parasites, extermal parasites, or high feeding; even if clue to habit alone it would be objectionable. Raise the tail and examine for crupper sores, warts, and signs of worms, the latter making the horse dull and hard to keep in flesh. Warts under the tail are usually found on old horses of gray color. They make the tail heavy and interfere with the crupper. 'The practice of "gingering" causes horses to carry, temporarily, high, unnatural tails. Naturally carried high tails are an indication of spirit and vigor.

The quarters should be round, full, heavily and smoothly muscled, and should strongly join the gaskin; the latter also should be heavily muscled. Quarters separated to an musual height when viewed from behind characterize an animal lacking a vigorous constitution. Atrophy of the muscles in the region of the stifle joint and dislocation of this joint are conditions which can totally incapacitate. Figure 27 shows quarters and gaskins of good conformation. They are well proportioned and firmly muscled.

Hind legs.-Figure 28, A, illustrates the proper direction of the hind legs viewed from the side. A vertical line from the hip joint should cross the center of the foot and divide the gaskin in the middle; a vertical line from the point of the buttock should coincide with the

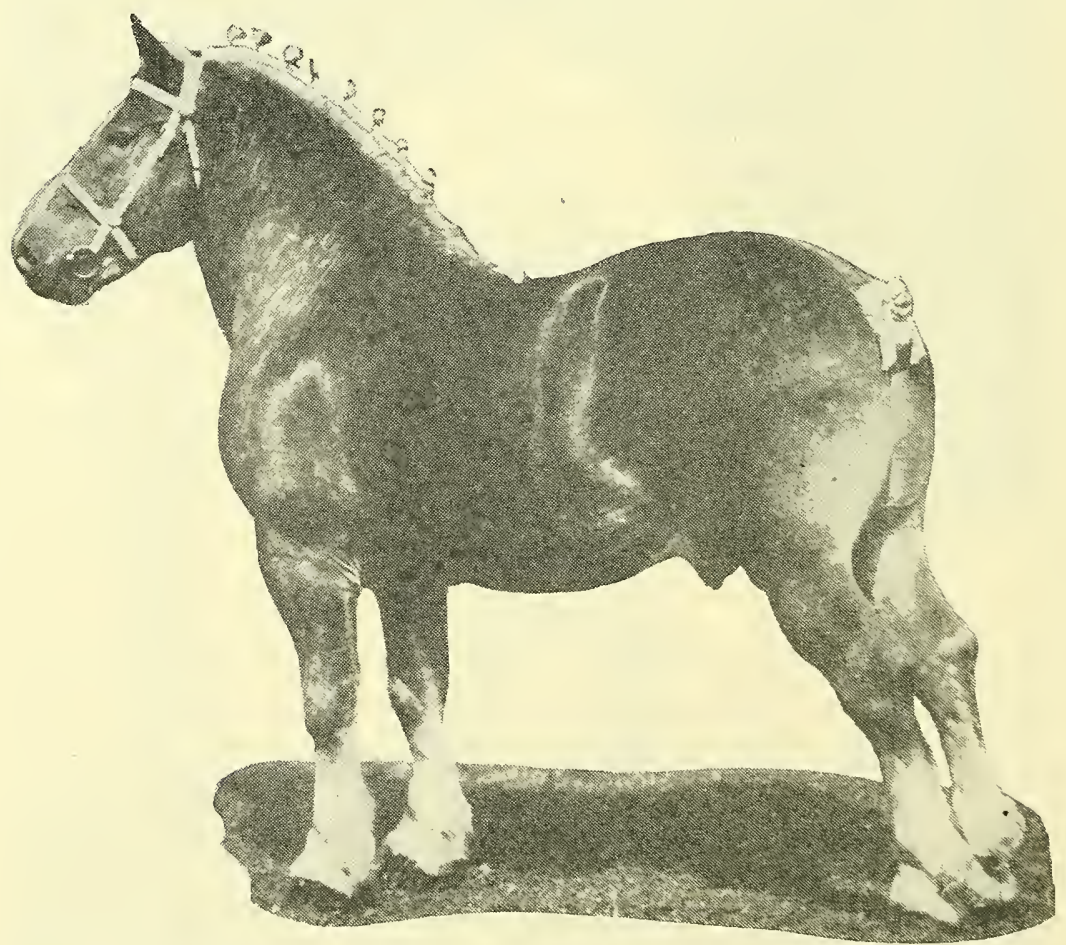

Frgure 27.-Rear view of a draft horse showing correct conformation of croup, quarters, gaskins, and hind legs. 
back of the camnon. In $B$ the hind legs stand too far under the body; in $\mathrm{C}$ the hind legs are set too far back; and in D the hoek joint is too straight. Other things being equal, the direction shown in $\Lambda$ makes the limb stronger and more serviceable than those in $\mathrm{B}, \mathrm{C}$, or D.

Vicwed from the rear, the hind legs have the greatest strength when they have the direction shown in figure 29, A. This direction is correct when a vertical line from the point of the buttock crosses the center of the hock, cannon, pastern, and foot. B shows hind legs set too far apart, tending to produce a sprawling gait. In $\mathrm{C}$ the hind feet toe in or are pigeon-toed, the joints being improperly formed, producing considerable undesirable lateral motion when the feet are carried forward. With such conformation the feet cannot be carried in a straight line. In D the hind legs are set too close together, predisposing the horse to interfere. The condition shown in $\mathrm{E}$ is generally known as cow hocked, and hind legs so formed do not have the strength of those in which the columns of bones are placed directly over one another.

Hock.-The angle of the hock determines to a large extent the direction of the hind legs. The greater the angle the straighter the hind legs and the more apt is thoroughpin to develop. If the angle is small the hind leg is erooked and may be weak. Puffy, meatylooking hocks covered with thick skin and coarse hair are apt to become unsound. Hocks on which the skin fits snugly against the bones and ligaments generally wear the best. Compare the hocks closely and see that they match exactly, as failure to do so would indicate unsoundness, and should cause the horse to be rejected.

A common defect of the conformation of the hind legs is known as "cut out below the hock." In this the junction of the hock with the front edge of the cannon is lacking in development, denoting weakness. It is sometimes associated with the following: The heavy bone on the outside of the hock (shown in fig. 35) extends too near or past the vertical line coinciding with the back of the hind leg, making curb very liable to develop. The cannon of the hind leg is much broader than the cannon of the foreleg. Figure 30 illustrates a fet-
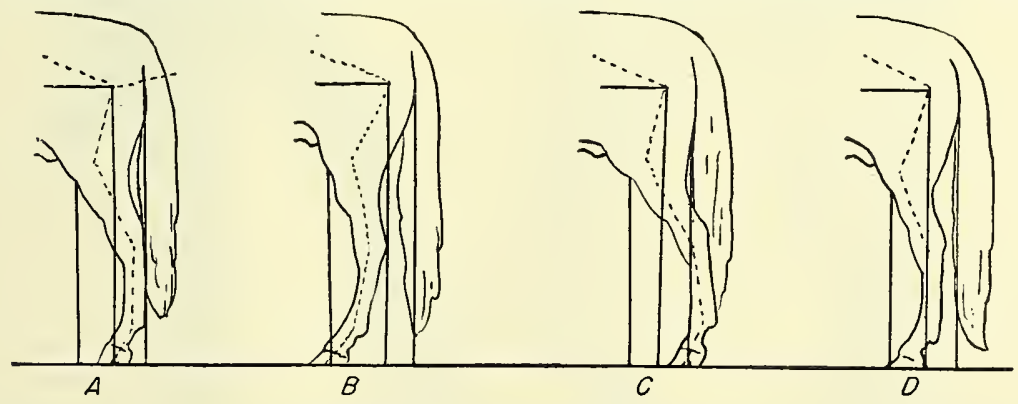

Figure 28.- Side view of hind legs.

lock joint that stands over the hoof, called cocked ankle. Contracted tendons at the back of the cannon cause cocked ankle, a condition making the leg stiff and weak. The remainder of the hind leg should correspond in general conformation to that of the foreleg, except that the hind pasterns and hoofs are slightly straighter with the heels slightly higher. 


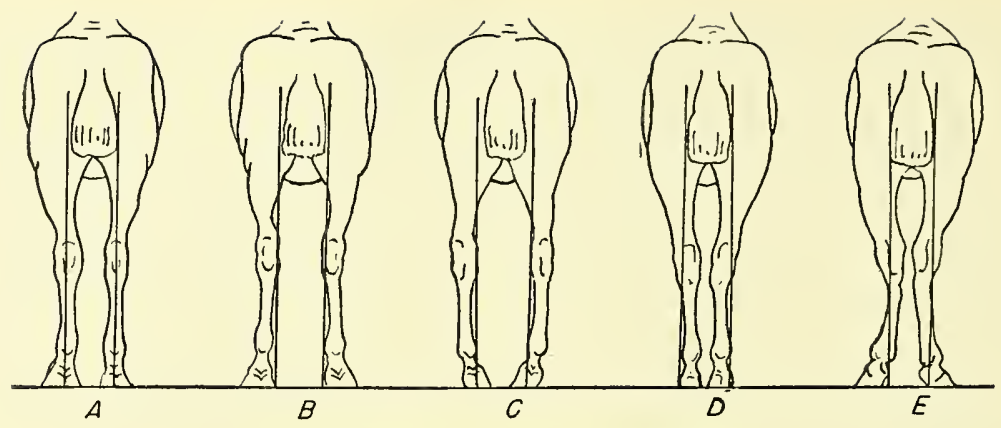

FIGURE 29.-Rear view of hind legs.

Thoroughpin (a very low one is shown in fig. 32) is due to a collection of synovia in the depressions which lie just below the tendon running from the point of the hock into the gaskin. It can best be detected by pressing the swelling on one side of the leg and noting the corresponding filling on the opposite side. Thoroughpin may canse lameness and consequently depreciates the value of the animal. The point of the hock sometimes becomes thickened from a bruise, which condition is shown in figure 33 and is termed capped hock. It does not cause lameness, but is unsightly and may indicate a kicker.

Bog spavin is an enlargement in the natural depression on the inner and front part of the hock, formed by a collection of synovia which is soft to the touch. It can best be seen from obliquely in front, as

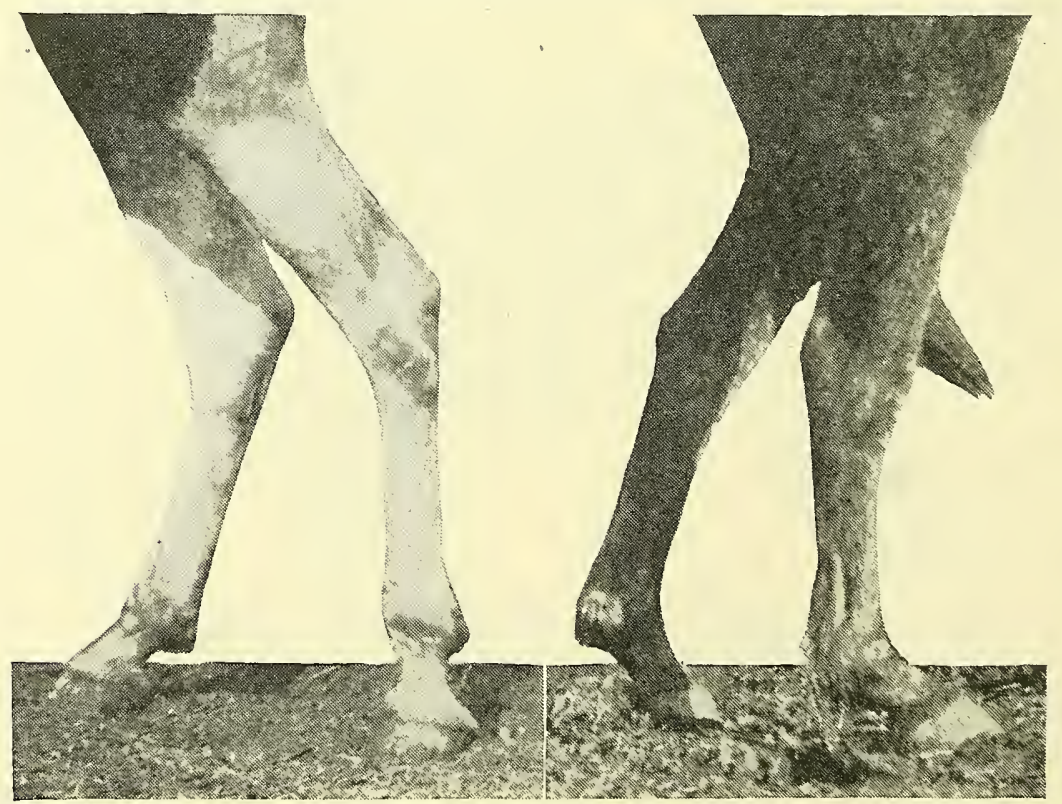

Figure 30.-Crooked hind legs with FIGURe 31.--Hind legs too straight, with cocked ankles. pasterns too sloping. 
shown in figure 34. This msonndness sometimes canses laneness, consequently lessening the animal's value. A large blook vessel passes nver this region of the hock, and this may become enlarged, giving the appearance of a bog spavin, but as this condition never leads to limeness it is considered a slight blemish lather than an unsomdness. Fullness at the back of the hock below the point and observed fiom the side as shown in figure 35 is due to a thickened ligament which may be ossified in long-standing cases and is known as curb. Curb, especially when first developing, causes lameness.

Bone spavin (fig. 36), located on the inside of the hock where the thick bony part taper's into the cannon, is a bony enlargement and can best be detected by comparing the inside of the hind legs from squarely in front or behind. Bone spavin can also often be seen from obliquely in front. If a horse appears to have a bone spavin, the following test will give further proof of its presence, provided the leg carries no other unsoundness that would cause limping. Pick up the suspected leg and hold it for a few minutes in a well-flexed position, then start the animal at a trot as soon as the foot reaches the ground. If bone spavin exists in an active form, the horse will limp.

Stringhalt, a disease eharacterized by extreme and unnatural flexion of the hind legs, hinders action. It can be most advantageously discerned when a horse backs out of a single stall after being idle for some time.

Splints do not generally oceur on the hind legs. Unless developed to an unusual size, sidebones do not interfere with the action of the hind legs. Ringbone frequently occurs on the hind pasterns, and is as objectionable there as on the front pasterns.

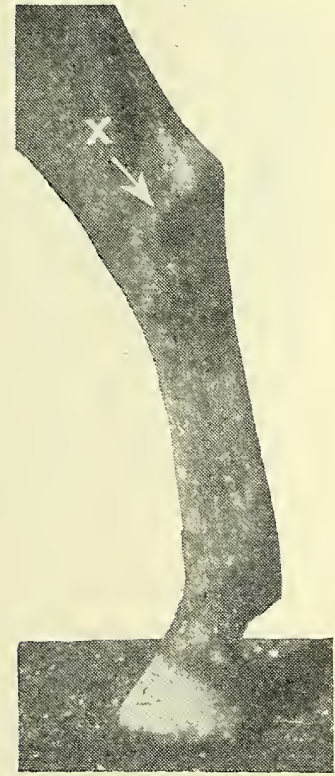

Figure 32.-Thoroughpin at $\mathrm{X}$.

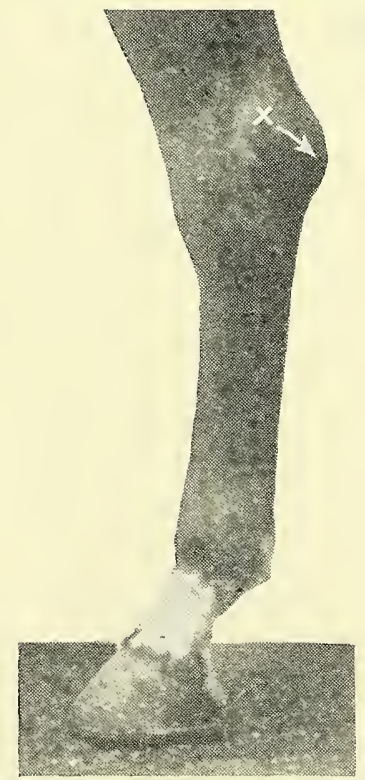

Figure 33.-Capled hock at $\mathrm{X}$.

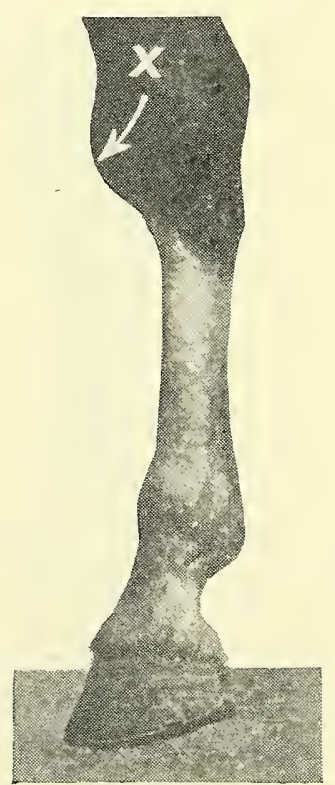

Figure 34.-Bog spavin at X. 


\section{THE HORSE IN ACTION}

Lameness due to a variety of causes and of various forms, some not at first apparent, should be carefully looked for when examining a horse in action. When lameness is present only at certain times it is known as intermittent lameness; consequently it is advisable to examine a horse on several different occasions. In cold lameness the animal will go sound after he is warmed up, while in warm lameness the impediment does not manifest itself until after considerable exercise. Flinching when the horse turns sharply indicates shoulder lameness. The various gaits should be observed from the front, side, and rear, in order that the desirable features and defects may not be overlooked.

Walking.-Perfection in this gait is characterized by the feet being brought up quickly from the ground, by their being carried in a straight line, by lengthy stride, and by the cycle being completed quickly. All these aid in producing a rapid, frictionless walk which is a great asset to horses used for any purpose. The defects of gait which may well be noted while the horse is walking are interfering, winging, toeing in or toeing out, and twisting the hind feet just before they are lifted from the ground, which wears out shoes rapidly and is otherwise undesirable.

Trot.-This gait must be square; that is, it must be without any tendency to wobble, shuffle, or mix gaits, and the hind feet should follow in line with the forefeet. In the roadster and trotting race horse speed is highly valued, while in the park saddle horse a fair

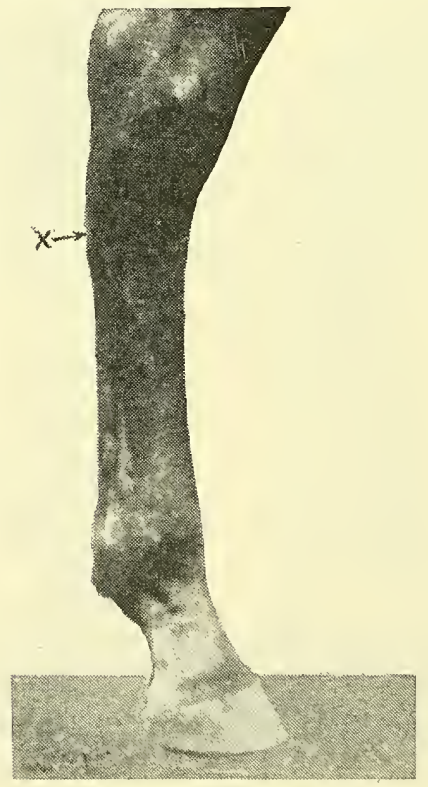

Figure $35 .-$ Curb at $\mathrm{X}$.

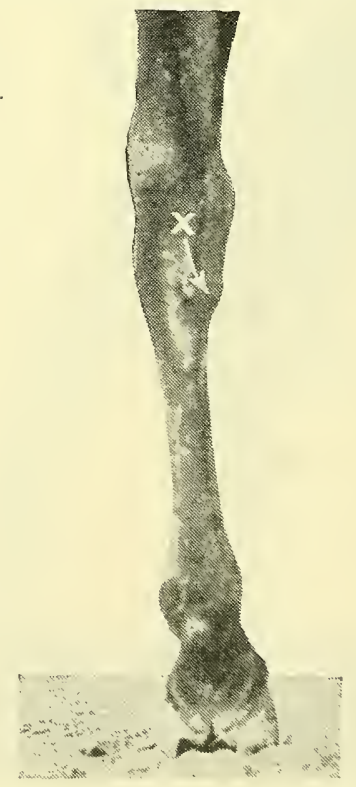

Figure 36.-Bone sparin at $\mathbf{X}$. 
degree of nicely balanced knee and hock action is demanded. The highest-prized factor of the fine harness horse expresses itself at the trot in extrenc knee and hock action. Even in the draft horse, a square, open, well-balanced trot with good knee and hock action adds many dollars to his selling price. The common defects of the trot are interfering, forging, scalping, sprawling, dwelling, hopping, and knee action without a proportionate amount of hock action or vice versa. Lameness may be detected in the trot when it may not be apparent in other gaits. Either an abundance or lack of energy and ambition is apparent during trotting by the general deportment and carriage.

Pace.-The pacing gait is more or less common in harness horses, and it is useful as a fast road gait on smooth surfaces. The characteristic movements of the limbs in this gait consist in the feet on the same side of the body working in unison and striking the ground simultaneously. The principle defects of the pace are cross-firing, quarter-cutting, and hitting the knees.

Easy gaits.-Plantation horses and 5-gaited saddle horses have special gaits that are usually easy on the rider as well as on the hor'se. Such gaits are often designated as "slow" and are desired principally for long rides. They are known as the slow pace, fox or dog trot, and rumning walk. Any one of them may constitute one of the gaits of a 5-gaited horse. A faster easy gait demanded in such a horse is the lack or singlefoot. This is intermediate between the trot and pace, the feet hitting the ground rapidly one at a time, producing a gait easy on the rider but tiring to the horse.

Canter.-The canter, classed as a saddle gait, may be described as a modified, collected, and very slow gallop. It should be graceful, easy, and handily performed.

Wind.-To test the wind have the horse ridden at a very fast gallop, stopping him abruptly so that you may hear the passing of air through the windpipe. In roaring, or broken wind, there will be a whistling sound each time the horse inhales. When a horse is affected with the disease called heaves, it has difficulty in forcing air out of the lungs, causing a peculiar and very characteristic movement in the flanks and abdomen, especially after exertion. Horses affected with heaves usually cough in a characteristic manner after drinking cold water. This cough may also be excited in affected hor'ses by tightly grasping the windpipe at the throatlatch for a short time. A horse's respiration is greatly hindered by either broken wind or heaves.

Adaptability for specific work. - A horse may possess proper conformation, be sound, and have a good action yet still not be well adapted for a specific work; consequently it is very essential that he be thoroughly examined at the work for which he is wanted. If the horse is to be used for heavy hauling or draft purposes, steady pulling under all conditions is an indispensable quality. For harness use the horse should drive promptly and freely with an easy, rapid gait and an alert expression, taking just sufficient hold of the bit to be in hand without causing the driver to pull on the lines. The saddle horse should have an easy, prompt mouth, good style, graceful carriage, and should stand quietly to be mounted and dismounted.

Vices.-Some horses are difficult to harness and object to taking the bit in their mouths; others jump when an attempt is made to place a saddle or harness on their backs; while still others offer a great deal of 
resistance to having the crupper placed under their tails, which, if due entirely to general muscular strength and tension, may be an indication of endurance. While being hitched up or mounted the horse should stand quietly and should start promptly but quietly on command. For any purpose the following vices should cause the animal to be rejected: Balking, backing, rearing, kicking, striking with the forefeet, or running away. Less important vices are: Throwing the head up or down, shying, scaring, breaking loose when tied, resting one foot upon the other, grasping the bit between the teeth, rolling with the harness on, or switching the tail over the lines. Occasionally the last-named vice causes the horse to kick, in which case it becomes dangerous.

\section{GENERAL RECOMMENDATIONS}

Enlargements or scars (due to deformity, unusual mishap, or uncommon disease) not conforming to any of those discussed should cause a horse to be rejected unless the nature of the cause and the detriment to the value and usefulness of the animal is self-evident.

Experience gained by examining large numbers of horses will aid in quickening the eye and judgment, thereby making it possible to perceive readily any unusual condition, but it should be remembered that a hurried examination is liable to prove a disappointment; consequently plenty of time should be taken in making the examination, because time is much cheaper than money tied up in an unsatisfactory horse. In some countries nine days are allowed by law to the purchaser in which to learn of the serious forms of unsoundness or vice in a horse, so that in this country it would seem fair to allow at least a day for a fair trial when practicable.

If possible, get a history of the animal, and while you are about it get a history of the person having it for sale. So many defects may be covered up by such unfair methods as drugging that it is a good plan to make purchases only from persons with good reputations.

Horses offered at auction sales should preferably be thoroughly examined previous to their being brought into the ring; at least they should be tried out in compliance with the rules of the sale before time for settlement.

Finally, it is well not to form the habit of seeing only the defects, for horses, like people, are seldom perfect; consequently in judging them weigh the good qualities against the bad. A horse should be valued by the amount of service it will perform rather than by its minor shortcomings. 

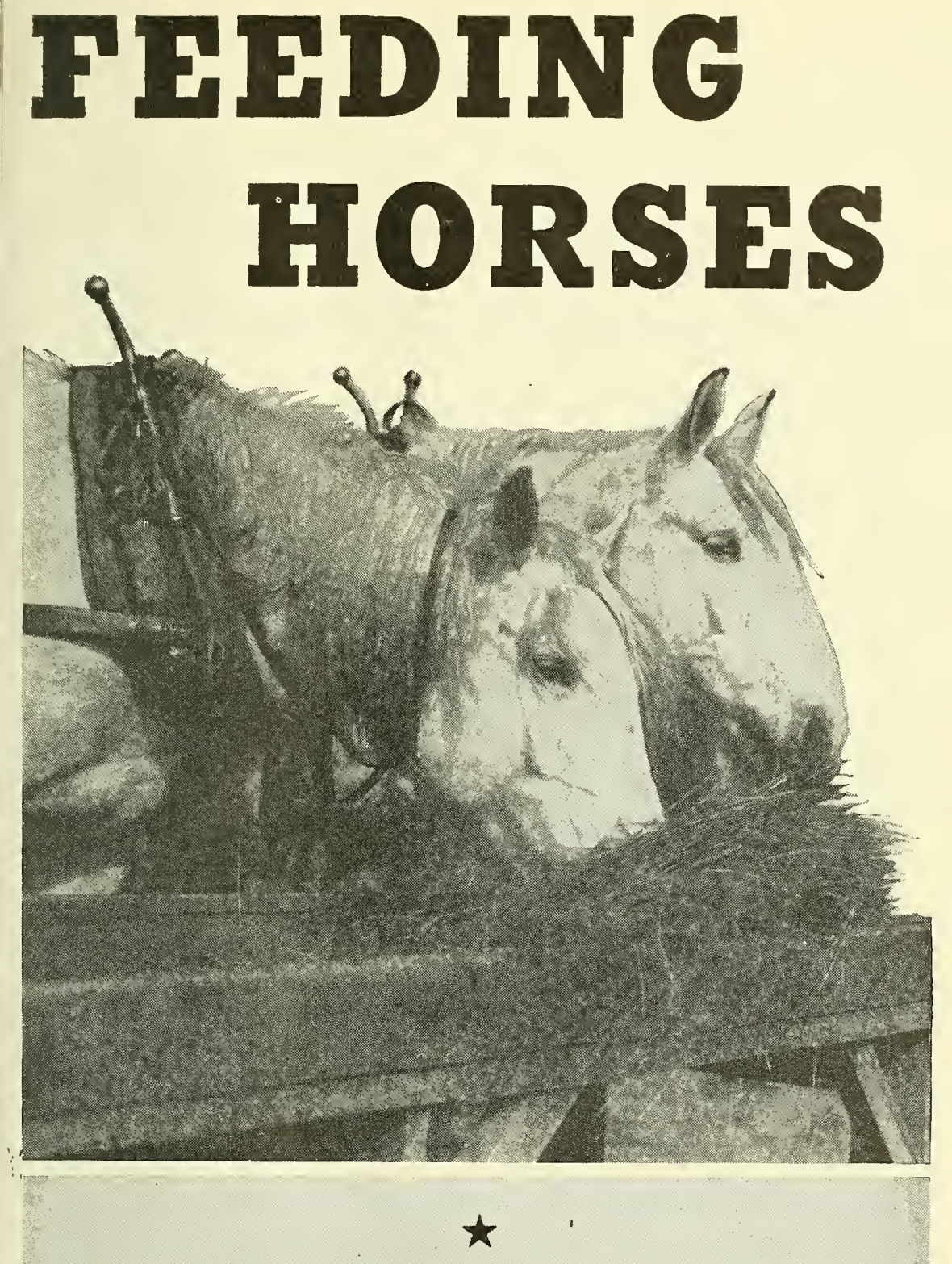

Furmers' Bulletin No. 1030

U. S. DEPARTMENT OF AGRICULTURE 
THE SELECTION of the most suitable ration for 1 horses is governd largely by local conditions. Choose those feeds which meet the requirements of economy, nutrition, and convenience.

Make slight changes in feeds occasionally. A horse appreciates a variety in his diet.

Knowledge of individual requirements of horses is essential to obtain best results. Close observation is probably a more vital factor in the feeding of horses than in the feeding of any other class of livestock.

This bulletin suggests certain feed combinations which approximately meet the needs of horses under varying conditions and reviews such factors of feeding as tend to make the horse more efficient. 


\section{FEEDING HORSES}

J. O. Wruдмs, animal husbandman, and N. R. EuLIs, principal chemist, Animal Husbandry Division, Bureau of Animal Industry ${ }^{2}$

\section{Contents}

\begin{tabular}{|c|c|c|}
\hline \multicolumn{2}{|c|}{ Page } & Page \\
\hline Suitable rations necessary_-_-_-_- & & Balancing a ration_-- \\
\hline Local influences important & & Feeding hints \\
\hline $\begin{array}{l}\text { Conditions affecting feed require- } \\
\text { ments }\end{array}$ & & $\begin{array}{l}\text { Feeding idle horses } \\
\text { Princinal feeds for horses }\end{array}$ \\
\hline Selecting a ration & & Suggested daily rations \\
\hline Preparation of feeds & & \\
\hline
\end{tabular}

\section{SUITABLE RATIONS NECESSARY}

THE FEEDING of horses calls for a suitable combination of feeds, 1 the same as with other farm animals, in order that various needed nutrients may be furnished for bodily maintenance and for energy to perform essential work. On most farms it is not difficult to obtain a combination of feeds as many grains and roughages required by horses are grown on the farm or may be obtained locally. Results in feeding a ration should be observed and the ration modified accordingly to the specific needs of the animals.

There is far more economy in supplying the required amounts of nutrients in the right proportions than in providing an excess of one and a deficeniecy of another. Proper attention given to the matter of balancing horse rations will result in benefit to both the health and the working efficiency of the animals fed, which in turn will effect a material reduction in the annual feed bill.

\section{LOCAL INFLUENCES IMPORTANT}

No one feed or combination of feeds will meet conditions in all parts of the country. Generally speaking, combinations of home-grown or locally raised crops constitute the most economical rations. Choose from the feeds available those which will most closely meet the requirements of economy, nutrition, and convenience. Substitution may often be made in rations in such a manner that, while the efficiency remains unchanged, the cost is materially lowered. Selection of the

I This is a revision of and supersedes former editions by G. A. Bell and Mr. Williams. Mr. Bell resigned from the Department in October 1920 ; Mr. Williams retired in September 1945. 
most economical and suitable ration is governed largely by local conditions.

\section{CONDITIONS AFFECTING FEED REQUIREMENTS}

The kinds of feed used, the quantity required per animal, and the manner of feeding depend on the age, size, and condition of the horse, the amount, kind, and speed of the work done, and the individual fed.

The horse at work usually requires more and richer feed than the idle one. To furnish energy for work, the feed allowance must be in excess of that needed for body maintenance. 'The amount of feed needed for maintenance is about two-thirds that required for a horse at moderate work. If the work done calls for more energy than is furnished in the ration, the stored-up energy of the body fat or other tissues will be drawn on, with a consequent loss in body weight and energy. Moreover, if such feeding practice is continued, the horse will be so weakened constitutionally that he will be unable to perform his work profitably and also will be especially susceptible to disease.

Horses of the same type and weight may have different feed requirements, which makes it necessary to study the individuality of the animals. If the horse is not doing well on a ration, a slight change should be made. Any change, however, should be made gradually in order to avoid digestive disturbances.

\section{SELECTING A RATION}

As no feed or combination of feeds. will meet conditions in all parts of the country, so no feed or mixture of feeds is suitable for all classes of horses. In choosing a ration for a horse, select the one that seems to meet best his requirements, whether for growth, maintenance, work, breeding, or fattening; estimate the amount of feed needed, and try out the ration. It may appear after a trial that too little is being fed or that the ration may be changed somewhat in the interest of either economy or efficiency. If a number of horses are kept, different rations may be tested on different animals and the best one selected for general use. Individual feeding gives the best results.

\section{PREPARATION OF FEEDS}

The advisability of chopping, cutting, or chaffing hay for horse feeding depends largely on the cost of preparation, the quality of the feed, and its price. Ordinarily, low-priced hay of good quality should not be prepared for feeding, but it may be economical to chop, cut, or chaff poor-quality hay, as it is eaten with less waste than the unprepared forage.

Such roughages as corn stover and sorghum can generally be fed to horses most satisfactorily when shredded or cut. Preparation makes the feed much easier to handle in the stable and results in a greater proportionate consumption of the roughage.

The benefits derived from grinding or crushing oats and corn for horses depend on the cost of preparation, working conditions, and the condition of the animals' teeth. Throughout the Corn Belt corn is usually fed on the cob or in the shelled form, and it ordinarily does not pay to grind it for horses unless the animals' teeth are in 
poor condition or if there is not time enongh for proper mastication of the grain. All small, hard grains, such as rye, barley, rice, and wheat, should be crushed or rolled before feeding, to avoid digestive disturbances, since horses cannot properly masticate those grains.

Ordinarily it is not advisable to cook, steam, or soak feeds for horses, since those methods of preparation do not materially improve digestion. When, however, the small, hard grains cannot be rolled or crushed it is a good plan to soak them. It is the accepted practice, moreover, of many horsemen to feed a warm mash occasionally as a tonic and to regulate the bowels.

\section{BALANCING A RATION}

Feeding stuffs are broadly divided into two general classes, protein and carbohydrate. The protein feeds are rich in nitrogenous compounds which are used by the animal body in building tissue, bone, hair, etc., and to provide energy. The carbohydrate foods are starchy in nature and are used by the animal body in the formation of fat and for energy and heat.

To obtain the best results in feeding, the ration should be so balanced that it properly meets the needs of the animal in building tissue and in supplying energy for work. In order to do this, feeds containing the nutrients which supply the required proteins and energy are needed in certain proportions to meet the body requirements. If feeds deficient in protein are fed, an excessive amount of carbonaceous nutrients must be consumed in order that the system may obtain the required quantity of protein, and vice versa, and so a waste of feed will be the result. It is essential, therefore, that a balanced ration be fed, that is, one containing proteins and carbohydrates in such proportions that the requisite amounts of each will be utilized without waste.

Feeds rich in protein are usually the most expensive. If more protein is supplied than is needed for nutrition, the cost of the feed is unnecessarily increased. It is more economical to supply the energy necessary to perform work in the form of carbohydrates than proteins. Thus for mature horses at work and for maintaining idle horses the protein feed allowance may be limited to the amount necessary to build tissue, and a large proportion of carbohydrates may be fed.

Another important class of feed nutrients is the mineral elements. Of chief importance are calcium and phosphorus, which are required for proper growth and maintenance of the bones or skeleton structure. An insufficient supply of either calcium or phosphorus leads to weakened bones and various deformities. The grains and the byproduct feeds made from grains and seeds are relatively rich in phosphorus, and most forages, especially legumes, are well supplied with calcium. Occasionally a mineral supplement is advisable, such as bonemeal, which supplies both calcium and phosphorus, and pulverized limestone or oystershell, which supplies calcium. In areas where goiter is prevalent, the use of iodized salt is advisable.

The requirements of horses for the various vitamin factors are not fully understood. Young animals kept out of the sunshine for extended periods may develop rickets. A lack of vitamin A can lead to trouble also if feeds devoid of this factor are fed for long periods. 
In the case of horses, it is usually associated with eyesight and hoofs. Fortunately, green pastures are very rich in vitamin A, and well-cured hays less than a year old are fairly good sources of carotene, from which this vitamin is formed in the animal body. Some of the B vitamins appear to be required by horses, but relatively few occasions are likely to develop when rations will be deficient in these factors.

\section{FEEDING HINTS}

The grain part of the ration for horses at work is usually divided into three equal feeds. If the horse does not clean up grain in a reasonable length of time, the quantity should be reduced. About two-thirds of the daily hay allowance is given at night, with most of the remainder fed in the morning, leaving only a very small allowance for the noon feed. The quantity of roughage should be limited within the maximum allowance, so that all the edible forage will be cleaned up every day. When there is forage remaining from the night feeding, do not put in a fresh supply, but stir up that which is in the manger, so that the chaff goes to the bottom, leaving the good hay available. Some hay should be fed before the grain at night, for the appetite of the horse is not appeased by the grain when it is fed first, and it fills up on hay, forcing the grain on through the stomach too quickly, thereby decreasing the quantity assimilated.

The method of feeding has a great deal to do with the utilization of the feed and the condition of the horse. It is important that the horse that bolts grain be made to eat slowly, which may be done by feeding the grain spread out in a large, flat box, by placing several smooth stones about 3 inches in diameter in the feed box, or by mixing the grain with bran, cut hay, or similar feed. Some horses waste their hay by pulling it out and trampling it under foot. This is sometimes caused by feeding two kinds of hay, one of which is especially palatable. In that case, the waste may be corrected by feeding the hay so that the horse can eat the more palatable first. The horse will then eat the other hay leisurely during the night. Another plan is to withhold the good hay until the other is eaten.

Overfeeding, rather than underfeeding, is the common practice when horses are working irregularly. It should be remembered that the amount of feed should vary, not only between winter and summer but also from day to day. It is a waste of feed if the amount is not varied with the degree of work.

\section{FEEDING IDLE HORSES}

Maintaining the farm work horse in healthful condition during the winter is the first start in fitting it for spring work. The horse should not be so fed during the winter that it becomes fat and soft. Moreover it is bad management to let a horse lose weight during the winter and then try to bring it back to normal by heavy feeding just before the beginning of spring work.

The liberal use of roughage, supplemented with the right quantity and kind of other nutritious feed, will maintain a horse properly during the winter. Farm hor'ses, except brood mares or growing stock, do well on a ration made up largely of the coarser hays, straw, or corn fodder. Cornstalk fields, grain-stubble fields, or pastures which have 
not been too closely grazed during the summer are very desirable sources of a large part of the winter maintenance feed. The common roughages, as the main part of the ration during this period, will supply bulky feed enough to keep the horse thrifty without putting on superfluous fat. The drinking of a large quantity of pure water' should be enconraged to increase the utilization of these dry roughages. When necessary, a tank heater should be used to keep the drinking trough free from ice.

It is advisable to supplement the coar'ser roughages with a legume, such as alfalfa, clover, vetch, soybean, or cowpea hay. These hays are very palatable and should be fed sparingly. They are rich in protein and mineral matter and supply the materials needed to replace those lost in the natural wear of the body. Being somewhat laxative in effect, they also help to keep the digestive tract in good condition. They are especially valuable in connection with straw and similar feed. The use of these hays with the coarser roughages is economical because a supplemental ration of grain is not ordinarily necessary.

In some instances, especially when it is not possible to feed a legume hay, a small quantity of grain is necessary to maintain the horses in thrifty condition. Oats are preferred for use with coarser roughages, but corn and barley are often used in the winter ration, especially when they are cheaper or when an increase in weight is desired. One or two bran mashes a week or a little linseed meal each day is recommended as an aid in keeping the system in good condition and in preventing impaction resulting from the use of large quantities of coarse roughage improperly supplemented.

Pregnant mares require more attention during the winter than the open mare or gelding. Leguminous feeds high in protein and ash are necessary in developing the fetus. Although the feeding of legume hay is usually of more importance than a supplemental grain feed, in most cases such feeds as oats, bran, and oil meal should be supplied, the proportions being largely controlled by the condition of the mare and the stage of development of the fetus.

\section{FEED FOR LIGHT HORSES}

In horses of the light breeds that are used for pleasure or racing, the qualities desired are spirit, action, and endurance, and large, paunchy stomachs are objectionable. Such horses require proportionately more grain and less hay than horses doing slow or heavy work. Oats easily rank first among the feeds for light horses; they may be supplemented with crushed or soaked barley and bran. Corn is too fattening to constitute the bulk of the concentrates for light horses; it may be used, however, if supplemented with linseed meal or bran. A mixture of one of the legume hays, as alfalfa or clover, with timothy or other hay, will furnish the roughage. A larger quantity of hay should be allowed for horses less actively employed and should be fed mostly at night. One pound of hay and 1 to $1 \frac{1}{4}$ pounds of grain per 100 pounds live weight will be sufficient for such light horses at moderate work.

\section{FEEDING WORK HORSES}

The quantity of feed for the work horse depends on the amount of work done and on the speed at which it is performed; a horse requires considerably more feed when working at the trot than at the walk. It is 
a good rule to allow $11 / 10$ pounds of grain and $11 / 5$ pounds of hay per 100 pounds live weight for horses at moderate work. At this rate a 1,200pound horse would require 13 pounds of grain and about $141 / 2$ pounds of hay per day. If the work is severe, the quantity of grain should be increased. The horse at very hard work requires $1 \frac{1}{4}$ to $11 / 3$ pounds of grain per 100 pounds live weight; the hay fed, however, should not be over $1 \frac{1}{4}$ pounds per 100 pounds live weight. On idle days during the work season the grain ration should be reduced approximately onehalf. The exact quantity to feed at any time will depend largely on the individuality of each horse.

\section{PRINCIPAL FEEDS FOR HORSES}

In connection with rations for horses a brief discussion of the merits of the more common feeds will assist in the choice of a ration. It is the special purpose of the following review to judge the feeds from the standpoint of the horse feeder.

For convenience the feeds will be classified as concentrates, roughages, succulent feeds, and condiments.

\section{CONCENTRATES}

Oats.-This grain ranks as one of the very best for horses. The kernel is incased in a hull which, although it has no great nutritive value, greatly improves the physical character of the feed by adding bulk. Oats probably come nearer to filling the requirements of a concentrate for horses than any other grain. Compared with corn, oats have more protein and less carbohydrates. Oats are readily available in almost every part of the country and may be fed either whole or ground. They should be rolled or ground for very young animals.

Some horses eat oats too rapidly. With such ravenous feeders, to prevent the danger of choking, it is advisable to place a little chopped clover hay or some whole corncobs in the feed box with the oats. The use of wheat bran with oats also lessens the tendency toward choking. Oats may form the entire grain ration of horses. The substitution of 2 or 3 pounds of wheat bran improves the daily ration, provided it does not produce a too laxative effect.

Corn.-In many sections corn is given preference over oats as a horse feed, as it is generally grown on the average farm or may be obtained easily. Corn may be fed on the cob, shelled, or ground. It is especially rich in carbohydrates; more energy is derived from a pound of corn than from a pound of any other suitable grain. It is considered as an economical part of a ration. Since this grain is somewhat low in protein, it is well to provide leguminous hay for the animals that are fed corn. The combination of alfalfa hay and corn is receiving much faror when fed to horses. In the absence of legumes, a little oil meal or some other protein concentrate may be included in the ration. Corn is fattening and heat producing and is greatly relished by horses.

It is sometimes claimed that horses which are fed corn are more subject to colic than those fed oats and other grains. Little difficulty, however, is experienced in the Corn Belt, where it is fed constantly. Horses that have not been accustomed to eating corn should not be changed to it suddenly; in fact, all changes in the horse ration should be made gradually. Corn is suited to form the major part of the grain ration for 
horses if a nitrogenous (protein) roughage is fed in combination with it.

Corn-and-cob meal.-Although the commonest practice in feeding corn to horses is to use ear or shelled corn, in oceasional instances this grain is fed in the form of corn-and-cob meal. This form is especially suitable for animals which do not have the necessary time to chew thoroughly the ear or shelled corn or in case a horse's age or the condition of the teeth makes the fecding of whole grain impracticable. Corn-and-cob meal is of about the same feeding value, pound for pound, as shelled corn, but certain precantions must be taken in feeding it. When stored for a time it has a tendency to generate heat, with the consequent formation of mold. It is therefore best to grind the grain only as needed.

Wheat.-Under ordinary conditions wheat is relatively too high in price to permit its economical use in the horse ration. If conditions permit, however, wheat may be satisfactorily used for horses provided it is crushed or rolled and fed in moderate quantities. Crushing or rolling is necessary because horses cannot efficiently chew the whole hard grains, and a limitation of the amount fed is essential to prevent digestive disturbances. Compared with com, wheat carries slightly more carbohydrates, more crude protein, but less fat. The most satisfactory feeding results will be obtained when wheat is fed in conjunction with a bulky concentrate and when the roughage is of protein nature, rich in mineral matter, as alfalfa.

Wheat bran.-This is a favorite feed among horsemen because it is especially palatable. A byproduct of milling, bran is usually somewhat expensive. Wheat bran is quite laxative, and for this reason it is valuable for occasional feeding to pregnant mares, idle horses, and colts. With horses doing irregular work, the movement of the bowels may be regulated by an allowance of bran once or twice a week. Because this feed is light and soft in character it makes a good mixture with other feeds, often making them more suitable for feeding. Wheat bran is higher in protein than either oats or corn. It is not suited to form a very high proportion of the concentrate ration for horses because it is too bulky and is likely to have an unfavorable influence on calcium and phosphorus utilization.

Barley.-Barley is used as a principal grain for horses in many parts of the West. Except in physical character it is well suited to the horse ration. This grain should be rolled before being fed. If finely ground, it will form a pasty mass with the saliva of the mouth. Barley is a little higher in total nutrients than oats, but is not so widely used nor so generally popular a feed among horsemen. Rolled barley is suitable to form the major part of the grain ration for horses.

Rye.-This may be used as a horse feed in combination with other grains. In some regions it is an economical feed. It is even higher in total nutrients than oats. The grain is small and hard and should be rolled or ground. Many horses will refuse whole rye when fed alone, and an abrupt change to rye feeding is liable to produce colic. Most of the charges against rye may be traced to the feeding of moldy or otherwise damaged grain. It is probably better to limit the amount of rye to one-third of the grain ration. It may be mixed with ground corn, bran, oats, or other grains. Rye is not generally considered desirable to form a major part of the grain ration for horses, as it is 
not palatable when fed alone and is liable to cause digestive disturbances.

Buckwheat.-This grain is not very commonly used as a horse feed, although it is only a little below the more common cereals in total digestible nutrients. It has a characteristic, hard, black hull which has practically no value as a feed. Unadulterated buckwheat middlings are not easily obtained. They are made from that part of the kernel just beneath the woody hull and are very rich in protein. The common practice is to mix the middlings with the woody hulls and sell it as buckwheat feed or buckwheat bran. This product has a lower feeding value than wheat bran. If the proportion of hulls is not too large, buckwheat bran may be well used in the horse ration. Buckwheat should be limited to one-third the grain ration.

Rice--Rice is considered economical for horse feed in some of the Southern States, the less valuable kind of rough rice being used. This grain is small and extremely hard; it should be ground or rolled before use in the horse ration. It is better to limit rough rice to onethird of the grain allowance. Rice may be used in connection with corn, blackstrap molasses, and a very limited allowance of some protein concentrate, such as cottonseed meal, soybean meal, or linseed meal.

Soybeans, cowpeas, velvetbeans, horsebeans, field peas.-All these are similar seeds of leguminous plants, and are suitable for use in limited amounts in the horse ration. Since all are hard seeds, they should always be ground. Their proper use in a ration for horses is as a somewhat concentrated protein feed to be combined with feeds high in carbohydrates, such as molasses, and corn. Digestive troubles are very liable to occur if one or more of these feeds exceed one-third of the concentrate ration. Used with care, they have a very valuable place in horse feeding.

Coconut meal.-A byproduct from the manufacture of coconut oil, coconut meal is considered a safe but rather unpalatable feed for horses. It is a little higher in nutrients than wheat bran, but has the disadvantage of becoming rancid after standing a few weeks. To the extent of one-fourth of the grain ration it may replace oats where economy justifies the measure. Coconut meal is not a very heavy protein concentrate.

Peanuts.-In the form of peanut meal this feed is often given to horses. Shelled peanuts are liable to become rancid if stored for any length of time. The commercial form of peanut meal is the ground hull and kernel combined. It is a comparatively safe feed for horses, but is so rich in protein that the allowance should be limited. When it is used, animals should be started on this feed gradually and it should be fed in connection with com or some other carbonaceous feed.

Linseed meal.-This feed is the ground cake resulting after the oil has been extracted from flaxseed. It is very high in protein, has laxative properties, but is not suited to form the bulk of the grain ration. Linseed meal is quite unpalatable, but is raluable, however, for combining with corn and other carbonaceous feeds, being a heavy protein concentrate. It is most successfully fer with ground feeds or in a mixture containing molasses, for if fed in combination with feeds from which it can be separated readily, horses will eat the palatable grains and refuse the meal. Some feeders use linseed meal as a con- 
ditioner, giving a small amount (about one-lualf pound) three times a week to keep the bowels in free condition. The more favorable results in the use of linseed neal are obtained when the quantity used is limited to 1 pound or less per day for each animal.

Shorts (wheat middlings.) - This is not extensively used as a horse feed because it is usually high in price and its heavy nature and high protein content make it unsuitable to form the major part of the ration. It is palatable, however, and may be used to supplement a horse ration that is low in protein. The quantity should be limited to one-fourth of the concentrate allowance.

Cottonseed meal. - The resulting ground cake after the oil has been extracted from the cottonseed is a heavy protein concentrate which, mlike linseed meal, is not laxative in character. This feed has met with considerable disfavor among horse feeders, as it is believed to have a tendency to produce digestive disorders. There is no doubt some foundation for this belief, but it has been found that the harmful results have usually followed either the use of a poor quality of meal or the feeding of too much. Cottonseed meal may be fed to horses in limited quantities if due care is exercised in obtaining bight, choice meal and if the animals are put on the diet gradually. Its proper use is as a supplement to a carbonaceous concentrate, such as corn. Favorable results have been obtained in some parts of the South in the feeding of cottonseed meal in connection with blackstrap molasses and grain. Since the meal is not palatable, it should be well incorporated with other feeds. While cottonseed meal has been fed in large quantities in isolated cases the best results may be obtained by limiting the amount to 1 pound daily per 1,000 pounds live weight, and giving special attention to the horses being fed. ${ }^{2}$

Alfalfa meal. - Chopped alfalfa is often desirable to improve the physical character of a ration, but feeding alfalfa as a meal is not to be generally recommended. Alfalfa is properly classed among the roughages, even though it is higher in nutrients than some of the concentrates. Finely ground alfalfa is dusty and must be dampened before it can be fed with satisfaction. There is no advantage which justifies the additional cost of grinding, except for horses with bad teeth or weak digestive organs.

Millet, kafir, and milo seeds.-These are very small, hard grains which must be ground before they are suitable for the horse ration. They compare favorably with oats in regard to total nutrients, and any of them, when ground or rolled, may be used in combination with other grains, but it is well to limit the amount used to one-third the total concentrate allowance. The sorghum grains are high in carbohydrates and tend to cause constipation when fed heavily. These grains, therefore, should be fed in conjunction with a laxative protein feed, such as wheat bran, to counteract this tendency.

Dried Brewers' or Distillers' Grains.-These grains, which are byproducts of fermentation industries, are rather heavy protein concentrates and suitable for balancing carbonaceous rations or for incorporation with chopped mixtures, but are not suitable for use as the major part of the grain ration. As supplements their use should be limited in amount to about one-fourth the total allowance

2For further information, see Farmers' Bulletin 1179, Feeding Cottonseed Products to Livestock. 
of concentrates. Some feeders claim that these feeds have a tendency to cause constipation.

Gluten Meal.-A byproduct of starch mamufacture, it is high in protein and fairly high in carbohydrates. It is classed as a protein concentrate, and should be limited to abont one-fourth the total grain allowance. It is not very palatable, but sometimes is valuable for use in chopped mixtures.

Gluten Feed.-This is also a protein concentrate but is somewhat less mutritious than gluten meal. Gluten feed is made by mixing corn bran with gluten meal, and is not very palatable. The proper use of gluten feed is for balancing more carbonaceous rations, and it should be limited in amount to one-third of the grain ration. Like gluten meal, it may well be used with other grains in a chopped mixture and fed with molasses.

Dried Beet Pulp.-A byproduct of sugar manufacture, this pulp is unpalatable, but by mixing with molasses or other well-liked feeds, it may be included in the ration. It is very low in protein. Dried beet pulp is a safe feed, but it is not desirable to use it in excess of about 5 pounds in the daily ration, and it should be fed in connection with some feed that is relatively high in protein.

Cane Molasses (Blackstrap Molasses).-The use of this feed is quite popular in cane-growing sections. It is high in carbohydrates and should be fed in connection with feeds relatively high in protein. Molasses is especially palatable and is well suited for combination with chopped mixtures containing nutritious but unpalatable feeds. It is usually desirable to dilute it with two parts of water before feeding over grain or roughage. The amount of molasses in the ration should be limited. Usually about 5 pounds daily is a very reasonable allowance, although some feeders use considerably more than that amount. Cane molasses is neither laxative nor binding in effect. Molasses is not usually an economical feed except in sugar-producing regions. However, it is often desirable to use a small amount, such as a quart (3 pounds) a day, as an appetizer.

Beet Molasses.-As a horse feed, beet molasses is not so satisfactory as cane molasses. The presence of certain constituents stimulates the action of the kidneys and bowels of the animals fed. Because of this action it is not desirable to exceed 5 pounds of beet molasses in the daily ration. Like cane molasses, it is a carbohydrate concentrate, very palatable and suitable for feeding as part of a concentrate ration that also includes a protein feed.

Milk.-Sometimes milk may be used with good results for feeding horses. Its particular advantage is in its use for colts and for horses that are out of condition. Milk may also be a valuable feed for horses doing very light work. It is palatable, easy to digest, and valuable for fattening. If cow's milk is to be substituted for mare's milk for young colts, there should be an addition of a little sugar and a little limewater. It is not desirable to feed a large quantity of milk to horses generally, but 3 or 4 gallons a day can well be allowed a horse not doing heavy work. Milk is a safe feed, and even in clabbered condition it is not harmful.

Tankage and Blood Meal.--These byproducts of slaughterhouses do not rank high as horse feeds. They are very high in protein, but are extremely unpalatable. They may be used, however, in amounts not 
exceeding 1 pound each day per animal in connection with some palatable carbonaceous mixture. Tankage and blood meal are used principally for young stock and for building up animals in extremely poor condition.

\section{COMMERCIAL FEEDS}

Various commercial feed mixtures on the market are made up expressly for feeding horses and these can be used to good advantage when suitable home-grown feeds are not available or other circumstances dictate. 'The merits of a particular feed can be judged to a considerable extent by the list of ingredients and the composition figures which can generally be found on the bag. Some of these feed mixtures are sold as meal and others in pellet form. Certain mixtures are made up expressly for feeding along with home-grown feeds. In the usual case, they are intended to replace or supplement the concentrate-portion of the ration.

\section{ROUGHAGES}

To be most valuable as a nutrient in a horse ration, hay should be cured properly before it is stored. Even hay that has been well cured deteriorates in feeding value if stored too long. It is important, therefore, that an adequate supply be provided for a few months. The practice of carrying hay over from year to year is inadvisable as it gradually loses its vitamin A (carotene) content, which is indicated by the green color of the hay.

Alfalfa hay.-This roughage is receiving very great favor as a horse feed. It contains nearly as much nutriment, pound for pound, as wheat bran. It is high in protein and minerals, especially calcium; hence it is especially valuable for young stock. Like other legume forages, it supplies more calcium than the grass hays and thus compensates for the deficiency of this element in the grains and other concentrates. Alfalfa is somewhat laxative in effect. Because of this and its high protein content, it is well to limit the amount to one-half or two-thirds the roughage allowance. Timothy hay may be used to make up the rest of the roughage supply. Alfalfa is especially suited for use with a grain ration that is low in protein. Corn as the grain, and alfalfa as the roughage, equal weights of each, very nearly make a balanced ration. In considering a roughage for horses, it is desirable to furnish one that is relatively high in nutriment, since the horse has a comparatively small stomach and is unsuited to take care of great quantities of nonnutritious material. Alfalfa meets this requirement. Because of its soft stems this roughage is often used in chopped mixtures.

Timothy hay.-This hay is highly recommended for horses. Notwithstanding the fact that it is not very high in nutrients, there is probably no other one form of roughage that is better suited for the horse ration. It is low in protein and is suitable for combination with alfalfa, clover, or some other legume. If timothy is fed as the only form of roughage, the concentrate allowance should be relatively high in protein. Because of its sharp, brittle stems it is not well suited for use in chopped mixtures. It is readily available in most sections of the country. 'Timothy hay and oats have long been regarded as the 
standard horse feeds, but the combination can be improved by including some feed that is relatively high in protein.

Clover hay. - This is a good feed for horses. The usual criticism of this hay is that it is often dusty. Dampening at the time of feeding will aid somewhat, but proper care in the curing of the hay is the best means of preventing dust. Bright clover hay that is free from dust is almost as valuable as alfalfa. It is more palatable than timothy, and a mixture of clover and timothy is to be preferred to timothy alone as a roughage for horses. Clover is a legume, high in protein, somewhat laxative in effect, is an excellent feed for colts, and is suited for use in connection with a grain ration that is rather low in protein. Where only one kind of hay is fed, a smaller quantity is required of clover than of timothy. Various kinds of clovers are used for hay in different parts of the country. Common red clover is most widely used. Mammoth or Big English clover is acceptable, but is somewhat coarse. The very coarse, large varieties, such as sweet clover, are usually too woody to be very desirable. Alsike is very good, but the yield of this crop is usually not large enough to encourage its growth in most localities. If hay from crimson clover is to be used as a horse feed, the crops should be cut before the blossoms are ripe, as the hairy growth on the head of the plant becomes wiry and indigestible and forms masses similar to hair balls, in the digestive tract, which often result in serious cases of impaction. Bur clover of the South may be used as a hay for horses' but its use is not common.

Corn stover.-Corn fodder from which the grain has been removed is a common feed for horses. The objections to it are that it is usually so carelessly handled that most of the nourishment is lost and the feed allowed to become partly spoiled. It is also unhandy to feed unless some special preparation is given, and there is usually considerable waste connected with feeding it. However, corn stover that is bright and clean and retains its leaves is very palatable, desirable, and safe for horses, and is suitable for use as the sole roughage during the fall and early winter. It is low in protein and should be fed in combination with a concentrate ration which will offset the deficiency. Cutting or shredding is usually advisable if it is to be fed in the stable.

Oat hay.-Hays from oats and similar cereals are commonly fed to horses. These crops should be cut before maturity if they are to be used as forage. They are palatable and nourishing, and care should be taken to limit the amount. On account of the grain, the allowance should be about one-third less than the quantity of the more common roughages that would be fed. Very little concentrated feed is needed with oat hay, but it is desirable to include a feed relatively high in protein. Cereal hay may be fed as half the roughage allowance in connection with a legume hay. With such a combination only about half the usual grain ration is necessary.

Cowpeas, soybeans, velvetbeans, and field peas.-These may be used as hay for horses. All are legumes, high in protein and calcium and suitable for use in connection with concentrates that are high in carbohydrates, such as corn or molasses. The peas and beans are slightly laxative in effect. It is well to limit these feeds to one-half the roughage allowance; timothy or prairie hay may well be used to form the other half. The amount of grain in the pods should be taken into 
consideration, and the ration of concentrates should be reduced accordingly. Field-pea vines that have been carefully cured after the peas have been threshed out are fairly acceptable as horse forage. A full grain ration and a little hay should be fed with them. Unthreshed compeas, soybeans, velvetbeans, and field peas are safe and failly palatable feeds, but are too concentrated to for'm the complete roughage allowance.

Millet, or Hungarian hay.-This is suitable for use in the horse ration, provided the crop has been cut before it is too mature and an excessive quantity is not fed. The small, hard seeds of mature millet are objectionable, as harmful action on the kidneys is clained when an excess of these is fed. This hay is carbonaceous in character and should be fed in connection with a legume hay, or the concentrate allowance should contain feeds a little high in protein. Bright millet hay of fine growth is quite satisfactory as a horse feed when limited to half the roughage allowance.

Prairie hay.-This hay is satisfactory for use as a horse feed and is commonly used in the West. It is slightly lower in nutrients than timothy hay, is carbonaceous, and should be fed in combination with a legume hay. It is a safe feed, fairly palatable, and may form the total roughage allowance if the concentrate ration is sufficiently high in protein.

Orchard grass hay.-Orchard grass makes a suitable hay for horses only when it is cut before maturity. It compares very favorably with timothy, and its palatability is not criticized in hay that is not too mature when cut. It is carbonaceous, and when used either the concentrates should be high in protein or a legume liay should form part of the roughage allowance. It is a safe feed for horses.

Johnson grass hay.-In certain sections of the South, particularly throughout the Cotton Belt States, Johnson grass grows luxuriantly, often producing three cuttings of good hay a year and forming excellent pasturage. In this district this grass may be utilized to advantage as forage for horses. Johnson grass is a carbonaceous roughage which has a feeding value equivalent to timothy, is slightly laxative in character, and is eaten with relish by horses. The principal drawback to feeding Johnson grass hay in those sections where clean cultivation of other crops is practiced lies in the fact that such feeding distributes the seeds of the plant and makes the confinement of its growth to a limited area very difficult.

Bromegrass.-This grass is of carbonaceous character and is common in the North and West. The hay is palatable and safe for horses. It is a little low in protein, and the grain ration that is fed with it should include a protein concentrate.

Straw.-Straw from various cereals such as oats, barley, wheat, rye, and rice, is often used as a feed for horses. It is bulky, nonnutritious, and not especially suitable, since the hor'se has a comparatively small stomach and its digestive anatomy is in no way suited to handle a large amount of bulky feed. So very little nourishment is derived from straw that it is not considered a suitable feed for animals doing hard work. Straw is carbonaceous, and its principal use is for idle horses. Some laxative feed should be fed in connection with it. Because of economy, it is often desirable to feed some straw, and in 
this case the concentrate allowance should be high in protein. A little straw may be included in a ration in which the principal roughage is alfalfa, clover, or some other legume. Oat straw is preferable; barley straw and wheat straw are good; straw from buckwheat or rye is not desirable; straw from rice is sometimes fed with good results when the remainder of the ration is high in protein. The economy of feeding straw is a factor which cannot be disregarded, but the practice should not be carried to the extreme, and care should be taken to supply sufficient protein through the concentrate ration.

Vetch.-This legume is not very commonly used as a horse feed. The plant is rich in nutrients, is suitable to form about half of the roughage allowance in a ration that is lacking in protein, and is fairly palatable. A combination that is meeting with favor is vetch and oat hay.

Sudan grass.-This plant makes a suitable hay for horses and is fairly palatable. As a carbonaceons feed the hay is suitable for use as part of the roughage allowance in combination with a legume hay. Its principal use is in the South.

Bermuda grass.- Hay from this plant is sometimes used in the South. It is a carbonaceous feed, suitable for use in connection with legume hay for the roughage allowance. If this hay is fed alone the concentrate allowance should be high in protein.

Sorghum.-Fodder from sorghum may be used as dry forage for horses but does not keep for a great length of time. It is especially high in carbohydrates and is palatable and suitable for use in connection with feeds which are high in protein.

Pumpkin.-As a succulent feed for horses, pumpkins have a fair value, their feeding value being about two-fifths that of silage and their main use improving digestion. The seeds have a laxative effect. It is not advisable to feed pumpkins which have been frosted. They are not usually fed in great amount and shonld be limited to about 8 pounds daily. No other laxative feed should be included in the same ration, there should be a slight decrease in the amount of roughage, and provision should be made for feeds relatively high in nutrients to balance the ration.

Silage.-Silage should not be considered as one of the principal roughages for horses. Its use is as a succulent, an appetizer, and a tonic to be fed in limited quantities as a supplement to the regular ration, preferably for idle horses. When used, this feed must be introduced gradually into the ration. It is a very dangerous practice to feed moldy or frozen silage to horses. Corn silage is the only kind that has met with any degree of favor as a horse feed. It has a valuable place in the winter ration if fed with care. The amount should not exceed 10 pounds daily per animal.

\section{WATER}

There is a diversity of opinion among horsemen on the question of watering horses. Some feeders maintain that horses should always be watered before feeding in order to prevent a flushing of the grain through the stomach into the small intestine. This system is not always practicable, however, as some animals will refuse to drink before eating. The consensus of opinion on watering horses indicates that water may be given either before, during, or after meals without 
injurious effects. Thus, individual convenience and attendant circumstances will largely determine the watering practice to be followed. In any practice, however, it is well to adhere to the same plan, once a definite watering time has been adopted, for to change frequently from one system to another will affect the animal's appetite. Regnlarity in watering methods as well as feeding methods should be adhered to.

The following factors should be considered in watering horses:

Horses that have been deprived of water for a long period or those that have undergone severe exertion should generally be watered before eating. It is dangerous, however, to allow an animal to drink heavily while very warm. If the horse is hot, give a moderate drink at this time, and water more freely when the animal is cool.

It is not a good practice to water heavily just before putting hor'ses to heavy work.

Weather conditions, the nature of the work done, and the kind of feed consumed will determine the quantity of water required. In hot weather and when at hard work, horses consume more water than in cold weather or when inactive. Horses will drink more water when fed a protein-rich ration, such as alfalfa hay, than when on a carbonaceous diet.

The average water consumption per individual horse is from 10 to 12 gallons daily.

One of the times when a horse requires and appreciates a drink most is when it has finished its nightly allowance of roughage. Every horse should be allowed to drink at this time if possible.

Horses at hard work in hot weather should be watered hourly. It is better to water frequently, in small quantities, than to allow the animal to gorge itself at any one time.

Watering at public troughs is to be avoided, as this is a common method of spreading disease.

\section{SUCCULENT FEEDS}

Pasture.-Pasture is foremost among the succulent feeds for horses. It acts as a laxative and general tonic to the system, is an appetizer, and a valuable feed. Succulent feeds are watery and do not produce solid flesh. While pasture alone is sufficient to maintain idle horses, it is well to consider the relative feed value of the pasture crop and the general condition of the pasture. Usually it is advisable to feed a light grain ration relatively high in protein in connection with pasture, even when the horses are idle. Pasture is very valuable in the management of work teams; regularly allowing horses the freedom of pasture during the night and on idle days enhances the health of the animals. There will be an increased tendency toward sweating while at work but this is not of great importance when the benefits are considered. For work horses that are given pasture, other laxative feeds should be taken out of the ration. Timothy hay may be used as the roughage, and the concentrate allowances should include grains that are not laxative in character, thus making a properly balanced ration. A necessary precaution is to avoid a sudden change to green feed; where a pasture crop is included in the ration for work horses, the pasturing should be continuous, not intermittent.

Soiling crops.-Most of the forage crops previously mentioned 
under "Roughages" may be cut green and fed to horses. This practice is probably most common with corn. Care should be taken, however, to prevent sudden changes to this type of green feed. 'There is to nutrients should be the same for soiling crops as for pasture. The pasture system provides exercise and on this account is far preferable to soiling.

Roots.-Carrots, parsnips, rutabagas, and beets are succulent feeds used principally as an aid to digestion. Their use in the horse ration is not considered economical, as they are low in nutrients, being equivalent to only about one-fourth their weight in hay. Where roots are fed other laxative feeds should be omitted, the roughage supply should be decreased, and the grain ration should contain feeds high in nutrients. Chopping the roots is usually advisable.

Potatoes.-Potatoes are relatively high in food value, palatable, and well suited for use as a horse feed where the cost is not prohibitive. It is safe to feed as much as 15 pounds a day to work horses. They are equivalent to about one-third their weight in hay. When potatoes are fed, a legume hay is a desirable supplement. If a carbonaceous hay is fed, the grain ration should contain feeds rich in protein. Potato sprouts are injurious to horses and should be removed. It is advisable to chop potatoes before feeding, as the danger from choking is thereby lessened.

Fruits. - When without stones, fruits may be used for feed and are much relished by horses. This addition to the ration is as an appetizer and relish rather than as a nutritions feed. Fruits are low in protein, and if they are used in considerable amount the main ration should be nitrogenous in character. Ten pounds of fruits daily is not harmful.

\section{SALT}

Horses should be given salt at frequent, regular intervals, or, better, salt should be accessible in the feed boxes, pastures, and paddocks at all times. When salt is given regularly, only enongh to meet the body requirements will be consumed. With irregular use, however, an abnormal appetite for salt develops, which, in turn, is often followed by excessive consumption and digestive troubles. An average of about $1 \frac{1}{2}$ ounces daily should be allowed most horses under normal conditions. Horses doing heavy work, particularly during hot weather, and those on dry feed will consume more than this quantity.

Aside from its value as a feeding requisite, salt is of benefit as an appetizer, for in many instances delicate eaters and shy drinkers will show an increased appetite when allowed free and regular access to it. Moreover, the consumption of adequate quantities of salt by work horses will do much in preventing excessive fatigue.

\section{SUGGESTED DAILY RATIONS}

The following daily rations have been prepared with a view of suggesting combinations of feeds that will suit conditions in various parts of the country, and from which the feeder may derive rations 
that will meet his local needs. Attention is invited to the fact that the rations suggested are for a horse weighing 1,000 pounds, and modification of these rations should be made for heavier or lighter horses. For example, in order to meet the requirements for a horse weighing 1,250 pounds the rations suggested should be increased in accordance with the increase in weight, which in this case is 25 per cent. Roughly this would give the feed requirement for the heavier horse.

\section{RATIONS FOR 1,000-POUND IDLE HORSE}

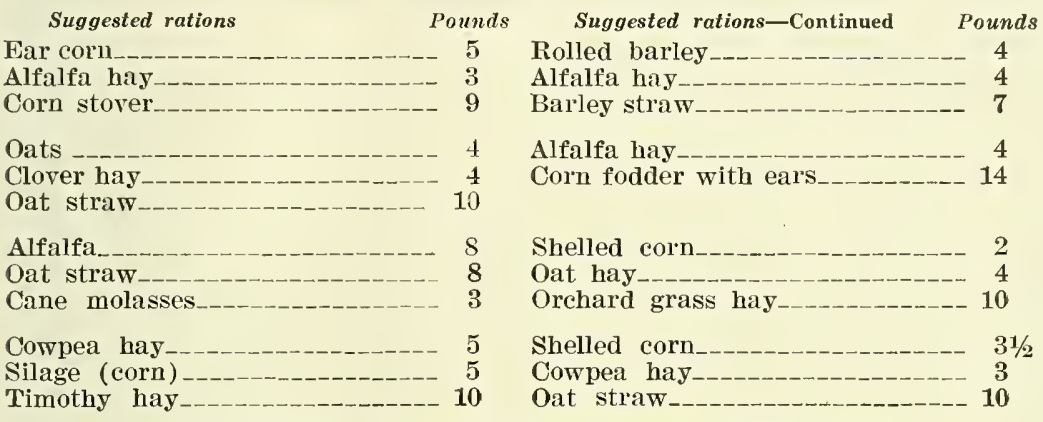

\section{RATIONS FOR 1,000-POUND HORSE AT LIGHT WORK}

$\quad$ Suggested rations
Ear corn
Alfalfa hay
Timothy hay

Oats

Alfalfa hay

'Timothy hay

Cowpeas (coarsely ground)

Molasses

Oat. straw

Rolled barley

Alfalfa

Prairie hay

Pounds 10

5

5

1 The meal may be replaced by 1 pound of cowpeas.

\section{Suggested rations-Continued}

Shelled corn

Cowpeas

Cottonseed meal ${ }^{1}$

Corn stover

Sorghum fodder.___________ $\mathbf{5}$

Shelled corn

Cottonseed meal

Cowpea hay

Corn stover

Shelled corn

Cowpea hay

\section{RATIONS FOR 1,000-POUND HORSE AT MEDIUM WORK}

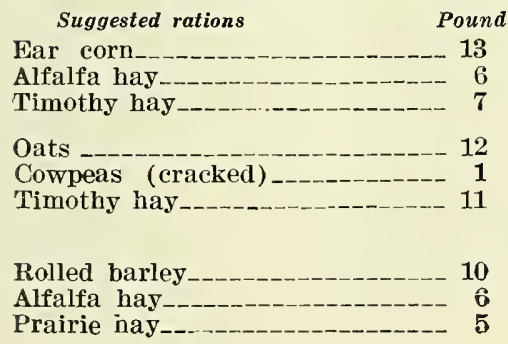




\section{RATIONS FOR 1,000-POUND HORSE AT SEVERE WORK}

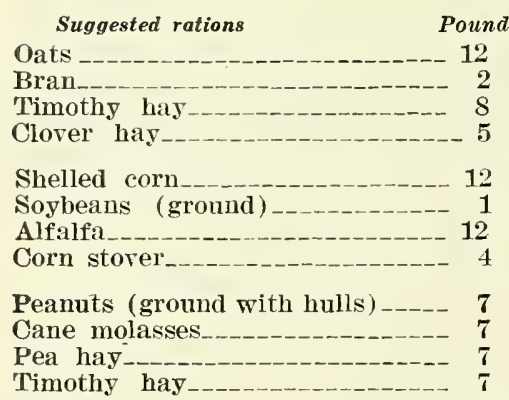

\section{Suggested rations-Continued}

Gluten meal _________ 2

Alfalfa_____________._. 8

Prairie hay

Cowpea hay___- 5

Corn stover

Shelled corn _.________ 13

Cottonseed meal 7

Pea hay _._.____________._. 7

Timothy hay____________ 


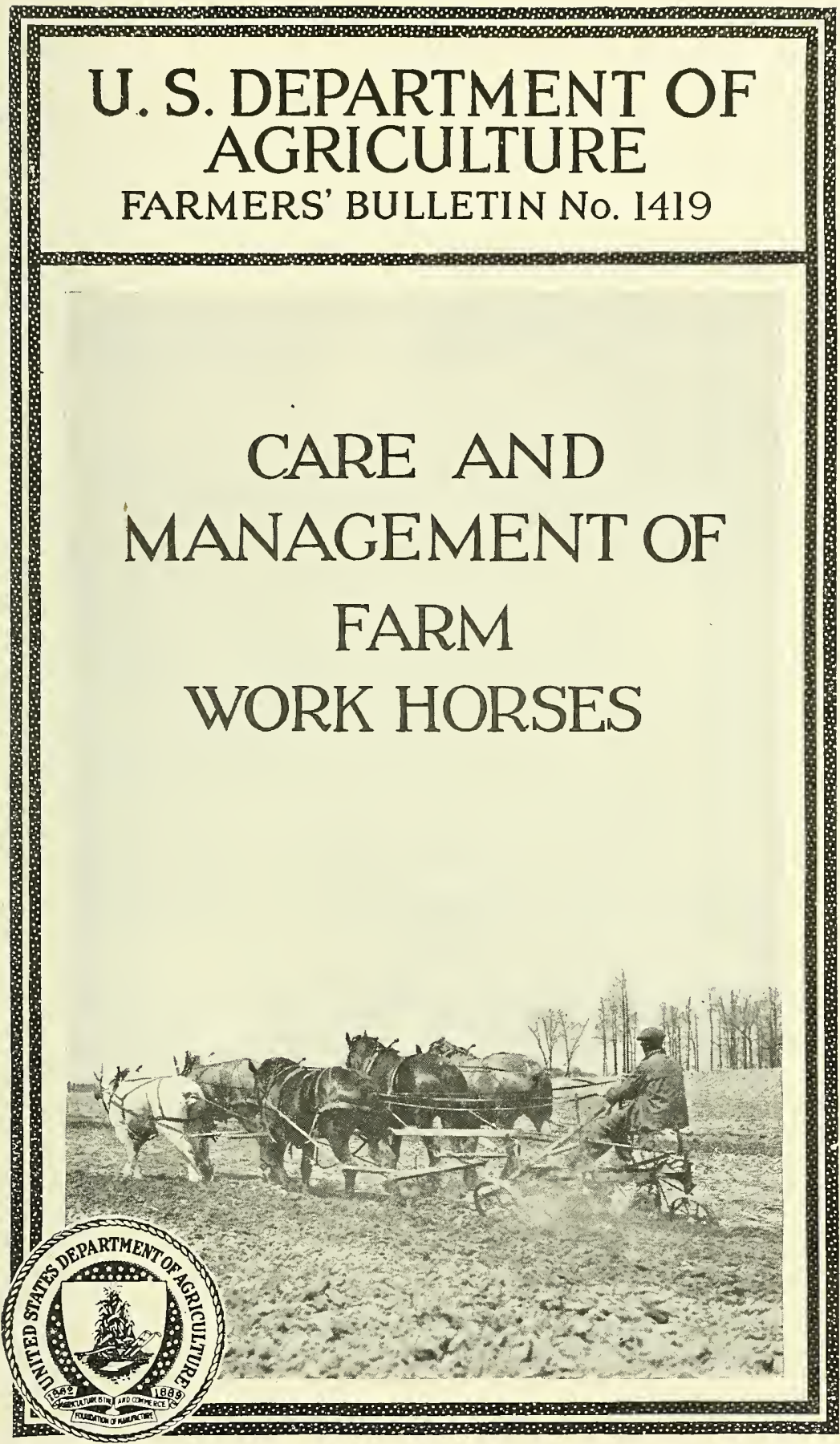


and cleaned regularly to insure satisfaction and durability; and (6) the shoulders, feet, and teeth must be well cared for.

\section{THE HORSEMAN.}

A fundamental factor in all problems of animal husbandry is the man. In no phase of animal husbandry is this "man " elenent more vital than in the care of horses. The horse responds readily' to the understanding and intelligence of his caretaker, and the diligence of the master often forestalls some of the things which might incapacitate the horse when his services are most needed. The rirtues in an ideal caretaker include: Fondness for horses; a kind,

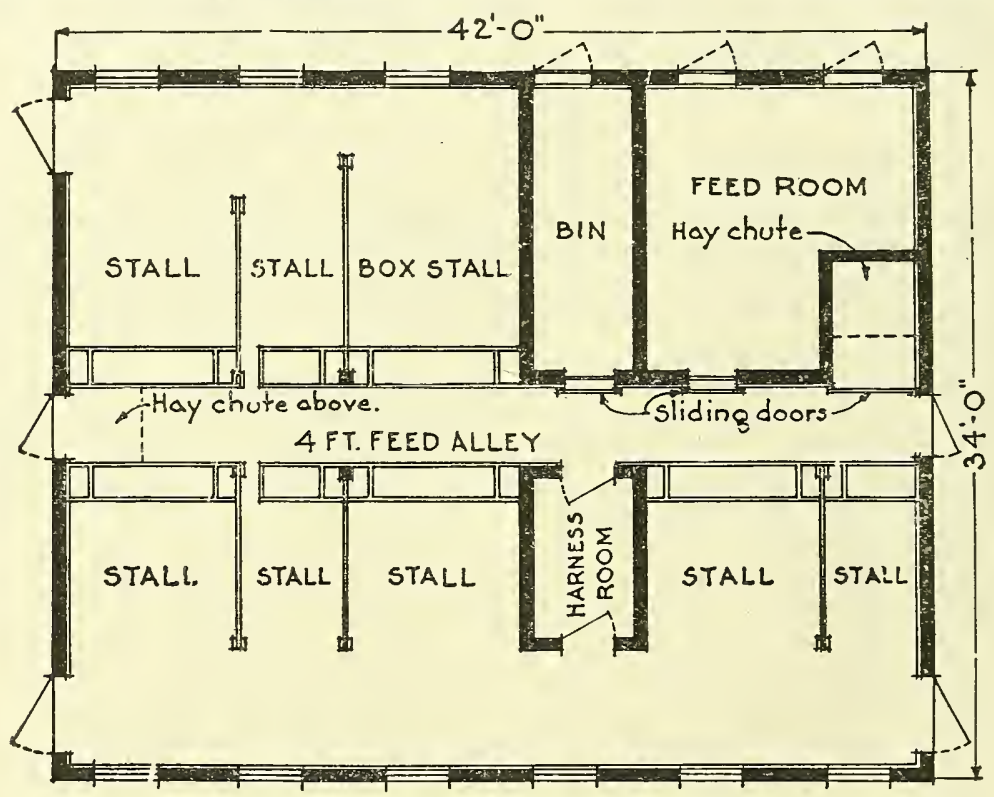

FIG. 1.-Convenient and compact stable for work horses.

quiet, even-tempered disposition; regularity of habits; and close observation.

When a man has the ability to keep horses in good condition so that they are ready when needer, he is a good hor'seman. Horsemen are spoken of as men having a "knack" for" handling horses, understanding thoroughly every horse under their care, knowing how much feed is required, how much work can be accomplished in a day, and having the ability to detect warning signs of overtrork, overheating, and disorders of all kinds.

\section{STABLE, SHED, AND PADDOCK.}

Much time is saved in the care of work horses if the stable is conveniently arranged so that the chores may be done quickly, and the feed, hainess, and equipment are readily accessible. (See fig. 1.) A 
conveniently located hamess room shonld be provided. By this arrangement many steps are saved and the life of the harness is prolonged. Common labor-saving appliances, such as carriers for mamure, feed, and harness, are especially important in large stables. Although the box stall provides the greatest comfort, the open stall has been found generally satisfactory for work horses and requires less space. A good-sized single stall for a horse weighing about 1.400 pounds is 5 by 10 feet, whereas a box stall should be abont 12 feet square.

Abundance of light and proper ventilation of the stables are essential for complete sanitation and the health of the horse. Where windows are relied upon for both light and ventilation they should be high up from the floor, and open inwardly from the top. Ventilation ${ }^{1}$

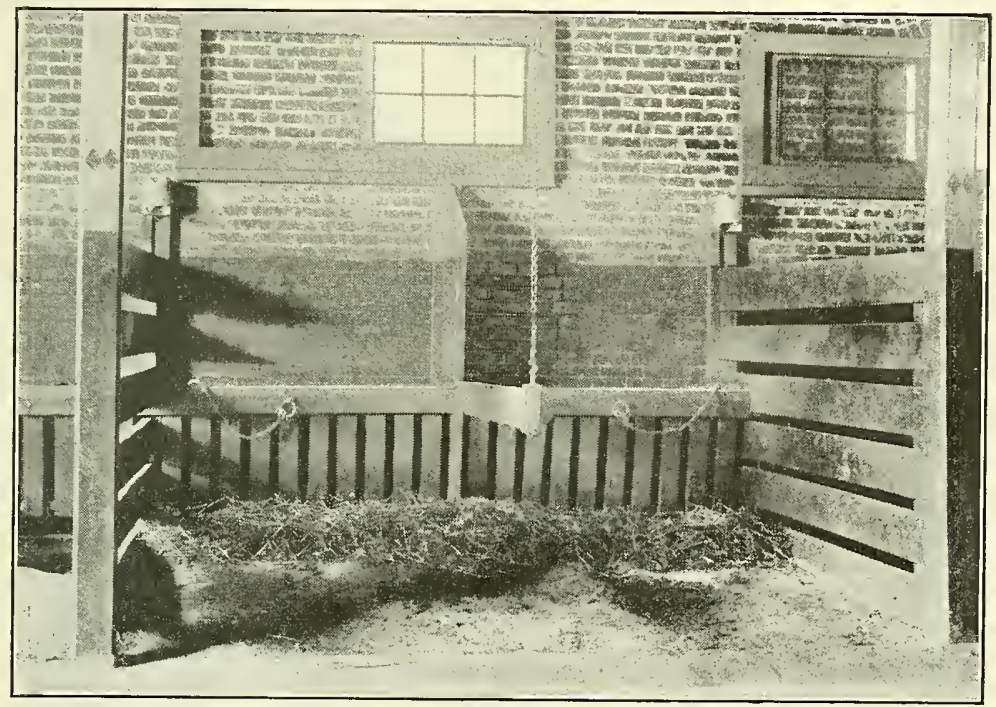

Fig. 2.-Double stall for work horses. Note the open partition, which permits free circulation of air, the slope of the clay floor, and the swinging pole. The bedding is thrown forward to the middle for sanitation.

is required in winter as well as in summer; therefore a system with floor-ontlet ventilators will tend to carry off foul air and regulate the temperature, especially in colder climates. In any system of ventilation it is important that the horses are not subjected to direct drafts. Stalls must be well bedded, and cleaned daily, in order to keep them dry and sanitary. (See fig. 2.) Wet mucky stalls predispose to the development of thrush and similar foot troubles. Many advantages are claimed by adrocates of the various kinds of floors. Concrete floors with board surfacing in the stalls are preferred by many, as they are easily kept in sanitary condition. Clay, however, is undoubtedly the best material with which to make floors for horses, but such floors are objected to by many farmers because of the difficulty in keeping them level and clean. To be satisfactory, clay floors must be kept smooth, with slightly more slope for drainage than is required by other types of floors. 
A large paddock in connection with the stable helps considerably to keep in fit condition horses that are worked irregularly. A series of sodded lots will be found preferable, as, in addition to the exercise the horse gets, he will be benefited by the grass which acts as a tonic. Paddock exercise, though not as good as regular work, helps to guard against filled hocks, azoturia (so-called Monday morning sickness) and other troubles.

When horses are wintered largely in open fields, a dry shed with the open side away from the prevailing winds will generally afford a satisfactory shelter. Although horses that are " roughed "through

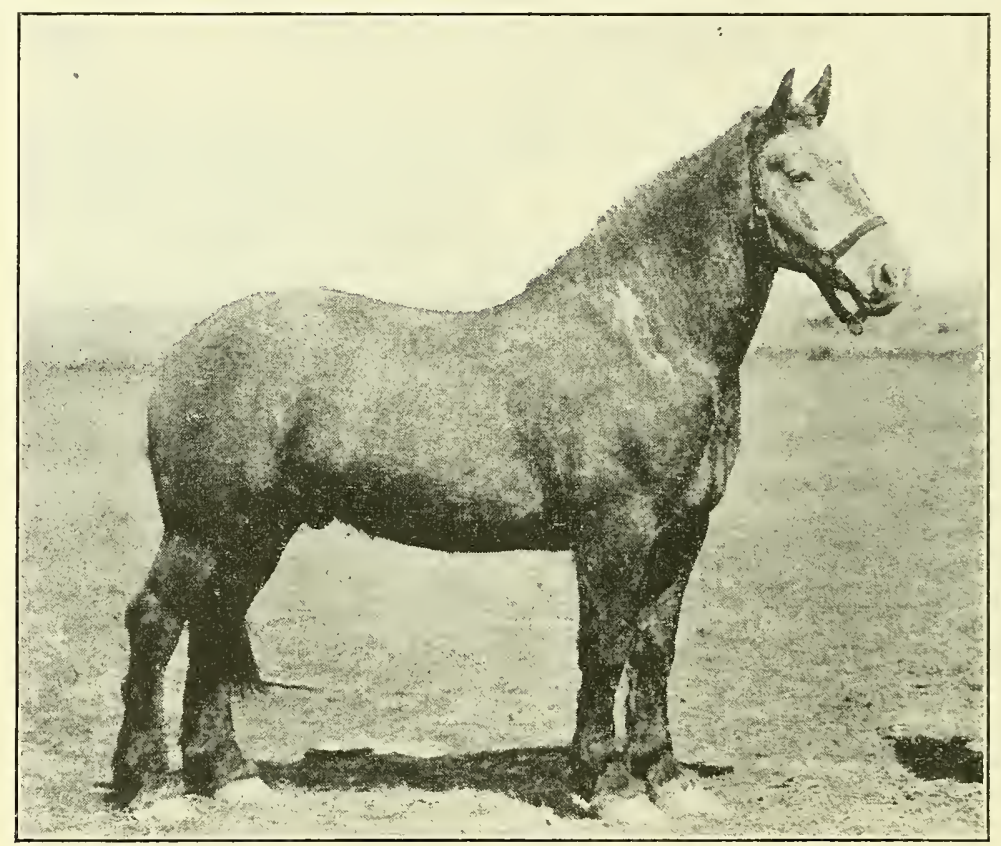

Fic. 3.- This deep-bodied, closely coupled, smoothly built gelding keeps in good tlesh on a small ration.

the winter in this manner develop long, heavy coats of hair which protect them from the cold, it is a mistake to assume that their coats afford sufficient protection from storms. When horses are stabled at night the shed is usually not required.

\section{FEEDING FARM WORK HORSES. ${ }^{2}$}

The most important factor in the care anci management of farm work horses is feeding. Feeding methods vary in different parts of the country and with the different scasons. There is no definite standard for feeding all classes of horses, but there are certain basic rules which serve as a guide in feeding under varying work conditions. Regularity and care are of primary importance. Ir- 
regular feeding, or sudden changes in rations, frequently result in digestive disorders. Any change in the ration should be made gradually, because an immediate change in feeds-for example, from oats to corn, or from old hay to new hay-may result in colic. Care in all feeding operations is necessary for complete utilization of the feed and consequent fitness for work at all times.

Trash or dirt must be removed from the grain box before each meal and chatf and refuse cleaned from the manger before the night feeding of hay. The feeder must also see to it that the feed used is of good grade. Musty, spoiled, or dirty feed may canse the horse to get "off feed" and not be fit for work.

Individuality has a special bearing on the feeding and management of work stock. (See figs. 3 and 4.) Some horses keep in good

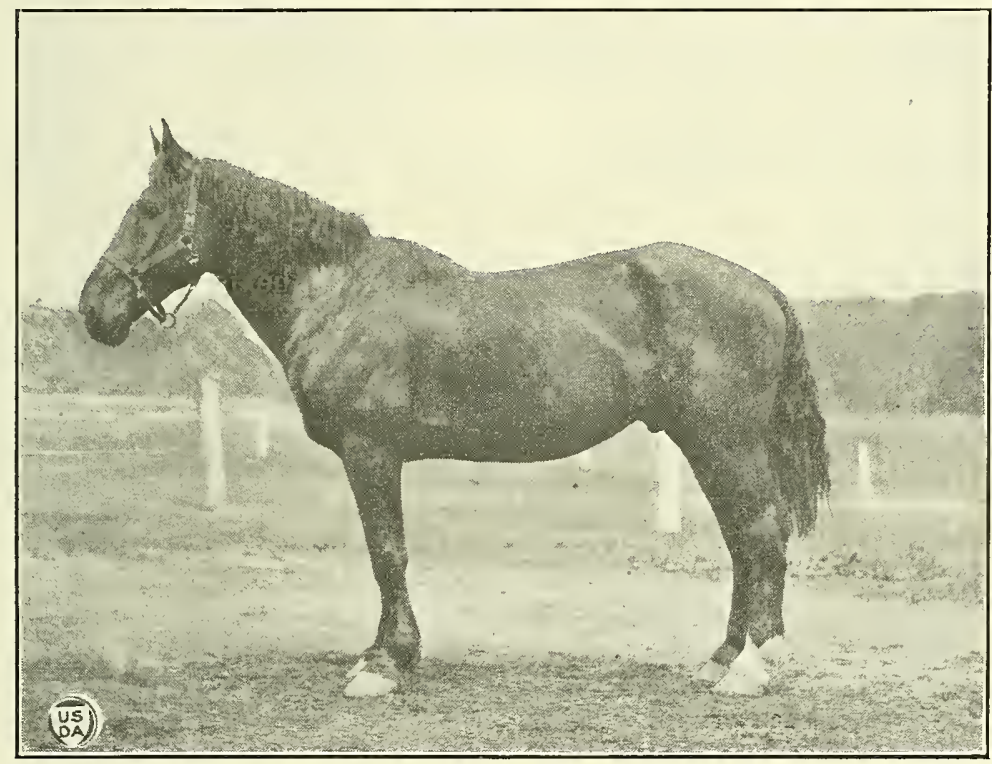

FIt. 4.-This shallow-bodied, loosely coupled horse requires proportionally more grain daily than the gelding shown in Figure 3.

condition on a minimum ration, while others require much more than the average quantity of grain and hay. The same feeds are not relished by all horses, and all feeds do not have the same effect on all horses. It is necessary, therefore, to observe each horse closely and to substitute special feeds when necessary if the best results are to be obtained.

\section{FEEDING UNDER WORK CONDITIONS.}

During the work season a holse should eat only at regular intervals. Concentrated feed is necessary to supply the energy for hard work. The use of large amounts of roughages during the work season should be limited to periods of rest. Excessive feeding of hay is a wasteful practice in many ways; it is expensive, reduces the 
dfficiency of the horse, and if dusty often causes respiratory disorders. It is especially important that the grains and hay be of the highest quality at this time in order to obtain the greatest returm in work.

The selection of nutritious, high-grade feeds is as essential as the methods of feeding and management. Inasmuch as home-grown or locally grown crops generally constitute the most economical basis for the ration, the feed will vary with such crops. The most common feeds for horses are oats, corn, barley, and bran, together with timothy, prairie, clover, and alfalfa hays. In the West, the grain hays are popular, while in the South, Johnson grass is widely used. Of the concentrates, oats most nearly supply the requirements for work horses and, on account of the uniformly good results obtained from their use, have always been recognized as the leading grain for them. The other grains, also, are widely used, particularly corn. It is often possible, however, to make substitutions in the ration, resulting in a noticeable saving, without affecting its nutritive value. The nutritive value may also be increased without increasing its cost. Bran, particularly when corn or barley is fed with timothy and the coarser roughages, improves the ration. Bran is high in protein and mildly laxative in character. The limited use of alfalfa, clover, or other legumes with timothy or similar hay increases the nutritive value of the ration.

The amount of grain and hay required by the farm work horse depends, among other things, on the kind, regularity, and speed of the work performed. Although the exact amount is variable, a general guide is to allow $1 \frac{1}{10}$ pounds of grain and $1 \frac{1}{4}$ pounds of hay per 100 pounds live weight for horses at moderately heary work; and $1 \frac{1}{4}$ to $1 \frac{1}{3}$ pounds of grain, with not to exceed $1 \frac{1}{4}$ pounds of hay, at heavy work. The following table may be used as a guide in feeding:

TABLe 1.-Average weight and measure of some common feeds.

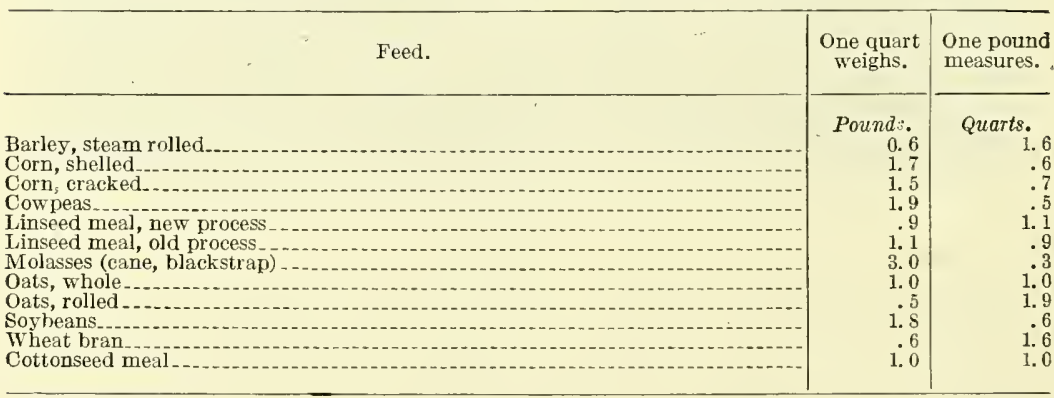

The grain part of the ration for horses at work is usually divided into three equal feeds. If the horse does not clean up his grain in a reasonable length of time, the quantity should be reduced. About two-thirds of the daily hay allowance is given at night, with most of the remaining hay fed in the morning, leaving only a very small allowance for the noon feed. The quantity of roughage should be limited within the maximum allowance, so that all the edible forage will be cleaned up every day. Then there is edible forage remaining from the night feeding, do not put in a fresh supply, but stir 
up that which is in the manger, so that the chaff goes to the bottom, leaving the good liay available. Some hay should be fed before the grain at night, for the appetite of the horse is not appeased by the grain when it is fed first, and he fills up on hay, forcing the grain on through the stomach too quickly, thereby decreasing the quantity assimilated.

The following daily rations (Table 2) are suggested as practical combinations and quantities of feed. As the rations suggested are for the average (1,000-pound) work horse, increase the ration by one-fifth, if the horse weighs 1,200 pounds, and by two-fifths if the horse weighs 1.400 pounds. For example, in the case of the first ration, a 1,400-pound hor'se should receive 15.4 pounds of oats, and 8.4 pounds each of timothy and alfalfa or clover. These rations are based on the theoretical requirement of horses at rather light work, such as cultivating corn. If the horses are at heary work, such as

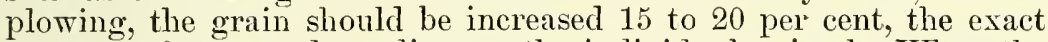
amount, of course, depending on the individual animal. When the 1,000-pound horse is on light work, he generally requires not more than 10 pounds of grain daily, and will probably keep in good condition on less.

\section{TABLE 2.-Daity rations for 1,000-pound horse at medium wort:}

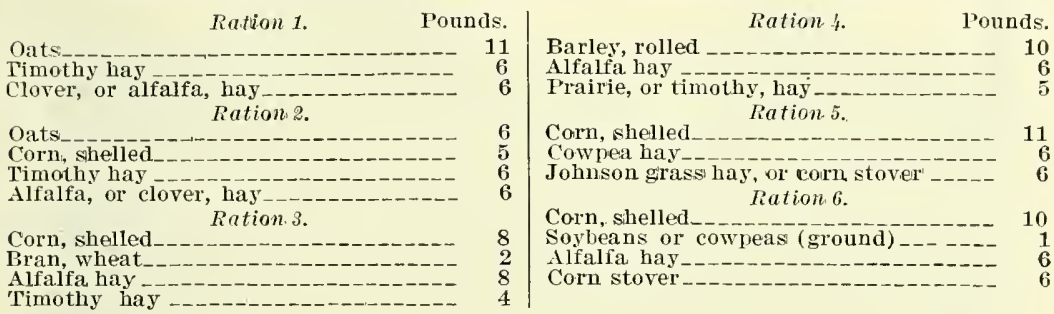

The method of feeding has a great deal to do with the utilization of the feed and the condition of the horse. Attention to the methods often results in increased utilization of the feed by the horse, and saving of feed. It is important that the horse that bolts his grain be made to eat slowly, which may be done by feeding the grain spread out in a large, flat box, by placing several smooth stones about 3 inches in diameter in the feed box, or by mixing it with bran, cut hay, or similar feed. Some horses waste their hay by pulling it out and trampling it underfoot. This is sometimes caused by feeding two linds of hay, one of which is especially palatable. In that case, the waste may be corrected by feeding the hay so that the horse can eat the more palatable first. The horse will then eat the other hay leisurely during the night. Another plan is to withhold the good hay until the other is eaten.

Overfeeding, rather than underfeeding, is the common practice when horses are working irregularly. It should be remembered that the amount of feed should vary not only between winter and summer, but also from day to day. It is a waste of feed if the amount is not varied with the degree of work. When horses are to be idle on the following day, as on Sunday, it is well to substitute a bran mash for the Saturday-night grain feed, and reduce the grain feed for Sunday 
to approximately half of the normal ration. A mash is made by mixing 3 or 4 pounds of dry bran (per horse) with hot water, and allowing it to steam in a covered receptacle until cool enough to eat. Do not cook or scald the bran by using water that is too hot. The palatability of the mash is increased by the addition of a tablespoon of salt per horse.

Pasture saves feed and labor and the grass acts as a laxative and a general tonic. While good pasture is sufficient for maintaining idle horses, a light supplementary grain ration, nonlaxative and relatively high in protein, is generally advisable for work horses. When horses that are accustomed to a heavy grain ration are turned on pasture for a long idle period, they shonld be given a small amount of grain for a few days; otherwise they may gorge themselves on the green roughage and suffer impaction, rupture of the stomach, or other serious tronble. When horses are laid off from field work for periods of only a few days at a time, the reduction in grain will depend some-

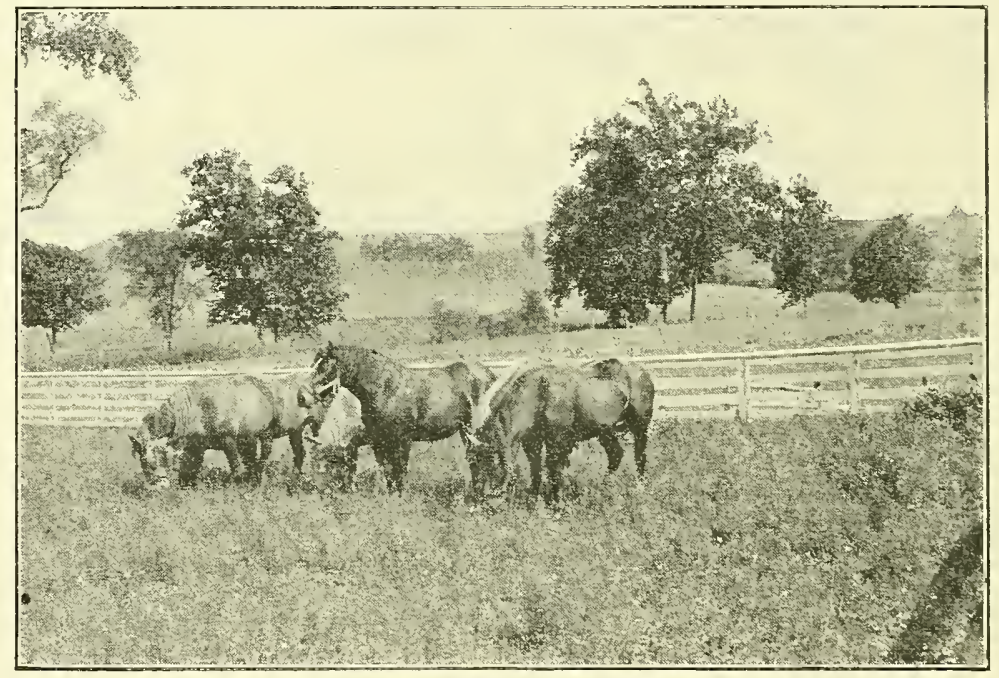

Fig. 5.-Grass acts as a general tonic to the system. Night pasture also provides a place to roll, water at will, and a clean, cool place to rest.

what on the feed value of the pasture, but generally the grain ration at this time should be about half the normal requirement. Irregularity, with sudden changes to green feed, is likely to result in digestive disorders. Turning the horses regularly on pasture at night is a means of keeping the digestive system accustomed to succulent feed. This practice decreases the quantity of hay needed by the horses, but they should receive a small feed of hay with the regular evening grain ration before being turned out. Horses that are turned on night pasture sweat more at work than horses on dry feed, but this is overbalanced by the benefits derived during hot weather, when the pasture provides a place to roll, water at will, and a clean, cool place to rest. 
WATER.

There is quite a diversity of opinion among horsemen on the question of watering horses. Some feeders maintain that horses should always be watered before feeding, in order to prevent a flushing of the grain through the stomach into the small intestine. This system is not always practicable, however, as some animals refuse to drink before eating. The consensus of opinion on watering horses indicates that water may be given either before, during, or after meals without injurious effects. Thus, individual convenience and attendant circumstances will largely determine the watering practice to be followed. In any practice, however, it is well to adhere to the same plan, once a definite watering time has been adopted, for to change frequently from one system to another will affect the animal's appetite. Regularity in watering methods as well as in feeding methods should be adhered to.

The following factors should be considered in watering horses:

Horses which have been deprived of water for a long period or those which have undergone severe exertion should generally be watered before eating. It is dangerous, however, to allow an animal to drink heavily while very warm. If the horse is hot, give a moderate drink at this time, and water more freely after the animal has cooled off.

It is not a good practice to water heavily just before putting horses to heavy work.

Weather conditions, the nature of the work done, and the kind of feed consumed will determine the quantity of water required. In hot weather and when at hard work, horses consume more water than in cold weather or when inactive. Horses will drink more water when fed a protein-rich ration, such as alfalfa hay, than when on a carbonaceous diet. Then horses are doing hard work, especially during hot weather, they should be watered every hour.

The average water consumption per individual horse is from 10 to 12 gallons daily.

One of the times when a horse requires and appreciates a drink most is when it has finished its nightly allowance of roughage. Every horse should be allowed to drink at this time if possible.

It is better to water frequently, in small quantities, than to allow the animal to gorge itself at any one time.

Watering at public troughs is to be avoided, as this is a common method of spreading disease.

SALT.

Horses should be given salt at frequent intervals, or, better, salt should be accessible at all times in the stable, pastures, and paddocks. When salt is given regularly, generally only enough to meet the hor'se's requirements will be consumed, while with irregular use an abnormal appetite for salt develops, which in turn is often followed by an excessive consumption and digestive troubles if unlimited access is allowed. 
An average of about $11 / 2$ ounces daily should be allowed generally. Horses doing heavy work, however, particularly during warm weather, or those on dry feed will consume more than this quantity.

Besides being a feeding requisite, salt is of benefit as an appetizer. for in many instances delicate eaters and shy drinkers will show an increased appetite when allowed free and regular access to it. Moreover, the consumption of adequate quantities of salt by work horses will do much in preventing excessive fatigue.

\section{WINTERING IDLE HORSES.}

Maintaining the farm work horse in healthful condition during the winter is the first start in fitting him for spring work. The horse should not be so fed during the winter that he becomes fat and soft. On the other hand, poor care during the winter, resulting in loss of weight and vitality, so weakens the horse that he is not in condition for spring work, and often his resistance is so lowered as to invite disease.

It is bad management to let a horse lose weight during the winter and then try to bring him back to normal by heavy feeding just before the beginning of spring work. If, however, the horse is thin or run down at the beginning of winter, he should be gradually brought into thrifty physical condition. Winter and early spring feeding should so strengthen the horse that he will be ready for the fitting period and heavy spring work.

The liberal use of roughage, supplemented with the right amount and kind of other nutritious feed, will maintain a horse properly during the winter. Farm horses, except brood mares or growing stock, do well on a ration made up largely of the coarser hays, straw, or corn fodder. Cornstalk fields, grain-stubble fields, or pastures which have not been closely grazed during the summer are very desirable sources of a large part of the winter maintenance feed for horses. The common roughages, as the main part of the ration during this period, will supply enough bulky feed to keep the horse thrifty without putting on superfluous fat. The drinking of a large amount of pure water should be encouraged to increase the utilization of these dry roughages. When necessary, a tank heater should be used to keep the drinking trough free from ice.

It is advisable to supplement the coarser roughages with a legume, such as alfalfa, clover, vetch, soybean, or cowpea hay. These hays are very palatable and should be fed sparingly. They are rich in protein and mineral matter and supply the materials needed to replace those lost in the natural wear of the body. Being somewhat laxative in effect they also help to keep the digestive tract in good condition. They are especially valuable in connection with straw and similar feed. The use of these hays with the coarser ronghages is economical because a supplemental ration of grain is not necessary. 
Corn silage, if fed with care, may be utilized in limited amounts in the winter ration of idle work horses. It is generally considered that the amount of corn silage should not exceed 15 pounds daily. Corn silage is bulky, appetizing, sncculent, and slightly laxative. None but choice, fresh silage should be given to horses. Severe losses from botulism (forage poisoning) have resulted when these precautions have not been observed. Frozen or moldy silage must not be used under any circumstances.

In some instances, especially when it is not possible to feed a legume hay, a small quantity of grain is necessary to maintain the horses in thrifty condition. Oats are preferred for use with the coarser roughages, but corn and barley are often used in the winter ration, especially when they are cheaper or when an increase in weight is desired. One or two bran mashes a week or a little linseed meal each day is recommended as an aid in keeping the system in good condition and in preventing impaction resulting from the use of large amounts of coarse roughage improperly supplemented.

Pregnant mares require more attention during the winter than the open mare or gelding. As a kick often causes the loss of a colt, the pregnant mare should not be turned out with other horses, especially if she fights with them. Leguminous feeds high in protein and mineral matter are necessary in developing the fetus. Although the feeding of the legume hay is of more importance than a supplemental grain feed, in most cases such feeds as oats, bran, and oil meal should be supplied, the proportions being largely controlled by the condition of the mare and the stage of development of the fetus.

\section{PREPARING FOR SPRING WORK.}

Preceding the spring season, the horse usually must be conditioned for the work that is ahead of him. The fitting necessary to condition horses for spring work depends largely on the way they have been wintered. The condition of the horse that has been properly cared for in the open during the winter is more nearly the ideal than that of the horse that has been kept in the stable. While the fitting period varies with the condition of the animal and other factors, the average time usually allotted for it is two to four weeks. A horse that is either very thin or very fat requires a longer fitting period than one in thrifty condition with fair flesh. A young horse also requires a longer time for fitting and training than a mature horse, especially if he has just been broken.

During this fitting period, the digestive system of the horse becomes adjusted to the change in kind and quantity of feed necessary to supply energy for the production of maximum work. This end is usually accomplished by gradually increasing the ration with the work done. Preparation of horses should begin several weeks before they are actually put to heavy work. While the use of coarse, nonsalable feeds is an economic practice during the winter, the horse should gradually be put on a smaller ration of finer-quality hay early in the spring, and started on a light feed of grain three times daily. When 
light work has commenced, a 1,400-pound horse should be getting about 14 pounds of grain together with 14 or 15 pounds of fine-quality hay, daily. This gradual change from coarse roughages to good-quality feed will have prepared the digestive tract for the use of from 18 to 19 pounds of grain, with from 16 to 18 pounds of hay, which will be needed by the horse at heavy work, such as disking or plowing.

It should be remembered that changes in both kind and quantity of feed should always be made gradually.

It is also necessary that the work horse be gradually conditioned, or hardened, for heavy work. By increasing the work gradually, the muscles are hardened, and the horse gradually develops strength for the heaviest work. During this period, special attention must be given to the shoulders, a discussion of which will be found on page 16.

\section{GROOMING AND CLIPPING.}

Grooming improves the general appearance of a horse, and, what is more important, remores the internal waste of the body which has been exnded through the pores of the skin, and the loose scurf.
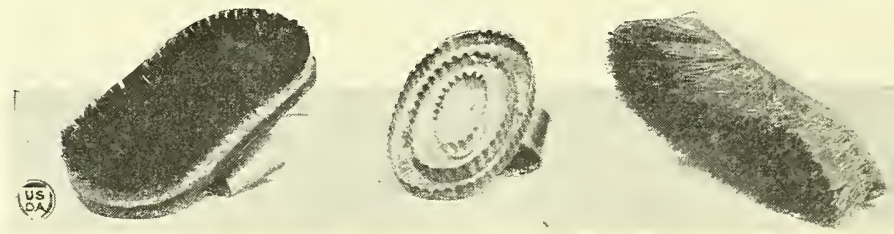

Fif. 6.-Good grooming is essential to the conditioning and health of the animal. Left to right: Bristle or body brush, corrugated comb, and fiber or mud brush.

If this waste matter is not remored by thorough grooming, the pores of the skin will be stopped, normal body activities hindered, and the general health of the animal impaired. This condition is indicated by a harsh skin and dry, rough appearance of the hair. 'The skin of a well-groomed, healthy animal is pliable and soft, and the hair glossy. Because regular grooming so improves the action of the digestive organs and the utilization of feed, it is often said that a good grooming is as valuable as a feed.

The amount of grooming necessary varies considerably. Horses that are pastured, or are outdoors, do not require much grooming, as under these conditions there is less perspiration and the waste products are more generally thrown off through the bowels and? kidneys. Fast or active work, together with heavy feeding, however, causes free perspiration and throwing off of body raste through the skin, making regular grooming necessary.

Care, regularity, and thoroughness are essential in grooming. It is a good plan to groom the horse at night, for he will rest better, and a good brisk brushing is sufficient the next morning before going to the field. Turning the horse out at night, or allowing him to roll, only partially removes the need of the evening grooming, for only the high spots are touched and very little of the body-waste material is removed. 
The common equipment for grooming is the currycomb, dandy brush, and body brush (lig. 6), while the rub rag, mane comb, and footpick are often needed. The currycomb should be used only when the horse is sweaty and dirty. As the skin is very sensitive, i round-corrugated comb is preferred. The dandy or fiber brush should be laid on hearily the first time over the horse. The body brush is then used to remove the loose body-waste substance and scur.f, and for the careful cleaning of the fetlocks and pasterns. The feet

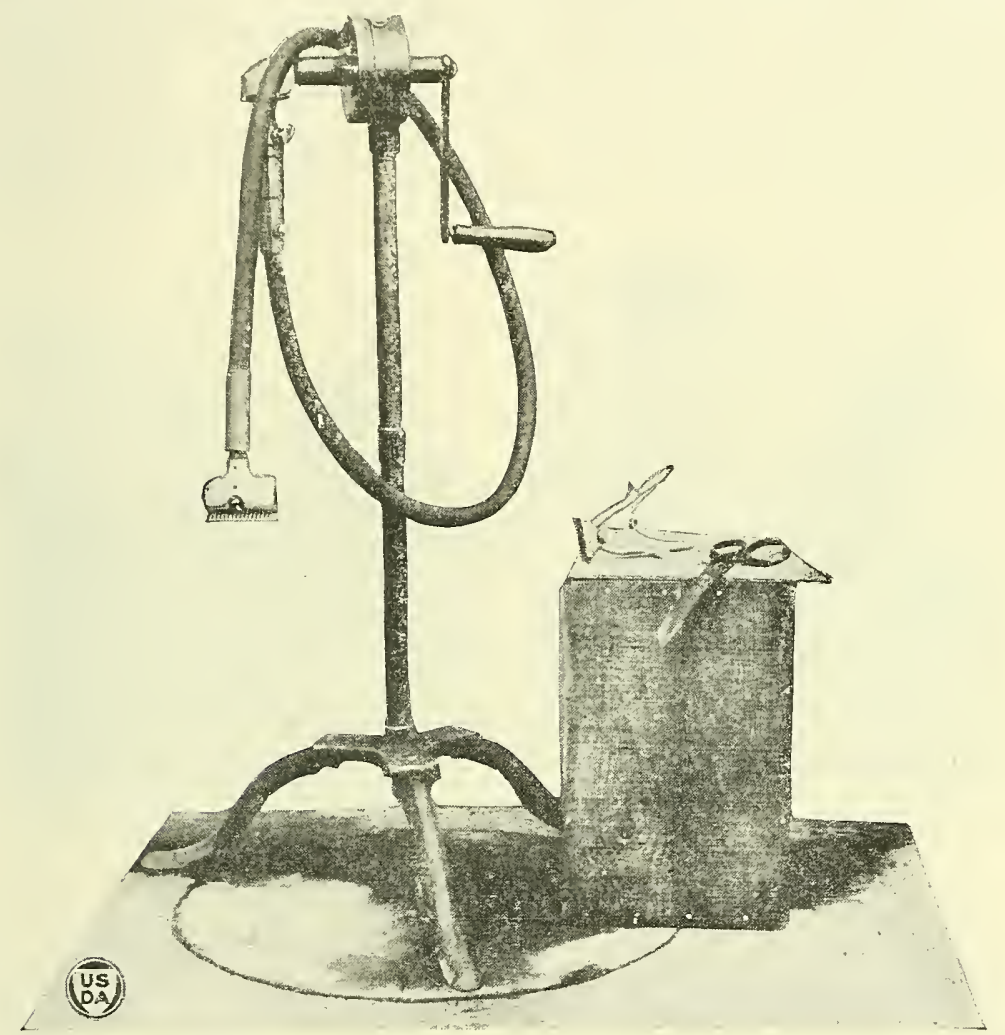

FIG. 7.-Clipping outfit-a hand-power clipping machine, with small hand clipper and sliears on box. Clipping saves the horse discomfort in hot weather.

of farm horses should also be cleaned and the mane and tail brushed and thinned regularly.

Farm work horses are seldom washed. When this is done, however, all parts should be thoronghly washed with tepid water and mild, alkaline soap and afterwards completely dried. Sawdust or bran is good for drying the legs.

Clipping is advisable, as it saves the horse a great deal of discomfort, and makes grooming easier. (See fig. 7.) The removal of the heavy winter coat makes the horse less likely to sweat, and helps to prevent shoulder soreness. The horse must be blanketed, 
however, for a time, if clipped early in the spring. The foretop of a farm work horse is often trimmed, but a sore neck is less likely if the mane is not trimmed at the collar seat. When draft horses are being produced for city use, the foretop should not be removed, as it is needed to satisfy the demands of the city trade.

\section{THE HARNESS, FITTING AND CARE.}

All parts of the harness should fit the horse comfortably yet snugly. It is of special importance for the collar to fit, so that when it is adjusted the pull will be distributed equally over the shoulders. The best plan is to have a good, heavy, leather collar for each horse, and always use his own collar on him. To fit, there should be barely room for the flat hand to pass between the collar and the windpipe, and for the finger tips to pass at the side of the neck just above the

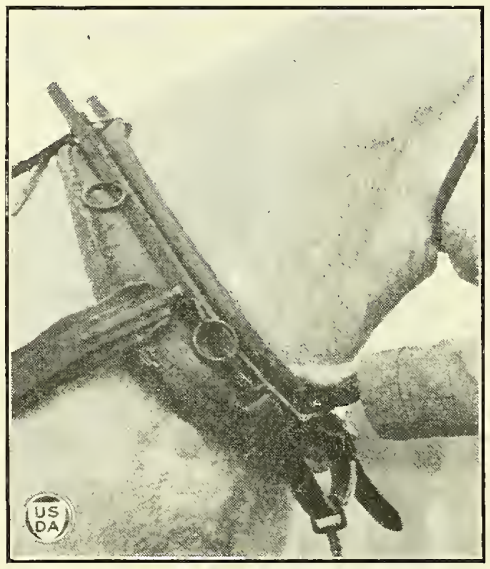

FIG. S. -Just room for the flat hand between collar and windpipe.

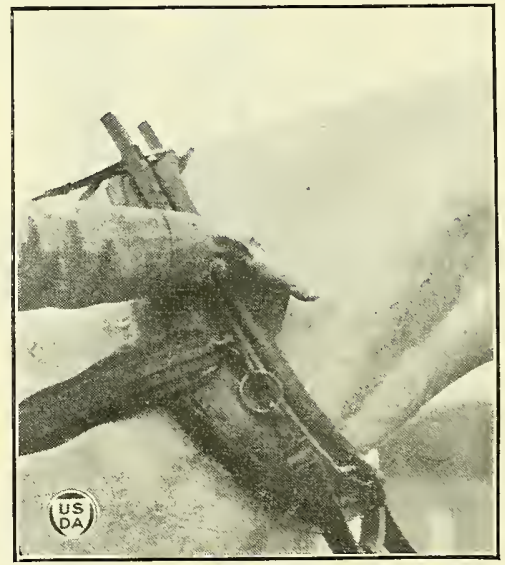
FIG. 9.-rioom for the finger tips at the

The First Step in Eliminatixg Sore Shoulders is a Correctly Fittixg Collar.

shoulder points. (See figs. 8 and 9.) A short collar chokes the horse when pulling, while a collar which is too long bruises the shoulder points and chafes the neck at the withers. A narrow collar will pinch. A wide collar will bring pressure and irritation on the side of the shoulder. The condition of the horse should be taken into account when a new collar is fitted, due allowance being made for excess hair and surplus flesh, if the fitting is done in the spring.

Sweat pads are a poor means of making a collar fit. They are hot, and easily wrinkled, stick to the shoulder, have a surface that is hard to keep clean, get hard when dry, and cause more sore shonlders than do smooth and solid smifaces. Hames that do not fit offset a good-fitting collar and cause sore shoulders, whereas properly fitted hames should assist in bringing about the right setting for the pull. The hames should fit snugly, and be drawn tightly on the collar, so that the point of draft will be about one-third of the distance above the point of the shoulder. 
All other parts of the harness must also be properly adjusted and fitted. In adjusting the bridle, the bit should rest snugly on the bar's of the month, and the checkrein should be used but mildly. The body parts of the harness should lit smugly, but not so as to retard free full motion, while the adjustment of traces and lines is required for an even pull and perfect control.

The life of the harness is prolonged by the care given it. When the harness is not in use, it should be humg up carefully, in a dry harness room. A little care in removing the collar from the horse, keeping it in shape, and hanging it on a peg or rack by itself, will probably prolong its life very materially. Many collars are broken and ruined by careless handling. Cleaning the face of the collar, and other bearing surfaces of the harness, with a damp cloth, at the time the harness is remored from the horse, lieeps these parts smooth and firm, thereby helping to prevent galls and sore shoulders, as

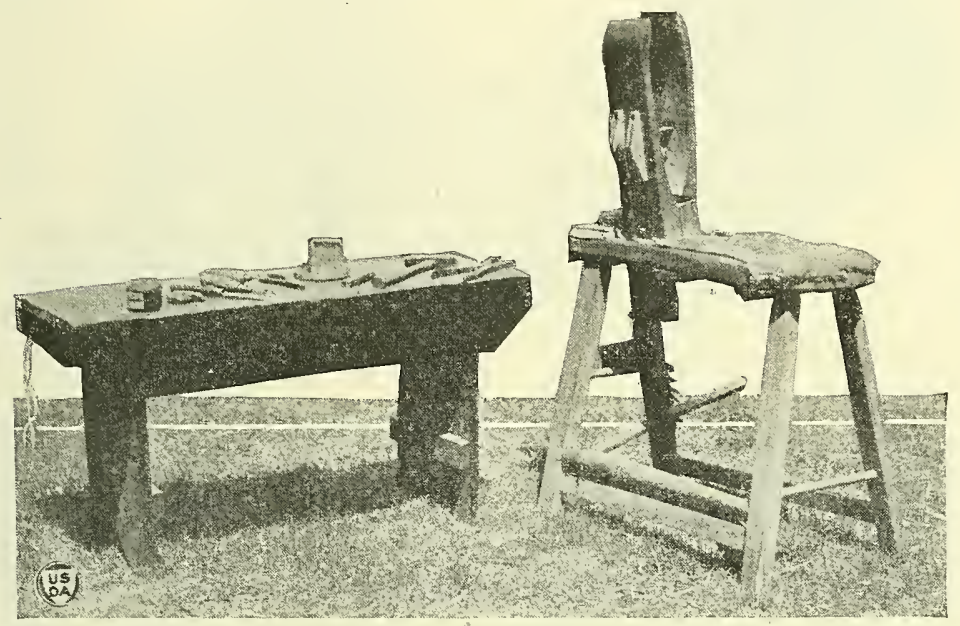

FIG. 10.-Harness-repair kit, consisting of clamp, 4-tube punch, riveting set, pliers, awls, knife, needles, thread, and wax.

well as adding to the life of the leather. While most of the mending must take place at the time of the breakage, it is well to go over all harness carefully during dull seasons, replacing weak parts and restitching ripped places. A harness repair kit (fig. 10) is essential equipment for every farmer. The kit consists of a riveting machine, 4-tube punch, a pair of pliers, awls, an assortment of needles, a ball of good thread with wax, a wood clamp, leather, snaps, buckles, and cleansing and oiling materials. The round knife, edged tools, and creasers make possible the use of side leather and more complete saddlery work.

A thorough overhanling, cleaning, and oiling of the harness once or twice a year in addition to the daily cleaning of bearing surfaces and careful handling, prolong its life. At least once a year the harness should be taken apart so that all parts may be thoroughly cleaned, oiled, and repaired. To clean, soak the liarness about 15 minutes in lukewarm water in which a mild soap has been dissolved. Adding a little soda makes the water a better solvent. 
Each strap should be scrubbed carefully and rinsed well. When nearly dry rub edge blacking on all parts where required, clean the metal parts, and make needed repairs. The leather should then be oiled while still damp, using neat"s-foot oil, castor oil, or one of the prepared harness oils. A very good mixture for heavy harness is neat's-foot oil, mixed with tallow to make a paste of about the consistency of butter, warmed slightly." All oils should be thoronghly rubbed into the harness, and be allowed to dry slowly. being hung neither in the sun nor close to a fire. When the oil has dried, the straps should be rubbed well with a lather made of white castile soap, or a good harness soap. This will remove surplus

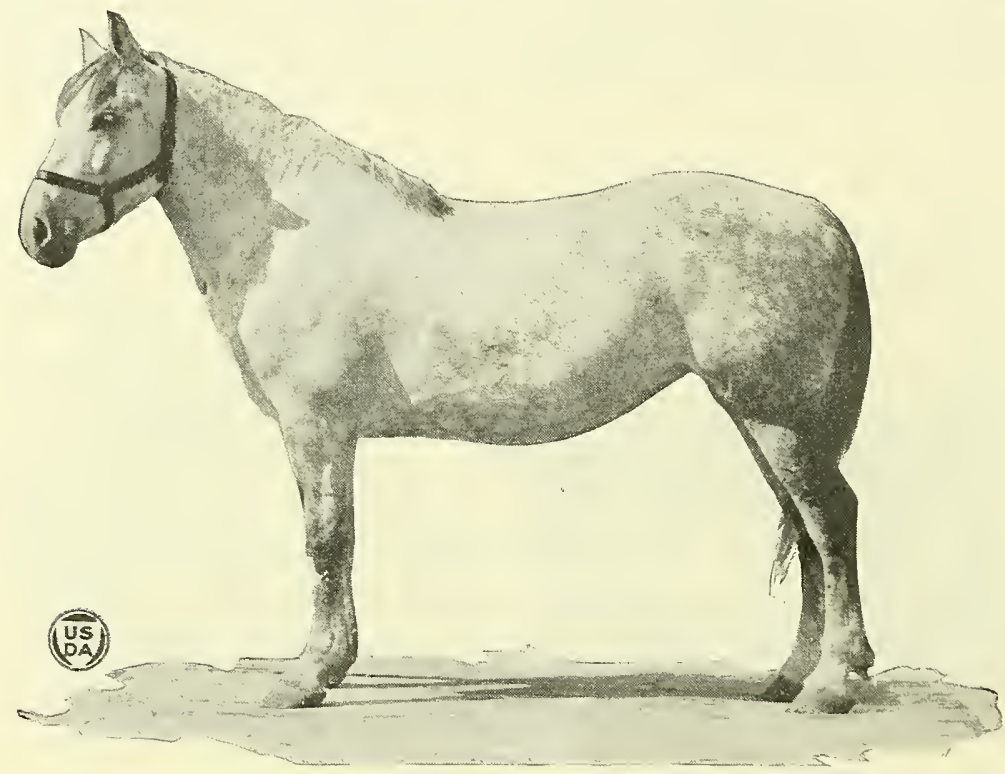

Fig. 11.--Farm mare with properly trimmed feet. Regular care of the feet, so that the horse stands square and plumb, will relieve needless tendon strain and aroid deformity of the feet, unsoundness, and improper action.

grease and take away the greasy appearance: With regular care the leather will be clean and pliable. Frequent sponging will keep the harness like new.

\section{PREVENTING SORE SHOULDERS.}

Correct fitting of the collar, and adjustment of the harness, is a big step in the elimination of sore shoulders. The shoulders of work animals should be given special attention during the spring fitting season until the muscles harden and winter hair sheds off. Clean the shoulders carefully after the day's work is done, and before harnessing next morning. Then the harness is taken off, wash the shoulders with warm water and castile soap, and rinse with cold water to which a small amomt of salt has been added. This treat-

${ }^{3}$ For further information, see Farmer's Bulletin 1523, Leather shoes, Selection and Care. Ont of print, but may be consultei in libraries. 
ment may be discontinued after two or three weeks, but careful daily grooming and cleaning of the collar are always required. A little time given in special attention to the shoulders in the field during the early spring is time well used. Raise the collar frequently and clean the sweat, dirt, and dead hair from both the shoulder and collar. Lift the collar forward on the neck and leave

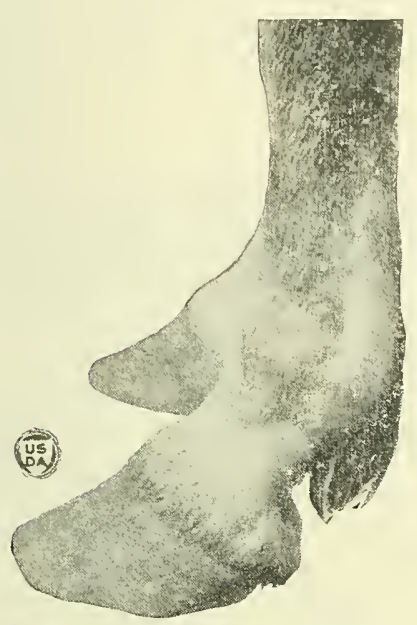

Fig. 12.- Left forefoot of hor'se ir Figure 11, before trimming.

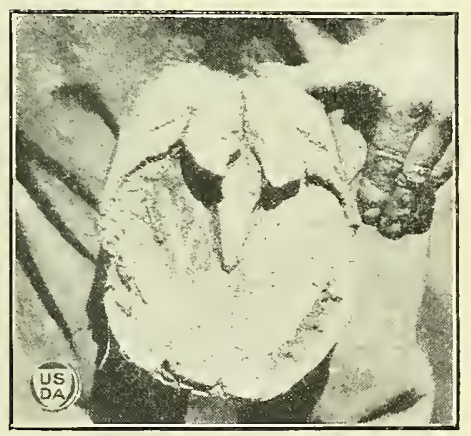

Fig. 14.-Bottom of hoof before trim-

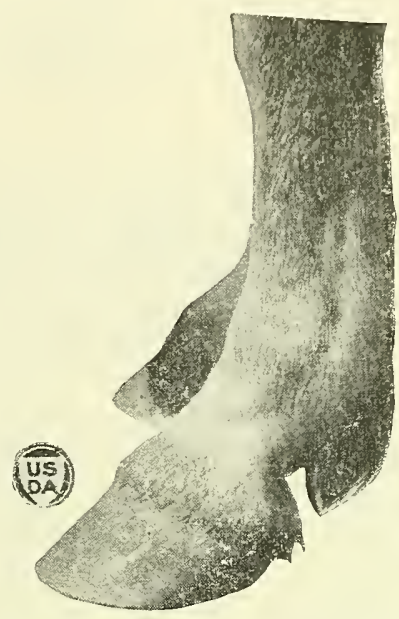

Fig. 13.-Same foot, after trimming. Notice cliange in angle of pastern.

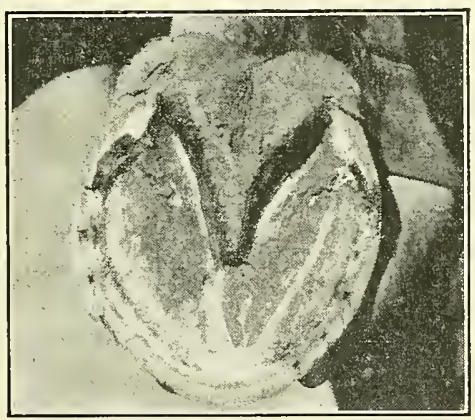

FIG. 15.-Same view, after trimming.

it there for a few minutes, so that the shoulder surface may cool off. It is especially important that the neck and shoulders be cleaned and given a chance to dry and cool off during the noon hour.

\section{CARE OF THE FEET.}

Care of the feet at all times, so the horse stands square and plumb, will relieve needless strain on tendons and prevent deformity of the feet, unsoundness, and improper action. (See figs. 11 to 15.) When the horse is not shod, loose pieces and rough corners of horn should be trimmed off with nippers, and the wall leveled regularly with the rasp. 
Horses used on hard roads, and in some cases those running on hard or frozen fields, should be shod. The shoes should be made to fit, and the reshoeing or resetting of the old shoes should be done regularly to prevent injury to feet and legs. Toe calks and heels should be provided during the winter to prevent slipping.

When the feet are cleaned daily, they usually remain healthy and the wall of the hoof tough, whereas lack of exercise and close stabling under foul conditions cause an unhealthy condition of the feet. 'The hoof occasionally becomes brittle, however, because of lack of moisture. Sometimes the right moisture conditions are obtained by soaking or poulticing the hoof and then dressing it with neat's-foot oil or sweet oil to prevent further drying out. Packing the feet with powdered white rock or blue clay is also a good corrective, and restores a healthy condition. Frequent cleaning of the feet of shod horses tends to prevent inflammation and more serious troubles which commonly result from stones or clods packing in the sole of the foot.

\section{CARE OF THE TEETH.}

At least once during the year a competent veterinarian should examine the teeth of all horses. Generally all that will be required is the "floating" or filing off of the long, sharp corners which are due to nneven wearing. This roughness first canses sore tongues or cheeks, followed by a lack of proper mastication together with digestive troubles. Older horses particularly are often greatly benefited by proper attention to the teeth.

\section{HINTS FOR THE HORSEMAN.}

Make hitches carefully, in order that the pull will be at the center of draft, and that each horse will pull his share of the load. The strongest horse should usually have as mucli of the load as suits his power.

Do not work a slow horse and a fast horse together. There will be friction and loss of power, in addition to irritation to both driver and horses.

Give special consideration to the arrangement of horses that are hitched three or four abreast. If a horse worries when worked between other horses, rearrange the team so that this horse works quietly.

At the beginning of the flay's work, warm up the horses gradually. The digestive tract will be emptied, the muscles and joints limbered up, the collar will be made pliable and set to the shoulder, and the whole machine will be in better condition for the day's work.

Work the horse at his normal gait in the field. He can not work efficiently above his normal gait for any great leugth of time, even though he is pulling a light load.

Sweating during hot weather indicates that the cooling system is working. Puffing may be a serious warning, especially if the horse has ceased to sweat, and overheating may result if the horse is pushed at this time. A brief rest, a swallow of water, or a sponging of the mouth will often restore normal action and avoid serious consequences.

An important phase of horse husbandry is to arert common ailments. Every horseman should know how to take necessary precautions in avoiding various troubles, to care for minor ailments, and start immediate-relief measures until the services of a competent veterinarian can be obtained.

4 For a detailed discussion of the care of a horse's feet, consult Farmer's' Bulletin 1535 , Farm Horseshoeing. 


\section{HORSE - BREEDING \\ SUGGESTIONS \\ for FARMERS}

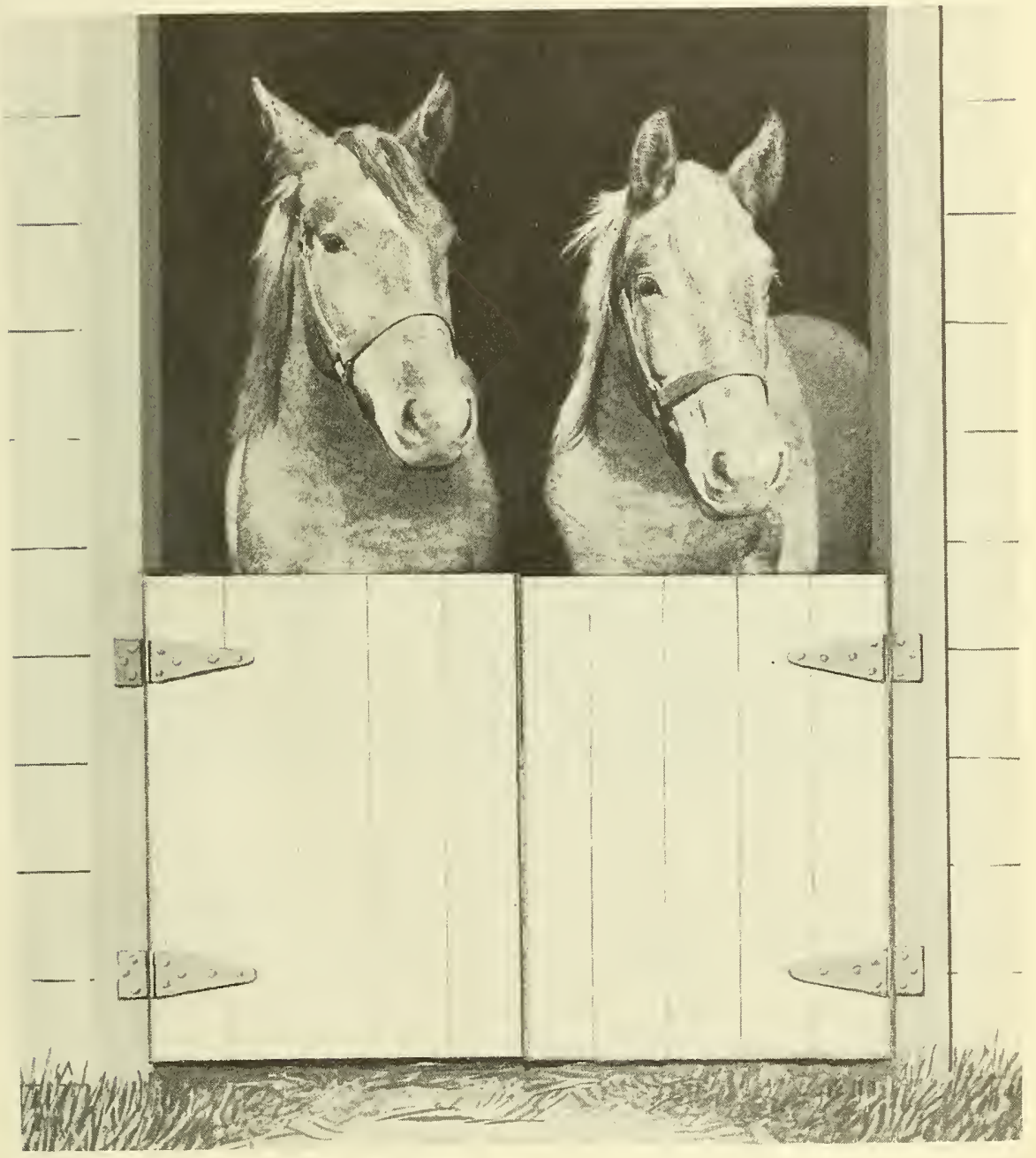

FARMERS' BULLETIN No. 803 U. S. DEPARTMENT OF AGRICULTURE 
TT WO LINES of profit are derived by the use of specially selected mares on farms: Raising colts and doing farm work.

To obtain the maximum returns from this system, the animals used for work on the farm should be brood mares and the young horses which are increasing in value.

Mares chosen for work and breeding must be wellbred, sound individuals of desirable conformation. It does not pay to raise scrub colts.

Mares doing this double duty must receive extra feed, care, and inanagement.

The selection of a stallion is highly important. A low service fee should not tempt one to use an inferior stallion.

It is advantageous to produce a uniform lot of foals. Select breeding animals with this in view.

There may be less interference with the farm work if the mares foal in the fall.

Careful choice in mating creates greater possibilities for the offspring, but these possibilities are realized only when nourishing feed and regular attention are given the young animals.

Washington, D. C. 


\section{HORSE-BREEDING SUGGESTIONS FOR FARMERS ${ }^{1}$}

By S. R. SpeElman, associate animal husbandman, Animal Husbandry Division, Bureau of Animal Industry

\section{CONTENTS}

\begin{tabular}{|c|c|c|c|}
\hline \multicolumn{2}{|c|}{ Page } & \multicolumn{2}{|c|}{ Page } \\
\hline rofit in breeding farm mares..................... & 1 & Abortions................ & 14 \\
\hline electing breeding and working mares & 1 & Approaching parturition & \\
\hline niformity of the mares. & 2 & Parturition. & . \\
\hline ndness & $\overline{3}$ & Care of the foal. & \\
\hline stallio & 5 & Feeding after foaling & \\
\hline lion.... & 6 & Raising the orphan foal & \\
\hline onsiderations & 7 & Weaning . . . & \\
\hline ination & 9 & Castration & \\
\hline nanagement of mares in foal. ...... & 12 & Fefding and management of young horses... & \\
\hline
\end{tabular}

\section{PROFIT IN BREEDING FARM MARES}

FINANCIAL profit results from breeding mares that earn their 1 feed by furnishing farm horsepower. Instances of this are often cited in farm papers. It is not uncommon to read of some remarkable mare that, besides doing her share of the farm work, has raised many hundreds of dollars' worth of colts (fig. 1). These accounts seldom tell of more than one such mare on a particular farm, whereas to obtain the greatest returns nearly all the work animals maintained on the farm should be mares of this kind.

Breeding the working mares places double duty on them; consequently they should be robust individuals of proper conformation and must have good care and treatment. With two sources of profit from one animal, farmers can well afford to pay more for such stock, feed it more heavily, and give it special attention. The small farmer is the one who is most likely to get the best results from such a plan, because he usually works his own teams or is in position to watch them closely and see that they are not ill-treated.

\section{SELECTING BREEDING AND WORKING MARES}

The two outstanding requirements in profitable farm mares are that they be breeders and workers. If a good, registered stallion is available, purebred mares of the same breed will probably give better returns than grades. It costs practically no more to raise a purebred colt than it does to raise a grade, and the returns are much greater. The amount of capital that can be invested in the mares is an important factor in determining whether purebreds should be used. The particular breed type that the purebreds or grades should conform to depends largely on local market demands. Some

1 This is a revision of former editions by H. H. Reese, who resigned in 1926. 
communities are noted for and attract buyers of high-class draft horses; others have local dealers who handle many saddle horses; and still others have a ready outlet for horses of the general-utility type, that is, horses that can be worked, driven, or used for riding purposes. In a locality favored with any such markets it is generally advisable to raise the prevailing type, since by so doing sales are more easily made and the services of high-class stallions are practically assured.

However, some persons have a decided preference for a particular breed or type, and where this is so a greater success often is made by raising the kind naturally preferred, although it must be
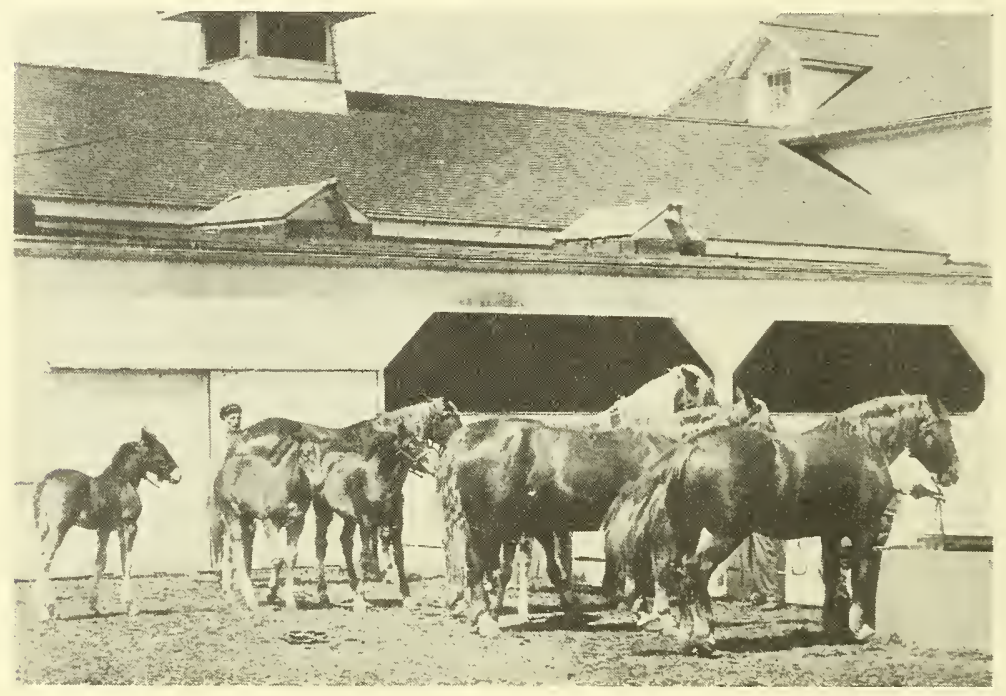

18979-C

Figure 1.-These farm mares do double duty. Besides paying for their feed with work, they annually produce foals that are sold at a profit.

remembered that it is difficult to show a profit when raising something for which there may be but a limited demand. It is generally accepted that light horses are best suited to rolling and semimountainous land, while draft stock is more adaptable to level country.

\section{UNIFORMITY OF THE MARES}

Uniformity in the mares kept on a particular farm generally is not given much consideration. There is satisfaction, economy, and convenience, however, in having mares similar enough in type and action so that one can readily fill the place of another at any kind of farm work. Such mares are especially desirable when it is necessary to work them 3 or 4 abreast. In case 4 to a wagon are needed, it is a good advertisement of the owner's judgment and ability as a horseman to have them all uniform, in good condition, and hooked up to a nicety. If the mares resemble one another and are bred to the same stallion it is often possible to sell the young horses as pairs, in which 
form they nearly always bring a premium. The market for horses bred in this manner will not be overcrowded very soon, as can readily be attested by anyone who has been confronted with the difficult task of purchasing matched pairs of a certain type.

\section{DESIRABLE CONFORMATION OF MARE}

Desirable characteristics in purebred or grade mares signify impressive ancestry and prepotency. Femininity of expression and of conformation is an indication of good breeding qualities. Style, good disposition, quality, clean, flat bone, concave, open feet, strong

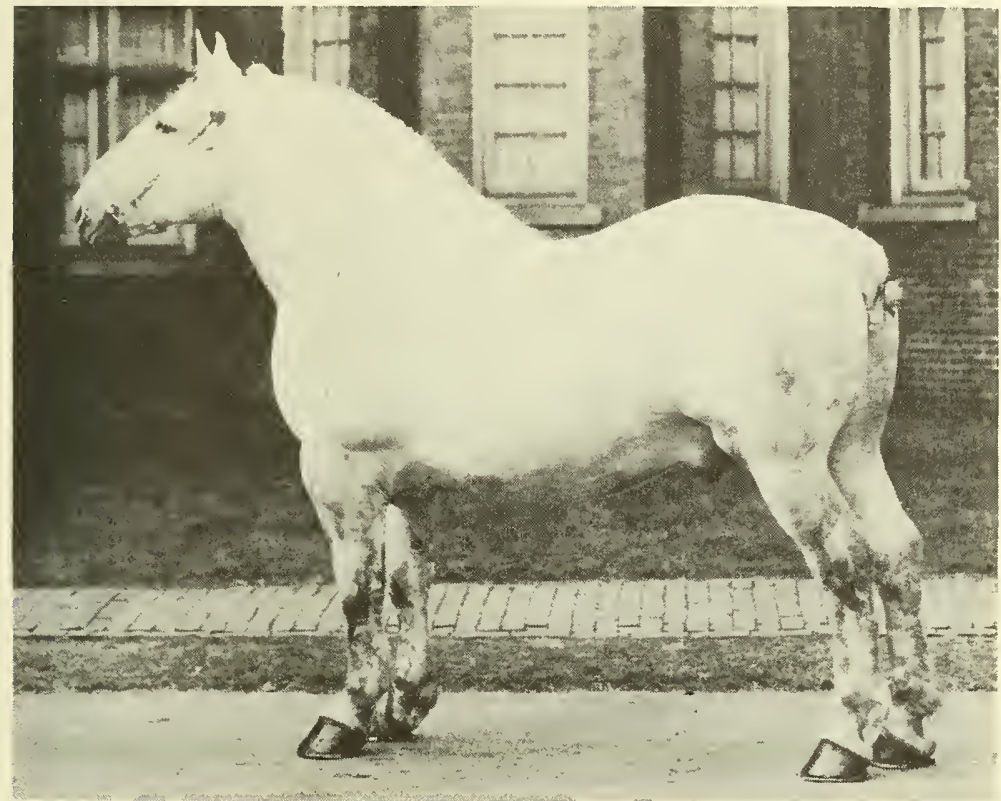

$189+1-\mathrm{C}$

FiguRE 2.-A draft stallion, showing well-set underpinning, substance with quality, short, smooth coupling, well-sloped shoulders, and a head denoting intelligence and refinement.

constitution, good proportions, deep, roomy barrel, width across the hips denoting a large pelvic arch, and well-developed vulva, udder, and teats are qualities especially desired in breeding mares. An inspection of the colts the mare produces is generally the best evidence of her worth as a brood mare. The length of usefulness as producers varies greatly with different mares. Some have excellent colts when 25 years of age, but if they produce until they are 15 years old they do very well. Much depends on the individuals and the way they are handled. Shy breeding mares are generally unprofitable producers.

\section{SOUNDNESS}

Unsound horses cause breeders much financial loss; consequently it is of great importance that all horses reared should be as sound as 
possible. Usually horses become unsound either because the tissue or the skeletal structure (or both) at a particular point of the body is weak, or because the strain exerted on the part is greater than the best tissue and best conformation can stand. Of course, if bad conformation exists, it is logical that such animals should not be used for breeding purposes whether they are sound or not. When considering horses that are unsound but apparently have good conformation, it usually is difficult to decide whether the conformation is at fault or whether an unbearable strain was the cause; consequently these animals, too, should not be used as breeders unless it is positively known that the unsoundness developed after severe labor had been

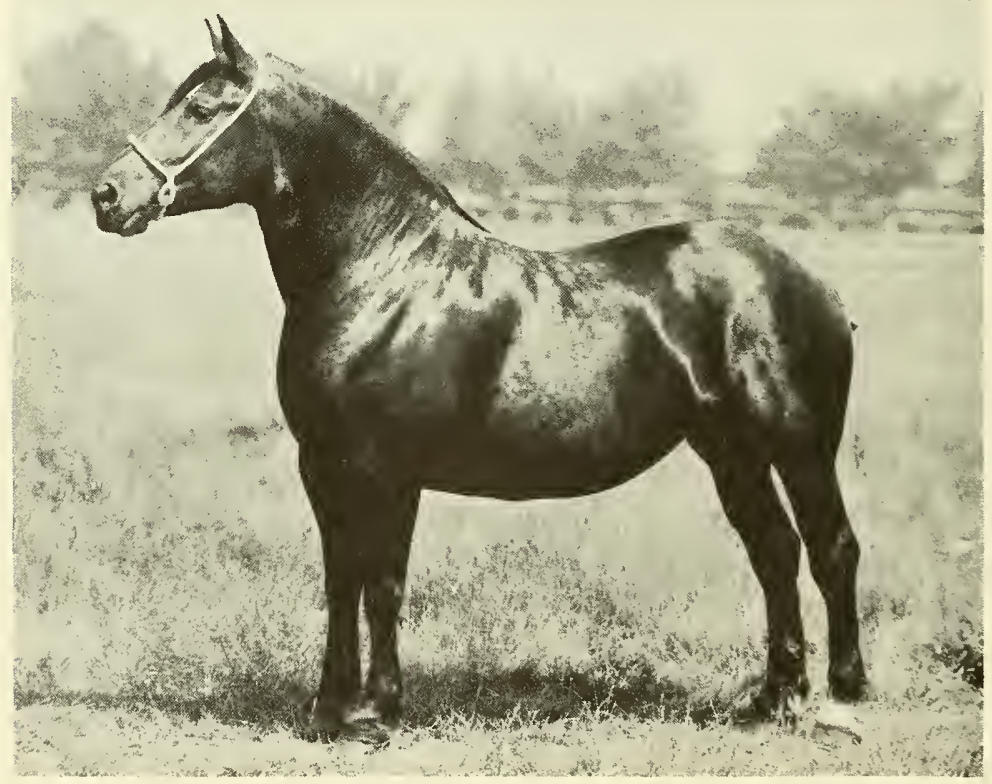

$14978 \mathrm{t}$

Figure 3.-Draft mare of desirable conformation. Note especially the femininity and quality of this mare and her exceptional breediness, as indicated by the clean-cut head and deep, roomy body.

performed in amount or degree much greater than that done by the average horse or that it resulted from purely accidental causes.

Unless caused by unusual circumstances, such as above indicated, any of the following kinds of unsoundness usually are sufficient reason for discarding a mare for breeding purposes: Bone spavin, ringbone, sidebone, heaves, stringhalt, roaring, periodic ophthalmia (moon blindness), and blindness, partial or complete. In the case of stallions, a more strict standard of soundness generally is followed than with mares. The stallion-registration laws of various States usually prescribe the unsoundnesses which bar stallions from public service. Some States have a longer list than others. Without discriminating, however, the foregoing list is one on which horsemen 
generally agree. The unsoundnesses there given are the most common and are detected readily. ${ }^{2}$ The elimination of unsound breeding stock, the feeding of balanced rations that will insure proper development of bone and tissues, and careful handling and management of colts are the right steps to take in eliminating unsoundness from horse stock.

\section{SELECTING A STALLION}

A low service fee should never tempt one to use an inferior stallion. It may also be better to use a stallion which stands at some distance rather than one that is more convenient. While the purchase price of a stallion is not always in proportion to his worth as a sire, the

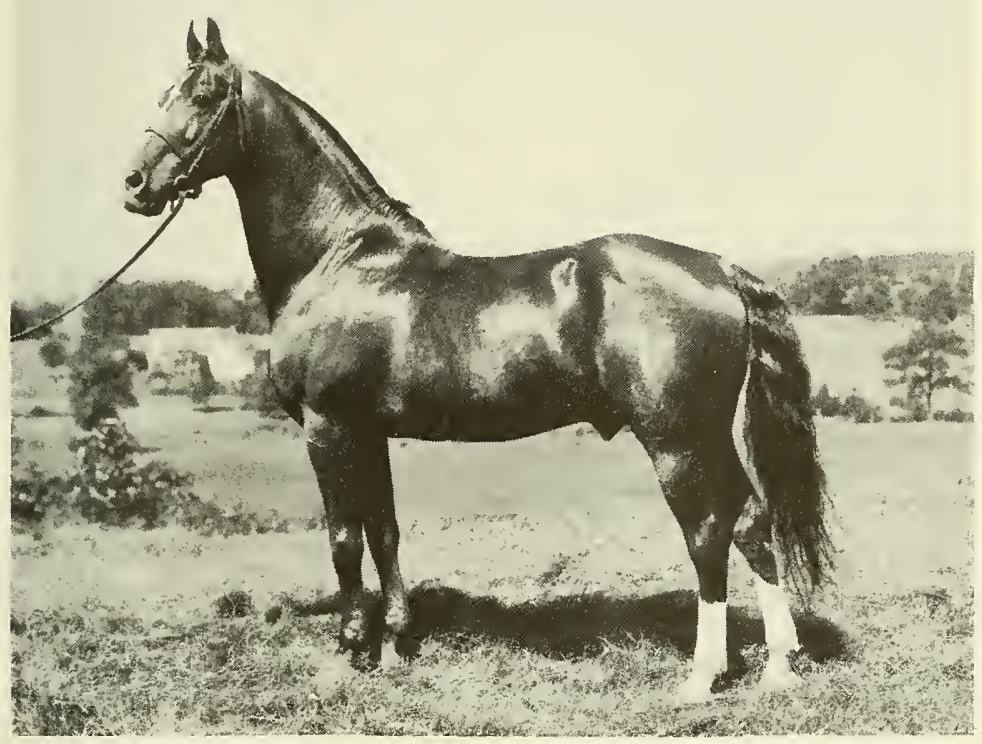

Figord 4.-Light stallion with well-set limbs, substance, and quality.

service fee generally is, if the horse has been standing long enough for mare owners to be able to pass judgment on his prepotency and on the quality of the colts he gets. The opinion of disinterested horsemen, together with the stallion's show winnings, will aid in making a good selection. Weight is an indispensable quality in a draft stallion, although it should not offset a deficiency in other respects. In the lighter stallions style, smooth lines, and swift, well-balanced action are necessary to improve light-horse stock. In any breed good feet, clean, flat bone free from meatiness, well-defined hocks, good disposition, quality, animation, and breed characteristics are well worth looking for in the sire. It is poor policy to use anything but a sound, purebred stallion free from manifest faults of

\footnotetext{
${ }^{2}$ For further information consult Farmers' Bulletin 779, How to Select a Sound Horse.
} 
conformation, and he should be of the same breed or type as the mare. It must be borne in mind, too, that a stallion that is not properly fed and exercised is not likely to get a large proportion of strong, healthy colts. In short, too much care cannot be exercised in obtaining a suitable mate for the mares and the fundamental law that generally holds in all breeding operations must always be remembered, viz, like produces like or the likeness of an ancestor.

\section{CARE OF THE STALLION}

The stallion should be kept in good condition throughout the year. Neglect during some periods and special attention during the breed-

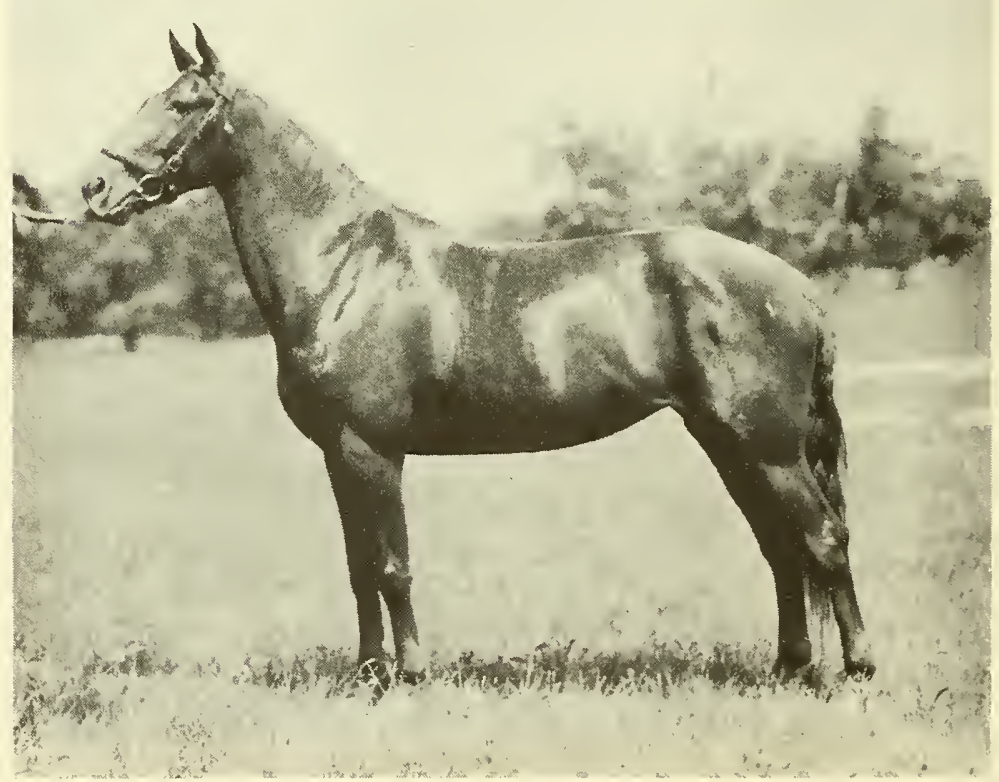

FIGURE 5.-Light mare of desirable conformation. Quality, smooth lines, animation, and indications of strong constitution are shown.

ing season form a too common practice that should be avoided. Each day the stallion should have suitable feed, water, and exercise. $\mathrm{He}$ should be groomed regularly and thoroughly, have access to salt, and be housed in well-lighted, sanitary, and comfortable quarters in the vicinity of other horses.

The quantity of feed required by a stallion depends on the amount of work or exercise he receives, his condition, size, and individuality, and the methods of feeding and management followed. The following are daily rations suggested for 1,200- and 2,000-pound stallions receiving moderate exercise: 
1,200-pound stallion:

(a) 10 pounds oats, 2 pounds wheat bran, 15 pounds mixed timothy and clover hay.

(b) 6 pounds shelled corn, 6 pounds oats, 8 pounds timothy hay, 7 pounds alfalfa hay. 2,000-pound stallion:

(a) 16 pounds oats, 4 pounds wheat bran, 22 pounds mixed timothy and clover hay.

(b) 10 pounds shelled corn, 10 pounds oats, 10 pounds alfalfa hay, 12 pounds timothy hay.

When comparatively little work or exercise is given, some laxative feed should be included in the ration. Among the best laxative feeds are grass, linseed meal, wheat bran, alfalfa hay, and carrots.

During the breeding season the stallion should receive a ration relatively high in protein and mineral matter. Linseed meal, soybeans, cowpeas, field peas, wheat bran, and the legume hays are high in protein content and suitable for use in the breeding ration. In practically all instances the protein-rich concentrates must be fed in limited amounts, preferably not more than one-third of the total allowance, with the legume seeds (soybeans, cowpeas, field peas) being used only in a ground form. Excessive use of linseed meal, wheat bran, or legume hay will make the ration too laxative.

Working the stallion is generally advisable. When the amount of exercise or work is increased, the grain allowance should be increased. A paddock for exercise is recommended. Six miles of jogging each day is considered moderate exercise for a light stallion. Walking 5 miles each day is usually sufficient exercise for a draft stallion.

The age at which young stallions should be used for service the first time depends greatly on the type of horse, its individuality and development, and the need for breeding service. No stallion should be put into service until he is at least 2 years old, and only exceptionally well-developed draft-type horses should be used when as young as that. Stallions of the light type usually do not mature so rapidly as draft stallions; they generally are not used for service the first time until they are 3 years old. Neither 2-, 3-, nor 4-year-old stallions are mature, and it is advisable to limit the number of services of such young sires until they are fully developed. If necessary, the well-grown 2-year-old draft stallion may serve 10 to 12 mares, with not more than 2 of such services coming in any one week. The 3-year-old sire may be used on 30 to 50 mares; the 4-yearold on 50 to 75 ; and the mature horse on 75 or more.

The stallion should not be excessively fat nor thin during the breeding season as either condition may render him impotent. One service daily is preferable in most instances for mature stallions. For immature stallions the matings should be spread as far apart as is possible and practicable. If it is necessary to breed the mature horse twice in 1 day, have the matings as far apart as possible, preferably one in the morning and the other late in the afternoon.

\section{MATING CONSIDERATIONS}

Only very well-developed draft mares should be bred when as young as 2 years of age. All others should go until 3 years, and some even until 4, if they are not strong or are slow in maturing. If bred at 2 years of age, usually mares should not be mated during 
their third year. This gives them a chance for further development without the retarding effects and physical strain caused by maternity.

In most instances producing mares may be expected to have their first estrual (heat) period in 5 to 11 days after the foal is born. This is known as the "foal heat" and, unless settled at this time, the mare will ordinarily come in heat again about every 15 to 21 days thereafter until she becomes pregnant. The length or duration of the heat period varies somewhat among different mares but on an average it approximates 5 days, with ovulation occurring most often from 24 to 48 hours before its termination. Thus, if only one mating is to be made during a heat period, it generally is best to have it on the third day. When two matings are made, usually the first one should be on the third day and the second on the fourth or fifth day. For mares that are very hard to settle, daily matings throughout the heat period may be advisable. The aim in any instance is to arrange the breeding date so that it occurs as near the time of ovulation as possible. This will insure the greatest percentage of conceptions and foals.

Although the foal heat period is often regarded as the best time to breed the mare, experimental evidence obtained from physiologyof-reproduction studies does not support this contention, and more favorable results may be expected normally if mating is postponed to the second or later seasons. This is due principally to the fact that the genital organs and reproductive tract often are not in the condition required for proper fertilization during the foal heat. Of the various types of mares, i. e., lactating, dry, and maiden, those running with foals (lactating) are generally the easiest to get settled, while the smallest percentage of conceptions may be expected from young mares that are being mated for the first time. Some mares do not show signs of being in heat even when tried ("teased") regularly with a stallion, but they often can be settled either by natural or artificial service, provided the approximate time of ovulation is determined and they are not suffering from either a diseased or abnormal condition of the reproductive system.

Taking the mare to the stallion usually results in the most satisfactory service because better accommodations are afforded there for teasing and serving mares, and accidents are less liable to occur. The mare will react at breeding time with more certainty if she is in moderate flesh and a healthy, vigorous condition. Extreme fatness interferes with both the mechanical and physiological performance of the reproductive organs, while thin or weak mares do not "catch" readily. The mare should have ample time to rest after she gets to the stallion's stand, and she may be kept in a box stall adjacent to his prior to mating time. Very often there is too much hurry at this time, and the mare is forced to take the service before she is ready and most receptive. If the weather is cold, the mare should be warmed up by moderate exercise before mating, but she should not be bred when she is either extremely hot or fatigued.

Considerable responsibility rests on the owner or caretaker of the mare in seeing that she is returned to the stallion to be tried and rebred if necessary when her next heat period is due. This is absolutely essential in order to get a large percentage of mares in foal, for many of them fail to conceive as a result of the first service. 
Moreover, if the mare is accustomed to dry feed, she should not be turned on pasture soon after breeding. Besides thus suddenly having her feed changed, she may be annoyed and teased by other horses. Hard work immediately after breeding also may hinder a mare from getting in foal.

\section{ARTIFICIAL INSEMINATION 8}

Artificial insemination is the introduction of male seminal fluid (semen) containing spermatozoa into the female genital tract (uterus or vagina) by artificial methods. Two distinct operations are involved in this process, (1) collection of semen, and (2) insemination of the mare with some of this fluid.

Various methods have been evolved and used for collecting semen, but the ones most favored now are: (1) The artificial vagina, (2) the breeder's bag, and (3) the semen aspirator. Each of these has its advantages and disadvantages, so it is well to study all aspects of the different collection procedures before selecting the one to be used.

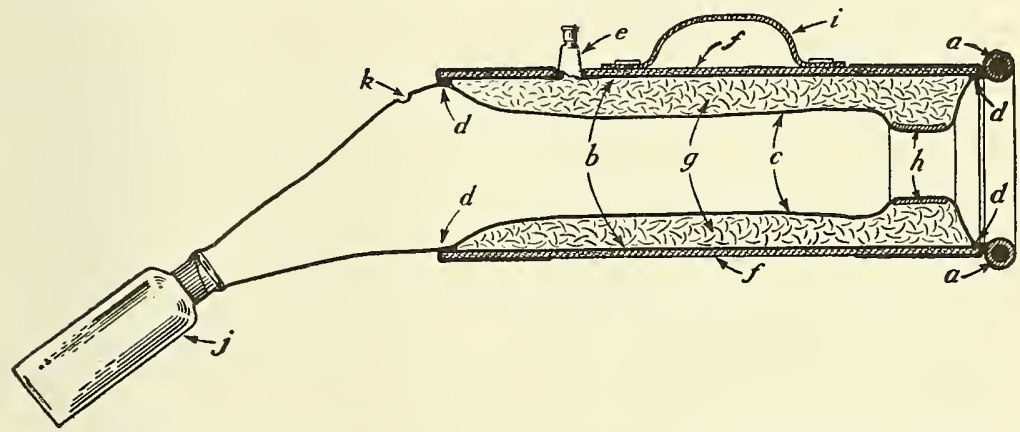

Figure 6.-Longitudinal section of the Missouri-U. S. D. A. model artificial vagina for the horse. Length 18 inches, 7 -inch rubber tubing, flat diameter; $a$, entrance ring made by enclosing section of $1 / 2$-inch garden hose; $b$, outer tube; $c$, inner tube; $d$, points at which the outer tube is vulcanized to the inner tube: $e$, air valve; $f$, leather casing to give support and rigidity; $g$, air space between inner and outer tube which allows for the adjustment of pressure; $h$, the "sphincter" rubber band, made of 3-inch flat-diameter tubing $11 / 2$ to 2 inches broad; $i$, handle grip attached to leather casing; $j$, 8-ounce collecting bottle; $k$, air vent to prevent ballooning.

Several types of artificial vaginas have been invented within recent years. Generally, however, such apparatus consists essentially of a rather thin, inner, rubber tube surrounded by an airtight and watertight jacket, made by attaching a heavy, outer cylinder of rubber, glass, ebonite, or metal to the inner one (fig. 6). One end of the inner tube has an opening large enough to permit entrance of the stallion's penis, while the other is tapered so it will fit tightly over the mouth of the glass container used for collecting the semen. Valves are provided in the outer jacket to allow entrance and discharge of the air or water which is used to warm and inflate the instrument before use.

The breeder's bag is an elongated rubber sack which is lubricated on the outside surface and then slipped over and fastened on the 
penis of the stallion just before mating. Such bags may be obtained in different sizes, those for draft stallions being the largest; when properly adjusted and used, they should capture the entire ejaculate. Collection of semen by aspiration involves the use of a suction-type device such as that shown in figure 7 . With this the seminal fluid generally is withdrawn from the bottom of the vagina.

In the practice of artificial insemination there are certain procedures which must be followed and precautions taken in order to obtain success. It is highly desirable that the work be conducted or supervised by a veterinarian. A primary consideration is that the operators be trained thoroughly in at least one of the approved methods of semen collection. Also, they must be familiar with the location and function of the mare's genital organs and with stallion and mare management during breeding work. Moreover, the proper apparatus must be on hand, rigid standards of cleanliness must be adhered to, and the entire process should be carried out in a careful, quiet, systematic, efficient fashion.

During collections for insemination purposes, the sire is handled in much the same way as for normal service. Usually at this time it is advisable to clean the penis of dirt, scales, and other foreign material. This can be accomplished by washing that organ with warm water and a mild soap, followed by a thorough rinse with clean, warm water. Moreover, some moderate exercise in the form of walking may be helpful in obtaining prompt service.

There should be evidence that the mare is in heat, and she should be restrained with breeding hobbles. Use of the twitch will not be required unless the mare is unruly and nervous, but her tail should be bandaged and tied, and the entire area around the vulva washed well with soap and warm water or a mild solution of a nonirritating disinfectant in warm water. The washing should be followed by a thorough rinsing with clean, warm water. If it is necessary to douche or flush out the mare's vagina before breeding, a solution made of 1 quart of boiled water (cooled to body temperature), 1 tablespoonful of baking soda, and $2 \frac{1}{2}$ tablespoonfuls of salt may be used. Do not breed or inseminate a mare thus treated, however, until 2 or more hours have elapsed.

Semen collections made with live mares and. the artificial vagina require at least three operators, one to hold the mare, another to manage the stallion, and the third to handle the instrument. In this procedure the stallion is led up to the mare quietly and slowly and is permitted to mount naturally. As this is accomplished, the operator holding the collection device grasps the penis and directs it sidewise through the front opening and into the lubricated inner chamber of the instrument. The artificial vagina must be maintained in position during service until ejaculation is compleced and the stallion dismounts. It is then removed and the bottle containing the semen is detached and either tightly stoppered or its contents emptied into the gelatin capsules to be used for insemination.

Collections made with the breeder's bag and semen aspirator (fig. 7) involve normal breeding service procedures with the exception that the ejaculate in the former method is caught in the rubber container, which is removed and emptied as soon as the stallion 
dismounts. Normally two or three operators are required to obtain collections in either of these ways.

The mare or mares to be inseminated must be fully in heat and preferably at that stage of estrus just prior to ovulation. As a precaution against kicking, it is well to apply hobbles, and the use of tail bandages is customary. The quarters used for the work should be clean, dry, dust-free, and fairly well lighted. Just prior to insemination the mare's vulva should be wiped and dried and its inner lips swabbed with clean pieces of cotton. Also, the mare should be placed and held so that her hindquarters are facing the light.

A simple, efficient, and convenient method of insemination is to use a gelatin capsule which will hold from $1 / 2$ to 1 ounce $(15$ to $30 \mathrm{cc}$.) of semen. After being filled and capped, this container is carried

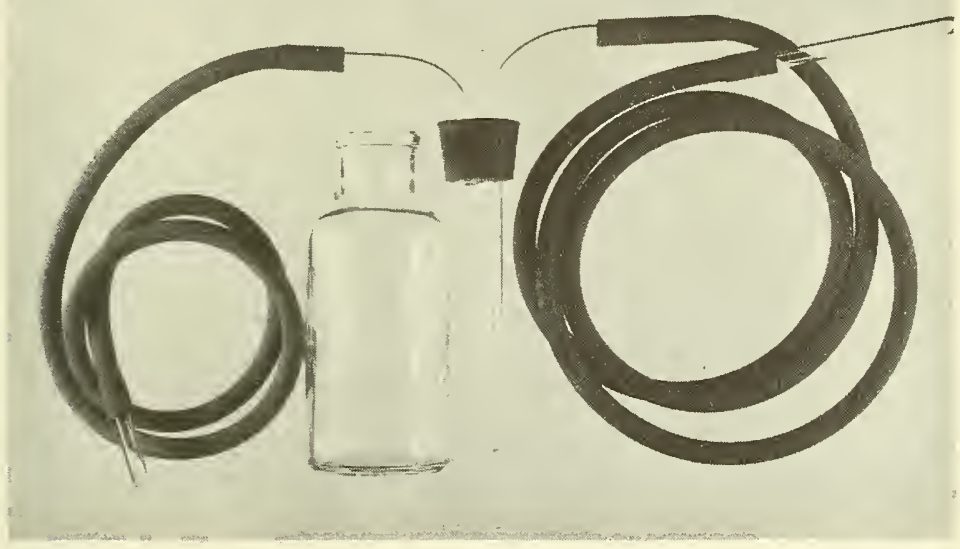

69579-8

FIgURE 7.-Semen aspirator. A 6-ounce bottle, 2-hole rubber stopper, heavy-walled 18-inch gum-rubber tubing, and 4 glass tubes are required for this equipment.

into the vagina by the hand and is placed well forward in the cervix, with the fingers. For this operation the hand and arm of the operator must be clean and well-lubricated, with the fingernails short and smooth. Some operators prefer to use a rubber glove and obstetrical sleeve during capsuling, because this reduces the chances of causing or spreading infection. Such equipment must be disinfected, washed, and rinsed thoroughly after each insemination, and it should be lubricated on the outside surfaces just before use.

After insemination is completed the hobbles and tail bandage are removed and the mare should be placed in a box stall where she may be watched for about an hour. Particular attention should be paid at this time to see there is no straining or wrenching with consequent expulsion of the semen, for if this occurs, another insemination may be required. 


\section{BREEDING RECORDS}

Records of the breeding of each mare should be kept in order that the approximate time of foaling may be known. The period of gestation, that is, the time between the fertilization of the ovum and the birth of the young, is variable. This period is ordinarily calculated at 11 months, but to be ready the owner must make preparations for the arrival of the foal prior to that time. The period, however, may vary between 330 and 365 days. A number of reasons have been advanced to explain why there is such a variance in the length of the mare's gestation period. One theory claims that a considerable time may elapse between the service and the actual fertilization of the ovum by the sperm cell. This does not appear to be very plausible, however, as the average length of life of spermatozoa in the female genital tract is known to be very short. Another explanation is that the date of foaling has considerable influence on the length of time that the mare carries her young. This latter consideration appears to have merit, for at the U. S. Morgan Horse Farm, Middlebury, Vt., records show that mares foaling after June 1 averaged 338 days for the gestation period, whereas those foaling earlier in the season had a gestation period of 347 days. This apparently was not due to the difference in individual mares, as the same animals showed a marked difference in the longer time they cariied early foals as against late foals. The natural time for foals to come is in the spring, when the air is warm and there are grass, ;unshine, and an opportunity for range and freedom. Modern farming methods, however, especially in certain localities, sometimes make it advisable to change nature's ways; consequently the farmer may find it better for the mare to be heavy in foal or suckling a foal in the fall, when the heaviest part of the farm work is over. Flies are not so troublesome in the fall as in the spring, and during the comparatively idle winter months the mare can give practically all her energy to furnishing milk for the foal. By the next spring, the young animal will be ready to turn on pasture, where it will require but little attention. However, fall foals can be raised successfinlly only when special care and feed are provided during the first winter and where a warm, dry, light, and well-ventilated box stall can be furnished each mare and her offspring.

\section{FEED AND MANAGEMENT OF MARES IN FOAL}

The mare will be healthier and the foal stronger at birth if she is used at slow, light work nearly every day; also, parturition is easier. In the summer, if it is not possible to work a mare, she should be turned into an open pasture, where she can get exercise, fresh air, and nutritious feed. Her feed should supply the demand for the maintenance of her own body and also for the development of the fetus. The ration, therefore, should contain a little more protein and minerals than that needed by a working gelding. Furthermore the proportions of these should be increased gradually as the gestation period progresses, particularly during the last half of the period. If the mare is idle in winter much of the feed may be good roughage, but a ration of grain and hay must be fed when work is done. The quantity of feed is determined by the size and condi- 
tion of the animal (whether thin or fat, sick or well), by the stage of pregnancy, by the appetite, by the amount of work done, and by individuality, condition of the droppings, and whether the animal is easy or hard to keep.

\section{GRAINS}

Oats are tho best single grain for the horse. They are a safe, light, palatable, well-balanced feed and may be used as the sole concentrate in the ration. Corn is a good concentrate but is used to best advantage if it forms only from one-third to one-half of the grain ration of the brood mare. When fed heavily, corn should be supplemented with concentrates or roughage rich in protein and mineral matter, as corn is somewhat deficient in these constituents. If wheat is fed it must be ground or rolled and used in small quantities

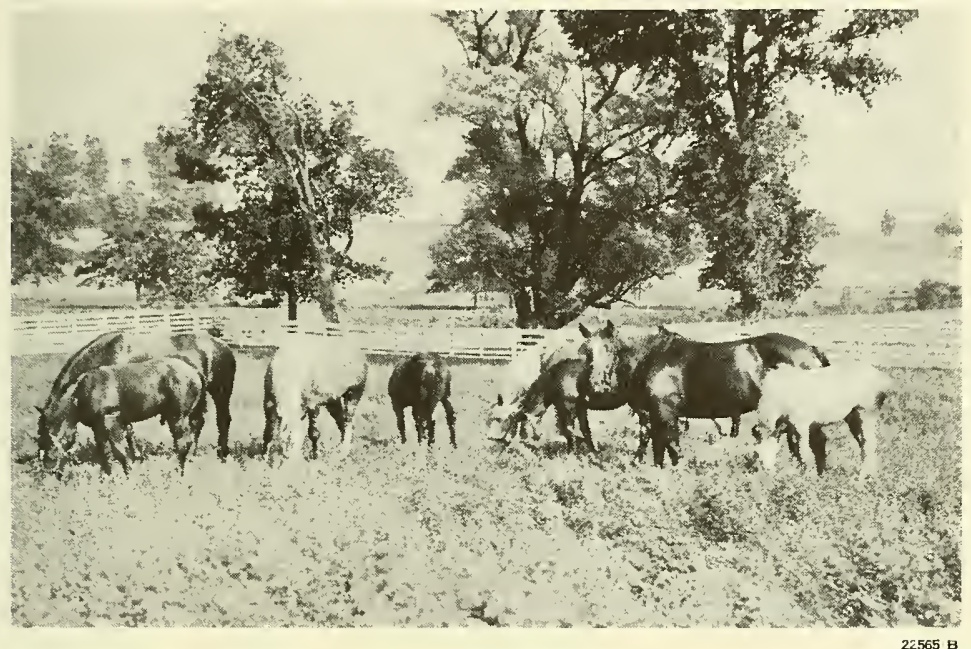

Figure 8.-Brood mares and foals in desirable condition and showing the effects of good pasture. Aside from its high cost in most localities, the board fence shown is ideal for surrounding horse pastures.

in order to prevent digestive disturbances. Barley is a good horse feed; it is more bulky than wheat and more nearly like oats than corn in composition. Barley is often cooked and fed once or twice a week in the evening. In most instances it is preferable to grind or roll barley. Wheat bran is an almost essential horse feed, particularly for breeding stock and young animals, and acts as a regulator and a preventive of overfeeding. It is bulky, nutritious, and palatable and lightens the ration. Soybeans and cowpeas are relished by horses and serve as a useful addition to the grain feed for mares in foal. They are relatively rich in protein and consequently combine well with corn. Soybeans and cowpeas should not constitute more than one-third of the grain ration, and they should always be ground for feeding.

\section{ROUGHAGE}

Timothy hay is a very popular roughage for horses. Bromegrass also makes good hay. It is higher in protein than timothy. Orchard 
grass, if cut in early bloom, is equal to the best of the hays made from grasses, and carries considerably more protein than timothy. Good Johnson grass hay is as valuable as timothy for horses. Sudan-grass hay is a safe feed for mares, and numerous native prairie grasses furnish hay that is equal to timothy. Clover hay is liable to be dusty, but it has good feeding qualities. Millet is not a safe feed for mares in foal. Corn fodder is used frequently to feed idle horses in the winter, but there is not enough nutriment in it alone for mares in foal. The same thing is true, in a greater degree, of straw. If either is used, good-quality hay, preferably legume, should be fed also. Unthreshed cowpea and soybean hay are valuable roughages which are relished by horses. Even the threshed hay is moderately nutritious. It should never be fed to brood mares if it contains any mold, however. Alfalfa hay makes an excellent feed for mares if it is fed once a day and timothy or corn fodder given at the other feeding. Occasionally alfalfa hay is not properly cured and molds badly, in which case it should not be fed. Also, farmers have reported occasionally that alfalfa causes the kidneys to act too freely, but it is probable that this trouble will not be noticed if the alfalfa does not make up more than one-half of the roughage allowance.

\section{SUCCULENCE}

Succulent feeds are those which are juicy, appetizing, and easily assimilated. Such feeds have a beneficial, laxative effect on the digestive system and stimulate the appetite. The most common succulent feeds on farms are green grass, carrots, rutabagas, sugar beets, and silage. Grass, although of a succulent nature, is often used as the entire ration throughout the summer if the mares are idle. If they are worked, grass forms a valuable supplement to hay and grain. Brood mares should be allowed access to grass whenever available, the precautions mentioned later being complied with.

\section{ABORTIONS}

Data obtained from various sources indicate that approximately 5 percent of the mares impregnated abort each year. It is possible that all abortions are not reported or are not known, in which case the percentage would be still higher. As abortions generally are due to kicks; strains; slips; squeezing through narrow doorways or partly closed gates; excessive and severe riding, driving, or pulling; and improper or moldy feed (such as moldy corn fodder and heavily frost-bitten grass), it is evident that American farmers are losing many thousands of dollars yearly by careless and injudicious handling and management of their brood mares. Furthermore, breeders often have difficulty in getting a mare in foal that has previously aborted, so that the loss may be a far-reaching one. If of the contagious character, abortion may turn a profitable band of brood mares into a practically valueless one, so far as breeding is concerned.

To sum up briefly : Proper feed of sufficient quantity and variety; regularly supplied, uniform, moderate work and exercise; and careful handling will maintain an in-foal mare in proper physical condition to develop a healthy, strong fetus. 


\section{APPROACHING PARTURITION}

Mares heavy in foal should not be taken from work suddenly, but should be kept in hamess at light work (if already accustomed to it) until within a week or a few days of foaling time. A week or so before parturition there is a sinking of the muscles of the croup, falling of the abdomen, and filling of the udder. Usually at this time the mare should be quartered in a dry, sanitary, pleasant, quiet, light, comfortable, roomy box stall. If not accustomed to pasture, she should not be allowed it, but should be given exercise in a dry lot after she is no longer being worked. Moderate exercise is desirable, and occasionally it is necessary to have a sluggish, idle mare led a short distance each day in order that she may get sufficient exercise. Too much exercise at this time is just as detrimental as not enough, and a knowledge of the mare's previous success in delivering a foal, coupled with judgment, will determine the nature and amount of exercise as well as feed, etc., that should be allowed. Wax and sometimes milk will be found on the teats a day or so before foaling. Idle mares frequently develop an udder a longer time before parturition than mares that are worked regularly.

\section{PARTURITION}

Indications of immediate parturition are restlessness, sweating, lying down and getting up, switching the tail, and biting the sides and flanks. When the water bag has broken, the foal may be expected momentarily. If possible, be present when the foal comes. Many mares, of course, will not bring forth their young (if able to keep from it) while they are being watched, but it usually is possible to hide quietly in an adjoining stall until the foal is delivered. The mare will foal with the greatest ease if she is lying flat on her side with all legs stretched outward. Moreover, she should not have her hindquarters close to a wall or corner of the stall. Parturition generally lasts 10 to 15 minutes; if it extends to 4 or 5 hours the colt will come dead. In normal presentation of the fetus, either the forelegs extended with the head resting on them or the hind legs extended will first make their appearance through the vulva. Any other presentation may be attended with difficult parturition, in which case a competent veterinarian should be summoned at once.

First after the foal is dropped see that it begins to breathe. Take the film of tissue from its nostrils, and if respiration does not begin immediately blow into the mouth, work the ribs, and rub the body briskly with a wisp of hay or rough towel. If the mare sweats much and the weather is chilly or cold she should be rubbed down, dried, and covered with a light blanket. The foal also should be dried to prevent chilling, and it may then be moved to one corner of the stall so that the afterbirth and discharged fluids may be removed. Clean the stall thoroughly, scatter lime on the bare floor, and then cover it with clean bedding. The afterbirth should be burned or buried deeply with a thick covering of lime. It is one of the best mediums for bacteria of various kinds to develop in; hence it is essential to dispose of it properly. 
Foals at birth usually weigh from one-twelfth to one-tenth as much as their dams.

Sunshine is a great enemy of disease germs; consequently plenty of light should be provided in the stables. A common but unhealthful practice, in sections where bank barns are prevalent, is that of having the box stalls next to the bank side of the barn. Besides lacking light, such stalls are liable to be damp; yet it is in such places that mares frequently bear their foals and that the latter are housed. A window is inexpensive and will do much good in such places.

\section{CARE OF THE FOAL}

Foals should nurse after they gain strength enough to get on their feet and walk around. If the foals are weak or very crooked-legged, it may be necessary to assist them in getting to the teat, but often an effort is made to force them to nurse before they are ready. Nature takes its own time on such occasions, and hurrying and bustling may do more harm than good. Before the foal nurses, wash the mare's udder and teats with a warm 2-percent solution of a good coaltar disinfectant and then rinse with warm water. The first milk which comes from the mare is known as colostrum and acts as a physic on the foal, causing the fecal matter in the intestines to be discharged. It is very important that the foal get the colostrum; hence the folly of milking the mare before the foal comes merely because there appears to be too much milk in the udder. If the contents of the bowels are not ejected naturally within 24 hours, 2 to 4 tablespoonfuls of castor oil shaken in milk should be given by mouth and it may also be advisable to inject warm water or 2 ounces of castor oil into the bowels through the rectum. Repeat this treatment every 3 or 4 hours until the bowels move. Petrolatum applied in the rectum may aid in ejecting subsequent dry matter.

To offset the danger of navel infection in foals (which causes a disease known as joint-ill), the navel cord should be washed several times a day by holding up around the cord a large-necked bottle which has been nearly filled with a 1 to 1,000 solution of corrosive sublimate (bichloride of mercury) or by saturating the stump with full-strength tincture of iodine. Then dust it with powdered slaked lime. This should be repeated each day until the navel cord drops off. In case the navel does not dry properly or shows inflammation, a veterinarian should be called. Mares are inclined to be peevish and cross when with their young; consequently it is advisable to perform the foregoing operations as speedily as possible and then leave the stable so that the mare and foal can rest.

\section{FEEDING AFTER FOALING}

The mare should not be fed heavily on grain or hay for the first 24 hours after parturition, and the first feeding should consist of a wheat-bran mash with a little cooked flaxseed meal in it. A little oatmeal soaked in warm water is also appropriate. If the mare is constipated give laxative feeds. In 2 or 3 days, if doing well, she may be put back on dry feeds. In a week, if she is put back to work, she can have full feed. The mare may be put in harness, if light work is done, 2 or 3 days after foaling, but it is hard on the foal and may 
injure the mare's udder. It is best to turn the mare and colt into a lot where they can exercise and yet be quiet, but care should be taken at first to see that the foal is not chilled by staying out too long in cool, disagreeable weather or by lying on cold, damp ground. They should not be on grass if the mare has not been on grass before.

In a little more than a week the mare may be safely put to work provided she has previously been worked. If the foal is left in the stall, the mare should be brought to the stable in the middle of the forenoon and afternoon in order that the foal may get its food (fig. 9), but in no case should a foal suckle a mare that is very warm, as digestive disorders are liable to follow. If possible, do not use the mare for purposes which will keep her away from the farm for a long time, because the foal will either go too long without nursing or will be worn out by following the mare. When left at the stable, the foal should be kept in a roomy, clean box stall in company with another foal of about the same age if possible.

At about 2 months of age the foal will take dry feed, which should be supplied at first through the dam's grain box. This makes it necessary to furnish her with such feeds as ground oats, corn meal, and wheat bran. A little later a creep should be built in the stall or pasture, inside of which the foal can be given grain without having to share it with its mother. A creep is simply a partition that keeps the mare out of the enclosure, but is far enough from the ground so that the foal can walk under it. A handful of ground oats should be given at first and the quantity increased slowly as the foal grow.s. The maximum amount should be about 1 pound a day till weaning time.

\section{RAISING THE ORPHAN FOAL}

Sometimes a mare dies shortly after foaling, thus leaving her young dependent on artificial feeding for its sustenance; and some mares furnish an insufficient amount of milk for their foals. Cow's milk makes a most logical substitute for mare's milk, but as the composition is different, certain changes or modifications are necessary in order that the supplied diet be not too dissimilar to the natural. Table 1 gives the average composition of the two kinds of milk:

TABLE 1.-Composition of milk from cows and mares

\begin{tabular}{|c|c|c|c|c|c|}
\hline Source & Water & Protein & Fat & Sugar & Ash \\
\hline $\begin{array}{l}\text { Cow } \\
\text { Mare }\end{array}$ & $\begin{array}{r}\text { Percent } \\
87.17 \\
90.78\end{array}$ & $\begin{array}{r}\text { Percent } \\
3.55 \\
1.99\end{array}$ & $\begin{array}{r}\text { Percent } \\
3.69 \\
1.21\end{array}$ & $\begin{array}{r}\text { Percent } \\
4.88 \\
5.67\end{array}$ & $\begin{array}{r}\text { Percent } \\
0.71 \\
.35\end{array}$ \\
\hline
\end{tabular}

Milk which is not rich in butterfat, preferably from a recently freshened cow, should be diluted about one-half with fresh boiled water. A tablespoonful of sugar and about three teaspoonfuls of limewater should be added for each pint. This mixture should be supplied to the foal at about body temperature. A bottle with a rubber nipple, or even a finger of a kid glove with a fair-sized hole in it fitted over the end of a spout of a vessel, such as a teapot, will serve as a convenient utensil in getting the foal to take the milk. If 
the finger of a kid glove is used it should be clean. At first about one-half cup of milk should be given every hour, the quantity being increased slightly and the intervals lengthened gradually as the foal grows older. In about 2 months skim milk may be substituted for whole milk, and in addition one of the following rations should be fed : 1 part flaxseed meal boiled to a jelly, and 2 or 3 parts wheat bran; or 2 parts ground oats, 1 part corn meal, and one-half part flaxseed meal; or 2 parts wheat bran, 2 parts corn meal, and 1 part linseed meal. Feed a double handful a day at first and increase the quantity gradually thereafter.

Raising a foal by hand is not a job for the careless and indifferent. It requires patience, painstaking care, perseverance, judgment, and cleanliness. The vessel in which the milk is supplied should be

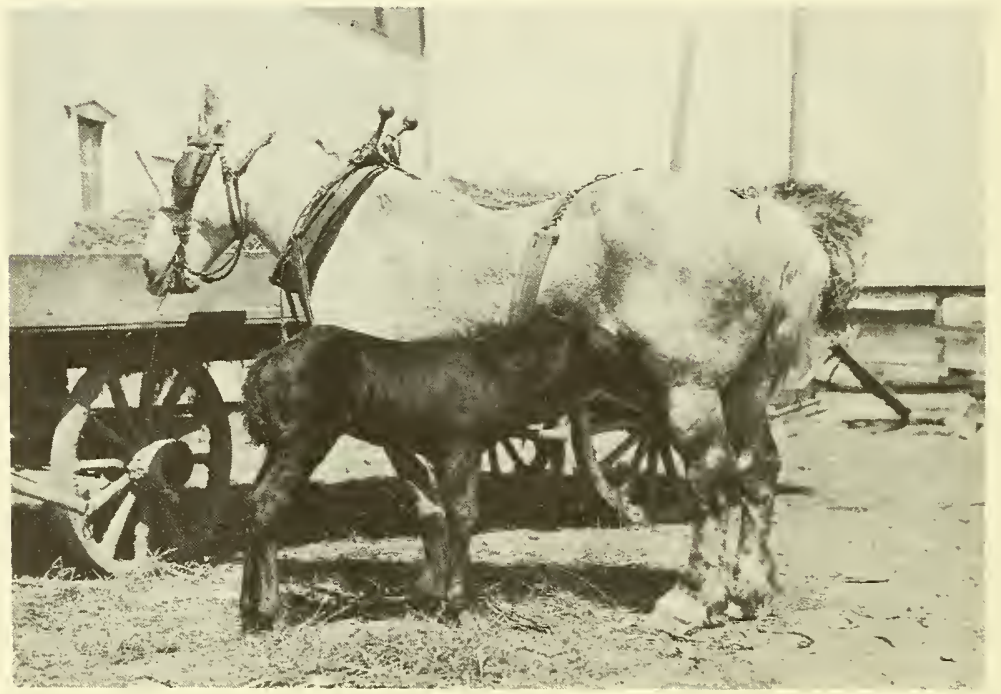

25c81-8

Figure 9.-The young foal should be allowed to suckle the working mare at regular intervals several times a day.

scalded thoroughly each time it is used. Unclean receptacles for the milk and irregular intervals for feeding probably will cause scours. The quarters should be kept very clean, and the orphan should have company of some kind. Another foal is desirable, but even a calf is better than no company. A grassy paddock with abundant shade, fresh, clean water, and protection from flies increase the orphan's chance of proper development.

\section{SCOURS}

A most common cause of scours in foals is feeding too much milk at irregular intervals; consequently, better management is the first step in remedying the trouble. Castor oil is often used to check scours, 1 or 2 ounces being the dose for a young foal. Raw eggs are also used successfully. Blood meal is considered one of the best. remedies, the quantity used being one-tenth to one-sixth of the 
grain ration. Powdered tannic acid also gives quick relief, the dose being from 5 to 15 grains. For other than a mild case a competent veterinarian should be consulted.

\section{WEANING}

Foals belonging to mares that work hard should be weaned earlier than those of mares which are practically idle. Although most foals are weaned when about 5 or 6 months old, it is well to remember that it is usually economical to feed a young horse through its mother. However, in case the mare is again in foal, if she is allowed to nurse for more than 6 months it may decrease the vitality of the next foal. If the foal is getting plenty of nourishment from grain, grass, and other roughage, the young animal will not be seriously set back when shut off from its dam's supply of milk. When taken a way from its mother it should be placed with another foal of the same sex and age in an enclosure where they cannot possibly get out or be injured. Feeding grain is not absolutely necessary if the foal is on good grass and has been accustomed to it; nevertheless, it has its advantage, especially with draft stock. Foal feeding should always be practiced with orphan animals.

The foal should not nurse more than once after it has been taken from its dam. The excess milk should be taken from the mare's uddel' from 3 to 5 times a day, but enough should be left so that her system will begin to absorb the milk; otherwise the drying-up process will be delayed unnecessarily. Not withdrawing milk enough may cause the udder to cake. Camphorated oil, petrolatum, or lard rubbed on the udder will aid in keeping it soft.

\section{CASTRATION}

Castration is usually performed at the age of about 1 year. However, it may be done when the colt is only a few weeks old, at which time there is less danger to the animal, but the operation at any early age tends to result in an imperfect development of the fore parts. Delaying the procedure until the age of 2,3 , or even 4 years will insure still better development and carriage of the forequarters. The essential steps of castration are the safe removal or destruction of the testicles and the arrest or prevention of bleeding from the spermatic artery which is located in the anterior part of the cord. The operation is best and most safely performed by an experienced veterinarian. ${ }^{4}$

\section{FEEDING AND MANAGEMENT OF YOUNG HORSES}

\section{CARE AND FEEDING DURING THE FIRST WINTER}

Foals may be housed satisfactorily in either the stable or an open shed. The shed shown in figure 10 is practicable where it is necessary to provide shelter for several head. The main requirements are that the quarters be dry and sanitary, and provide fairly. good protection from winds. Several foals may be run together if the

4 For further information on castration of the horse see Diseases of the Horse, for sale by the Superintendent of Documents, Government Printing Office, Washington, D. C., at $\$ 1$ a copy. 
weaker ones are not driven away from their feed by the stronger. The quarters should be kept clean and well-bedded and occasionally should be disinfected. Lice are to be suspected when the animals get to rubbing and lose patches of hair. It costs money to feed lice; consequently efforts should be made to keep the foals free from them. ${ }^{5}$ Foals should be in the open almost every day that is not stormy; it is harmful, however, for them to be in a cold rain, heavy snow, or sleet. During the first winter they should be taught to lead and to stand tied.

Feeds that promote growth are highly essential and should be supplied regularly. Good, clean clover hay is palatable, nutritious, and slightly laxative. Timothy hay also is commonly fed. Wellcured alfalfa hay, free from dust, is one of the best roughages for growing, but because of its relatively high protein content it generally is economical to supplement it with other dry roughage, such as timothy, mixed hay, or corn fodder. Besides lending variety to

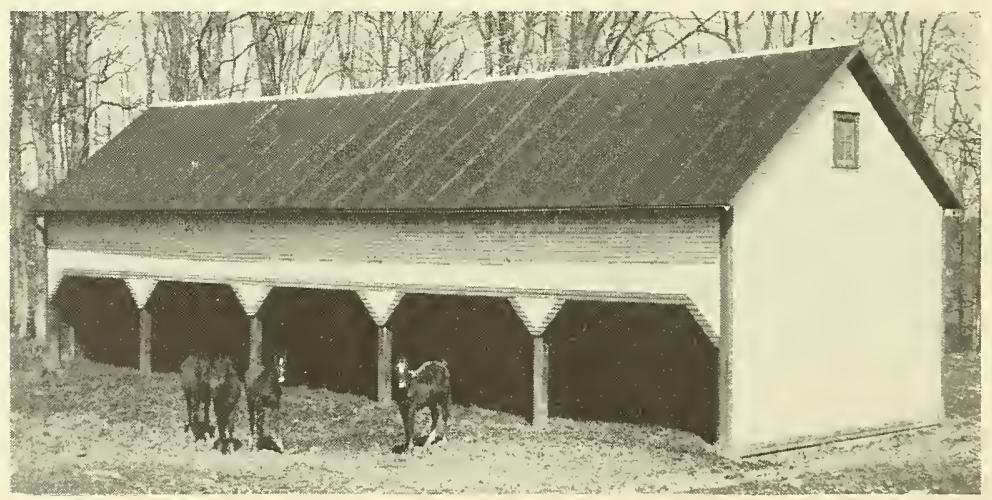

$3876-\mathrm{C}$

Figure 10.-A shed open on the south side. A desirable place in which to winter colts unless the climate is too severe.

the ration, such a method of feeding alfalfa offsets any likelihood of kidney or bowel irregularities. Sheaf oats can be used to advantage to supplement other roughage. With such feed little grain of other kinds will be required. The animals should not be allowed to gorge themselves on dry feed. They should be given only what they will clean up readily, but at the same time enongh feed should be supplied. Oats, corn, and peas, preferably well-ground, are suitable. Wheat bran, linseed meal, or gluten feed will add protein and lend variety. Cottonseed meal should not be fed to foals. Appropriate grain rations for the first winter are: 2 parts corn, 5 parts oats, 3 parts wheat bran, and 1 part linseed meal; or 4 parts oats, 1 part cor'n, and 1 part wheat bran.

Silage should not be fed to foals to any considerable extent. Sliced roots, such as carrots and sugar beets, are very palatable and have a

\footnotetext{
5 For further information on lice consult Circular 148, Purasites and Parasitic Diseases of Horses, obtainable from the Superintendent of Documents, Washington, D. C., at 10 cents a copy.
} 
beneficial effect on the digestive system. The quantity of feed generally should be regulated by the appetite, although occasionally the appetite may be too ravenous to be a good indication of the animal's needs. The general condition of the foal and the droppings should be observed daily. Usually not more than 1 pound of grain per 100 pounds of live weight should be fed until the animal is 2 years old. A liberal supply of salt and pure water and plenty of fresh air and exercise are essential for the proper development of young horses. Idleness succeeding exercise causes constipation. It is often said that a horse is made during its first winter. Certainly this is a critical time in the animal's life, and at no other age will proper feed and attention do as much to make a good horse. If stunted during the first winter, the animal never gains proper size and shape.

\section{CARE AND FEEDING DURING THE SECOND SUMMER}

Foals should be changed from dry feed to pasture gradually, and they should not be turned on pasture until the grass is old enough not to be washy. Grass is an indispensable factor in, the economical and proper physiological development of young horses. Frequently in protected bluegrass mountain valleys they thrive the year round on pasture alone. A visit to the pasture every few days may be the means of promptly discovering cases of sickness or injury. The feet of the young animals should be noticed on such visits, and if the hoofs are too long at the toe or high on one side they should be trimmed properly. Failure to keep the feet level may result in crooked legs, cracked hoofs, or crooked joints. Barbed wire should not be used for fencing the pasture; a board fence is preferable. Smooth, woven-wire fences also may be used.

If a foal should be cut, disinfect the wound; and if the cut is very large, have it sewed up. The wound should be dusted frequently with boric acid or air-slaked lime until healed, and then greased with petrolatum so that the hair will grow. The animals should have plenty of fresh water and salt, and in hot weather they require shade.

\section{CARE AND FEEDING DURING THE SECOND WINTER}

During the second winter the feed and management should be nearly the same as for the first winter, except that the quantity of feed should be increased somewhat, the colt tier up in his stall, and handled frequently. Education by gentle and careful but firm handling at this age will save much strenuous labor later. In this connection Farmers' Bulletin 1368, Breaking and Training Colts, should be consulted.

\section{THE 3-YEAR-OLD}

The succeeding years are largely a repetition of those already discussed, so far as feed and management are concerned, although the quantity of feed must be gradually increased as the animal grows. In general, the prime essentials for the proper development of horses from the yearling stage until they are put to work are: Fresh air; pure water; plenty of exercise; nutritious, palatable feed in sufficient quantity; and protection from severe weather. 



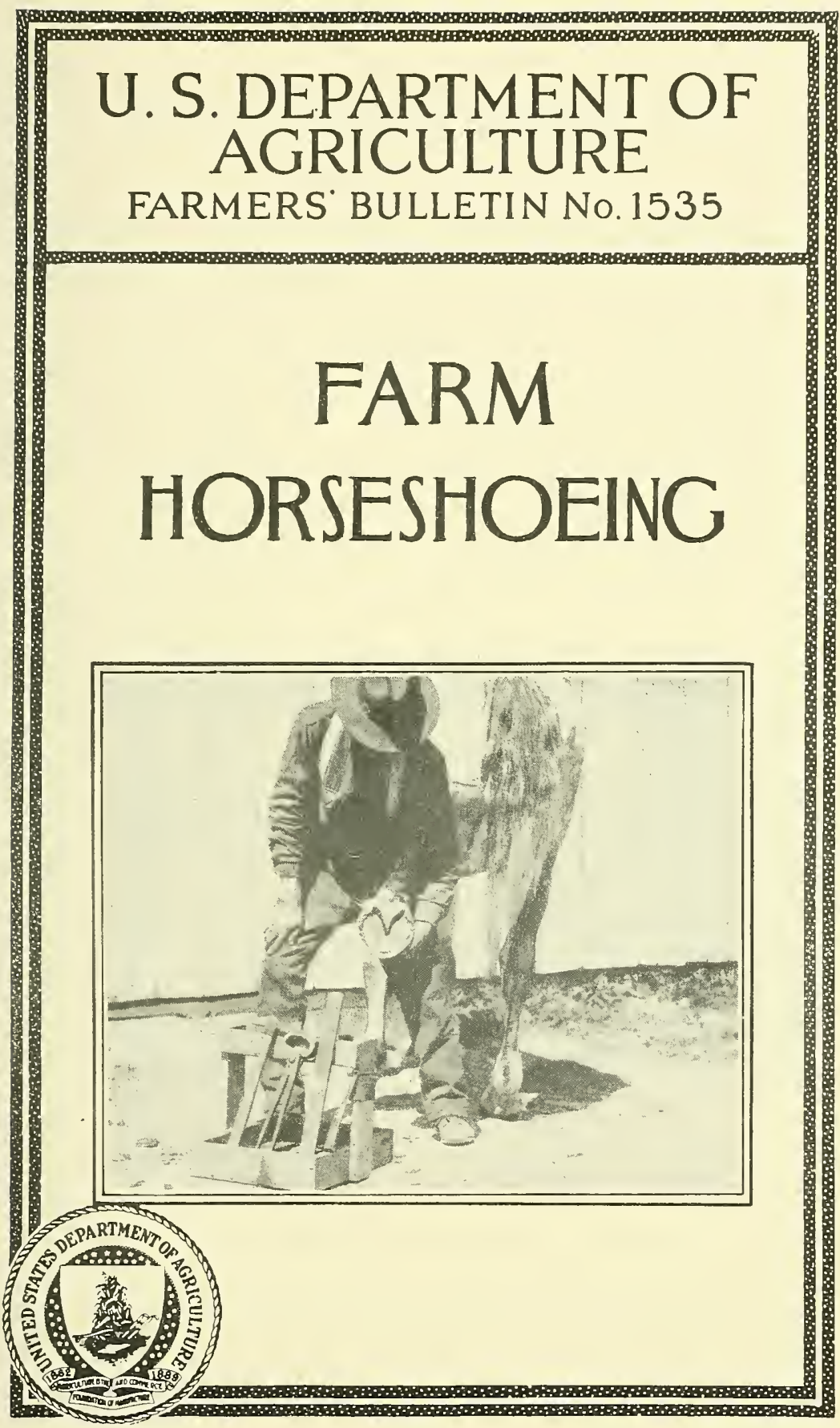


THE SHOEING of farm horses in the United I States in the past was done largely by the trained farrier, whose shop in every village and hamlet was a familiar institution. The advent of hard-surfaced roads and motor vehicles has been accompanied, in many localities, with a transformation of our countryside, in which the village blacksmith shop has gradually been supplanted by gas stations and garages, so that the problem of shoeing farm horses is a serious one in many communities.

The solution of the problem in a large measure devolves upon the farmer himself in learning to do the work on his own farm. It is for the purpose of assisting the farmer to care for the feet of his work stock properly and to shoe his horses, if necessary, that this bulletin has been prepared.

Ready-to-wear shoes of various sizes for horses and mules can now be obtained and greatly simplify the shoeing problem for farmers.

Trimming and leveling hoofs, fitting shoes, and nailing them on, while explained in this bulletin, are much more readily understood if presented in an actual demonstration by a competent horseshoer. Many agricultural colleges give instruction in this work, and it is recommended that farmers apply to them for a community demonstration.

Washington, D. C.

Issued July, 1927 


\section{FARM HORSESHOEING}

By Henry Asmus, Professor of Farriery, New York State College of Velerinary Medicine, and J. O. Williams, Amimal In usbandman, Animal IIusbandry

Division, Bureau of Animal Industry

\section{CONTENTS}

Page

The need for shoeing farm holses_The growth of the hoof 'rimming the colt's feet.

Trimming the foot for shoeing
Fitting the shoe

Railing ----- shoes

Ready-to-wear shoes
Rubber shoes and rubber hoof pads_-
Page

TO FOOT-NO HORSE is a time-honored adage among horsemen. It is a phrase which may be interpreted almost literally so far as the serviceability of horses is concerned. Bad feet incapacitate clraft horses on hard pavements and very materially reduce the efficiency of horses for any work. It is vital, therefore, to consicler carefully the principles involved in the proper care of the hoof, and in shoeing horses so that they may be kept in service and so that their sale value may not be impaired. Improper care of the hoof and improper shoeing frequently lead to diseases of the feet and

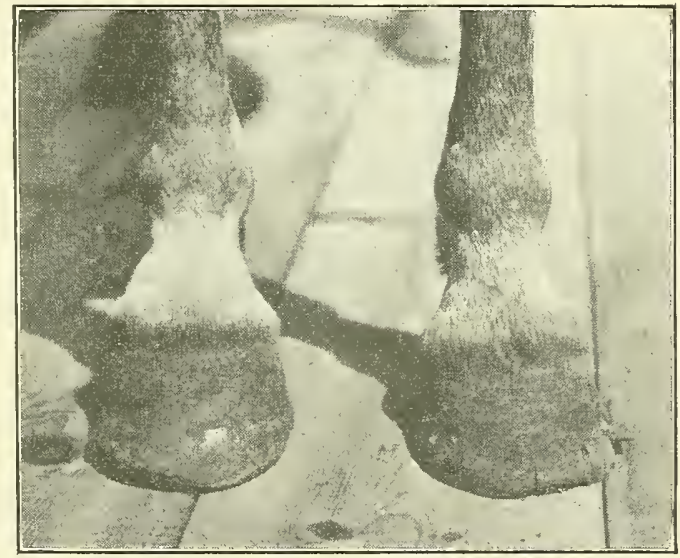

FIG. 1.-Long, poorly kept forefeet; left shoe off for several days. Note the cracks developing in the wall and the broken wall in the outside quarter irregularities in gait, which may render the horse unserviceable and unsalable.

\section{THE NEED FOR SHOEING FARM HORSES}

Using unshod horses and mules for pulling heavy farm machinery wears off the horny wall of the foot at the ground surface more rapidly than growth is supplied from above and will result in tender feet. In many cases the wall will split, break, or separate from the sole of the foot (as in fig. 1) and permit small stones or gravel to 
become embedded and cause serious lameness. This may occur during peak periods of work, when the animal is most needed in carrying on farm operations, and delay the farmer in getting important work done. A well-shod horse not only is kept in service but he is a more efficient worker in that he can better apply his strength because he has a better footing. The better footing makes him a better puller. It is important, howerer, that shod horses have regular attention--that about erery four to six weeks the shoes be removed, the hoofs trimmed, and the shoes refitted. Permitting the shoes to

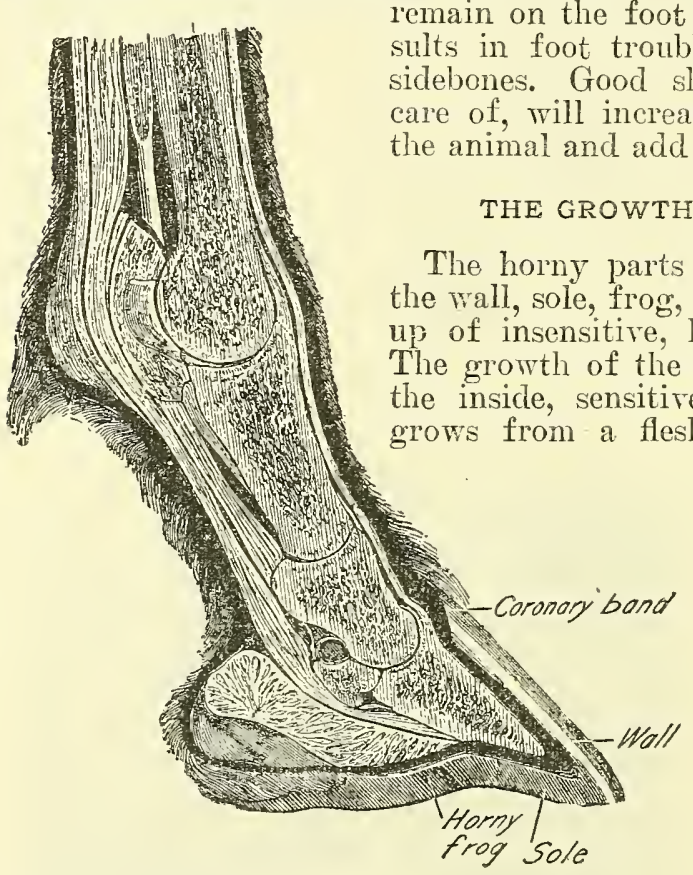

F'IG. 2.-Vertical section through miadle of forefoot. In trimming or shoeing the foot be careful not to injure the inside, sensitive structure

from the fleshy sole and grows solid to a certain extent. As it continues to grow the old sole will crack and check, and a network of small, black lines will be formed all over the bottom of the sole. The horny frog growrs from the fleshy frog and is a cushiony, elastic wedgo between the bar's and the edges of the sole in front of the bars. In unshod hoofs the bearing edge of the wall, the sole, frog, and bars are on a level, and each of these structures assists in bearing the body weight. The bars are extensions of the wall from the heel along the sides and to the point of the frog. The purpose of the bars is to assist in absorbing the shock when the foot strikes the ground. As the function of the bars is important, they should not be cut away in trimming the hoof. Contracted heels will result if the bars are cut away. 


\section{TRIMMING THE COLT'S FEET}

The newborn foal has a rather pointed, narrow hoof, which is very soft, and the bottom is covered with a thick cushion of soft, horny material. 'This, however', falls off in a few days, and the development of the permanent hoof begins. The horny sole begins to grow in an arch shape, and the new wall grows down from the coronary band. In a few wceks there is a distinct difference between the old and the new horny mass in that a complete ring forms around the hoof. 'The new hoof is circular and spreads considerably at the sole surface, and the leg assumes its natural shape. The foot becomes more slanting from the fetlock joint down, and ciuring the first few weeks there is very little to be done to improve the standing position of the legs. A little later, however, when much can be done toward developing normal conformation by the proper trimming' of the little hoof, one should carefully observe the development of the legs. When the colt

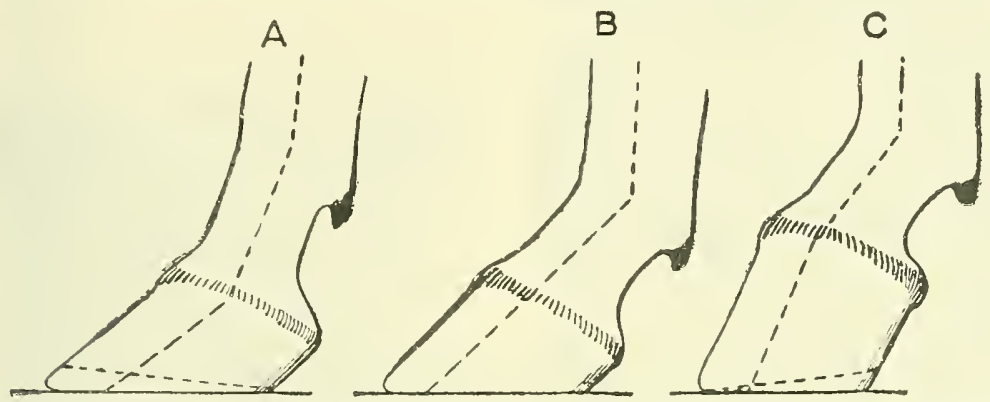

FIG. 3.-Legs and hoofs in profile: A. Side view of foot with foot axis broken backward as a result of too long a toe. The amount of horn to be removed from the toe in order to straighten the foot axis is denoted by a dotted line. B. Side view of a propelly balanced foot, with a straight foot axis of desirable slant. C. Side view of a stumpy foot with foot axis broken forward as a result of overgrowth of the qnarters. The amount of horn to be removed in order to straighten the foot axis is shown by a dotted line.

is three months old one can begin using the hoof knife for trimming the feet. 'To do this work properly, first observe the standing position of the front legs from the side. If the leg is placed too far forward it is an indication that the toe is too long. (Fig. 3.) By close examination of the hoof it will be found that the heels are curving under and that the toe is growing in a straightforward direction. If the hoof is trimmed in the manner described, the legs will take their proper position. Now, observe the hind legs. One will usually find that the legs are too straight from the fetlocks down, because the heels are long. If the heels are pared down, the legs will assume a more normal position. By observing the colt from the rear and the front it will usually be found that its legs are "base wide" or in a spreading position. As the colt matures, this condition usually corrects itself. By closely observing the colt occasionally, possibly once a month, and keeping the hoofs properly trimmed, one can do much to promote the development of a normal conformation, which brings good returns to the owner. 
The colt should have abundant exercise on dry ground. The hoofs will then usually wear gradually, and it may be necessary only occasionally to rasp and round off the sharp edges around the too in order to prevent the breaking away of the wall. Colts in the stable, however, can not wear down their hoofs; therefore the feet of such colts should be rasped dom every few weeks. 'The soles and clefts of the frog should be picked out every few days and the entire hoof washed ont thoroughly.

\section{TRIMMING THE FOOT FOR SHOEING}

Before beginning the trimming of the hoof one must observe the standing position of the limbs, particularly from the fetlock joint down. The position of the foot must correspond to the angle of the

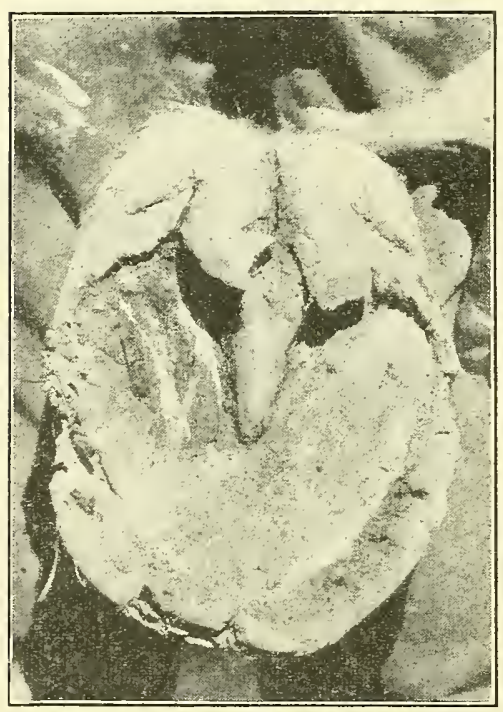

FIG. 4.-An untrimmed foot leg, as indicated in Figure 3, B. If the standing position of the foot is too slanting it is an indication that the toe is too high, and

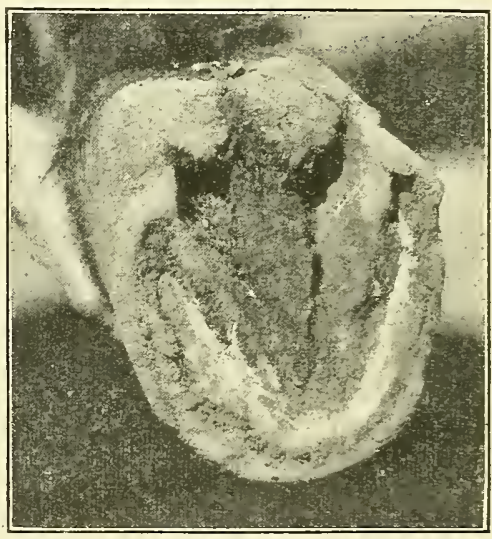

FIG. 5.-An untrimmed foot. Note the long heels

a line, the so-called foot axis, is broken backward. Reducing the too will change the angle and bring the foot axis into a straight line.

After the standing position has been observed, raise the foot and begin with the hook knife to remore the overgrowth of the sole, starting at the quarter. 'This overgrowth is indicated by cracks and checks and loose material. (Figs. 4, 5, and 6.) It should be removed down to the solid sole. The solid sole should not be touched under any circumstances, as the horse needs this as a protection for the inner organs of the foot. After the solo is cleaned the wall extending far beyond the sole can be reduced to its normal length with hoof cutter's, as shown in Figure 7 . The amount of cutting is determined by the upper edge of the trimmed sole: in other words, the hoof cutters will follow the upper border of the trimmed sole all the way along the hoof, and by so doing give the heel and toe the proper length. (Figs.9, 10, 11, and 12.) After this is done 
the hoof rasp should be held in a level position and the hoof sole rasped so that the wearing surface is in a level plane, as shown in Figure 8. One can observe this plane level in the position illustrated on the title-page of this bulletin, which shows also the proper method of holding the hor'se's foot. 'The handy shoeing outfit illustrated consists of a box, hammer, clinch cutter, large pincers for pulling shoes, hoof knife, and hoof cutters, and a pair of small pincers for pulling and cutting nails.

\section{FITTING THE SHOE}

The hoof is now ready for the fitting of the shoe. For ordinary farm work the shoe does not need to extend much beyond the end of the wall. The type of shoe, whether calked or plain, depends largely on the work which the animal performs. The plain shoe should be even with the end of the wall. If a callied shoe is needed, it is necessary that the shoe be a trifle longer. In fitting the shoe

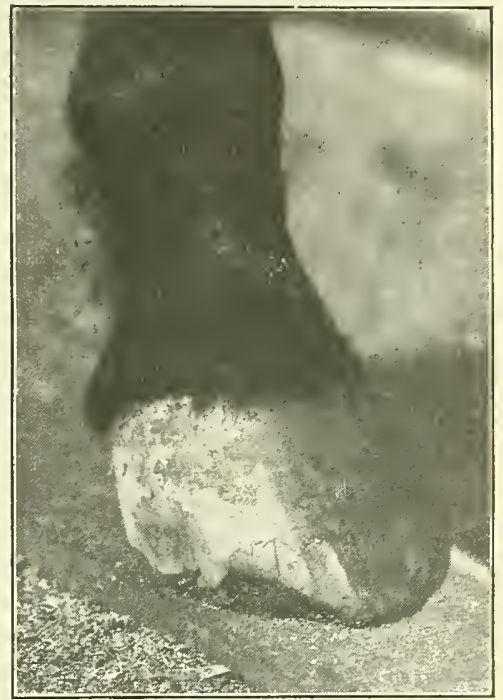

FIG. 6.-A bad break in the wall, caused by neglect in trimming and shoeing

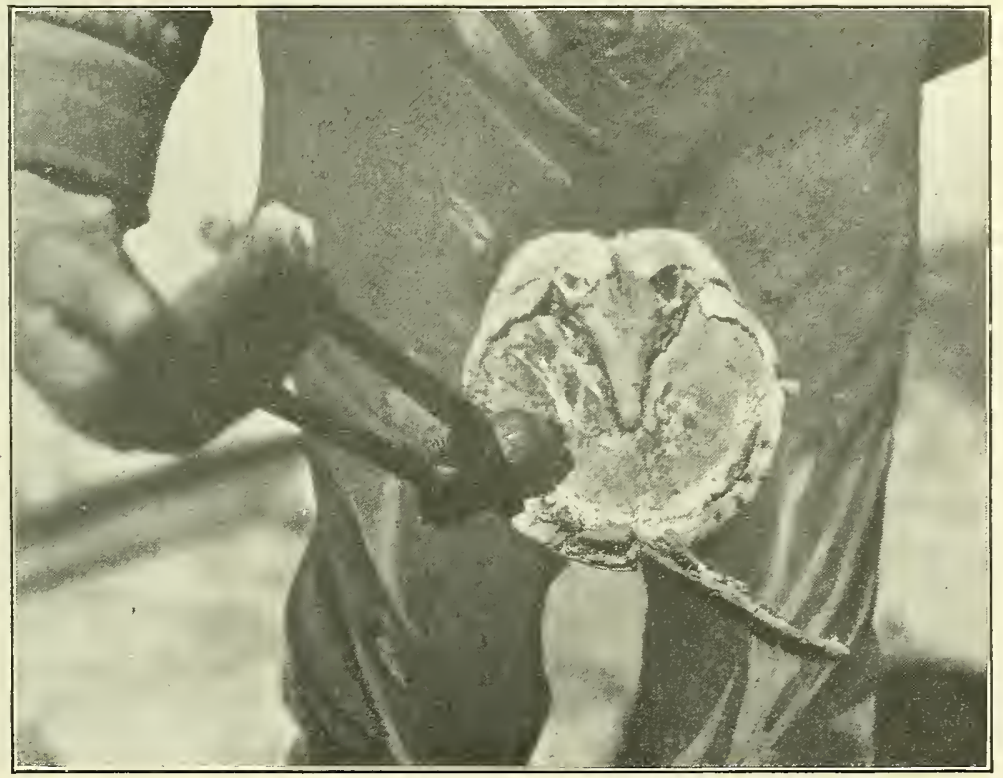

Fig. 7.-Proper use of the hoof cutter 


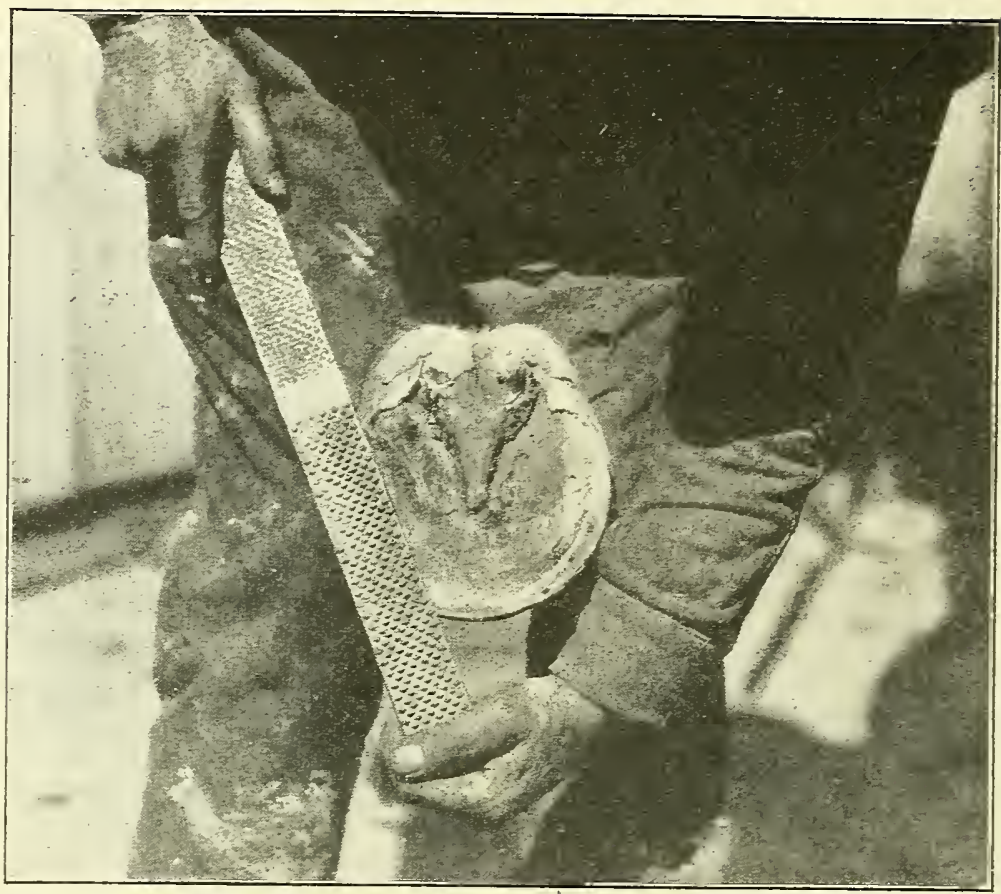

FIG. 8.--Proper position of rasp in leveling hoof

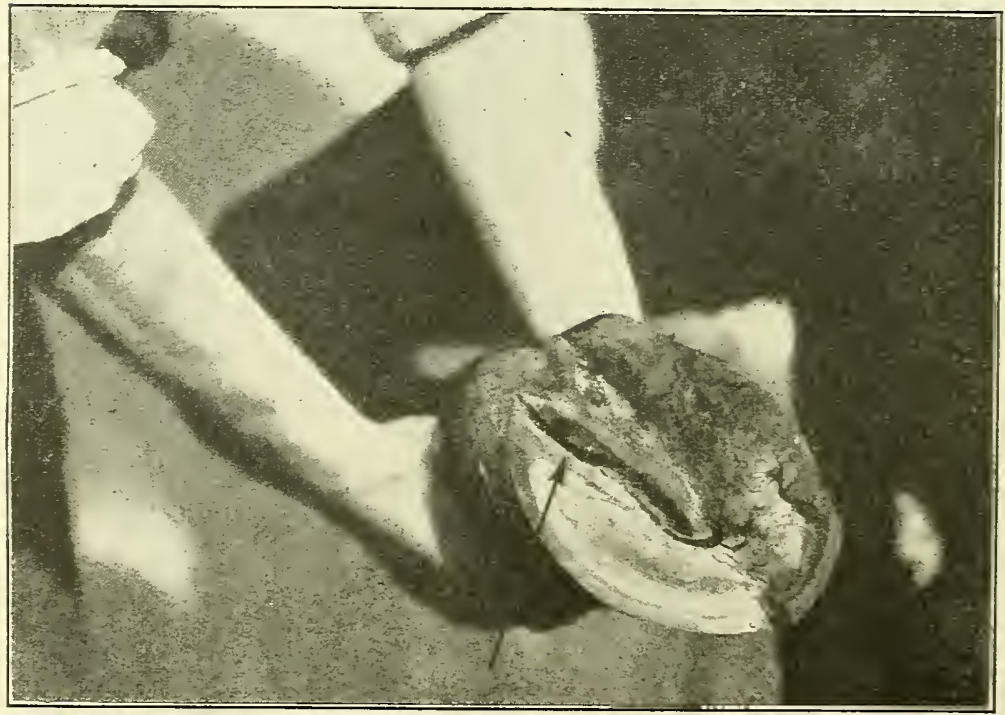

Fig. 9.-A hoof which has been properly trimmed on one side; the other half is untrimmed. Note the difference especially in the amount of trimming necessary to balance the foot properly. Note the bars 


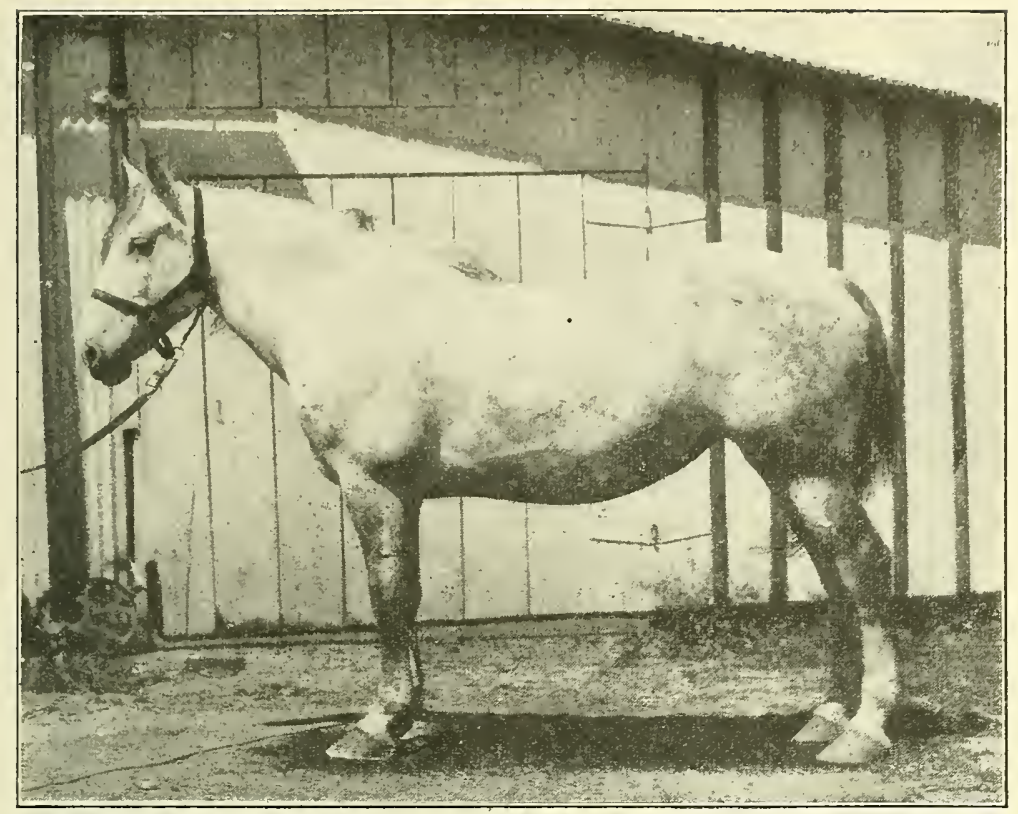

FIG. 10.-Mare with untrimmed feet. Note the long, slanting position of the foot from the fetlock to the ground

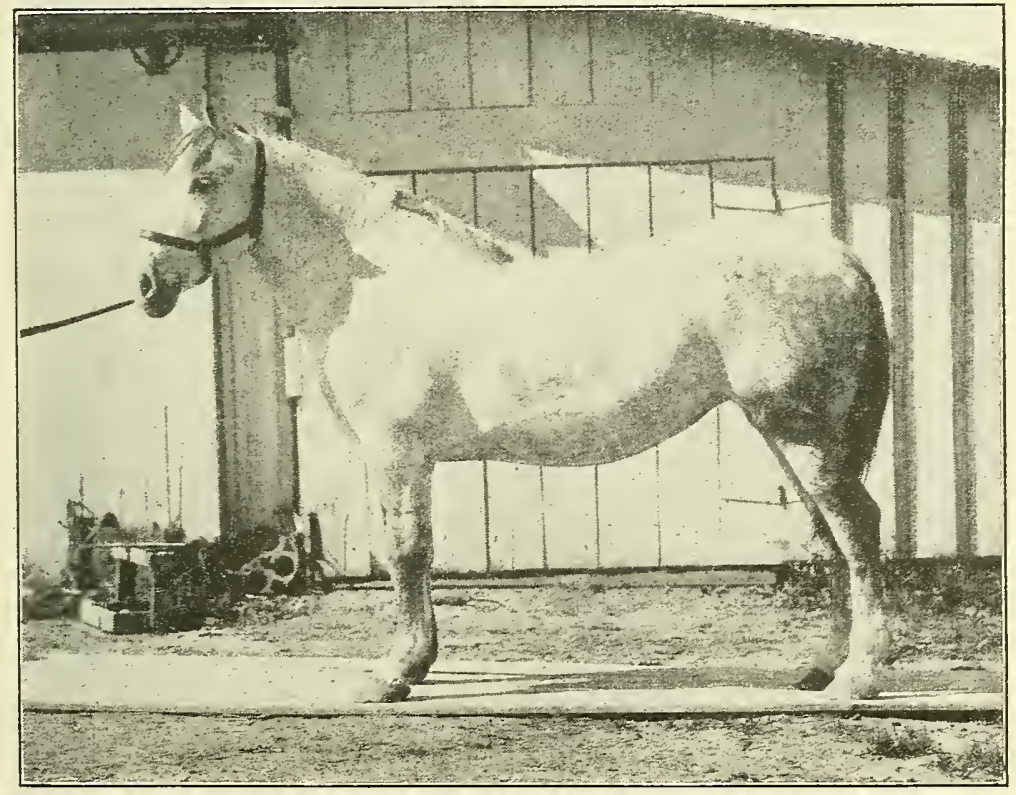

FIG. 11.-Trimmed feet. Note the corrected position of the feet and compare their position with that shown in Figure 10 
it is necessary to give an absolutely even fit, as the outline of the hoof shows. In other words, fit the shoe flush with the outline of the onter borcler of the wall. The heels of the shoe should be well

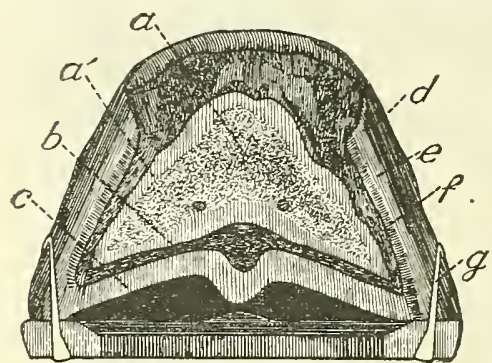

FIG. 12.- Fertical cross section of wellshod hoof showing correct position of rails: " Pedal bone; $a^{\prime}$, onter layer" of pedal bone; $b$, sensitive sole; $c$, horny sole; $d$, horn wall; $e$, outer layer of laminal sheath; $f$, laminal sheath; $g$, nail

against the wall to guide the direction of the nail, and the shoe is
held in position, the hand resting on the shoe to hold it in proper

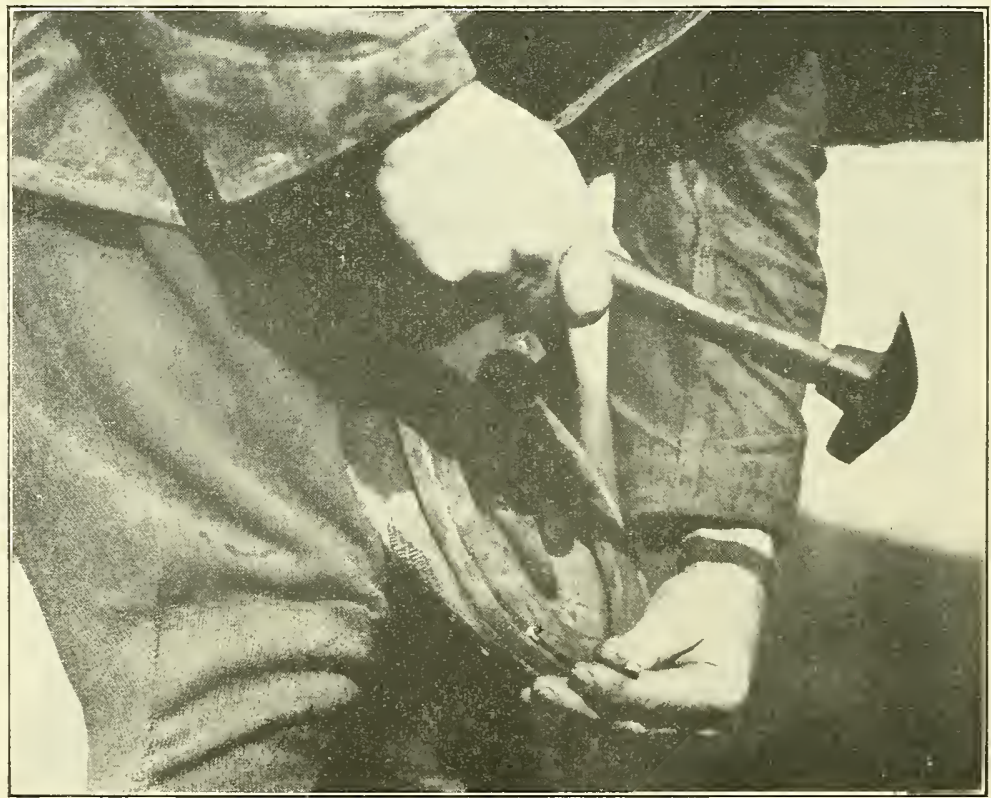

FIG. 13.-Proper method of nailing a shoe on. Note position of hands

position in driving the outside nail first. (Fig. 13.) The nail should be driven just outside that portion of the wall known as the "white line," so called because of its well-defined "white" appearance. Be 
careful not to allow the nails to go inside this line into the sensitive portion of the foot. The proper course of the nail is shown in Fing. 12. After the first nail is driven it is best to make sure that the shoe is in

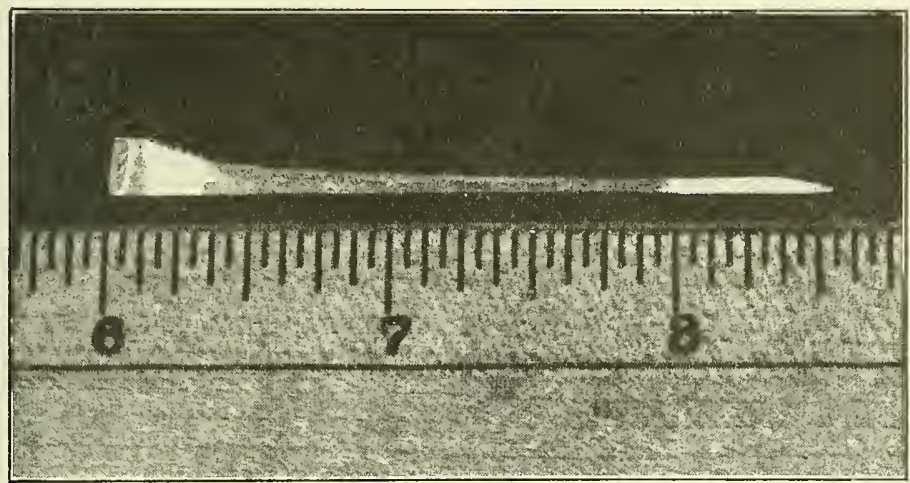

FIG. 14.-The inails used for shoeing horses have one straight side, and the other side is beveled at the point. In driving a nail, the straight edge should always be held to the outside, the beveled point to the inside. This will guide the nail out through the wall. The nail should be driven just outside the "white line" described in the text

its proper place. Then the nail on the opposite side is driven, and so on until the nailing is completed. In tightening the nails, a clinching block or the pincers should be held underneath the nails, and the

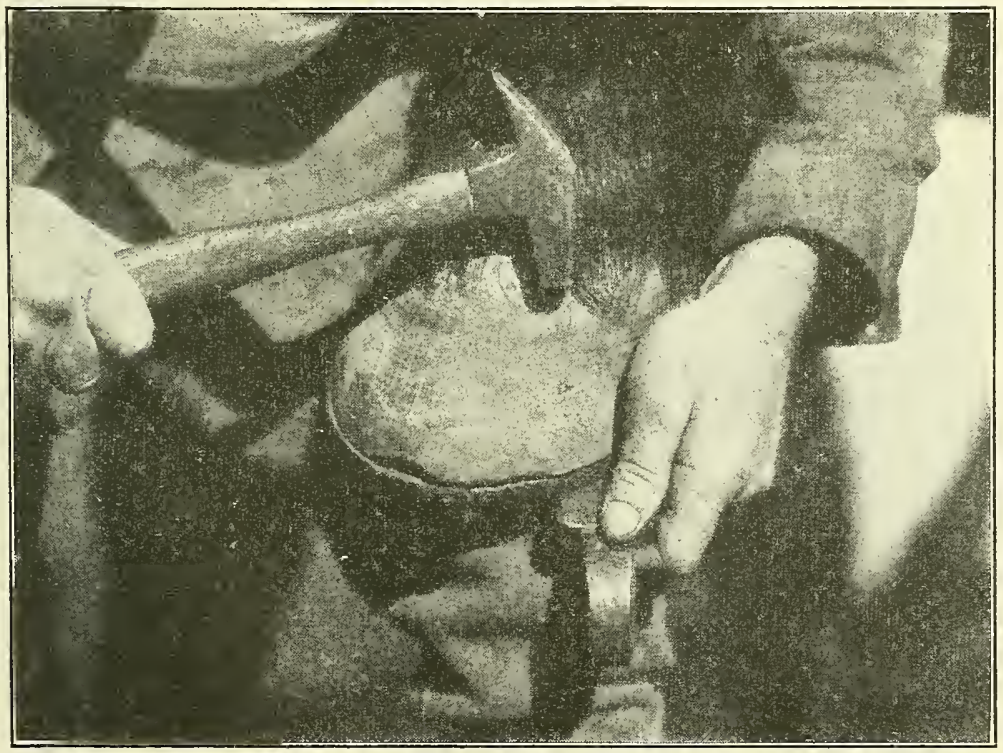

FIG. 15.-Proper method of clinching the nail. Note position of hammer and clinch block

head driven with the hammer tight into the crease of the shoe. In clinching the nails, as shown in Figure 15, the foot is brought forward on the knee of the operator, and the nails are cut close to the wall, and 


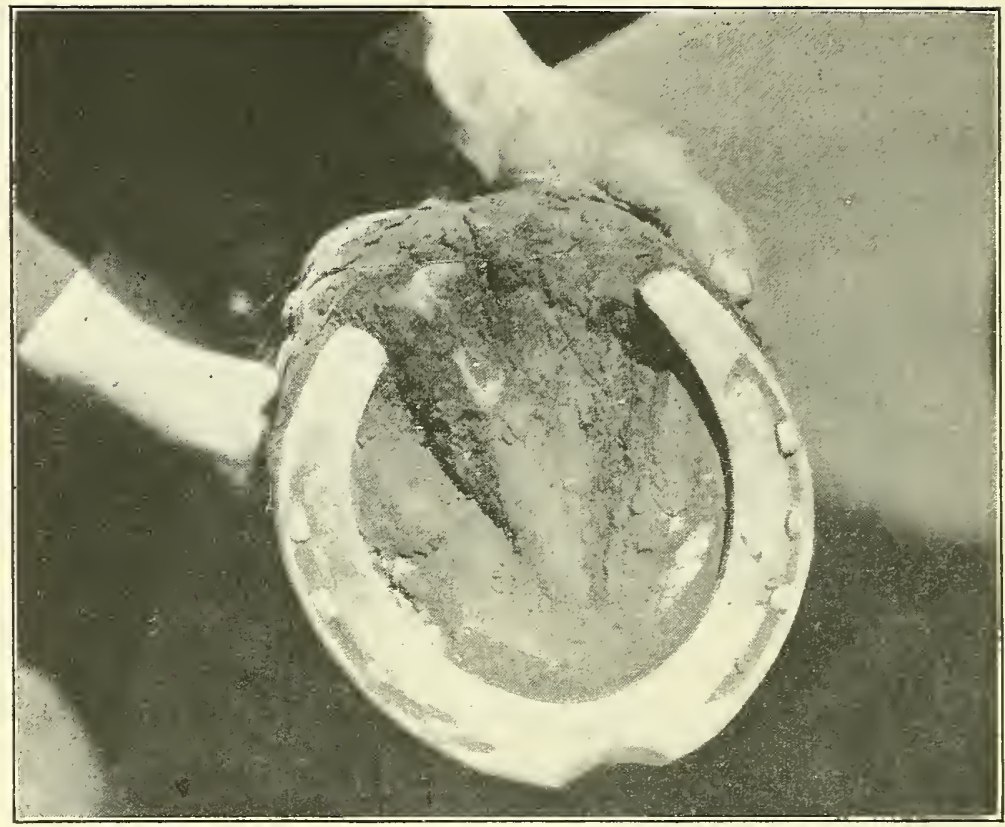

Fig. 16.-Plate shoe, well fitted

with the rasp a clearing cut is made underneath the nail on top of the wall. Cut or twist off end of nail with pincers or claw of liammer; place the clinching block underneath the nail, and with the hammer

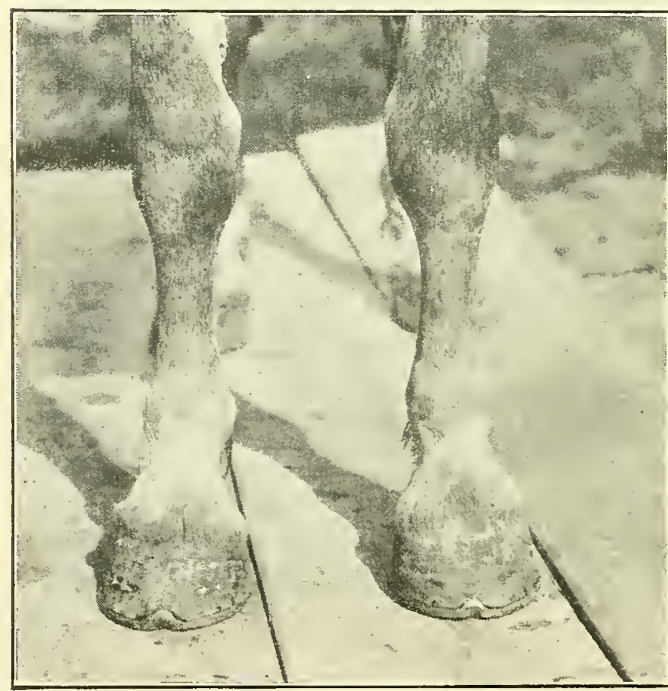

Fig, 17.-Well-shod feet bring the nail orer in a small, bending forme so as to form the clinch. With the hoof rasp smooth or rasp over the rough spots on the outside. Rasping the outsicle of the wall should be aroided as much as possible. Figure 16 shows a plate shoe, well fitted.

\section{READY-TO-WEAR SHOES}

Horseshoe manufacturers are now making and distributing horse and mule shoes of all types (figs. 18 to 21) suitable for shoeing farm work stock. In 
many places they can be obtained at the general store or from the local hardware nerchant.

In using the ready-to-wear shoe it is important that the farmer exercise particular care in measuring the feet of horses or mules to

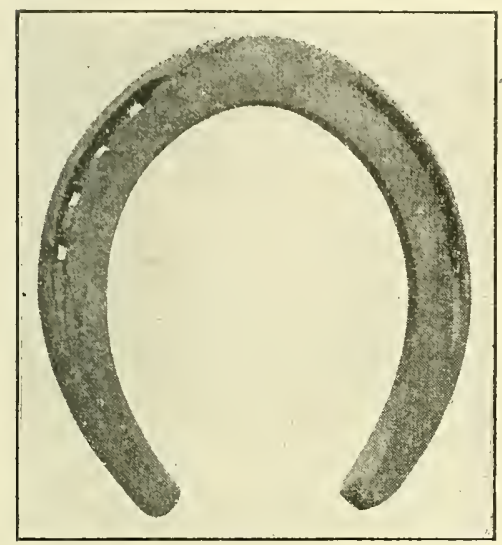

Frg. 1S.-Ready-to-wear shoe. Plain shoe

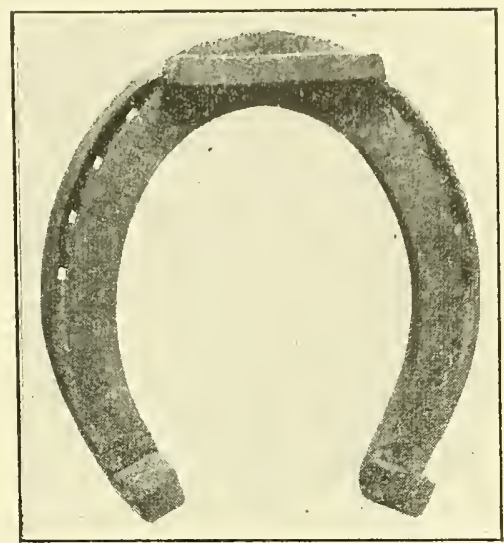

Fig. 19.-lieady-to-wear shoe, with toe and heel calks

be shod before he purchases the shoes. The following system of measurement should be applied: After the feet are trimmed (one front foot and one hind foot), measure the width of the foot, in

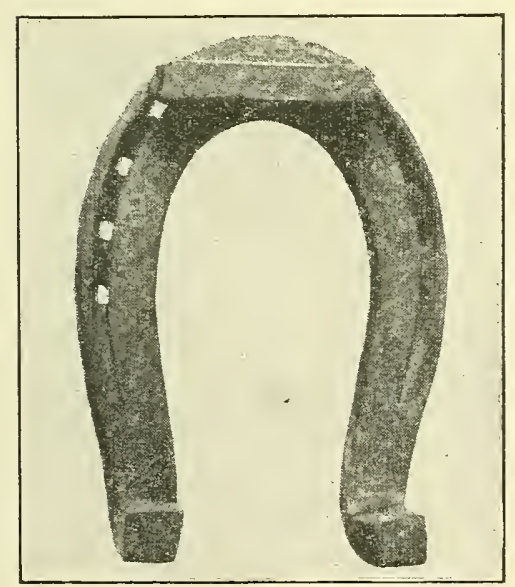

FIG. 20.-Ready-to-wear mule shoe, with toe and heel calks

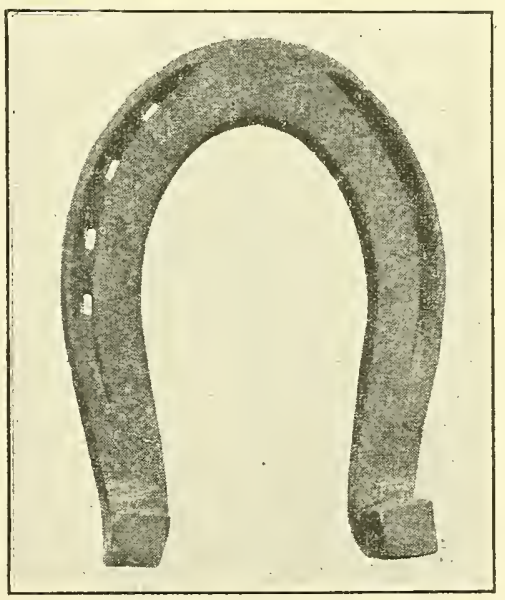

FIG. 21.-Ready-to-wear mule shoe, with heel calks

inches, and the length of the foot from heel to toe, making sure, however, that an allowance of at least one-half inch is made in the length of the shoe beyond the wall of the foot at the heel. 


\section{RUBBER SHOES AND RUBBER HOOF PADS}

Because horses are often worked on hard-surfaced streets and highways, the use of rubber shoes and rubber hoof pads has become common. These modern devices not only relieve sore and lame horses, but many times prevent corns and other foot sorenesses and lengthen the usefulness of horses used on hard surfaces. This type of shoeing is also valuable in preventing slipping on such surfaces and reduces to a minimum the number of injuries to horses cansed by falling. Hoof pads and rubber shoes should be used as a preventive rather than as a cure for the many leg ailments caused by the constant use of horses on hard-surfaced roads.

Rubber pads are not recommended for horses that work on the farm, as the soil works its way under the pad, causing lameness by extra pressure in the navicular joint. Whenever rubber pads are nsed, pine tar with a thin layer of oakum should be applied to the sole to keep it moist and prevent contraction. 


The mature male horse has 40 teeth (fig. 1). Twenty-four of these are molars or grinders, 12 are incisors or front teeth, and 4 are tushes or pointed teeth. The 2 central incisors are known as centrals or nippers; the next 2, 1 on each side of the nippers, are called intermediates or middles, and the last, or outer pair, the corners. The tushes are located between the incisors and the molars. They are not usually present in the mare, and accordingly she may be considered to have a total of 36 teeth rather than 40 , as in the male.

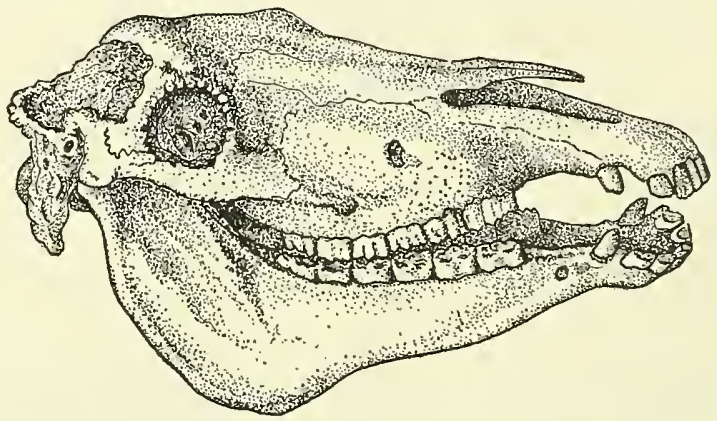

FIGURE 1,-Skull of the horse (from Frateur).

The young animal, whether male or female, has 24 temporary teeth, commonly called milk teeth, as they are much whiter than the permanent teeth. These milk teeth consist of 12 incisors and 12 molars. The latter are the 3 back teeth on each side of both the upper and the lower jaw. The milk teeth are shed and replaced by permanent teeth at fairly definite periods, which serve as an index in determining the age of young coits.

The temporary central incisors or nippers may be present at birth (fig. $2, A$ ); otherwise they appear before the colt is 10 days old. There are two in each jaw.

At the age of from 4 to 6 weeks the two temporary intermediates, upper and lower, appear (fig. $2, B$ ). These teeth immediately adjoin the nippers.
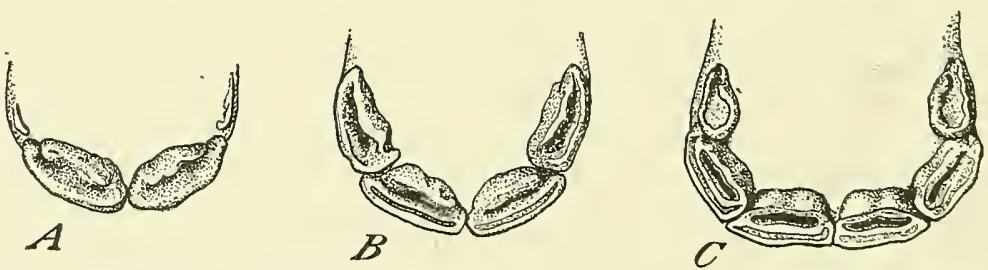

FIGURE 2.-Temporary incisor teeth of a young colt: $A$, Immediately after birth; $B$, at 6 weeks; $C$, from 6 to 10 months after birth.

When the colt is from 6 to 10 months old the corner or outer incisors, two above and two below, are cut (fig. 2, C). This gives the young animal a full set of temporary front teeth.

By the time the colt has reached the age of 1 year the crowns of the central incisors show wear (fig. $3, A$ ). In another 6 months the intermediates or middles become worn (fig. $3, B$ ), and at 2 years all the teeth are worn (fig. $3, C$ ). During the following 6 months there are no 
changes which will distinguish the exact age. At about $2 \frac{1}{2}$ years, however, the shedding of the milk tecth begins and at 3 years the tem-
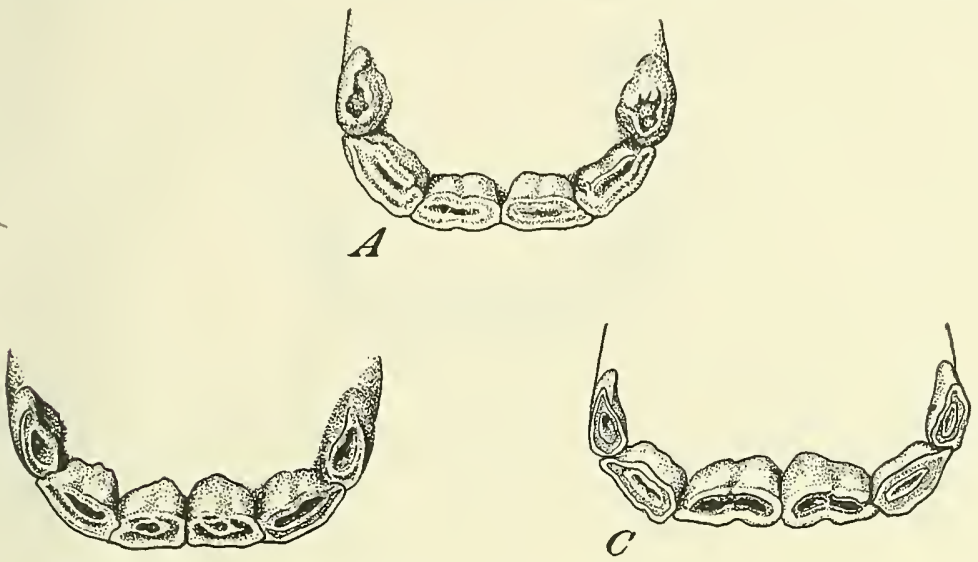

$B$

FIGURE 3.-Appearance of the incisor teeth of a colt: $A$, At 1 year; $B$, at 18 months; and $C$, at 2 years. porary central nippers, two above and two below, are replaced by the permanent central incisors.

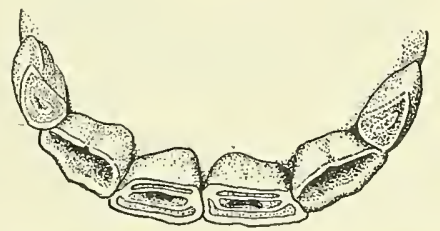

FIGURE 4,-Incisors of a horse at 4 years. The permanent incisors are the four in the center, and the temporary ones are at the corners.

At 4 years the four permanent intermediates have taken the place of the four temporary middles (fig. 4).

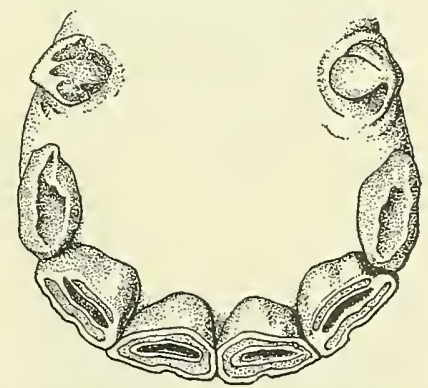

FIGURE 5.-Permanent incisors of a horse at 5 years. The tushes also shown here indicate that the animal is a male.

When the animal is about $4 \frac{1}{2}$ years old the shedding of the four corners begins, and at 5 years the permanent teeth which replace them are well up but not in contact (fig. 5). 
In a 6-year-old horse the corner incisors are on a level with the adjoining teeth, with a well-marked dental cavity or "cup" showing practically no wear (fig. 6). The nippers show wear over the entire

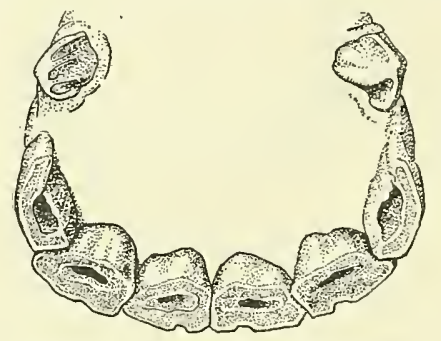

FIGURE 6.-Incisors of a horse at 6 years.

surface; the "cup" though visible shows indications of gradual disappearance and at this stage is without a hollow.

When the animal is 7 years old, not only the nippers but also the middles show wear (fig. 7). Each upper corner tooth has an indenta-

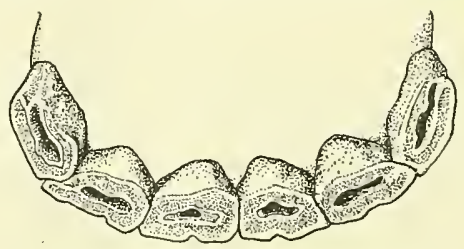

FIGURE 7.-Incisors of a 7-year-old horse.

tion caused by wear from the corresponding lower tooth, resulting in a downward triangular projection of the posterior edge. This projection is commonly termed "dovetail" (fig. 8).

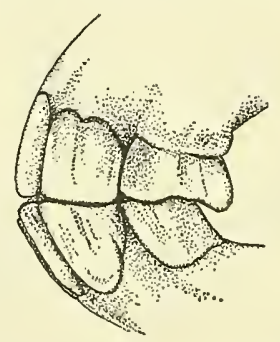

Figure 8.-Side view of incisors of a 7-year-old horse. Note, in upper corner incisors, the notch which appears at this age.

In the 8-year-old horse all the incisors are worn, the cup has entirely disappeared from the nippers, but shows to a slight extent in the middles, and is still well marked in the corners. At this stage what is termed the "dental star" makes its appearance as a yellow transverse line just back of the front edge of the table, or flat surface, of the nippers and middles (fig. 9). 
Between the ages of 9 and 13 ycars there is a gradual change in the contour of the tables of the incisors. In a 9-year-old animal the

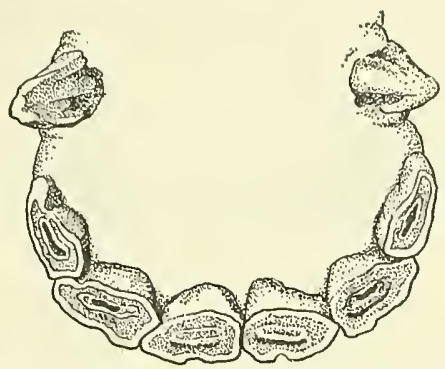

Figure 9.-Inoisors of 8-year-old horse. Dark line in front of cup is the dental star.

nippers take on a more or less rounded contour; the dental cavity or cup has disappeared from all but the corners; the dental star is found

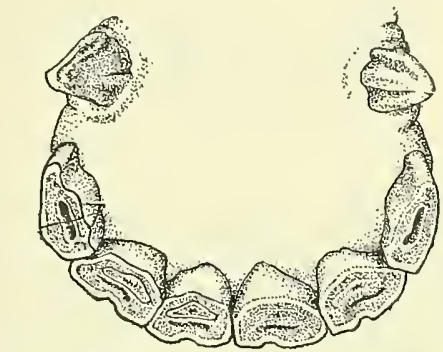

Figure 10.--Ineisors of a male horse 9 years old.

in both the nippers and middles and in the former is near the center of the table (fig. 10). At 10 years the middles become rounded, and

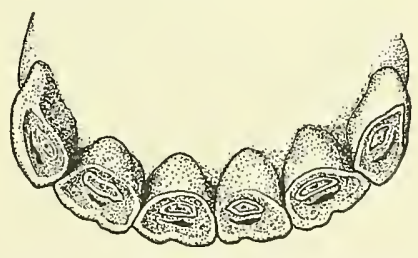

FIGURE 11.--Incisors of a horse at 10 years.

the dental star, now seen on all the incisors, is near the center of both the nippers and middles (fig. 11). At 11 or 12 years the corners bave

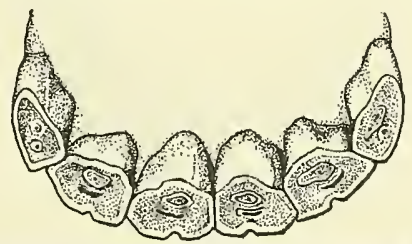

Figure 12.-Incisors of a horse at 11 or 12 years.

a somewhat rounded form, and the dental star approaches the center of the table (fig. 12). As the horse reaches 13 years of age all the 
lower incisors are unmistakably rounded, the dental star is found in the center of all the tables, and the enamel rings which formerly surrounded the cups have entirely disappeared (fig. 13).

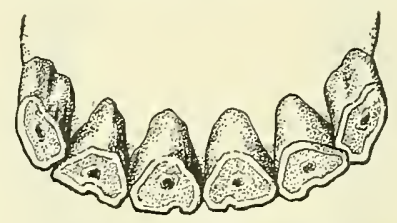

Figure 13.-Incisors of a horse at 13 years.

In a horse about 14 years of age the tables of the incisors begin to change from a rounded to a triangular contour. This change occurs

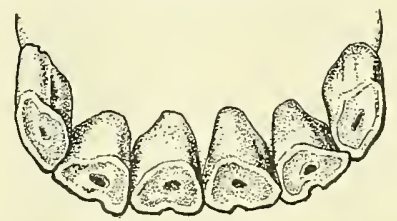

Figure 14.-Incisors of a 14-year-old horse.

in the nippers at 14 years (fig. 14), in the middles at 15 years, and in the corners at 16 or 17 years (fig. 15).

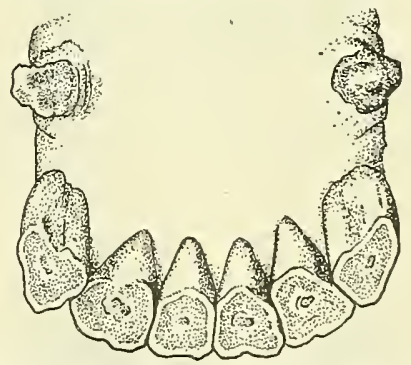

FIGURE 15.-Incisors and tushes of a male horse at 17 years. The mouth of a female has the same appearance except for the absence of tushes.

During the following 4 years after the appearance of the triangle, there is a gradual approach of the tables to the form of a rectangle, as shown in figure 16. The teeth during this period are usually

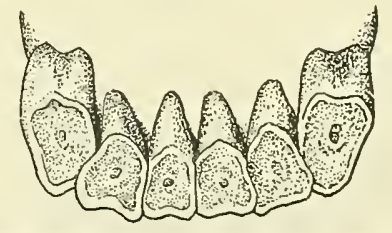

FIGURE 16.-Characteristic shape of an old horse's lower incisors at 18 jears.

elongated and directed obliquely. The dental arch also becomes contracted and pointed and the under edges of the lower jaw are thin and sharp as compared with their appearance in a young horse (fig. 17). 

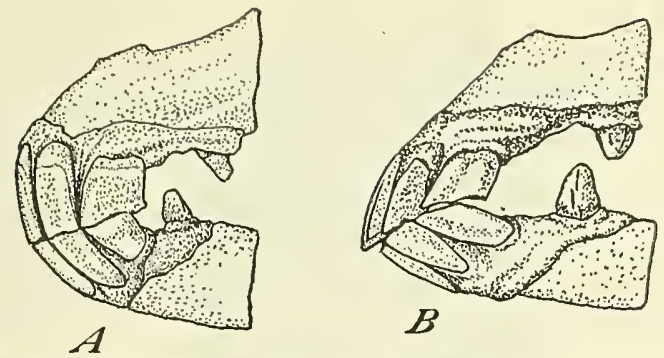

Figuak 17.-Comparison of izcisors and tushes of horses at different ages: $A$, At 6 years, and $B$, at 20 years.

Should the animal live more than 20 years, these conditions become more marked and are accompanied by excessive wear and loosening or loss of molars.

\section{CATTLE}

Cattle at maturity have 32 teeth, of which 8 are incisors. All incisors are in the lower jaw (fig. 18). The two central incisors are

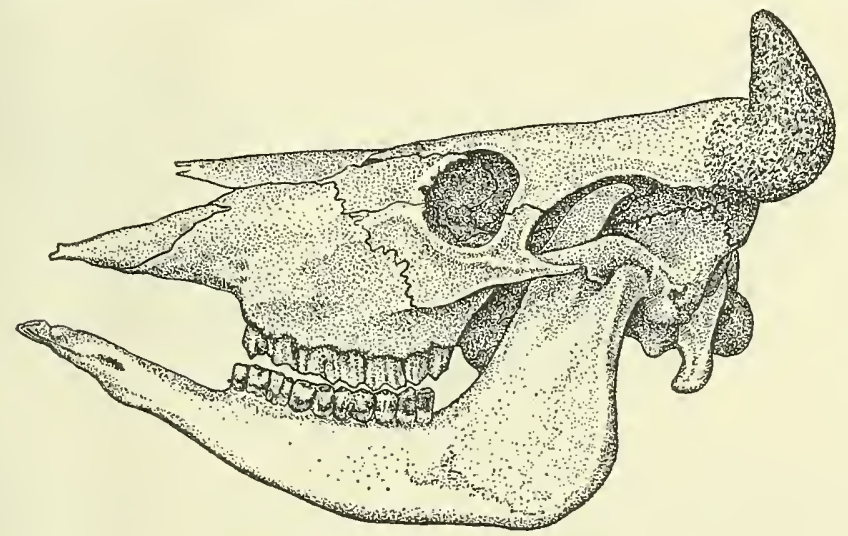

Figure 18.-Skull of an ox (from Sisson).

called pinchers; the next two, first intermediates; the third pair, second intermediates or laterals; and the outer pair is known as the corners. In place of the upper incisor teeth there is a thick layer of the hard palate called the dental pad (fig. 19). 


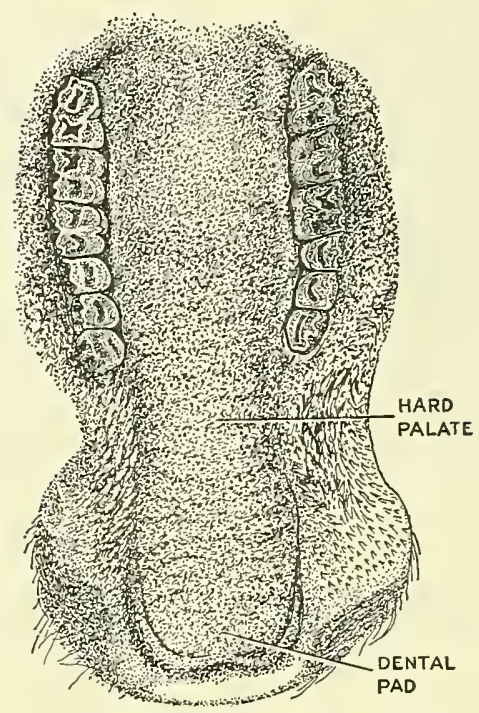

Figure 19.-Hard palate of an ox showing dental pad (from Sisson).

In the calf at birth two or more of the temporary or first set of incisor teeth are present. Within the first month the entire eight incisors have appeared (fig. 20).

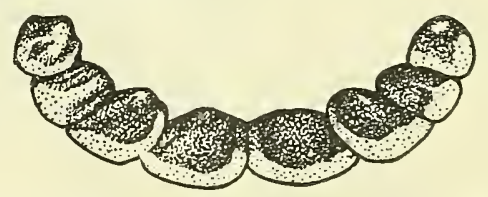

FIGURE 20.--Internal face of incisors of the calf at 1 month.

As the animal approaches 2 years of age the central pair of temporary incisor teeth or pinchers is replaced by the permanent pinchers. At 2 years these teeth attain full development (fig. 21).

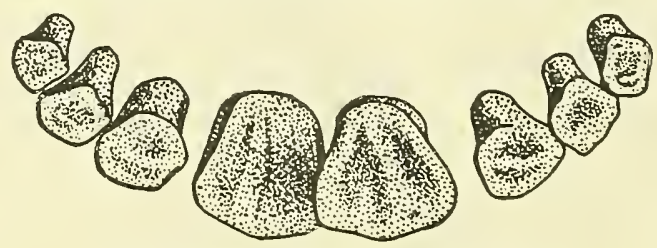

FIgure 21,-Internal face of incisors at 2 years.

At about $2 \frac{1}{2}$ years the permanent first intermediates, one on each side of the pinchers, are cut and are usually fully developed at 3 years (fig. 22). 


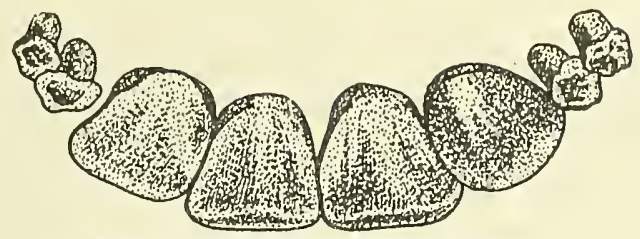

Figure 22.--Internal face of incisors at 3 years.

At $3 \frac{1}{2}$ years the second intermediates or laterals are cut. They are on a level with the first intermediates and begin to wear at 4 years (fig. 23).

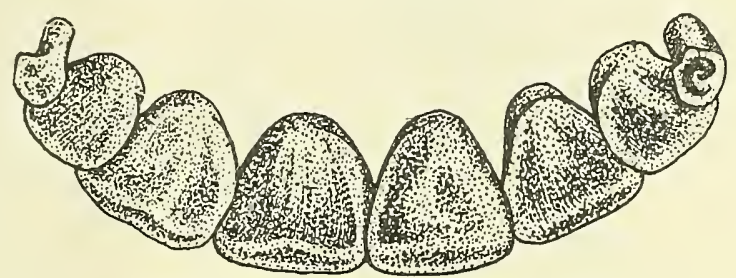

Figure 23.-Internal face of incisors at 4 years.

At about $4 \frac{1}{2}$ years the corner teeth are replaced. At 5 years the animal usually has the full complement of incisors with the corners fully developed (fig. 24).

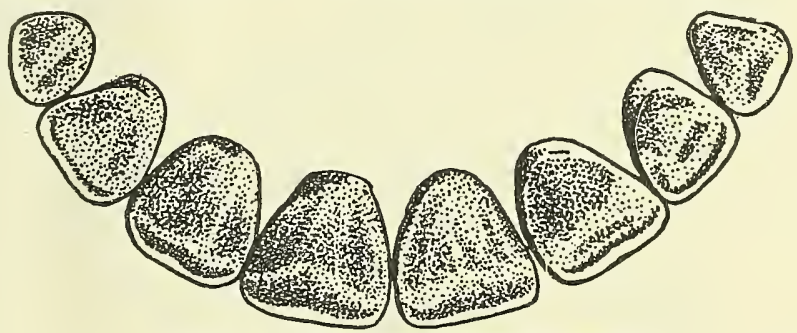

FIgURE 24.-Internal face of incisors at 5 years.

At 5 or 6 years there is a leveling of the permanent pinchers, the pinchers usually being leveled at 6 years and both pairs of intermediates partially leveled and the corner incisors showing wear.

At 7 or 8 years there is a noticeable wearing of the pinchers; at 8 or 9 years, of the middle pairs; and at 10 years, of the corner teeth.

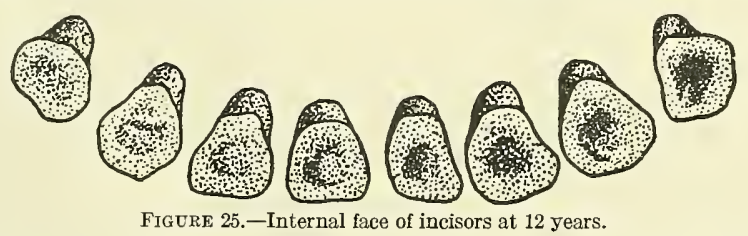

After the animal has passed its sixth year, the arch gradually loses its rounded contour and becomes nearly straight by the twelfth year (fig. 25). In the meantime the teeth have gradually become triangular in shape, distinctly separated, and show progressive wearing to stubs. This condition becomes more marked with increasing age. 


\section{SHEEP AND GOATS}

Mature sheep and goats have 32 teeth, of which 24 are molars and $\varepsilon$ are incisors (fig. 26). There are no tusks and, like those of cattle, all the incisors are in the lower jaw. As in the case of cattle, also, the two central incisor teeth are called pinchers; the adjoining ones, first intermediates; the third pair, second intermediates; and the outer ones, corners. The temporary incisors are readily distinguished from the permanent ones by their smaller size and milky whiteness.

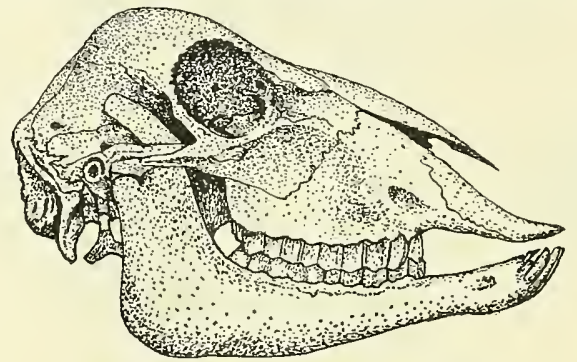

FIGURE 26.-Skull of a sheep (from Sisson)

In the new-born animal none of the teeth may have made their appearance though sometimes the two pinchers and also the two first intermediates are pressing through the gums or even have cut through. In a few days these teeth and the second intermediate incisors will appear, followed somewhat later by the corners, thus giving the animal, by the time it is 3 months old, a full set of completely developed temporary incisor teeth, as shown in figure $27, A$.

When the animal is between 12 and 15 months of age the temporary pinchers are replaced by the two permanent ones (fig. $27, B$ ).
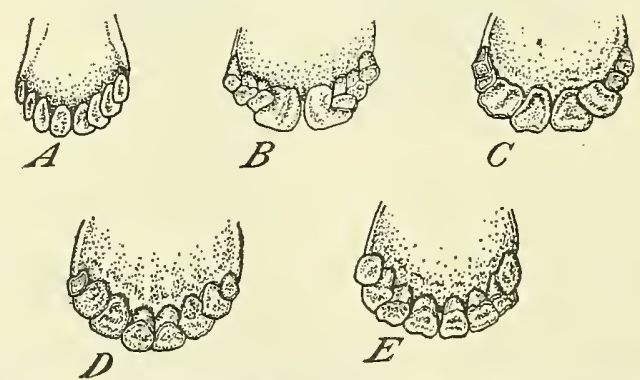

Figure 27.-Incisors of sheep at different ages: $A$, At 3 months; $B$, at 12 to 15 months; $C$, at nearly 2 years; $D$, at 3 years; and $E$, at 4 years.

The shedding of the first temporary intermediates and their replacement by permanent teeth indicate that the animal is approaching its second year (fig. 27, $C$ ).

The replacement of the second temporary intermediates by the permanent ones takes place when the animal is about 3 years old (fig. 27, D).

The two temporary corner incisors are replaced by permanent teeth as the sheep reaches the age of 4 years. All the permanent teeth are then present, and the animal has what is termed a "full mouth" (fig. 27, E). 
After this time there is a distinct and progressive increase in size of the spaces between the teeth, which gradually become vorn to stubs and frequently attain an unnatural and uneven length. In old sheep some teeth may be broken or loose; in such eases the animal is said to have a broken mouth.

\section{SWINE}

A mature hog has 44 teeth (fig. 28). Of these, 12 are front teeth or incisors, and 6 are in the upper and 6 in the lower jaw. Four others lie in the open spaces back of the incisors and are known as tusks, or tushes. They are usually more prominent in the male than in the female. Back of each tush is a tooth commonly called the premolar, and immediately back of this on each side of the upper and lower jaws there are 6 molars, the first 3 in each row sometimes being termed premolars. As in the horse, the incisors are grouped in three pairs in each jaw and are termed centrals, intermediates, and corners in accordance with their relative positions.

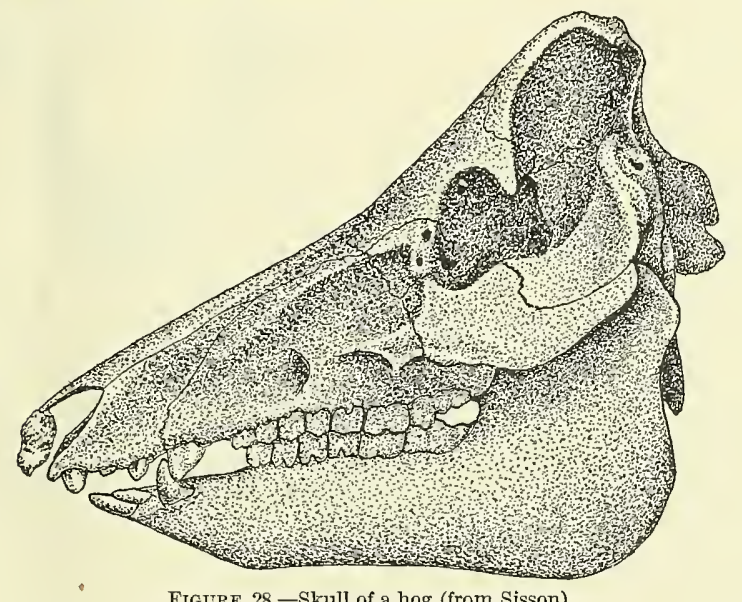

Figure 28.- Skull of a hog (from Sisson).

The young pig at birth usually has 8 teeth. These consist of the 2 tusks and 2 corner incisors on each jaw. They are all sharply pointed and are sometimes known as needle teeth (fig. 29, A). It is a common practice to cut them off, about halfway between the gum and point of the tooth, in the new-born pig, in order to avoid discomfort and injury to the nursing sow.

When the pig reaches the age of 4 or 5 weeks the cential temporary incisors appear, two in the upper and two in the lower jaw (fig. 29, $B$ ).

As the animal approaches the age of 6 to 8 weeks the two intermediate incisors will have cut through the gums of the lower jaw between the corners and the centrals and will be fully grown at 3 months (fig. 29, $C$ ).

As the pig passes 6 months of age the temporary corner incisors are shed, and the permanent corners appear. Shortly after 9 months the permanent tusks take the place of the temporary tusks. At approximately 12 months the central permanent incisors replace the temporary centrals, and the lower teeth appear as shown in figure $29, D$. 


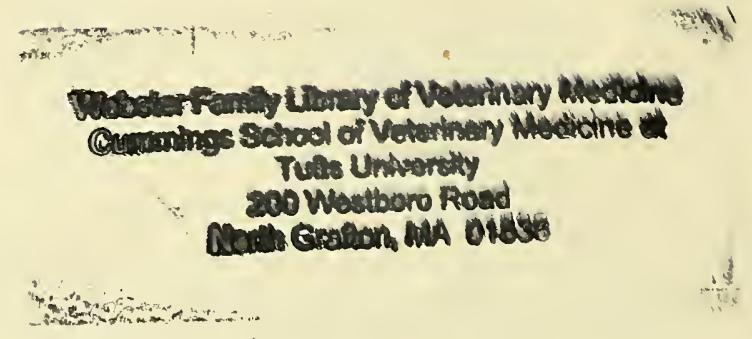



